DANMARKS GEOLOGISKE UNDERS $\varnothing$ GELSE

II. REKKKE. NR. 75

GEOLOGICAL SURVEY OF DENMARK. II. SERIES. NO. 75

\title{
Vegetation and its Environment in Denmark \\ in the Early Weichselian Glacial \\ (Last Glacial)
}

by

Svend Th. Andersen

Dansk sammendrag:

Vegetationen og dens kår $\mathbf{i}$ Danmark $\mathbf{i}$ tidlig

Weichsel Glacialtid (Sidste Istid)

With 15 Plates

1 kommission hos

C. A. REITZELS FORLAG (JØRGEN SANDAL)

KøBENHAVN 1961 
DANMARKS GEOLOGISKE UNDERSØGELSE

II. RÆKKE. NR. 75

Geological Survey of Denmark. II. Series. No. 75

\section{Vegetation and its Environment in Denmark \\ in the Early Weichselian Glacial (Last Glacial)}

by

Svend Th. Andersen

Dansk sammendrag:

Vegetationen og dens kår i Danmark i tidlig

Weichsel Glacialtid (Sidste Istid)

With 15 Plates

I kommission hos

C. A. REITZELS FORLAG (JØRGEN SANDAL)

KØBENHAVN 1961 


\section{PREFACE}

In 1928 Knud Jessen and V. Milthers published their monumental study of interglacial fresh-water deposits in Denmark and Northwest Germany. This work, the palaeobotanical part of which was carried out by K. JEsSEN, continued the tradition established by N. HaRTZ, in 1909. However, its pollen-analytical part represented a pioner work still of great importance for studies of Pleistocene stratigraphy in Northern Europe.

With the progress of pollen-analysis during the past 30 years it became clear that a re-study of our interglacial deposits especially using this technique would be desirable and promising, and it was with high expectations that the present author in 1954 undertook this project. In the years 1954 to 1959 the work was supported by the DANISH State Research Foundation and the Geological Survey of Denmark, since 1959 by the latter institution alone. The present publication comprises only the new studies of the "Upper Temperate Stage" of the Last Interglacial as described by Jessen and MILTHERS. A re-study of this problem seemed especially desirable, and the author believes that the information obtained now is representative, and that a publication of the detailed results is useful.

Travels to England, Switzerland and Norway have been supported by RASK-ØRSTED Fondet and Apotheker P. C. N. Friderichsens Legat.

I thank Professor Knud Jessen, Director H. Ødum, and State Geologist Johs. Iversen for promoting the project, and especially Dr. Iversen for his stimulation of the work.

Colleagues at the Geological Survey have offered valuable help, first of all the late State Geologist Keld Mirthers. I thank State Geologist W. Christensen and Chemist K. Skousbøll Hansen for the chemical analyses, and discussions of the results. C. Westergando has offered excellent assistance with the photographic work. Special thanks go to the boring team of the Geological Survey, with whom I have spent many rainy and wind-swept days, especially to J. Spang Nielsen, boring master. His careful and accurate work created a foundation for the entire study.

Numerous recent pollen samples have been collected at the Botanical Museum of the University of Copenhagen.

Miss Ingeborg Frederiksen has drawn the complicated profiles and pollen diagrams. Her skill and care have been invaluable.

I gratefully acknowledge the cooperation of the late Professor H. DE VRIEs, Groningen, Professor E. S. Deevery jr., New Haven, and H. Tauber, civil engineer, Copenhagen, in carrying out the radiocarbon dates mentioned in chapter VIII.

Dr. John Franks of the University of Manchester has helped invaluably in correcting the English manuscript.

The English manuscript was completed June 1960.

Geological Survey of Denmark, 16. November 1960.

Svend Th. Andersen 


\section{CONTENTS}

Abstract . . . . . . . . . . . . . . . . . . . . . . . . . . . . . . 7

I. Introduction . . . . . . . . . . . . . . . . . . . . . . . . . . 9

II. Methods . . . . . . . . . . . . . . . . . . . . . . . . . . . 12

Sampling Techniques . . . . . . . . . . . . . . . . . . . 12

Descriptions of the Sediments . . . . . . . . . . . . . . . . 12

Pollen Analyses . . . . . . . . . . . . . . . . . . . . . . . . 15

Preparation of the Samples . . . . . . . . . . . . . . 15

The Pollen Diagrams . . . . . . . . . . . . . . . . . . . . 15

Pollen Zones . . . . . . . . . . . . . . . . . . . . . . . . 16

III. Identifications . . . . . . . . . . . . . . . . . . . . . . . . . . 19

General Remarks . . . . . . . . . . . . . . . . . 19

Pteridophyta . . . . . . . . . . . . . . . . . . . . 21

Gymnospermae . . . . . . . . . . . . . . . . . . . . . 22

Angiospermae . . . . . . . . . . . . . . . . . . . . . . . . . 22

Species Identifications of Pollen and Spores by Statistical Methods 29

Isoëtes, p. 30, Picea, p. 33, Betula, p. 35, Empetrum, p. 38, Plantago, p. 41

IV. Descriptions of the Sites and the Pollen Diagrams . . . . . . . . . . . 47

Brørup Hotel Bog . . . . . . . . . . . . . . . . . . . . . . . 47

Sediments . . . . . . . . . . . . . . . 47

Chemical Analyses . . . . . . . . . . . . . . . . . . . . 48

Pollen Analyses . . . . . . . . . . . . . . . . . . . . . . . . . . . 50

Rebedded Pollen . . . . . . . . . . . . . . . . . . . 50

Pollen Zones . . . . . . . . . . . . . . . . . . . . . 55

Rodebæk I . . . . . . . . . . . . . . . . . . 61

Sediments . . . . . . . . . . . . . . . . . 61

Pollen Analyses . . . . . . . . . . . . . . . . . . . . . . . 63

Rebedded Pollen . . . . . . . . . . . . . . . . . . . 63

Pollen Zones . . . . . . . . . . . . . . . . . . . . . . 63

Herning . . . . . . . . . . . . . . . . . . . . . . 65

Sediments . . . . . . . . . . . . . . . . . . . 65

Chemical Analyses . . . . . . . . . . . . . . . . . . . . 69

Pollen Analyses . . . . . . . . . . . . . . . . . . . . . . . 70

Rebedded Material . . . . . . . . . . . . . . . . . 70

Pollen Zones . . . . . . . . . . . . . . . . . . . . . . 71

Norbolling . . . . . . . . . . . . . . . . . . . . 74

Sediments . . . . . . . . . . . . . . . . . . . . . 74

Pollen Analyses . . . . . . . . . . . . . . . . . . . . . . . 74

Pollen Zones . . . . . . . . . . . . . . . . . . . . . . 75

Solsø . . . . . . . . . . . . . . . . . . . 75

Conclusion . . . . . . . . . . . . . . . . . 76 
V. Vegetation and its Environment in Western Jutland in the Pollen

Zones W 1-W 5 . . . . . . . . . . . . . . . . . . . 78

General Remarks . . . . . . . . . . . . . . . . . 78

Zone W 1... . . . . . . . . . . . . . . . . . . . . 81

Sediments . . . . . . . . . . . . . . . . . . 82

Temperature . . . . . . . . . . . . . . . . . . 82

Precipitation . . . . . . . . . . . . . . . . . . . . . 83

Soil . . . . . . . . . . . . . . . . . . . . . . . . . 84

Zone W 2. . . . . . . . . . . . . . . . . . . . . . . . . 85

Sediments . . . . . . . . . . . . . . . . . . 85

Temperature . . . . . . . . . . . . . . . . . . . . 87

Soil and Precipitation . . . . . . . . . . . . . . . . . . . . 91

Zone W 3. . . . . . . . . . . . . . . . . . . . . . . . . . . 94

Sediments . . . . . . . . . . . . . . . . . . . . . . . . . 94

Temperature . . . . . . . . . . . . . . . . . . . . . . . . 94

Precipitation . . . . . . . . . . . . . . . . . . . . . . . . 99

Soil . . . . . . . . . . . . . . . . . . . 100

Zone W 4. . . . . . . . . . . . . . . . . 101

Sediments . . . . . . . . . . . . . . . . . . . . . 101

Temperature . . . . . . . . . . . . . . . . 101

Precipitation . . . . . . . . . . . . . . . . . . . . 102

Soil . . . . . . . . . . . . . . . . . . . . . . . . . 103

Zone W 5. . . . . . . . . . . . . . . . . 103

Sediments .. . . . . . . . . . . . . . . . 103

Temperature . . . . . . . . . . . . . . . . . . 103

Soil and Precipitation . . . . . . . . . . . . . . . . . . . 104

Zone Wx . . . . . . . . . . . . . . . . . . . . . . 105

The Flora List . . . . . . . . . . . . . . . . . . . . . . . . . 106

VI. Climate and Chronology of the Early Weichselian Glacial in

Terminology . . . . . . . . . . . . . . . . . . 113

Temperature . . . . . . . . . . . . . . . . . 114

Humidity . . . . . . . . . . . . . . . . . . . . . . . . . 116

Chronology. The Rodebæk and the Brørup Interstadials . . . . . . . 117

VII. Remarks on the Vegetation of Northern Europe during the Early Weichselian

Glacial and Correlation of Early Weichselian Deposits in that Area . . . 120

Denmark . . . . . . . . . . . . . . . . . . 122

Sweden . . . . . . . . . . . . . . . . . 122

Germany . . . . . . . . . . . . . . . . . . . . 125

Poland . . . . . . . . . . . . . . . . . . . . . . . . . . 127

The Netherlands . . . . . . . . . . . . . . . . . . . . . 128

England . . . . . . . . . . . . . . . . . . . . . . . . . . . 128

VIII. Radiocarbon Dates . . . . . . . . . . . . . . . . . . . . . 130

Tables 27-33 . . . . . . . . . . . . . . . . . . . . . . . . . . . . . 135

Dansk sammendrag: Vegetationen og dens kår i Danmark i tidlig Weichsel

Glacialtid (Sidste Istid) . . . . . . . . . . . . . . . . . . . . 152

Literature . . . . . . . . . . . . . . . . . . . . . . . . 166

Plates I-XV 


\section{ABSTRACT}

The present work deals with the layers found above certain Eemian Interglacial fresh-water deposits in Denmark. Earlier investigations at these sites had indicated a "Lower Temperate Stage" and an "Upper Temperate Stage" separated by clay layers ("Middle Bed"). The existence of an upper temperate stage has been doubted by some authors. The "Lower Temperate Stage" is now usually considered the Eemian Interglacial, and the post-Eemian layers have been referred to the Last Glacial of Northern Europe, or the Weichselian Glacial, which may be defined as the time interval, which separated the Eemian Interglacial from the Postglacial.

Methods of investigation are described in the chapters II-III. The basis for establishing the pollen diagrams is discussed, and it is maintained that the pollen zones should be considered bio-stratigraphic units. Problems in the identification of pollen grains and spores are discussed, and selected identifications are mentioned briefly. Statistical observations are mentioned in a special part.

Chapter IV deals with the individual sites investigated, and their sediments and pollen diagrams. It can be shown that certain layers earlier referred to the "Upper Temperate Stage" contain abundant plant fossils rebedded from the Eemian Interglacial layers, but layers of interstadial character also occur. The segregation of the secondary (rebedded) elements in the fossil floras, and zonation of the pollen diagrams are discussed.

The chapter on the earlier vegetation and its environment includes a discussion of various problems in palaeoenvironmental analysis. The vegetation and indications of temperature, precipitation and soil conditions in the various pollen zones are discussed. A list of remains of higher plants referred to the pollen zones is presented with indications of their probable primary or secondary status. The primary flora is compared with the Danish Late-Glacial flora.

The chapter on climatic development and chronology deals first with principles of Pleistocene chrono-stratigraphy. The author supports the opinion that climatic changes may serve as chronological limits. Glacials and interglacials constitute main stages, and stadials and interstadials are considered substages within the glacials. Vegetational succession and climatic changes within the sequence studied are summarized in table 24 (p. 115). The limit between the Eemian Interglacial and the Weichselian Glacial is distinguished as a large decrease of temperature. The Rodebæk and the Brørup Interstadials, two interstadials within the early Weichselian Glacial, are delimited by temperature changes. Some of the layers earlier referred to the "Upper Temperate Stage" mentioned above belong to the Brørup Interstadial.

The probable composition of the vegetation in Northern Europe in the early Weichselian Glacial is mentioned. A development similar to the Danish sequence occurred in the Netherlands, and various plant-bearing deposits from Germany, Poland and England can be correlated with these sequences.

Finally, radiocarbon dates are mentioned. The Amersfoort (Rodebæk) Interstadial is dated at 64000 years before present, and the Brorup Interstadial at 59000 years before now. Other "old" dates from Germany, England and Italy are mentioned. The results corroborate EmiLiani's palaeotemperature curve. 


\section{INTRODUCTION}

Knud Jessen and V. Milthers ${ }^{1}$ ) in their survey of interglacial freshwater deposits in Jutland and Northwest Germany (J\&M 1928), presented pollen diagrams from 2 sites in Western Jutland from the Penultimate Interglacial, and from 13 sites, which could be dated to the Last Interglacial with certainty. These authors showed that similar vegetational successions characterize deposits of similar age in North Germany. It appeared that each interglacial had its own characteristic succession, and pollen analysis thus proved to be a useful tool for the dating of late Pleistocene pollen bearing deposits. Later investigations have demonstrated the validity of the principle of regional parallelism for interglacial pollen diagrams from Northern Europe (see especially surveys by Gams 1935, Selle 1941, 1953 a, Woldstedt 1949, 1950, 1954 a, van der Vlerk and Florschütz 1953, Szafer 1953, Dyakowska 1959, Gritchuk 1955, and works by West 1956, 1957, Duigan 1956, Jessen, Andersen and Farrington 1959, WATts 1959). The pollen analytical investigations have also confirmed the reference of the Eem marine transgression to the "Lower Temperate Stage" of the Last Interglacial (cp. the works quoted above).

J \& M (l. c.) included the "Upper Temperate Stage" at Herning into the Last Interglacial, but they did not succeed in demonstrating such a stage outside of Denmark. Climatic oscillations post-dating the Eemian Interglacial have been demonstrated from a number of fields now, but no later investigations of post-Eemian sequences from Northern Europe have revealed clear indications of a warm stage with a vegetation and flora similar to that of the "Upper Temperate Stage" at Herning, which was characterized by high frequencies for the pollen of Quercus, Corylus and Alnus, (see chapter VII). Hence, only the interval represented by the "Lower Temperate Stage" at Herning (corresponding to the pollen zones $\mathrm{c}-\mathrm{h}$ of the classic pollen diagrams of $\mathrm{J} \& \mathrm{M}$ ) is now usually considered to represent the Eemian Interglacial, and the following stages have been referred to the Last Glacial of Northern Europe (Tubantian, Weichselian, Baltic or Waldai Glacial, cp. Woldstedt 1949, 1953, and later, Selle 1952, 1953 a, van der Vlerk and Florschütz 1953, Florschütz 1957, van der Vlerk 1955, 1957, 1959, Szafer 1953, Dyakowska 1959, Zeuner 1954, Gritchuk 1955, von der BreLIE 1955)²).

The lack of a stage that resembles the "Upper Temperate Stage" from Herning has been explained by reference to experiences from elsewhere that such a horizon may consist of rebedded interglacial material. Thus Thомson (1941) in a pollen study of the interglacial at Ringen, Esthonia, observed that the covering layers contained material derived from the interglacial deposit itself. Later Thомson (1951) found similar conditions at the interglacial profile at Wallensen, Germany. Here pollen and spores from plants typical of the flora of the interglacial deposit such as Carpinus, Alnus, Quercus, Picea and Osmunda re-appear in the covering mineral layers together with

1) For convenience these authors will be abbreviated $J \& M$ in the following.

$\left.{ }^{2}\right)$ "Weichselian Glacial" will be used in the following for the cold interval which separated the Eemian Interglacial from the Postglacial (see also p. 114). 
pollen of definitely Tertiary age. Thomson (1. c.) recognized these upper layers as redeposited material brought into the basins by periglacial erosion during a following cold interval, and mentioned the possibility that the "upper temperate horizon" at Herning and other sites described by $\mathrm{J} \& \mathrm{M}$ had formed in a similar way (cp. also WoLDSTEDT 1949 and later).

Conditions similar to those from Ringen and Wallensen are known from the famous interglacial deposits at Hoxne in East Anglia, England, too. During the investigations of ReID (1896) a bed of clay mud (bed C) with fruits and leaves of arctic as well as temperate plants had been found above the interglacial deposit. Reid (l. c.) assumed that this layer had formed during an aretic interval, and that the remains from temperate plants had been derived by erosion of older deposits, an opinion, which was confirmed by the studies of WEST (1956). According to WEST (1. c.), Mork's concept of an "upper temperate horizon" was based on a misinterpretation of weathered marginal parts of the interglacial deposit proper. Based on his own and ReID's observations from the sequence at Hoxne West (l. c.) also advanced the opinion that the "upper temperate horizon" at Herning and other sites in Jutland could have formed by periglacial erosion processes similar to those having taken place at Hoxne.

Improvements of the technique of pollen analysis during the past 30 years made it clear that a revision of the results of $\mathrm{J} \& \mathrm{M}$ was desirable. The improvements of special significance for the present problems are the introduction of the HF-technique, which makes it possible to obtain saticfactory pollen spectra from deposits of clay and silt, a realization of the significance of non tree pollen, and the discovery that the pollen found in predominantly mineral sediments may be contaminated with pollen derived from older deposits (cp. especially Iversen 1936 a). To this may be added that confidence in the potentialities of pollen analysis to reflect the character of earlier vegetation and its environment has increased substantially. Especially the interpretation of the relationship of pollen representation and environmental factors in the Late-Glacial (cp. especially Iversen 1954) is important for an understanding of the present problems.

Another point of improvement is the boring technique. The deposits in question are difficult to sample, and J\&M (l. c.) themselves expressed discontent with the technique available, which did not allow sampling at close intervals. Furthermore, the technique did not allow recovery of the samples in an undisturbed condition, a fact which was a disadvantage in the description and interpretation of the sediment sequences.

The "Upper Temperate Stage" is not represented in the pollen diagrams of J \& M (l.c.) in detail. It appears also that rebedded pollen may be present in some of the strata. Deposits formed at the end of an interglacial and in a following cold interval are especially likely to become contaminated in such a manner, as pollen may have been washed out not only from the boulder clays, but also from the interglacial land surface and from interglacial deposits within the local basin. A source of rebedded macrofossils would also be immediately at hand.

Preliminary accounts of the present investigations have appeared in ANDERSEN (1957a) and in ANDERSEN, DE Vries, and ZaGwisn (1960). The investigations were concentrated on the interglacial sites at which the "Upper Temperate Stage" was represented according to the investigation of J \& M (1928), namely Brørup Hotel Bog, Rodebæk I, Herning and Nørbølling. New borings have also been carried out at the site Sols $\sigma$. At the sites mentioned the strata described by $\mathrm{J} \& \mathrm{M}$ could be re-identified. The investigation of the Eemian Interglacial layers has not been finished, and only the sequences above them have been examined in detail. Evidence of a rise of the water table at the end of the Eemian Interglacial was found (cp. also J\&M l. c.), and at all of the sites investigated the mineral strata found above the interglacial layers were deposited in water in the central parts of the basins. Their marginal parts were 
often developed as solifluction deposits. It appears, accordingly, that allochtonous material may have been brought into the basins partly by wave erosion of marginal deposits, partly by washing or sliding into the lake of surface material from the area ajacent to it. Both of these sources of rebedded material have become destroyed by the erosion, and the pollen and spore content of the rebedded material cannot be determined immediately.

During the new investigations the profile from Brorup Hotel Bog has proved to offer an unusually complete record of the development during the early Weichselian Glacial. At this site rebedded pollen is absent or scarce in the layers that represent the pollen zones W 1 and W 3-5 (see below p. 16), but in zone W 2, which is represented by principally mineral layers, rebedded pollen is obviously present, and a separation of primary and secondary pollen is necessary if information about the contemporary vegetation is to be reached. Obvious difficulties exist, however. Iverses's method for a calculation and deduction of secondary pollen in Late-Glacial deposits (1936a) depends on a knowledge of the pollen content of the source of erosion and cannot be used here. A more indirect method has been used as objectively as was possible, and some results have been reached, but the method may seem elaborate. At the other sites mentioned the contamination with rebedded material has proved to be severe, and within these profiles reliable results could be obtained only for relatively short time intervals. 


\section{METHODS}

\section{Sampling Techniques}

The new borings were carried out in 1954 to 1958. As they were carried out at the sites already surveyed by $\mathrm{J} \& \mathrm{M} 1928$ (cp. above, p. 10) the borings could be placed in such a manner, that the most representative parts of the sediment series were penetrated. Furthermore, the sampling was carried out at such parts of the profiles, where the layers described by those authors could be re-identified. The separation of strata could usually be carried out in more detail. New sections based on bored profiles were established at Rodebæk I and at Herning. At Rodebæk I the section is nearly identical to the previous ones. At Herning a few revisions occur (cp. p. 68).

The sampling was carried out with a core sampler. The cores were taken in advance of a lead pipe, which was cleaned completely of loose material before each core was sampled. The sampling tubes were $14 \mathrm{~cm}$. long and $4 \mathrm{~cm}$. wide. Usually cores at a length of $10-13 \mathrm{~cm}$. were taken, depending on the hardness of the sediment. In most cases only 1-3 cm. of sediment were lost between the cores. Only sands and gravels without a fine-grained fraction could not be sampled.

The sampling method used has secured undisturbed samples of high purity, but the samples obtained were rather small. As material had to be saved for chemical analysis, radiocarbon measurements, or other purposes, the amounts available were too small for macrofossil analyses, especially as the sediments encountered were rather poor in such fossils. J \& M (l. c.) in their investigation analyzed much larger amounts of material from identical layers, and their results have been relied upon, as far as possible.

Samples for radiocarbon dating by the enrichment method (cp. Haring, de Vries and DE VRIEs 1958 and p. 131) were obtained from the uppermost peat layers at Brorup Hotel Bog (BP 1 a and BP 2, STA, cp. p. 47) with a larger core sampler. The diameter of the cores was $10 \mathrm{~cm}$. in this case. The sampler worked satisfactorily only in soft deposits, and it was not generally useable.

In some cases it has been possible to reach the deposits concerned by excavations, but long profiles have not been accessible.

\section{Descriptions of the Sediments}

The sediment sequences will be described in chapter IV. The layers subjected to a closer analysis have designations of sediment components indicated according to the system proposed by Troels-Smith (1955, slightly modified). Symbols for the sediment components have been used in the profile drawings as in Troels-Smith (l. c., slightly modified). Abbreviations and symbols for the sediment components are indicated on plate V.

The classification of sediments according to Troels-Sмitu (l. c.) is based on the relative proportions of the volumes of the components. The degrees of proportions are usually sufficiently coarse for an estimate in the field or during preparation of the samples for pollen analysis (see p. 15). 
In certain cases it has been important to know the amount of allochtonous mineral matter more exactly. As silicates dominate the mineral proportion of the samples (for details, see chapter IV), the content of allochtonous minerals could be estimated by determinations of mineral versus organic content.

Organic content was determined as loss on ignition and by determination of "humus" content. The determination of loss on ignition can be carried out even on very small samples, and is used widely as a measure of organic content. In addition to organic matter, $\mathrm{CO}_{2}$ derived from carbonates, $\mathrm{S}$ from ferrosulfides, and chemically bound water enter this quantity. Carbonates and ferrosulfides are virtually absent in the present cases (see pp. 48 and 69), but chemically bound water constitutes an unknown factor within the loss on ignition. For control, the "humus" determinations were carried out on larger samples. The $\mathrm{C}$ content was determined by wet combustion with dichromate, and the "humus" content calculated according to the methods described by BONDORF (1945). The calculation factor $(\times 1.72)$ used by Bondorf (l. c.) is presumably somewhat too small in the present cases (cp. HANSEN 1959). Pairs of determinations of organic content by the two methods just described are shown in table 1 .

Table 1. Determinations of the loss on ignition and "humus" content (see the text).

The figures indicate percentages of the dry weight. Bestemmelser af glødetab og "humus"-indhold (se teksten).

Tallene angiver procenter af tørvægten.

\begin{tabular}{l|c|c}
\hline & $\begin{array}{c}\text { Loss on } \\
\text { ignition }\end{array}$ & $\begin{array}{c}\text { "Humus" } \\
\text { content }\end{array}$ \\
\hline Brørup Hotel Bog: & $13 \%$ & $8 \%$ \\
& 21 & 14 \\
& 24 & 22 \\
& 32 & 27 \\
& 46 & 37 \\
Herning: & 81 & 73 \\
& 90 & 84 \\
& 9.1 & 1.4 \\
& 17 & 8.1 \\
& 18 & 6.4 \\
& 22 & 12 \\
& 24 & 16 \\
& 31 & 24 \\
\hline
\end{tabular}

The figures in table 1 show that the relative differences of the results arrived at by the two methods are largest in the cases with a high mineral content, where chemically bound water is of greatest influence. The determinations are shown graphically in fig. 1.

It may be concluded with regard to this material that the true organic content is approximately intermediate between the figures reached by the determinations of the loss on ignition and the "humus" content, and that it differs from these figures by only a few per cent. The detailed results of the determinations will be discussed in chapter IV.

The main part of the mineral matter must be assumed to have been transported into the lakes. Its proportion in the sediments must have depended on wave erosion, extent and rapidity of affluents, extent of superficial erosion within the catchment area, and on the intensity of organic production in the lakes. Material transported by wind could not be demonstrated in significant quantities. Figures for the mineral content in 


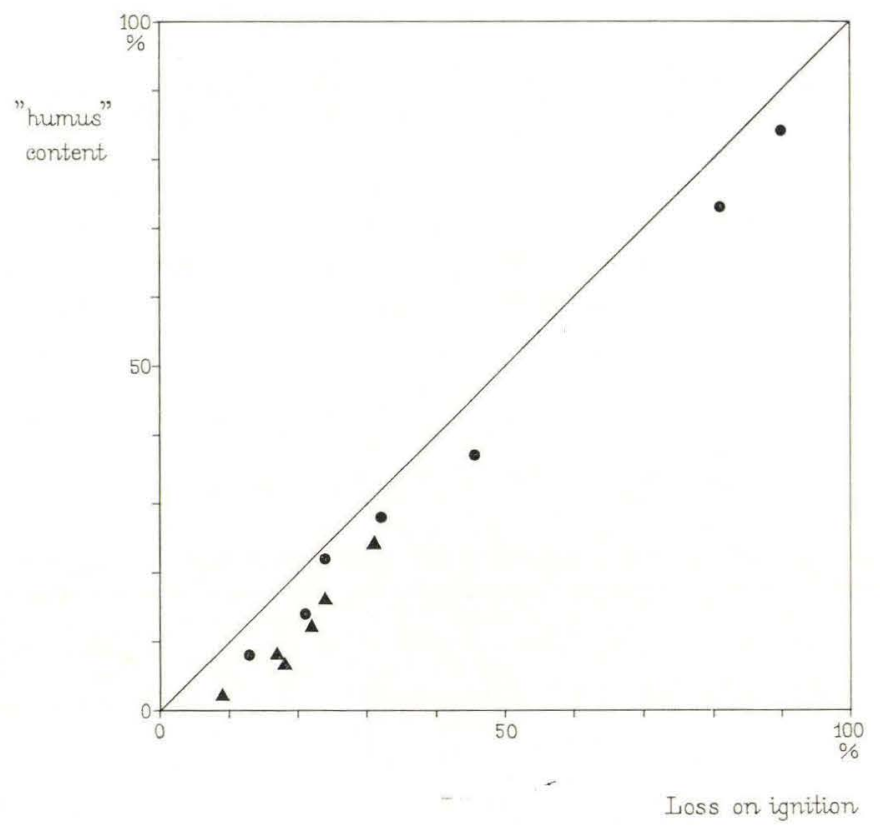

Fig. 1. Correlation of loss on ignition and "humus" content in the samples from Brørup Hotel Bog (•), and from Herning ( $)$, in percentages of the dry weight. Korrelation af glødetab og ,humus““ indhold i prøver fra Brørup Hotel Mose (•) og fra Herning ( $\mathbf{A})$, i procent af torvægten.

similar sediments in present-day Danish lakes may be found in Hansen (1959). Autochtonous peats very often contain little or no mineral matter. Frey and Stahl (1958) have shown that the production of organic matter is low in arctic lakes (cp. also Fuerdingstad 1954, Frey 1958), and predominance of mineral sedimentation in lakes in connection with a cold climate is well known for Late-Glacial profiles. LIvingstone (1957) has shown for Linsley Pond in Eastern United States that an excess of mineral content (loss on ignition less than 15\%) in the deepest layers was due to allochtonous influx in connection with lack of forest and a cold climate.

A high mineral content may be connected with presence of rebedded pollen and spores. IvERSEN (1936a) showed for Late-Glacial sediments that there may be a close correlation between their content of allochtonous mineral matter and the occurrence of rebedded pollen and spores. In the material discussed here it must be supposed that interglacial deposits were eroded at certain times. It will be shown in chapter IV that there may be a close correlation between the proportion of allochtonous mineral matter and the occurrence of rebedded pollen and spores.

In certain cases the grain size of the mineral fraction was determined by mechanical analysis. However, such a procedure was impossible where organic content exceeded $15-20 \%$.

The composition of the sediments and their content of remains of local plants may give information about the degree of wetness, the succession of the local vegetation, and changes in the local environment. Thus changes of water level may be reflected. The deposits studied here formed in depressions without major affluents or outlets. Their water level depended, accordingly, to a high degree on precipitation, evaporation, and run-off from the catchment areas. The run-off may depend on many factors such 
as size and topography of the catchment area, texture of the soils, precipitation and evaporation, but changes in the amount of run-off are likely to have been due to climatic changes. Hence, it is likely that the changes in the water levels of the lakes were due to climatic changes, such as changes in precipitation, changes in temperature or a combination of the two. It will be mentioned in chapter VI that changes in water level and temperature changes seem to have been interrelated in detail.

\section{Pollen Analyses}

Preparation of the Samples.

All the samples used for pollen analyses were treated chemically in identical ways. The procedure may be summarized as follows,

(1) Boiling with $10 \% \mathrm{KOH}$ for 6 minutes (in water bath).

(2) Removal of sand by decanting, and of coarse-detritus by sieving.

(3) Boiling with $40 \% \mathrm{HF}$ for $5-10$ minutes. Heating with $10 \% \mathrm{HCl}$.

(4) Boiling with $10 \mathrm{ml}$. acetic anhydride $+1 \mathrm{ml}$. conc. $\mathrm{H}_{2} \mathrm{SO}_{4}$ for 1 minute (in water bath).

(5) Washing with glycerin and staining with fuchsin.

The material was mounted in glycerin. The slides were kept unsealed. All measurements were carried out shortly after the preparation to avoid swelling (cp. ANDERSEN 1960).

\section{The Pollen Diagrams.}

The pollen analyses comprise pollen and spores of vascular plants, and Sphagnum. The results are shown in the pollen diagrams, plates VI-XIV. Pollen and spore types represented by a few finds only are listed in the tables 28-33 (pp. 138-151). Pollen and spore types noticed in a sample outside of the analysis are indicated in the pollen diagrams and in the tables by $\mathrm{a}+$. The investigation of the layers from pollen zone $\mathrm{h}$ is unfinished, and only the most important curves are shown.

The pollen diagrams illustrate the relative frequencies of pollen and spores incorporated in the sediments. In pollen analysis it is usually attempted to eliminate the influence of facies by omittance of pollen and spores produced by plants from the local basins, where the deposits formed, from the basis of calculation. Each taxonomic unit identified from pollen or spores (family, genus, species group, or species) may represent (1) only plants known to grow in well drained soils, (2) plants, which may have grown in well drained soils as well as in soils with a high ground water level, and (3) only plants preferring water-logged soils. Pollen and spores from plants presumed to belong to group (3) have been omitted from the pollen totals, as they may be overrepresented in most of the sediments due to pollen or spores, which fell or sank from the parent plant directly into the sediment. The plants from group (2) may have become overrepresented in the same manner, but they do not seem to be seriously overrepresented in the lacustrine sediments. In such deposits the curves for e. g. the Gramineae and the Cyperaceae follow the frequencies for herbs from group (1) (e. g. Artemisia, Rumex acetosella). In the peats, the plants from the groups (2) and (3) are very likely to become overrepresented by pollen or spores dispersed from individuals that grew locally. Here the influence of facies may become prevalent, and it may be impossible to obtain a picture of the vegetation outside of the basin. In the present pollen diagrams maxima of the Cyperaceae pollen at certain levels correspond to peat layers, and clearly indicate local overrepresentation. 
The pollen totals comprise about 1000 pollen grains and spores, except for some of the samples from Herning, where the totals comprise about 500 pollen grains and spores. The figures are indicated in the text at the pollen diagrams.

The percentages shown in the pollen diagrams are based on numbers directly without reduction to eliminate the effect of the different pollen production rates of the plants represented (cp. i. a. FAgRI and IvERSEN 1950). The mode of representation of the various components of vegetation poor in trees in the pollen content of contemporaneous lake sediments is not known very well. Iversen (1947) compared the pollen content in lake sediments with the composition of the vegetation in Greenland. According to this study it appeared that Betula nana was overrepresented in the pollen flora of the lake sediments, and that Salix, Ericaceae (Calluna absent), Gramineae and Cyperaceae were underrepresented there. Empetrum hermaphroditum was represented equally in the pollen flora and in the general vegetation. However, no species of trees occur in the area investigated by Iversen (1. c.). Scattered individuals of trees such as Pinus silvestris and Betula pubescens may become overrepresented because of intense flowering due to full illumination, or they may produce very few flowers due to low temperatures. Insect pollinated herbaceous plants are certainly underrepresented. Hence, the pollen percentages can be interpreted only in general terms in the present cases. Changes in the relative abundance of the plants, however, may be clearly detected.

The pollen diagrams have been divided into the parts A, B and C. Part A is a total diagram, which illustrates the relative abundance of the pollen from trees + shrubs, herbs and Ericales with special curves for Betula and Cyperaceae. Part B illustrates in silhouettes the frequencies for plants belonging to the groups (1) and (2) mentioned above. The curves have been arranged according to earliest maximum frequencies within the diagram. They have been numbered, and the numbers will be indicated in the description of the pollen diagrams in order to facilitate the reading of the diagrams. Part C illustrates the relative frequencies of pollen and spores from local plants. They have been calculated on basis of the pollen totals used for the other curves (see above). The values of the frequencies for the plants that occurred locally have little meaning, as such species may disperse their pollen and spores into the sediment at highly different rates, depending also on the location of the sampling point within the local basin. However, the changes in their frequencies may be of interest for a study of the local successions. These curves have been arranged and numbered in the same way as those found in part B of the pollen diagrams. Summation curves for ecological categories of local plants (Limnophytes, Amphiphytes and Telmatophytes, cp. Iversen $1936 \mathrm{~b}$ ) are shown. They include pollen and spores identified sufficiently narrowly to allow a classification into one of the categories mentioned.

In some of the sediments predominance of mineral matter indicates erosion and influx of allochtonous material. Here problems as to a distinction between primary and rebedded pollen arise. They will be discussed in detail in chapter IV.

Other microfossils have been counted only exceptionally. Algae especially occur usually in highly varying modifications, and a quantitative examination will require special techniques (cp. Iversen 1954, Fjerdingsted 1954).

\section{Pollen Zones.}

The units of vegetational history are the pollen zones. A distinction of pollen zones is usually based on characteristic shifts in the relative frequencies of certain pollen types, and such pollen zones should, accordingly, be considered to be biostratigraphic units (cp. Hedberg 1954). As it is possible to minimize the influence of facies (see above), the pollen zones do not refer to the local basins. Their borders may be synchronous 
and pollen zones may be useful for time correlations in a limited area, but pollen zones cannot be considered to be time units in a wide area, and time units must be distinguished on some other basis (see also p.113). Pollen zone borders may reflect climatic changes, but they cannot always be assumed to coincide with the climatic changes, as there may be a time lag between such a change and its response in the vegetation. Thus van DER Hammen (1951) discussed the conventional Late-Glacial zone borders in Northern Europe and concluded that some of them may be assumed to reflect a climatic change directly (i. e. a decrease in the summer temperature), but that others reflect the reaction of the vegetation to a climatic change, which took place somewhat earlier (cp. also Iversen 1954).

J\&M (1928) established their pollen zones for the Eemian Interglacial and the following sequence at a time, when the significance of non-tree pollen had not become realized. For that reason it has been necessary to define new pollen zones for the intervals studied.

With the increased application of pollen analysis to deposits of interglacial and glacial age it has become convenient to number the pollen zones from interglacials and glacials separately (SELLE 1953a). For such reasons it seems to be convenient to let the Eemian Interglacial pollen zones end at the point, where forest vegetation decreased and pollen from non-forest vegetation became prevalent. A new system of pollen zones was established for the vegetational sequence which followed upon the Eemian Interglacial in Western Jutland (cp. ANDERSEN 1957 a). Below, the main features of the pollen zones will be described in terms of pollen representation and vegetation.

\section{Zone h (cp. J\&M 1928).}

Picea, Alnus and Pinus are frequent. Quercus, Carpinus, Ulmus, Fraxinus and Taxus are represented, but their values are low. The values for Pinus increase somewhat in the course of the zone. At the end of the zone Alnus and Pteridium decrease to insignificant values, or disappear.

\section{Zone W 1.}

Pinus, Picea and Betula pubescens are represented with values, which indicate that only scattered individuals may have been present. The values for Betula nana, Juniperus, Salix, Calluna, Empetrum, Gramineae, Cyperaceae, Rumex acetosella (type), R. acetosa and other herbs increase.

\section{Zone W 2.}

Picea, Pinus and Betula pubescens may be represented with low values, and most of their pollen was presumably due to wind transport from a far distance. Betula nana, Juniperus and Salix are common in most of the zone. Calluna and Empetrum become rare (except for rebedded pollen). Gramineae, Cyperaceae, Rumex acetosella (type) and other herbs prevail. The zone has been divided into the subzones a-e, which are not always clearly distinguishable.

Subzone a. Maxima for pollen of Juniperus, Artemisia a. o. Remains of aquatic plants common.

Subzone b. Maximum for Gramineae. Remains of aquatic plants rare.

Subzone c. Maxima for Juniperus, Artemisia a. o. Remains of aquatic plants common.

Subzone d. Juniperus decreases (and disappears?). Maxima for Gramineae and Cyperaceae. Remains of aquatic plants rare.

Subzone e. Increasing values for Betula pubescens, Populus, Artemisia, Filipendula, Urtica and a few others. Remains of aquatic plants common. 


\section{Zone W 3.}

Betula pubescens dominates and Populus is frequent. Pinus may be represented by pollen transported from far distance. Betula nana remains fairly frequent. The herb pollen values decrease strongly. Filipendula, Urtica, Thelypteris dryopteris and Rumex acetosa are quite common. The zone is divided into the subzones a-e.

Subzone a. Maximum for Betula pollen. Decrease for i. a. Salix, Gramineae, Cyperaceae, Rumex acetosella (type).

Subzone b. Minimum for Betula. Maxima for Salix, Gramineae, Cyperaceae etc.

Subzone c. Maximum for Betula. Strong increase for Juniperus. Minima for Salix, Gramineae etc.

Subzone d. Minima for Betula, Populus and Juniperus. Maxima for Salix, Gramineae etc.

Subzone e. Maxima for Betula, Populus, Juniperus and Frangula. Minima for Salix, Gramineae etc. Larix is represented.

\section{Zone W 4.}

Betula decreases somewhat. Pinus, Picea and Larix are represented with considerable values. Quercus, Alnus and Corylus are also represented, their pollen was probably transported from far distance by wind. Frangula and Pteridium are quite common. Calluna and Empetrum increase somewhat. Juniperus and most of the herbs are rare.

\section{Zone W 5.}

Pinus pollen dominates. Picea and Betula decrease. Calluna increases. The zone is divided into the subzones a-c.

Subzone a. Juniperus and the herb pollen have low values.

Subzone b. Small maxima for Betula, Juniperus and herb pollen.

Subzone c. As subzone a.

Upwards the record is truncated.

\section{Zone W $\mathrm{x}$.}

The zone is represented only at Brorup Hotel Bog, and is separated from zone W 5c by a hiatus. The pollen spectra are dominated by herb pollen. 


\section{IDENTIFICATIONS}

\section{General Remarks}

All identified remains of higher plants from the pollen zones W 1-W 5 are listed in table 23 (pp. 107-111). The identification of the finds from zone h has not been finished. A majority of the identifications of macrofossils listed in table 23 derive from the investigation of J \& M (1928). Particulars as to the dating of the remains will be mentioned in the chapters IV-V.

The plant remains have been identified with present-day species. This implies that the fossil remains resemble similar organs from these species. The identifications based on macrofossils are considered to be more reliable than the identifications of pollen grains and spores. It is characteristic of the identifications of pollen and spores, that many of them are restricted to family, subfamily, genus or species group, and a distinction of species may be reached rather exceptionally. "Type" has been added to generic and specific names to indicate that other present-day taxa of the same rank are possible. The taxa embraced by the types will be mentioned below. Genera monotypic in North and Central Europe today are usually indicated with species name. In the pollen diagrams (plates VI-XIV) genera, which are represented by macrofossils identified with a species, have been indicated with this species name in brackets.

The species names are in accordance with HyLander (1941), and authors' names for species not mentioned there will be indicated in the list on table 23 and in the descriptions below.

The relationship of Pleistocene floras to the flora of the present day will be mentioned in some detail in chapter $\mathrm{V}$.

The degree of reliability of the identifications of pollen grains and spores is indicated in table 23 too. Identifications from table 23 of particular interest will be discussed below.

The modern reference material is found in the collection of the Geological Survey of Denmark. It has been supplemented in some cases with material borrowed from the National Museum, Department of Natural Science, at Copenhagen. The extent of the reference material will be mentioned in the descriptions.

Apochromatic objectives of a high numerical aperture (ca. 1.30) were used for the study of the morphological details of the pollen grains and spores. Phase-contrast equipment has been used in a complementary way, and introduction of a lamp of a high luminosity (LEITz zenon lamp) has improved the use of that technique greatly. It will be stated expressively in the descriptions below, when phase-contrast was used in making the observations.

Only details necessary for the identifications will be mentioned, and discussions of general morphology will be omitted. The observations have been based on the reference material itself, and they make no claim to originality. The work of Erdtman (1952) is referred to for an extensive bibliography. A majority of the problems coincide with those dealt with by IvErsen in his studies of Late-Glacial deposits. Cases where unpublished observations by IVERSEN and others have been guiding for the identifications will be stated. The terms are defined in Iversen and Troels-Smith (1950). Abbrevia- 
tions used are listed in table 2, in alphabetical order. Most of the reference slides had been treated with $\mathrm{KOH}$ and acetolysis mixture, and were mounted in glycerin-jelly, as the work was carried out before the qualifications of silicone oil as a mounting medium (ANDERSEN 1960) had been realized. In general, only large size differences have been relied upon.

The problem of possible variability in the morphological characteristics used for identifications should be considered. As variability may be genotypical or phenotypical, modern reference material from several individuals, and from individuals from various habitats should be examined, and an effort has been made that the reference material should not be too limited. The discontinuities between the taxa are in many cases so large that they need no special investigation. It has been possible to use statistical methods for a distinction of species in some cases. They will be mentioned on pp. 29-46. Jentys-Szaferowa and Truchanowicz (1953) demonstrated outstanding examples of the usefulness of a comparison of the variability in the fossil and the modern material, and similar investigations on a comprehensive basis are highly desirable.

Table 2. Abbreviations for morphological terms and parameters (cp. Iversen and Troels-Smith 1950).

Forkortelser af morfologiske udtryk og mål (sml. Iversen og Troels-Smith 1950).

\begin{tabular}{|c|c|c|c|}
\hline aeq & aequator, aequatorialis & $\mathrm{Lg}$ & longitudo \\
\hline anl & annulus, annuli, annulatus & lum & lumen, lumina \\
\hline ap & apex, apices & M & mensura \\
\hline C & colpus, colpi & med & medianum \\
\hline C 1 & Monocolpatae & mur & murus, muri \\
\hline C. 3 & Tricolpatae & op & operculum, opercula \\
\hline C 3 P 3 & Tricolporatae & $\mathrm{P}$ & porus, pori \\
\hline C. P stp & Stephanocolporatae & P 3 & Triporatae \\
\hline & clava, clavae, clavatus & P peri & Periporatae \\
\hline col & columella, columellae & perprol & perprolatus \\
\hline $\operatorname{cost}$ & costa, costae & pol & polus \\
\hline D & diameter & polar & area polaris \\
\hline ech & echinus, echini, echinatus & prol & prolatus \\
\hline ekt & ektexina & psi & psilatus \\
\hline end & endexina & ret & reticulum, reticulatus \\
\hline foc & focus $(0-5$, see plate $X$, in & rug & rugulatus \\
\hline & Iversen and Troels-Smith l.c.) & sea & scabratus \\
\hline fos & fossula, fossulae, fossulatus & subsph & subsphaeroideus \\
\hline fov & foveolatus & str & striatus \\
\hline I & index, indices & tec & tectum, tectate \\
\hline inter $\mathrm{C}$ & intercolpium, intercolpia & tec (perf) & tectum perforatum \\
\hline inter $\mathrm{P}$ & interporium, interporia & val & valla, vallae \\
\hline 1 & limes & ver & verruca, verrucae \\
\hline Lg & longitudo & inter $\mathrm{P}-\mathrm{M}$ & length of interpore meridian \\
\hline Lt & longitudo transversalis & ex-M & thickness of exine \\
\hline P-M & pore diameter & end-M & thickness of endexine \\
\hline $\begin{array}{l}\text { P-Lg and } \\
\text { P-Lt }\end{array}$ & $\begin{array}{l}\text { longitudo and longitudo trans- } \\
\text { versalis of the pore in bipolar } \\
\text { grains }\end{array}$ & $\begin{array}{l}\text { ekt-M } \\
\text { col-D } \\
\text { polar-M } \\
\text { polar-I }\end{array}$ & $\begin{array}{l}\text { thickness of ektexine } \\
\text { diameter of columellae } \\
\text { longest side of polarea } \\
\text { polar-M/Lt }+\end{array}$ \\
\hline
\end{tabular}

C $\alpha$ 1-4 refers to the shape of the colpus, P $\beta$ 1-3 to the delimitation of the pore (cp. IvERSEN and Troels-Smith l. c.).

perf has been used as an abbreviation for perforations or holes of the tec smaller than $1 \mu$ in diameter, perf-D for their diameter. 
Pollen zones and sites will be indicated at the finds mentioned below $(\mathrm{B}=\mathrm{Brørup}$ Hotel Bog, $\mathrm{R}=$ Rodebæk I, $\mathrm{H}=$ Herning, $\mathrm{N}=$ Norbølling).

Serial photo-micrographs (cp. Iversen 1954) of fossil finds are listed in table 27 (pp. 135-136). Usually 6-8 micrographs at $1000 \times$ magnifications of each pollen grain exist. A few of the pictures have been reproduced in the plates I-IV.

\section{Pteridophyta}

\section{Azollaceae}

Azolla filiculoides Lam. One massula was referred to the species (cp. West 1953). It occurred at Herning (zone W 2) in a stratum, which is rich in material rebedded from the Eemian Interglacial bed. From Europe the species is known mainly from deposits from the Cromerian and the Hoxnian Interglacials (VAN DER VleRK and Florschütz 1953, West 1956, ZagwiJn and Zonneveld 1956, Sobolewska 1956a). The find from Herning suggests presence of the species in the Eemian Interglacial, but remains of the species have not been found in a primary position at that site. Hiltermann (1954) reported remains of the species from Eemian Interglacial deposits also in a secondary position. Iversen (1936a) found one massula in moraine A at Esbjerg.

\section{Lycopodiaceae}

Lycopodium. Fossil spores were identified with the following species: L. selago, L. inundatum, L. clavatum, L. complanatum ssp. chamaecyparissus and $L$. alpinum-complanatum type, which comprises $L$. alpinum and $L$. complanatum ssp. anceps. An unpublished key by FæGRI was used for the identifications. The spores from the species $L$. selago, L. inundatum, L. annotinum and $L$. clavatum are identified without difficulties. The spores of $L$. alpinum and $L$. complanatum ssp. anceps are rather uniform in our material. 6-8 lum may be counted on a med of the distal face, and the ret covers a variable part of the proximal face in spores from both species. The spores of $L$. complanatum ssp. chamaecyparissus are somewhat similar, but the corresponding number of lum is usually 10-12, and the mur appear to be broader than in the spores of the species just mentioned.

\section{Osmundaceae}

Osmunda. The fossil Osmunda spores vary somewhat more than the spores of European Osmunda regalis, according to our reference material. The spores of the present-day species of the genus differ as follows (O. regalis: Denmark, 2 collections, Ireland, Spain. O. claytoniana L.: Wisconsin and New York, U.S.A. O. cinnamomea L.: Ontario, Canada, and Pennsylvania, U.S.A.),

a. Sculpture elements on proximal side fused into a ret or

rug pattern, on distal side \pm fused............. O. regalis, O. claytoniana

aa. Sculpture elements on proximal and distal side separated $O$. cinnamomea

The spores of $O$. regalis vary so widely, that they can hardly be distinguished from those of O. claytoniana. The fossil Osmunda spores vary continually, and it cannot be considered to be certain that two distinct species were present. The extremes correspond to modern O. regalis and O. cinnamomea respectively. Szafer $(1953,1954)$, West $(1956)$, Dyakowska (1956) and ZAGwiJn (1960) identified interglacial Osmunda spores with O. claytoniana, and Ananova (1954) referred such spores to O. cinnamomea. All of the spores illustrated by the authors mentioned may be referred rather to $O$. cinnamomea. This applies probably also to the spores identified with O. claytoniana by Erdtman (in G. Lundouist 1955), Sobolewska (1956 b) and ŚRoDoñ (1957), at least, the spores of that species can hardly be distinguished from those of $O$. regalis.

Macroseopic remains (leaves i. a.) from Eemian Interglacial deposits have been identified with $O$. regalis (HARTZ 1909, RABIEN 1953).

The Osmunda spores occur in the Eemian Interglacial layers, and in rebedded state in the younger layers.

\section{Polypodiaceae}

Thelypteris palustris type. The spores referred to the type are naked and monolete. Similar spores may be found in the genera Asplenium, Athyrium, Blechnum, Cystopteris, Dryopteris, 
Phyllitis, Polystichnum, Thelypteris (excl. T. dryopteris) and Woodsia. The trends of the curves suggest that the majority of the fossil spores belong to Thelypteris palustris.

Thelypteris dryopteris $(=$ Dryopteris linnaeana). Naked monolete spores of a long and narrow shape, and with a faint sculpture were referred to the species. Similar spores occur commonly in Danish Late-Glacial deposits, where they, just like the finds described here, have a characteristic mode of occurence (Iversen 1954, Krog 1954, Degerbøl and KROG 1959).

\section{GYMNOSPERMAE}

\section{Ephedraceae}

Ephedra distachya L. 9 pollen grains similar to those of $E$. distachya were found (zones W 2 (B, R, H), W 3 (B, H). WeLten (1957) described the pollen morphology and distribution of the Eurasiatic species with similar pollen grains. According to that author only the species E. distachya (incl. var. helvetica C. A. Meyer), E. nebrodensis Tineo, and E. equisetina Bunge come into consideration. Due to a great variability within our modern collections, a species identification does not seem to be possible. However, E. distachya is certainly the species most likely to have occurred in North and Central Europe during the Weichselian Glacial (cp. Gams 1953, Iversen 1954, Welten l. c.).

Ephedra cf. strobilacea Bunge. 5 pollen grains similar to those of the species were found (zones W $2(\mathrm{H})$, W $3(\mathrm{~B}, \mathrm{H})$, W $5(\mathrm{~N})$ ). According to Welten (l. c., cp. also Steeves and BARGHOORN 1959) the pollen grains from species with a similar pollen type may be distinguished by the number of ridges. However, the ridges cannot be counted in any of the fossil grains mentioned here. Structural features such as those described by WeLten (l. c.) have not proved to be useful for a distinction of the various species in our material. WELTEN (1. c.) found abundant pollen of a similar type in Late-Glacial deposits from Switzerland, and assumed for ecological and geographical reasons that E. strobilacea is more likely to have occurred in Europe during the Late-Glacial than the other species mentioned by him, probably with justice. Such a result applies presumably to the present material too.

Krog (1954, and in Degerbøl and Krog 1959) reported 3 finds of E. strobilacea type from Late-Glacial deposits in Denmark. Krog (1954) considered the first pollen grain found by him to be rebedded from Tertiary deposits, as pollen of such an age occurs in the sample in question. The later finds mentioned by Krog (Degerbøl and Krog l. c.) may be of similar origin, but in view of WeLTEN's results from Switzerland just mentioned, it appears to be likely, that all of the Late-Glacial Danish finds are primary. The finds from Brørup and Herning (W 3) occur in samples with no Tertiary material. These finds are, accordingly, quite reliable, but the other finds from Herning mentioned might have been derived from Tertiary deposits, as other pollen types of such an age occur in the samples in question. However, all of the finds from Denmark may be considered to be primary now.

It is interesting to notice that the ratio E. distachya: E. strobilacea pollen grains in the present material is 9:5, and in WelteN's (much larger) Late-Glacial material (l. c.) 4:1. The pollen of $E$. cf. strobilacea seems to have been extremely rare in the Danish Late-Glacial.

\section{Pinaceae}

Larix. Characteristic pollen grains occurred in the zones W 3 (B), W 4 (B, N), W 5 $(B, N)$, and leaf fragments with epidermis cells referable to the genus (cp. FLoriN 1931, Trautman 1953) were found in layers from zone W 3 and zone W 4 (B, see plate I). One leaf fragment was found in the material originally examined by J \& M (1928, see also plate I).

\section{Angiospermae}

Alismataceae

The pollen grains found within the family belong to P peri. They are tec, ech or sca. $\mathrm{P}$ are often surrounded by an area, where the col are densely crowded (anl). Below, details of the sculpture are described as seen with ordinary optics, structural features as seen with phase contrast.

Sagittaria sagittifolia. Ech, P irregular, col evenly spaced.

Damasonium alisma Mill. Sca, P number about 10, col evenly spaced.

Caldesia parnassifolia (Bassi) Parl. Sca, P number about 15, col evenly spaced. 
Alisma plantago-aquatica. Sca. P surrounded by a broad anl, the 1 of which usually is sharp. The col found in the inter $\mathrm{P}$ are arranged in a ret, mur are delicate with col in one or two rows. The ret may be rather diffuse. A. graminea and lanceolata: ret usually diffuse and col rather irregularly scattered.

Echinodorus ranunculoides. Similar to the pollen of Alisma plantago-aquatica. P may be somewhat smaller.

Elisma natans. Sca, the sculpture is definitely coraser than that found in the pollen of the other genera mentioned (except Sagittaria, the pollen of which is ech), and the sculpture elements (microech) may be seen along the outline of the grains in foc 5 (ordinary optics!). Anl indistinct, formed by rather few col. The col found in the inter P are arranged in an irregular ret, mur are broad with clumps of densely crowded col.

Fossil pollen grains referred to Elisma natans occurred rather commonly at Brorup Hotel Bog (see plate I), and at Nørbølling (zone W 3). One pollen grain referred to the species was found at Herning (zone W 3). J \& M (1928) referred 6 achenes found at Brorup Hotel Bog to Thalictrum? The achenes occurred in the layers $\mathrm{E}$ and $\mathrm{F}$, which correspond to pollen zone W 3 (p. 57). Thalictrum pollen is rather common in that zone (see the pollen diagram from BP 1 STA, plate VI), but the achenes found by J \& M cannot be referred to any North or Central European species of the genus, i. a. as the basis of the achenes are too broad, and as the longitudinal ribs are by far too numerous. They have, however, proved to be identical to the achenes of Elisma natans. The 6 achenes are $2.3-2.6 \mathrm{~mm}$. long, oblong and somewhat compressed, the basis is broad, and the basis of the style is preserved at the apex. The achenes have 15-20 longitudinal ribs (see plate I). They do not resemble those of any other European species of the family (cp. GL ̈̈̈K 1908). Finds of fruits of Elisma natans were reported from a late Pleistocene deposit in Germany by Firbas and Grahmax (1928, see p. 126), and from early Pleistocene deposits in Poland by Szafer (1954).

\section{Boraginaceae}

The family is represented in the reference material by 15 genera.

Cf. Lithospermum arvense. 1 pollen grain ( $\operatorname{Lg} 21.6 \mu$, Lt $14.4 \mu$, P 3, psi, with rudimentary C) occurred in zone W 2 (B). Only Lithospermum arvense has pollen grains somewhat similar to the fossil one. The pollen grains of $L$. officinale and $L$. purpureo-coeruleum L. differ more.

Symphytum. 1 fossil pollen grain (C stp, C 9 P 9, psi) was referred to the genus with certainty (zone W 3 (B), see plate IV).

\section{Caryophyllaceae}

It has been possible to identify fossil pollen with genera or species of the family in some cases. In other cases many genera or species have pollen grains similar to each other, and a still larger reference material will be necessary for more definite results. The modern material used for comparison includes the following genera: Agrostemma, Arenaria (4 spp.), Cerastium (8 spp.), Corrigiola, Dianthus (10 spp.), Gypsophila (4 spp.), Herniaria, Heliosperma, Holosteum, Illecebrum, Kohlrauschia, Lychnis, Melandrium (6 spp.), Minuartia (9 spp.), Moehringia (6 spp.), Saponaria (2 spp.), Scleranthus (2 spp.), Silene (10 spp.), Spergula (3 spp.), Spergularia (2 spp.), Stellaria (11 spp.), Tunica, Vaccaria and Viscaria (2 spp.).

Cerastium-Stellaria. The pollen grains of the 2 genera are characterized: Pperi, P 10-36, anl diffuse, sca, perf numerous and crowded, col heterogenous, finest around the $\mathrm{P}$, unevenly scattered in the inter $\mathrm{P}$, denser near the $\mathrm{P}$ and \pm fused with the anl. Fossil pollen grains occurred in most of the pollen zones (for Stellaria holostea, see below).

Dianthus. The pollen grains of the genus are rather characteristic: ca. $12 \mathrm{P}$, anl $0.5-1 \mu$, ech or sca, sculpture elements distinguishable in foc 5 , in foc 0 very distinct, perf very distinct, widely scattered (distance $2-5 \mu$ ), perf-D $0.5 \mu$, col conical, often distributed in pairs and often \pm arranged in a ret, col-D proximally $0.5 \mu$, distally $0.5-1.0 \mu$. Somewhat similar pollen grains occur in Saponaria officinalis (col coarser, distally $0.5-1.5 \mu$ ), Kohlrauschia, Tunica, Vaccaria, and Saponaria ocymoides (outline of the grain smoth, sculpture in foc 0 indistinct). 3 fossil grains occurred in zone W 3 (B). They resemble the pollen grains of $D$. arenarius, D. caesius Sm., D. caryophyllus L., D. deltoides and D. superbus the most.

Gypsophila. Within the family, pollen grains with anl $1.5-2.0 \mu$ broad were noticed only in Gypsophila (cp. LANG 1952) and only in the species G. repens L., G. fastigiata and G. paniculata (in $G$. muralis $0.5 \mu$ ). In pollen grains from $G$. repens and $G$. fastigiata the P number is usually 12 , in $G$. paniculata it varies and may be up to 20 .

The genus is represented with 6 fossil pollen grains, all with $12 \mathrm{P}$, and it seems accordingly, that $G$. repens or $G$. fastigiata were represented (zone W 2 (B, R, H), W 3 (B)). The Late- 
Glacial Gypsophila pollen grains from Denmark were referred to $G$. fastigiata by Iversen (1954). LANG (l. c.) identified seeds of G. repens from SW Germany also of Late-Glacial age.

Melandrium. The pollen grains of the genus are quite characteristic (perf- D $0.5 \mu$, col arranged in a ret). One exception is $M$. viscosum, the pollen grains of which resemble those of Silene species. Pollen grains of the type found in Melandrium occur in Silene conica too. One fossil pollen grain was identical to the pollen of the genus (zone W $1(\mathrm{R})$ ).

Sagina nodosa. The pollen grains of the genus are characterized by their unusually small $\mathrm{P}$ (P-M ca. $2 \mu$, ca. $25 \mathrm{P}$, sca, many fine perf). The coarseness of the sculpture varies somewhat, it is less distinct in $S$. nodosa than in the other species investigated ( $S$. caespitosa, S. ciliata, $S$. procumbens, $S$. saginoides and $S$. subulata). 2 fossil pollen grains were referred to $S$. nodosa with good probability (zone W 2 (B)). One pollen grain from the Danish LateGlacial was identified to $S$. cf. procumbens by Iversen (1954).

Scleranthus. The beautiful pollen grains of the genus are unique. The species are well distinguished, as the pollen grains of $S$. perennis have $12 \mathrm{P}$ and those of $S$. annuus (incl. $S$. polycarpos Torner) ca. 20. One fossil pollen grain of $S$. perennis occurred in zone W 2 (B, see plate II). Jessen referred a calyx from the same layer at Brørup Hotel Bog to Scleranthus perennis? (J \& M 1928). Simpson and WeSt (1958) identified a pollen grain of the same species.

Silene-Arenaria type. Pollen grains similar to each other are found in Silene, Arenaria, Heliosperma, Minuartia and Moehringia (15-30 P, anl not diffuse, sca sculpture indistinct, perf fine, rather dense, and regularly distributed). Fossil pollen grains referred to the type occurred in zone W $2(\mathrm{~B}, \mathrm{H})$ and $\mathrm{W} 3(\mathrm{~B}, \mathrm{H})$.

Stellaria holostea. The pollen grains of the species are unique among the 11 species of the genus examined (P 12, sca, scabrate elements $0.5 \mu$, perf fine and crowded, col heterogenous, coarse in inter $\mathrm{P}$, very fine around the $\mathrm{P}$, the $\mathrm{P}$ in depressions, the inter $\mathrm{P}$ forming ridges of a pentagonal pattern). The fossil pollen grains occurred in zone W $1(R)$ and W 2 (B, rebedded?).

cf. Vaccaria pyramidata. The pollen grains of the genus differ slightly from those of Dianthus (perf-D $0.5-1.0 \mu$, col-D proximally $0.5 \mu$, cp. above). Somewhat similar pollen grains occur in Kohlrauschia (sculpture coarser), Tunica and Saponaria ocymoides (perf-D and col-D $<0.5 \mu$ ). Only 1 pollen grain occurred (zone W $3(\mathrm{~B})$ ), and in view of this the identification may be considered not to be quite certain.

Viscaria. The pollen grains of the genus resemble the Silene-Arenaria type (see above) but differ as the $\mathrm{P}$ are unusually large ( $\mathrm{P}-\mathrm{M}=$ inter $\mathrm{P}-\mathrm{M}) .2$ fossil pollen grains occurred in zone W 2 (B).

\section{Droseraceae}

Drosera. In the pollen tetrads of D. rotundifolia and $D$. anglica ech are heterogenous and often of two size orders. In $D$. intermedia ech are only slightly heterogenous and rather small. 1 tetrad was referred to $D$. intermedia, (zone W $2(\mathrm{R})$ ), and 3 retrads to $D$. rotundifolia or D. anglica (zone W $2(\mathrm{R}, \mathrm{H})$, W $4(\mathrm{~N})$ ).

\section{Ericaceae}

Arctostaphylos alpina. Pollen tetrads $>40 \mu$, Polar-I $0.20-0.25$, fov-fos. 1 pollen tetrad occurred in zone W 1 (R).

A. uva-ursi. Pollen tetrads ca. $40 \mu$, polar-I $<0.35$, polar psi. Similar pollen tetrads occur in Cassiope tetragona and Chamaedaphne, which are unlikely to have occurred. In tetrads of Vaccinium type (see below) polar-I is $0.30-0.50$. The ranges overlap somewhat, and some pollen tetrads of Vaccinium type may have been included in the curves. Pollen referred to the species occurred rather commonly, especially at Brørup and Rodebæk I. Fruit-stones of the species were recorded repeatedly by J \& M (1928).

Cassiope hypnoides. The pollen tetrads of the species are quite characteristic (polar-I $0-0.30$, ver(-fos). Phyllodoce pollen may be similar ( $\mathrm{C} \pm$ diffuse). The identification of 1 tetrad from zone W 2 (B) with a very small polar-I is fairly certain.

Erica tetralix. The pollen tetrads of the species are quite characteristic (polar-I 0.25-0.40, polar psi, inter C ver(-fos). The pollen of E. cinerea is similar to that of $E$. tetralix, but the species may be disregarded in the present cases. Pollen referred to E. tetralix occurred in the zones W $1(\mathrm{R})$, W 2 ( $\mathrm{R}, \mathrm{H}$, probably rebedded), and W 4 (B).

Vaccinium type includes Andromeda, Ledum and the species V. myrtillus, V. vitis-idaea and $V$. uliginosum (polar-I $0.30-0.50$, psi). Pollen tetrads from Rhododendron and Pyrola media are somewhat similar (polar-I usually $>0.50$ ). The fossil tetrads referred to the type range $25-50 \mu$ in size, and the polar-I is $0.35-0.55$. They occurred in all the pollen zones. 


\section{Gentianaceae}

The pollen grains of the family are rather heterogenous. The reference material comprises the genera Blackstonia, Centaurium (3 spp.), Gentiana (9 spp.), Gentianella (6 spp.), Lomatogonium and Swertia.

Gentianella amarella type. The pollen of the Gentianella species (except G. tenella) are usually ret with col arranged correspondingly, but the pollen grains vary greatly within the species, and may be fov or fos, or nearly rug. Similar pollen grains occur in Gentiana bavarica L., G. kochiana Perr. and Song., G. nivalis, G. praecox A. and J. Kerner, and G. verna. Fossil pollen grains of the type are especially common in the zones $h$ and $W 1(R)$, and scattered grains were found in zone W 2 (B, R, H). Similar pollen grains were found by Iversen (1954).

Gentiana pneumonanthe. The pollen grains are strictly str (tec(perf), val parallel to C) in Gentiana asclepiadacea L., G. lutea L., G. cruciata L., G. purpurea and G. pneumonanthe. One fossil pollen grain is very similar to the pollen of $G$. pneumonanthe, which has a rather coarse sculpture (cp. Krog 1954). It was found in zone W 2 (B). Krog (l. c.) found a similar Late-Glacial pollen grain.

Swertia perennis L. Iversen (1. c.) considered the pollen grains of Swertia to be quite characteristic (C 3 P 3, psi with coarse perf, or sometimes indistinctly rug-str, col evenly scattered). The pollen grains of Lomatogonium are somewhat similar (larger and with a coarser sculpture) and similar pollen grains may occur rarely in the Gentiana species with str pollen grains mentioned above. 5 characteristic pollen grains were found in the present material (zone W 2 (B), see plate II), Iversen (1. c.) reported one Late-Glacial find.

\section{Labiatae}

The reference material comprises 24 genera.

Mentha type. Pollen grains similar to each other $(6 \mathrm{C}$, ret, col arranged in a corresponding ret) occur in Lycopus, Mentha, Origanum and Thymus. Pollen of Salvia argentea and Satureja have a similar, but finer sculpture. A few fossil pollen grains of the type occurred (B, R).

Teucrium montanum L. The pollen grains of the genus are unique (3 C, sca, ect (especially tec) thickened near the pol, but not on the polar itself (which is very small), col coarser near the pol (cp. FAgri and Iversen 1950). The fossil pollen grain (with a delicate sculpture and distinct col, from zone W 2 (R), see plate III) is similar to the pollen of $T$. montanum, and differs somewhat from the pollen of $T$. botrys L. (much larger, sculpture coarser), T. scorodonia L. (sculpture coarser), T. scordium and T. chamaedrys L., (col almost invisible).

\section{Leguminosae}

An unpublished key for Astragalus species by Iversen has been available. During the work a key by FÆGRI (1956) appeared. It has also been helpful, although its range of genera and species is too limited for the present material. The reference material comprises the following genera: Anthyllis, Astragalus (17 spp.), Coronilla, Cytisanthus, Cytisus (3 spp.), Dorychnium, Genista (4 spp.), Genistella, Lathyrus (10 spp.), Lotus (3 spp.), Medicago (4 spp.), Melilotus (3 spp.), Onobrychis (2 spp.), Ononis (2 spp.), Ornitopus, Sarothamnus, Tetragonolobus, Trifolium (14 spp.), Ulex and Vicia (14 spp.).

Anthyllis vulneraria. IvERSEN (1954) identified Late-Glacial pollen grains with the species. The pollen grains are very characteristic ( $\mathrm{Lg}$ ca. $40 \mu$, C 3 P 3 , cost C may be present, ex-M 1-2 $\mu$, sculpture rudimentary, rug or psi). 5 fossil pollen grains were found, they occur in zone W 2 (B, R)

Astragalus. The pollen grains of the species of the genus are fairly uniform, yet differences allow some species identifications. Observations made by Iversen (see above) have been guiding for the identifications mentioned below.

A. alpinus. Characteristics of the pollen grains are, $\mathrm{Lg}<30 \mu$, C $3 \mathrm{P} 3$, P-Lg $18-29 \%$ of $\mathrm{Lg}$, delicately ret on inter $\mathrm{C}$ and polar, col not visible. Somewhat similar pollen grains occur in Ononis (outline seen in foc 5 very rough, muri very distinct), A. frigidus ( $\mathrm{Lg}>30 \mu$, sculpture coarser) and species of Melilotus (P-Lg $13-22 \%$ of $\mathrm{Lg}$, polar very small, the grain almost syncolpate. As A. alpinus is a very widespread species, the fossil pollen grains found belong almost certainly to that species (cp. also Iversen l. c. ${ }^{1}$ )). Several pollen grains were found in the zones W 2 and W 3 (B). Iversen (l. c.) identified several Late-Glacial pollen grains with the species.

A. (Oxytropis) cf. campestris. 4 fossil pollen grains were referred to the species tentatively. 3 of the pollen grains mentioned may also belong to A. exscapus L. (zones W 2 and W 3 (B)). The pollen grains of the species may be characterized as follows, Lg ca. $35 \mu$, C 3 P 3 , fov on inter C, fov-psil on polar, col invisible. Similar, but somewhat smaller pollen grains

$\left.{ }^{1}\right)$ A. penduliflorus has very similar pollen 
occur in A. (Oxytropis) lapponicus and A. (Oxytropis) pilosus. One of the fossil pollen grains approaches those of A. glycyphyllus as to the sculpture (fos). Pollen from Late-Glacial deposits were identified with A. (Oxytropis) campestris type by Iversen (l. c.).

A. danicus. The pollen grains of the species may be characterized as follows, C 3 P 3 , P-Lg 13-22\% of Ig, ret on inter C, psil on polar, col invisible. Rather similar pollen grains occur in $A$. arenarius (pelar fov) and in A. cicer (somewhat larger). 2 fossil pollen grains were identified with the species with some certainty (zones W 2 (B), see plate II), IVErSEN (l. c.) identifed pollen from the Danish Late-Glacial with the species.

A. frigidus. The pollen grains of the species are rather similar to those of $A$. alpinus (see above), but they are larger, and their sculpture is coarser. 2 fossil pollen grains were identified with the species with some certainty (zones W 2 (B) and W $3(\mathrm{H})$ ). Iversen (l. c.) identified Late-Glacial pollen with the species.

Cytisus nigricans L. The pollen of the Cytisus species (C. capitatus Scop., C. nigricans L., C. ratisbonensis Schäffer) are characterized as follows (sculpture features as seen with phase contrast), subsph, C 3 , polar psil, polar-I $>20$, inter C delicately ret, col invisible. Somewhat similar pollen grains occur in Genistella sagittalis and in Genista anglica (polar ret, inter C usually ret-fov), and in Cytisanthus radiatus, Genista germanica, G. pilosa and G. tinctoria (polar-I $<20$, inter C ret-fov, larger). The pollen grains of Sarothamnus, Ulex, Onobrychis and Hedysarum differ more (prol-perprol, $\mathrm{Lg}>30 \mu$, except for Hedysarum). The fossil pollen grains were very small $(\mathrm{Lg}<20 \mu)$, and they are best referred to Cytisus nigricans, which has the smallest pollen grains. They were found in zone W 2 (B).

Genista. The characteristic fov-ret sculpture ("blocked" lum, according to FÆGRI 1956) is usual in all Genista species, according to our reference material. 3 fossil pollen grains have such a sct lpture, and were referred to the genus. They occurred in zone W 1 (B).

Lotus cf. corniculatus. The pollen grains of the genus are rather characteristic $(\mathrm{Lg}<20 \mu$, C 3 P 3, P-Lg ca. $10 \%$ of Lg, psil). Somewhat similar pollen grains occur in Ornithopus (P-Lg ca. $15 \%$ of $\mathrm{Lg}$ ) and in Hippocrepis (P-Lg ca. $20 \%$ of $\mathrm{Lg}$ ). Pollen grains referred to the genus, and tentatively to $L$. corniculalus, occur repeatedly in the present material, and especially in zone W 2 (B, H). Iversen (l. c.) identified Late-Glacial pollen grains with the genus.

Trifolium alpestre. Characteristics of the pollen of the species are, C 3, polar psil, inter C ret, col distinct. $\mathrm{P}$ are rather distinct in most other Trifolium species. Somewhat similar pollen grains may occur especially in $T$. pratense (polar ret), T. aureum, T. badium Schreb., T. fragiferum and $T$. hybridum (sculpture on inter C fov), and in T. medium (psil area extending on inter C). 3 fossil pollen grains were identified with the species with some reliability. They occur in the zones W 2 (B) and W $3(\mathrm{H})$.

Trifolium arvense. Characteristics of the pollen grains are, C 3, polar psil, psil area extends on inter $\mathrm{C}$, inter $\mathrm{C}$ fov-fos near aeq. The pollen grains of $T$. medium may be quite similar, but they are larger, and the sculpture is coarser. 3 fossil pollen grains were referred to the species (zone W 2 and W 3 (B)). The identifications seem to be rather reliable.

Vicia-Lathyrus. The pollen grains of the genera are characterized by their distinct $\mathrm{P}$, vigorous cost and usually rather short $C$ (much less pronounced cost $C$ may occur in the pollen of other genera of the family, e. g. in Anthyllis and Lotus). It seems to be impossible to reach species identifications of the fossil grains found. They occur in the zones W $1(\mathrm{H})$, $\mathrm{W} 2$ (B) and W $3(\mathrm{~B}, \mathrm{H})$.

\section{Liliaceae}

Allium cf. schoenoprasum. 12 fossil pollen grains were referred to the species tentatively. They occurred in zone W 2 (B) and repeatedly in zone W 3 (B, 1 grain at $H)$. The pollen grains of the genus are characterized (phase-contrast): $\mathrm{C} 1$, tec, on the non-apertural side psi or indistinctly ret or fov, often with numerous fine perf and in most cases with distinct $\mathrm{col}$; on the apertural side psi with densely crowded or invisible col (margo). In the pollen grains of most of the species the $\mathrm{C}$ reaches from one end of the apertural side to the other, but in a group of species (A. sphaerocephalum L., A. vineale, A. rotundum L., A. scorodoprasum) its ap extend on the non-apertural side. The pollen of the other species may be distinguished by the coarseness of sculptural features, but these features vary somewhat within the species. The pollen grains of $A$. angulosum L., A. paradoxum and $A$. ursinum are usually psi, the perf invisible or very fine, and col minute and indistinct. The pollen grains of the species A. schoenoprasum, A. montanum, A. strictum Schrad. and A. suaveolens Jacq. are usually fov-ret, perf are quite distinct and col are clearly separated from each other. In the pollen of $A$. carinatum, A. victorialis L., and A. oleraceum the sculpture and the col are definitely coarser. The fossil grains fall within the variability range of the A. schoenoprasum group, and their similarity to that species is great. 


\section{Linaceae}

Linum austriacum type. Linum pollen grains may be dimorphic in regard to size and the shape of the sculpture elements (cp. Erdtman 1952). Dimophic pollen grains were observed in the species $L$. alpinum L., L. austriacum, L. flavum L., L. hirsutum L., L. perenne L., L. tenuifolium L., and L. viscosum L. Dimorphic pollen occurs probably also in L. angustifolium L., but not in L. catharticum. In the pollen type from longistylic plants the distal ends of the sculptural elements (cla or ech) are rounded with one or a few pointed excrescences. In the other pollen type the sculptural elements are usually completely flat topped (ver), in some species with a few pointed excrescences from the edge of the platform. In the fossil material a fragment of a pollen of the type from brevistylic plants was found (see plate III). Its ver are homogenous and without excrescences, slightly polygonal in transect (foc 2). It resembles especially the pollen of $L$. austriacum, $L$. hirsutum and $L$. tenuifolium (zone W $2(\mathrm{~B}))$.

\section{Lobeliaceae}

Lobelia dortmanna. Characteristics: C 3, C $\alpha 3 \mathrm{~d}$ or f, psi, col minute but distinct (FÆGRI and Iversen 1950, describe the surface as pitted, with phase-contrast, however, the phenomenon described proves to be caused by interference from the \pm regularly distributed col underneath). A similar pollen type is found in Digitalis, which may be disregarded in the present cases. The pollen grains of Elatine proved to be "pitted" (tec(perf)) with phasecontrast equipment. 9 fossil grains were identified with Lobelia dortmanna (zone W $3(\mathrm{~B}, \mathrm{H})$ ).

\section{Polygonaceae}

Polygonum s. l. The pollen morphology and the taxonomy of the genus were treated by Hedberg (1946).

Subgenus Persicaria. The pollen grains of $P$. amphibium are well distinguished (cp. Hedierg 1. c.). Fossil pollen identified with the species occurred in zone W 2 and W 3 (B, H). P. persicaria type includes here $P$. hydropiper, $P$. lapathifolium, $P$. minus, and $P$. persicaria. Pollen grains of the type occurred in zone W 1 and W $3(\mathrm{H})$.

Subgenus Polygonum s. str. $P$. aviculare type includes here $P$. aviculare, $P$. oxyspermum and $P$. raji. 2 pollen grains were found (zone W 3 (B)).

Subgenus Bistorta. P. bistorta type includes $P$. bistorta and $P$. viviparum. Fossil pollen grains occurred in zone W 1 (R), W 2 (B, R), W 3 (B, H) and W 4 (N). Their mode of occurrence at Brorup suggests presence of $P$. viviparum in zone $\mathrm{W} 2$ and $P$. bistorta in $\mathrm{W} 3$ (see p. 92 and 97).

Subgenus Tiniaria. $P$. convolvulus type comprises here $P$. dumetorum and $P$. convolvulus. Our modern material does not support the distinction of the pollen of the two species mentioned by Hedberg (l. c.). One fossil pollen grain occurred (zone W $3(\mathrm{H})$ ).

Rumex. Modern pollen from 18 European species was examined.

The pollen of the species belonging to the sections Acetosa and Acetosella are quite well distinguished from those of the other species. The pollen grains of this type with very short $\mathrm{C}$ (large polar) were referred to $R$. acetosa (including $R$. arifolius All.), and the others to $R$. acetosella type, which comprises $R$. acetosella s. 1 . (R. acetosella, $R$. graminifolius, $R$. tenuifolius) and $R$. thyrsiflorus (cp. Iversen 1954). R. thyrsiflorus is essentially a lowland species to-day, and the species represented in zone W 2 is presumably $R$. acetosella $\mathrm{s} .1$.

$R$. domesticus type includes the species $R$. alpinus, $R$. crispus, $R$. maritimus and $R$. obtusifolius. The pollen grains are about $30 \mu$, perf numerous, col evenly distributed, P. rather large and indistinct. 1 fossil pollen grain occurred (zone W 2 (B)). Pollen of a similar type was noticed by IVERSEn (1954).

$R$. aquaticus-hydrolapathum. The pollen grains of the two species differ from the $R$. domesticus type by larger size (about $40 \mu$ ) and smaller P. 3 fossil pollen grains belong to the type (zone W 2 (R), W 3 (B and $\mathrm{H})$ ).

\section{Ranunculaceae}

The reference material comprises the genera Aconitum (3 sp.), Actaea, Adonis, Anemone (11 sp.), Aquilegia, Caltha, Clematis, Coptis, Delphinium (3 sp.), Eranthis, Helleborus (5 sp.), Isopyrum, Myosurus, Nigella, Paeonia, Ranunculus (22 sp.), Thalictrum (4 sp.), and Trollius. Pollen of Caltha, Thalictrum and Trollius have been identified repeatedly in fossil material. cf. Adonis. Pollen grains resembling those of Adonis occurred in the zones W 1 (B, R), 
W $2(\mathrm{R})$, and W $3(\mathrm{H})$. Similar pollen occurred in the interglacial peat at Rodebæk I, and the identifications do not appear to be quite reliable. They will be examined in more detail together with the interglacial finds.

Anemone. The pollen grains of the genus are rather typical (C 3 or $\mathrm{C}$ peri (4-6 C), sca, tec with numerous fine perf, col homogenous, coarse, isodiametric). Somewhat similar types in Nigella (col \pm fused, in foc 2 oblong), Eranthis (col of two size orders). The fossil pollen grains occurred in zone W 1 (R, H), W 2 (B, H), W 5 (B).

Ranunculus. The pollen grains of the genus are quite characteristic (C 3 or C peri (4-12 C), \pm sca, no perf, col of two orders, the coarse ones rather few, often penetrating the tec forming sca elements, the fine ones rather numerous). The pollen grains of the species are variable, and it has been possible to distinguish only 2 main types, $R$. trichophyllus type (fine col evenly distributed, $R$. circinnatus, $R$. fluitans, $R$. glacialis, $R$. hyperboreus, $R$. obtusiflorus, $R$. peltatus, $R$. pygmaeus, $R$. sceleratus, $R$. trichophyllus) and $R$. acer type (fine col \pm fused, arranged in a circle around each of the coarse col, $R$. acer, $R$. auricomus, $R$. bulbosus, $R$. ficaria, $R$. flammula, $R$. illyricus, $R$. lanuginosus, $R$. nemorosus, $R$. repens, $R$. lingua and the genera Clematis and Myosurus). It may be seen that the $R$. trichophyllus type comprises aquatic species. At Brørup Hotel Bog the curve for this type differs from the curve of the $R$. acer type and resembles that for Hydrophytes closely (cp. p. 56). J \& M identified nutlets with $R$. aquatilis (coll.), R. repens and $R$. sceleratus.

\section{Rosaceae}

Identifications within the family were based in part on an unpublished key by IvERSEN.

Geum-Sieversia type. In the pollen of the Sieversia species (especially S. montana (L.) R. Brown) the val often turn across the inter C (in Geum s. str. val are usually parallel to the C). The curve for the pollen grains referred to Sieversia, however, is quite parallel to that for Geum s. str.

Prunus. The pollen grains of the species $P$. avium, $P$. padus and $P$. spinosa are similar to each other ( $3 \mathrm{C}, \mathrm{C} \alpha 3 \mathrm{~d}-\mathrm{e}$, str, val delicate but distinct, end-M = ekt-M). Somewhat similar pollen grains occur in species of Sorbus, especially in $S$. aucuparia $(\mathrm{C} \alpha 3 \mathrm{~h})$ and $S$. hybrida (larger, $\mathrm{C} \alpha 3 \mathrm{c}$ ), and in Amelanchier (val coarser). 6 fossil pollen grains occurred (zones W 2 (B), W 3 (B)).

Malus silvestris. Characteristics of the pollen: $\mathrm{C} 3, \mathrm{C} \alpha 3 \mathrm{~h}$, rug, val indistinct, end-M $=$ ekt-M. Somewhat similar pollen grains occur in Sorbus hybrida, S. intermedia, S. rupicola, $S$. torminalis and Crataegus (much larger, $\mathrm{Ca} 3 \mathrm{c}-\mathrm{e}$ ). 3 fossil pollen grains were referred to the genus rather tentatively (zone W 3 (B)).

Rosa. The pollen grains of the genus are highly characteristic (C 3, P 3, distinct op, str, val fine but very distinct, often transverse to the $C$ ). The size of the pollen varies considerably within the species. 2 fossil pollen grains were referred to the genus (zones W $2(\mathrm{~B}), \mathrm{W} 3(\mathrm{H})$ ). They are rather large $(42 \times 36 \mu$, and $39 \mu)$.

Rubus. The pollen grains of $R$. chamaemorus are highly characteristic (C 3, ech), and fossil grains have often been identified. The pollen of the other species of the genus resemble those of Geum and Dryas, but they differ as to sculpture (faintly rug or str in the Rubus spp ) and shape of the $\mathrm{C}$ ( $\mathrm{C} \alpha 3 \mathrm{c}-\mathrm{f}$, indistinct $\mathrm{P}$ in the Rubus spp., cp. Krog 1954). The pollen grains of the species differ from each other as follows, $R$. arcticus and $R$. saxatilis: rug (or psi), polar-I in $R$. arcticus $>30$, in $R$. saxatilis $<30$ (cp. Krog, l. c.). $R$. fruticosus: str, val fine and parallel to C. $R$. idaeus: str-ret (or tec(perf)). 2 fossil pollen grains with polar-I 38 and ca. 35 were referred to $R$. arcticus (zone W 1 (R) and W 3 (B)), 7 fossil grains to $R$. saxatilis (zones W 1 (R) and W 3 (B)). One pollen grain was referred to $R$. fruticosus (zone W 3 (B)), and 4 to $R$. idaeus (zone W 3 (B)). Fruit-stones of $R$. idaeus were recorded by J \& M (1928).

\section{Scrophulariaceae}

Reference material: 15 genera. Sculptural and structural details were studied with phase contrast equipment.

Euphrasia-Rhinanthus. Characteristics: C 3, polar-I 21-25, psi, ex-M $1.5 \mu$, col very fine, distinct. 3 fossil grains (zone W 2 (B)).

Veronica. Characteristics: C 3, polar-I 31-35, ex-M $2 \mu$, psi, col rather coarse. 1 fossil pollen grain (zone W 2 (B)).

\section{Typhaceae}

The pollen grains of the Sparganium species and of Typha angustifolia vary considerably within the species and no reliable identifications could be made. Typha-Sparganium type 
comprises all single Typhaceae pollen grains. Tetrads were referred to $T$. latifolia. 2 dyads from zone W 2 (B) are of doubtful identity. Fruit stones of Sparganium angustifolium and S. minimum were recorded repeatedly by J \& M (1928).

Urticaceae

Urtica dioica. The pollen grains of $U$. dioica and $U$. urens differ substantially, when seen with phase contrast equipment. In the pollen grains of $U$. dioica the elements of the sca sculpture are of irregular size and distribution, in $U$. urens they are very distinct and evenly spaced (cp. Krog 1954). All the fossil pollen grains could be referred to $U$. dioica.

\section{Valerianaceae}

Valeriana. The results of WAGENitz (1956) were used for identifications. All the fossil pollen grains belonged to the ech-sca type. 7 fossil grains were referred to $V$. officinalis $\mathrm{s}$. 1 . $($ ech $0.5-1.5 \mu)$. They occurred in zone $h(B, H)$, W $2(B, H)$, W $3(B, H) .2$ pollen grains were referred to $V$. dioica (incl. V. simplicifolia (Rchb.) Kabath, ech 2.0-2.5 $\mu$ ). They occurred in zone W 3 (B).

\section{Species Identifications of Pollen and Spores}

\section{By Statistical Methods}

Statistical methods may be useful for an identification of pollen and spores, especially where small differences between species exist. The method has especially been based on differences in size (see especially Firbas 1927, Firbas and Firbas 1935, JentysSzaferowa 1928, Bertsch 1931, Fegri 1936, and later, Eneroth 1951, Cain 1940 a and later, and other literature mentioned below) in numbers of apertures (e. g. von Post 1929), and in certain parameter ratios (DONnER 1954, Walker 1955). Cases from the present material will be mentioned below. Size or pore number have been used as measureable quantities.

Genotypical and phenotypical variation in pollen and spore characteristics are difficult to distinguish. Sсносн-Вормев (1940) found that the size of untreated pollen may depend on the nutrition state of the parent plants. WAGENITZ (1955) has shown in experiments with grasses, that acetolyzed pollen of very poorly developed plants may be somewhat smaller than the pollen of fully developed plants, but that a difference is hardly appreciable in pollen of sub-normal plants. The variability in size in pollen from naturally grown plants of different geographic origin usually is small (cp. ENEroth 1. c., Christensen 1946, Cain and Cain 1948 b, Cain and Andersen, unpublished, and below). The variability in Pinus echinata pollen demonstrated by CAIN and CAIN (1948 a) is probably unique, so far, but it is not known whether it is due to genetical or physiological factors.

Speaking of the use of size statistics for identifications of pollen and spores, F EGRI and Iversen (1950) express an opinion that "as the size of a pollen grain is a rather indefinable quantity, as the method is extremely laborious, and as the reliability of the results is generally rather dubious, the method should be used only when no other is available".

Unfortunately, fossil pollen may react differently from modern pollen to chemical treatment, and the size of fossil and recent pollen mounted in glycerin is apparently only exactly the same in cases where the fossil pollen derives from an acid sediment, and if the fossil and the modern pollen was prepared with $\mathrm{KOH}$ only (Firbas and Firbas 1935, Fæari 1940, 1945, Losert 1940, Christensen 1946, Wenner 1947), but even then the results may be doubtful (Aario 1941, Wenner 1953). Christensen (l. c.) stated the following ranges in average sizes for pollen of Corylus avellana, mounted in glycerin (all averages from 100 pollen grains), 


\begin{tabular}{|c|c|c|}
\hline & \multicolumn{2}{|c|}{ Range of average sizes } \\
\hline & Fossil & Modern \\
\hline Untreated ... & $22.1-23.7 \mu$ & $24.6-26.7 \mu$ \\
\hline $\mathrm{KOH}$ & $22.8-25.5 \mu$ & $25.4-25.9 \mu$ \\
\hline Acetolysis & $33.3-34.6 \mu$ & $27.3-29.2 \mu$ \\
\hline $\mathrm{KOH}$, acetolysis & $33.0-35.0 \mu$ & $30.7-32.2 \mu$ \\
\hline $\mathrm{HF}$, acetolysis. & $27.8 \mu$ & \\
\hline
\end{tabular}

If the size difference in the species is only a few microns, and if the fossil pollen displays a unimodal size-frequency distribution curve, it may be difficult to reach an exact identification, unless a correction factor can be calculated (cp. Christensen l. c., Wenner 1. c.). However, if two or more such species are represented together in the fossil material, size-frequency curves with modes for the species involved may be obtained, the success depending on the degree of overlap, and the accurateness of the measurements. Even if the overlap in size ranges is large, the relative heights of the modes may provide an estimate of the relative abundance of the species in the individual samples (see also the discussion in Welten 1944). Examples of the application of the method were shown i. a. for Betula species by Welten (l. c.), for Picea species by Firbas (1927), Cain (1948) and Reich (1953), and for Pinus species i. a. by Cain (1940 a) and CaIN and CAIN (1948 b).

In the present material bimodal size-frequency distribution curves could be obtained for microspores of Isoëtes, and for pollen of Picea, Betula and Empetrum, and they have proved useful for an estimate of the representation of the various species. The measurements were always carried out immediately after the preparation of the samples in order to avoid swelling (cp. Andersen 1960). The measurements were continued until a reasonably smooth curve was obtained in each case.

\section{Isoëtes.}

Oberdorfer (1931) mentioned that it may be possible to distinguish the microspores of Isoëtes echinospora and I. lacustris by size (cp. Erdtman 1943, LANG 1955), but Godwin (1956) expressed some doubt as to the possibility of an effective separation.

The microspores of Isoëtes are monolete and the exine is surrounded by a loose and thin perine, which is connected with the exine only along the furrow (see illustrations e. g. in Erdtuan 1943). The perine is very often wrinkled, and the measurements were carried out on the exine alone. The largest diameter parallel to the furrow was measured.

Table 3. Measurements of microspores of Isoëtes echinospora, modern ( $\mathrm{KOH}$, acetolyzed, Aesculus gum). $\mathrm{M}=$ mean size. $\sigma=$ standard deviation.

Målinger af mikrosporer af Isoëtes echinospora, recente $(\mathrm{KOH}$, acetolyserede, Aesculus harpiks). $\mathrm{M}=$ middelstørrelse. $\sigma=$ standardafvigelse.

\begin{tabular}{|c|c|c|c|}
\hline $\begin{array}{l}\text { Ref. no } \\
\text { D.G.U. }\end{array}$ & Locality & $\begin{array}{l}\mathrm{M} \\
\mu\end{array}$ & $\begin{array}{l}\sigma \\
\mu\end{array}$ \\
\hline 2442 & North Wales, England......... & 23.74 & \pm 1.76 \\
\hline 806 & Hardanger, Norway. . . . . . . . . . & 24.22 & \pm 1.78 \\
\hline 2399 & Les Vosges, France $\ldots \ldots \ldots \ldots \ldots$ & 24.39 & \pm 1.59 \\
\hline 2435 & Muonio, Finland $\ldots \ldots \ldots \ldots \ldots$ & 24.68 & \pm 1.53 \\
\hline 2400 & NW Jutland, Denmark ......... & 25.20 & \pm 1.47 \\
\hline \multirow[t]{2}{*}{52} & Baden, Germany ............ & 25.33 & \pm 1.14 \\
\hline & Total... & 24.66 & \pm 1.65 \\
\hline
\end{tabular}


Modern material of 6 individuals of each species from different localities was measured. The material was boiled with $\mathrm{KOH}$ ( 6 min., in water bath), acetolyzed, and in this case mounted in Aesculus gum (cp. Christensen 1954). 100 microspores of each individual were measured (size class $1.20 \mu$ ). The results are shown in the tables 3 and 4. Modern Corylus avellana pollen measured in 4 of the preparations averaged $26.97 \mu \pm 1.14 \mu$ (100 grains).

Table 4. Measurements of microspores of Isoëtes lacustris, modern (KOH, acetolyzed, Aesculus gum). $\mathrm{M}=$ mean size. $\sigma=$ standard deviation.

Målinger af mikrosporer af Isoëtes lacustris, recente $(\mathrm{KOH}$, acetolyserede, Aesculus harpiks). $\mathrm{M}=$ middelstørrelse. $\sigma=$ standardafvigelse.

\begin{tabular}{|c|c|c|c|}
\hline $\begin{array}{l}\text { Ref. no } \\
\text { D.G.U. }\end{array}$ & Locality & $\begin{array}{l}\mathrm{M} \\
\mu\end{array}$ & $\begin{array}{l}\sigma \\
\mu\end{array}$ \\
\hline 2437 & NW Jutland, Denmark . . . . . . . . & 32.11 & \pm 1.71 \\
\hline 221 & W Jutland, Denmark . . . . . . . . & 32.94 & \pm 1.59 \\
\hline 2443 & Brandon Mt., Ireland . . . . . . . . . & 33.24 & \pm 2.15 \\
\hline 2440 & Westmoreland, England ......... & 33.77 & \pm 1.74 \\
\hline 2436 & S Jutland, Denmark ........... & 33.95 & \pm 1.82 \\
\hline \multirow[t]{2}{*}{39} & Norrbotten, Sweden........... & 34.81 & \pm 2.10 \\
\hline & Total... & 33.47 & \pm 2.02 \\
\hline
\end{tabular}

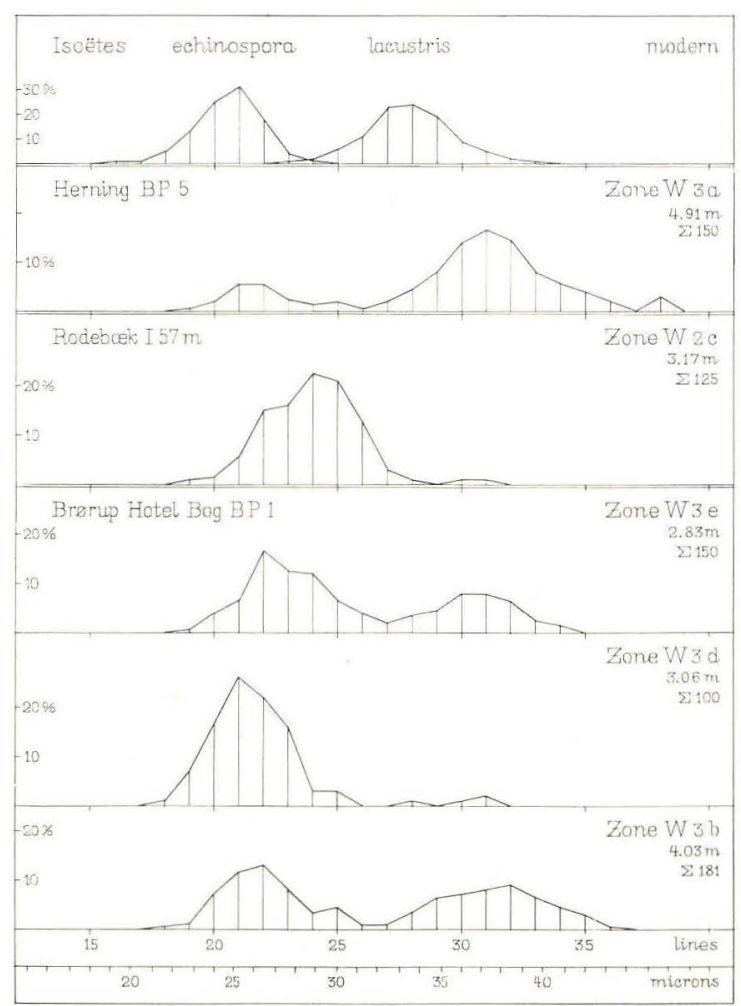

Fig. 2. Size-frequency distribution in microspores of Isoëtes, modern and fossil. Størrelsesfordeling hos mikrosporer af Isoëtes, recente og fossile. 
It may be seen from the tables that the variation in average size within the two Isoëtes species mentioned is small. Summation size-frequency distribution curves for the species are shown in fig. 2. It may be seen that the overlap of size ranges is small. Size-frequency distribution curves for Isoëtes microspores from 5 fossil samples are also shown in fig. 2. Two species are obviously represented, and the size curves correspond quite well to those for the modern Isoëtes echinospora and I. lacustris microspores.

The size-frequency distribution curves for the fossil microspores in fig. 2 show very little overlap of ranges. Average sizes for the two species from the fossil material are shown in table 5 together with the average sizes for the two modern species. It appears, that the variation between the samples is small. The range of means for the species with the smaller microspores is $26.4-28.6 \mu$, and for the species with the larger microspores $36.8-37.6 \mu$. As one might expect in this case, the averages for the fossil microspores are slightly larger than those for the modern microspores, and the fossil microspores may be referred to Isoëtes echinospora and I. lacustris with a great degree of probability.

Table 5. Measurements of microspores of Isoëtes echinospora and I. lacustris, modern ( $\mathrm{KOH}$, acetolyzed, Aesculus gum), and fossil (KOH, HF, acetolyzed, glycerin). $\mathrm{M}=$ mean size. $\sigma=$ standard deviation.

Målinger af mikrosporer af Isoëtes echinospora og I. lacustris, recente

( $\mathrm{KOH}$, acetolycerede, Aesculus harpiks) og fossile ( $\mathrm{KOH}, \mathrm{HF}$, acetolyserede, glycerin). $\mathrm{M}=$ middelstorrelse. $\sigma=$ standardafvigelse.

\begin{tabular}{|c|c|c|c|c|c|c|}
\hline \multirow[b]{2}{*}{ Source } & \multicolumn{3}{|c|}{ I. echinospora } & \multicolumn{3}{|c|}{ I. lacustris } \\
\hline & Total & $\begin{array}{l}\mathrm{M} \\
\mu\end{array}$ & $\begin{array}{l}\sigma \\
\mu\end{array}$ & Total & $\begin{array}{l}\mathrm{M} \\
\mu\end{array}$ & $\begin{array}{l}\sigma \\
\mu\end{array}$ \\
\hline Modern (see above) . . . . . . & 600 & 24.66 & \pm 1.65 & 600 & 33.47 & \pm 2.02 \\
\hline Herning, zone W 3 a...... & 29 & 26.40 & \pm 1.84 & 120 & 37.58 & \pm 2.52 \\
\hline Rodebæk I, zone W 2c ... & 123 & 28.61 & \pm 2.03 & & & \\
\hline Brørup Hotel Bog, zone W $3 \mathrm{e}$ & 95 & 27.47 & \pm 1.93 & 52 & 36.80 & \pm 1.85 \\
\hline,$--W 3 d$ & 95 & 25.72 & \pm 1.73 & & & \\
\hline,-- W3b & 92 & 26.42 & \pm 2.02 & 89 & 37.55 & \pm 2.48 \\
\hline
\end{tabular}

As the size ranges overlap so little, individual microspores may be referred to one of the two species without difficulty. Table 6 shows a list of the percentages of the pollen total for the microspores referred to I. echinospora and to I. lacustris as found by counting, and the corresponding figures computed from the size-frequency distribution curves.

Table 6. Frequencies for the microspores of Isoëtes, in percentages of the pollen total. Hyppigheder for mikrosporerne af Isoëtes, i procent af pollensummen.

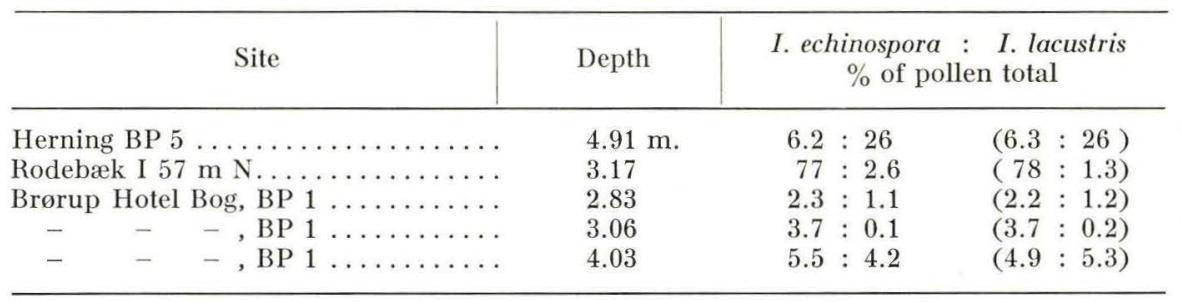


Picea.

Weber (1898) discovered that the Picea remains in late Pleistocene deposits from North Europe represent besides $P$. abies a species related to $P$. omorica Panč. Weber (1. c.) found remains of this species first at Aue in the Erzgebirge, and later at Lüneburg in North Germany (Müller and Weber 1904). Weber in his careful investigations pointed out the similarity of the fossil remains to $P$. omorica, but he preferred to refer the fossil finds to $P$. omoricoides Weber, considered to be an extinct species, which was formerly widely distributed and variable. WEBER considered $P$. omorica, growing only on a few mountains in Serbia to-day, to be a relic of that species. He noticed also that the fossil Picea pollen from Lüneburg was rather small (MüLLER and Weber 1. c.). Firbas (1927) showed that the pollen grains of $P$. omorica are considerably smaller than those of $P$. abies (see table 7). He found a small type of Picea pollen in late Pleistocene deposits in the Inn valley, and referred it to $P$. omoricoides. Later Firbas and Firbas (1935) showed that similar pollen occurs in the peat from Lüneburg, where WEBER made some of the original finds of macrofossils of $P$. omoricoides. Small Picea pollen grains identified with $P$. omoricoides have also been mentioned from a late Pleistocene deposit at Wartha, Schlesien, by Stark and Overbeck (1932), from the Northern Alps by REICH (1953), from Switzerland by LüDI (1953), and macroscopic remains and pollen referred to $P$. omoricoides are reported from Poland from the Masovian Interglacial (i. a. Dyakowska 1952, Brem 1953, Środón 1957, Sobolewska $1956 \mathrm{~b})$.

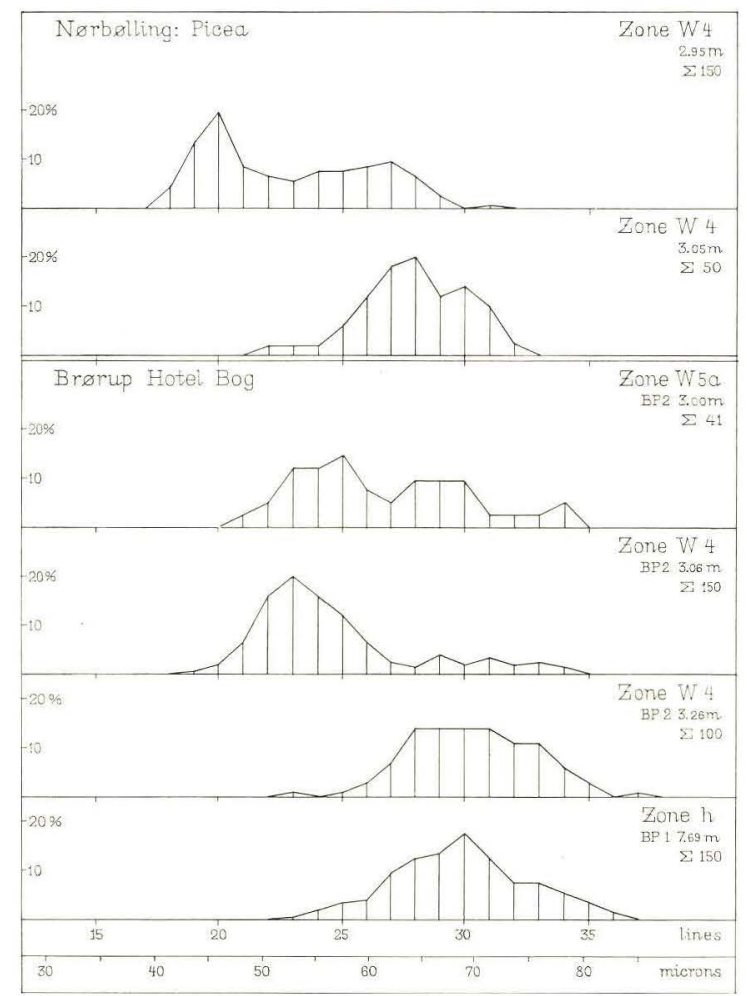

Fig. 3. Size-frequency distribution in fossil Picea pollen (height of air sacs). Størrelsesfordeling hos fossilt Picea pollen (højde af luftsækkene). 
Macroscopic remains of Picea abies have been found in Danish interglacial deposits (J \& M 1928). Thus leaves, fruits and seeds of that species occurred i. a. in the Eemian Interglacial deposits at Brørup Hotel Bog (pollen zone h), Rodebæk I, Herning and other sites, and in the "upper mud layer" at Brørup Hotel Bog (belonging to the pollen zones W 4-5 according to the present studies).

Size-frequency data for Picea pollen from Brørup Hotel Bog and Nørbølling are shown in fig. 3 (size class value $2.30 \mu$ ). The dimension measured is the same as that measured by the authors mentioned above, i. e. the height of the air sacs at the line where they join the main body of the grain, seen in side view. As Picea pollen grains are large and thin walled the dimensions are easily influenced by variations of shape, and a careful selection of the grains to be measured is necessary, if the distribution curves are not to become too flat. The curves from Brorup from zone $h$ and the lower part of zone W 4 (at $3.26 \mathrm{~m}$.) appear to be symmetrical with a major representation around $69 \mu$, and the upper curve from zone W 4 (at $3.06 \mathrm{~m}$.) is asymmetrical with a major peak at $53 \mu$ and a minor representation at $65-75 \mu$. The Picea pollen from zone W 5 was too scarce to give a sufficient number of measureable grains, and the curve is quite irregular. Yet it may appear that the curve is bimodal too, with modes at ca. $53 \mu$ and at ca. $68 \mu$. The curves from Norbolling are similar to those from zone W 4 at Brørup. The lower curve (at $3.05 \mathrm{~m}$.) appears to be symmetrical with a peak at $64 \mu$, and the upper one is asymmetrical with a major peak at $46 \mu$ and a minor one at ca. $61 \mu$.

Table 7. Measurements of modern and fossil pollen of Picea (height of the air sacs).

Målinger af recent og fossilt pollen af Picea (højde af luftsækkene).

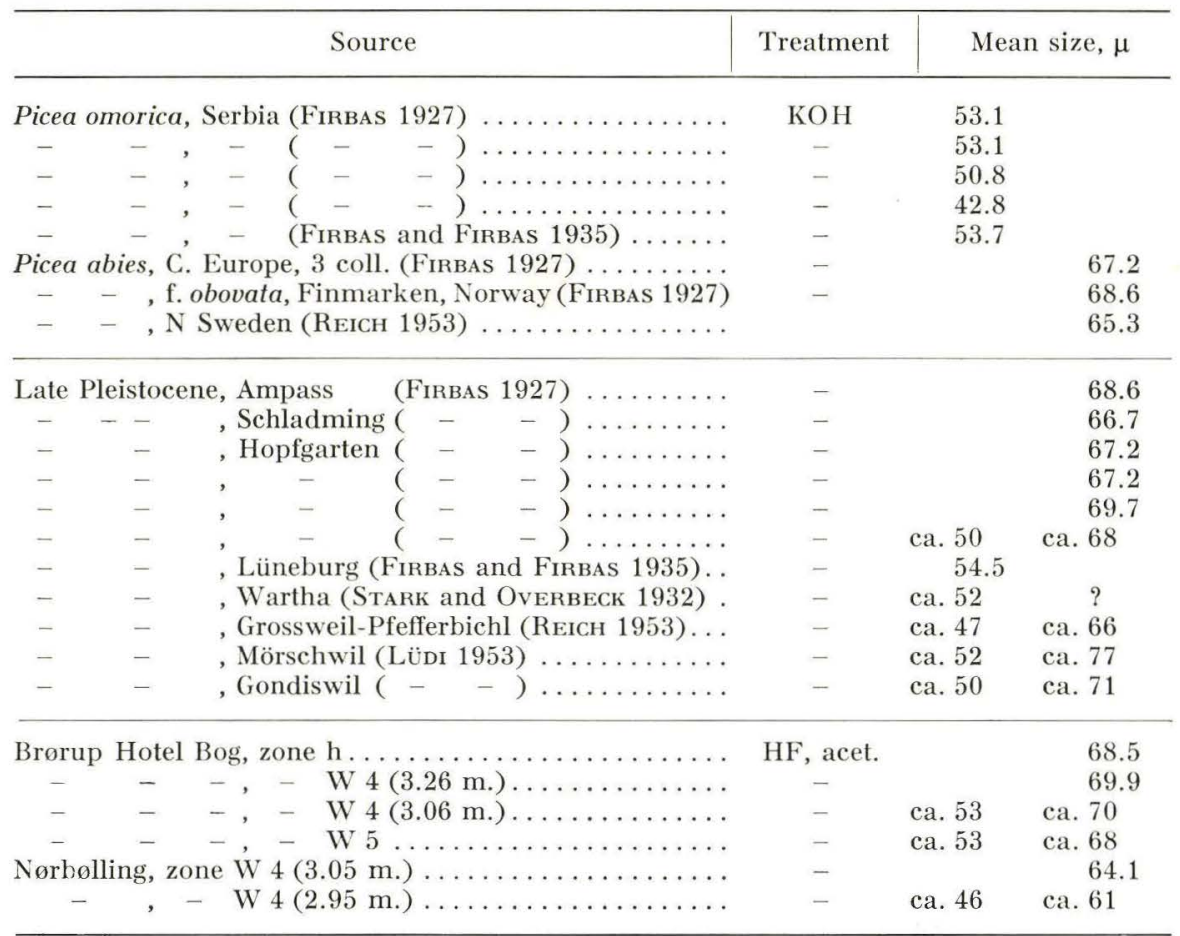


The size-frequency distribution curves from fig. 3 suggest that the Picea pollen represents two species, the pollen of which differs as to mean size. The modes representative of the species with the larger pollen are found at $60-70 \mu$, and the other ones at $46-53 \mu$. The Picea pollen from Nørbølling appears to be somewhat smaller than the pollen found at Brørup Hotel Bog, presumably due to differences in the fossilization conditions.

The measurements from Brørup Hotel Bog and from Nørbølling have been compared with the data for modern and fossil Picea pollen in table 7. It can be seen that the measurements of the pollen from Brørup Hotel Bog and Nørbølling agree with the measurements of modern pollen of $P$. omorica and $P$. abies, and with measurements of interglacial finds of $P$. omoricoides and $P$. abies, considering the various origin and chemical treatment of the pollen. It may be concluded that the fossil Picea pollen from Brørup and Norbølling is referable to $P$. omoricoides and $P$. abies with a fair probability. The measurements show that $P$. abies is represented alone in the samples from zone $\mathrm{h}$ and the lower part of zone $\mathrm{W} 4$, and that $P$. omoricoides and $P$. abies are represented in the samples belonging to the upper part of zone W 4 and zone W 5 . It can be seen from fig. 3 that the size ranges of the pollen from the two species overlap considerably, and it is not possible to identify individual pollen grains with one of the species in the cases where the two species occur together.

It is remarkable that only $P$. abies is represented by macrofossils at Brørup Hotel Bog (cp. above). However, the sediment from the zones W 4 and W 5 at that site is peat, and it is possible that only the species that grew in the immediate vicinity of the sampling points became represented by macrofossils.

\section{Betula.}

$\mathrm{J} \& \mathrm{M}$ (1928) found macroscopic remains of $B$. nana and $B$. pubescens in layers corresponding to those mentioned in the present study. However, B. tortuosa cannot be excluded. Jentys-Szaferowa (1928) reported a difference in the average size of the pollen of Betula nana, B. verrucosa and B. pubescens (see table 8), and these results were confirmed in the extensive investigation of ENEROTH (1951), who also showed that the average size of the pollen of $B$. tortuosa is larger than that of the species just mentioned (see table 8). The size ranges of the pollen from the species mentioned overlap greatly, and individual pollen grains can hardly be referred to one of the species.

Most attempts at identifying Betula species in fossil pollen samples by size-statistical methods (i. a. Jentys-Szaferowa 1928, Bertsch 1931, Fregri 1940, 1945, Eneroth 1951) have been based upon a direct comparison of uni-modal size curves for fossil pollen with modern pollen in samples treated with the KOH method. WELTEN (1944) obtained bi- or even trimodal size-frequency curves for KOH-treated samples.

WaLker (1955) proposed to distinguish $B$. nana from $B$. pubescens by computation of the average ratio for pore protrudence to pollen size (cp. Terrasmä̈ 1951, WeLteN 1944). Here too, the pollen of the two species differs only slightly, and dealing with mixed populations this method also becomes very exacting to accurateness and number of the measurements, and may become even more laborious than the method used here.

In the present material chemical treatment with $\mathrm{HF}$ and acetolysis have been indispensable. The Betula pollen grains were measured with a very small size class value $(0.56 \mu)$. Bimodal size-frequency distribution curves could be obtained, and the measured results can be used without re-calculations (cp. Welten l. c.).

Fig. 4 shows size-frequency distribution curves for 11 selected samples. It may be seen that the curve from Herning (zone W 3 a) and one curve from Brørup Hotel Bog 


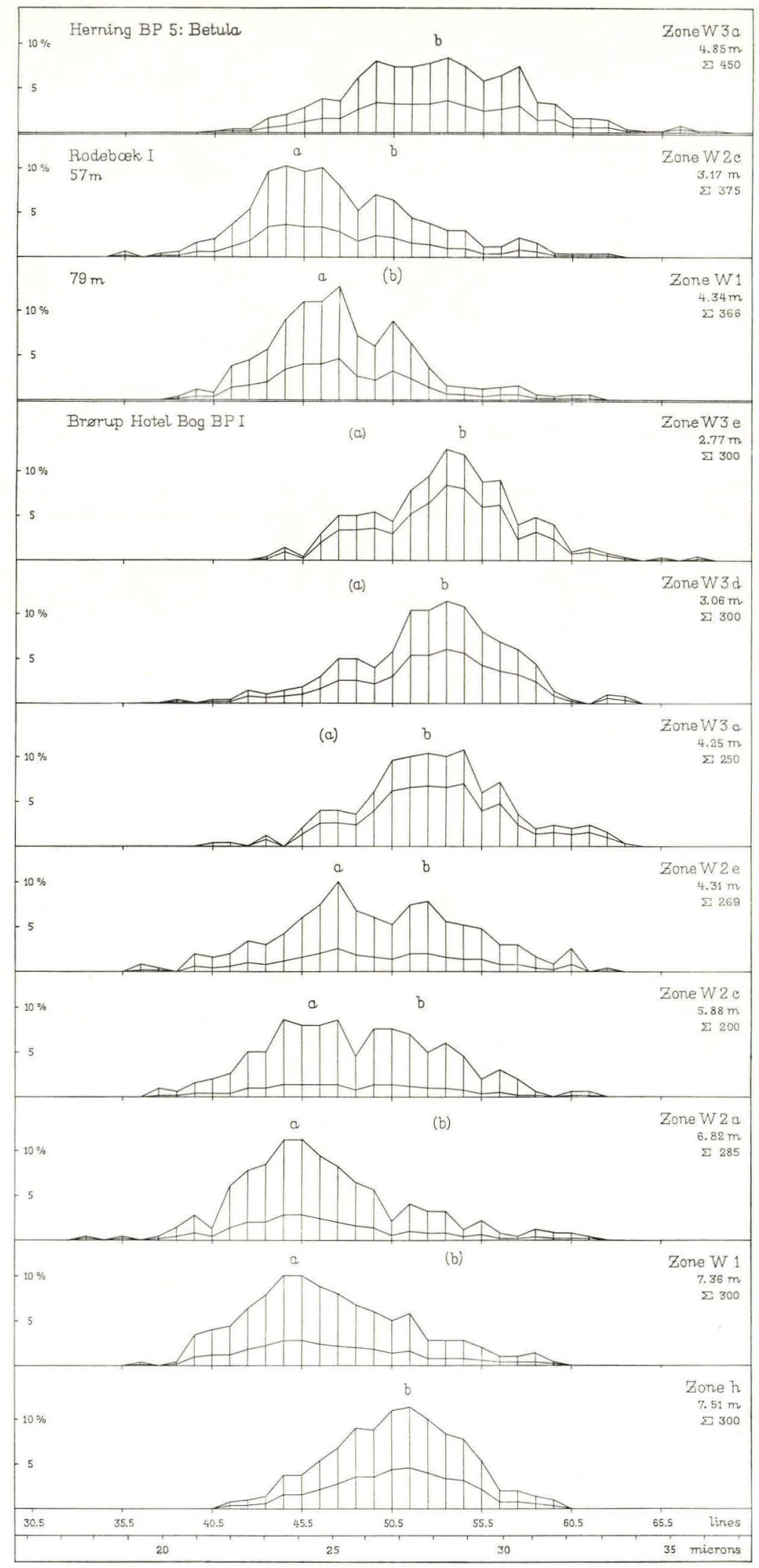

Fig. 4. Size-frequency distribution in fossil Betula pollen. Storrelsesfordeling hos fossilt Betula pollen. 
Table 8. Measurements of modern and fossil pollen of Betula. $\mathrm{M}=$ mean size. Målinger af recent og fossilt pollen af Betula. $\mathrm{M}=$ middelstørrelse.

\begin{tabular}{|c|c|c|c|c|c|c|}
\hline \multirow{2}{*}{\multicolumn{2}{|c|}{ Source }} & \multirow{2}{*}{$\begin{array}{l}\text { Preparation } \\
\text { method }\end{array}$} & \multicolumn{4}{|c|}{$\begin{array}{l}\mathrm{M}, \mu \text { (figures in brackets indicate } \\
\text { numbers of collections measured) }\end{array}$} \\
\hline & & & nana & verr. & pubesc. & tort. \\
\hline 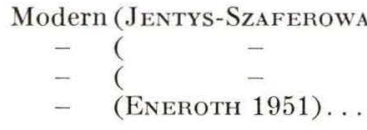 & $\begin{array}{l}1928) \\
1928) \\
1928) \\
\ldots\end{array}$ & $\begin{array}{c}\text { fresh } \\
\text { boiling in } \mathrm{KOH} \\
\mathrm{H}_{2} \mathrm{SO}_{4} \text { conc. } \\
\text { boiling in } \mathrm{KOH}\end{array}$ & $\begin{array}{l}21.7(2) \\
18.4(5) \\
18.9(3) \\
19.4(38)\end{array}$ & $\begin{array}{l}24.3(2) \\
21.5(1) \\
22.0(3) \\
22.1(11)\end{array}$ & $\begin{array}{l}27.5(2) \\
23.8(1) \\
24.7(4) \\
25.0(10)\end{array}$ & $26.1(6)$ \\
\hline Fossil, present material.. & $\cdots$ & HF, acetolyzed & $23-25$ & & $27-29$ & \\
\hline
\end{tabular}

(zone h) are approximately symmetrical, and that the other curves are skewed more or less obviously to one side or the other. It is indicated, accordingly, that the two samples mentioned first contain pollen from one species only, and that the pollen found in the other samples is likely to originate from two species with different average pollen sizes. Two modes, a and b, can be recognized in two of the curves from Brørup Hotel Bog (zones W 2c and W 2e). Mode a may be recognized in the curves from zone W 1 and W $2 \mathrm{a}$ at that site, and mode $\mathrm{b}$ in the curves from zone W $3 \mathrm{a}, \mathrm{W} 3 \mathrm{~d}$ and W 3 e. Mode a can also be recognized in the curves from Rodebæk I (zones W 1 and W 2c), and mode b in the curve from Herning (zone W 3 a). Thus, although slight variations exist, the modes a and $\mathrm{b}$ may be traced in the various curves without difficulty.

It can be seen from the graphs in fig. 4 that mode a varies at $23-25 \mu$, and mode b at $27-29 \mu$. The measurements have been compared with measurements of modern Betula pollen in table 8. Considering the preparation methods used (see table 8), it is to be expected that the fossil pollen is somewhat larger than the modern. Hence, it seems to be justified to assume that $B$. nana contributed the pollen constituting mode a, and $B$. pubescens the pollen constituting mode $\mathrm{b}$, especially as these two species were identified from macrofossils in the same layers (see below). As the pollen of $B$. tortuosa is somewhat larger than that of $B$. pubescens (see table 8), mode $b$ is unlikely to be due to pollen from that species, but it cannot be concluded that it was entirely absent.

The following picture of the composition of the Betula populations from the three sites at different times may be obtained on a basis of the curves in fig. 4 .

\section{Brørup Hotel Bog.}

Zone h: Only one species represented, presumably B. pubescens. Wood of an arboreal Betula species occurred in the layer (at BP 3, J\&M 1928).

Zone W 1: Betula nana pollen dominant, probably with a slight representation of B. pubescens pollen.

Zone W 2 a: Similarly, probably a still smaller proportion of $B$. pubescens pollen. Leaves of $B$. nana occurred in the subzone (at $6.60 \mathrm{~m}$. at BP 1 (STA), see p. 56). Fruits of Betula nana were found by J\&M in a layer from the subzone (BP 3, J\&M 1. c., see p. 56).

Zone W 2c: B. nana and B. pubescens represented almost equally. As it will be discussed later (p. 53) most of the Betula pubescens pollen is likely to be derived from older deposits here. Macroscopic remains were rare in the layer (layer $\mathrm{H}$, J\&M l. c.). 
Zone W $2 \mathrm{e}: B$. nana and $B$. pubescens represented almost equally. The sample represents the transition to zone W 3 . Rebedded pollen is scarce (p. 53), and the presence of $B$. pubescens pollen indicates a beginning increase in the frequency of that species.

Zone W $3 \mathrm{a}, \mathrm{d}$ and e: The 3 curves from the zone are uniform. $B$. pubescens pollen dominates, and $B$. nana was rather common, yet. Fruits and catkin scales of $B$. pubescens were very common, and similar remains of $B$. nana rather rare in these layers (E-G, J\&M l. c.).

Rodebæk I.

Zones W 1 and W $2 \mathrm{c}$ : $B$. nana pollen dominates both samples, and pollen of $B$. pubescens is rare. Fruits and catkin scales of $B$. nana were quite common in zone $\mathrm{W} 2 \mathrm{c}$, and such remains of $B$. pubescens were rare (layer D, J\&M l. c.).

Herning.

Zone W 3 a: $B$. pubescens pollen dominates, and the amount of $B$. nana pollen is quite insignificant. The two species are represented by macroscopic remains (layer F, J\&M l. c.).

The size-frequency distribution curves discussed above give only information about the frequencies for the pollen of the Betula species in relation to each other. The frequencies for the Betula pollen in percentages of the pollen totals are shown in table 9 .

Table 9. Frequencies for the Betula pollen, in percentages of the pollen totals.

Hyppigheder for pollen af Betula, i procent af pollensummen.

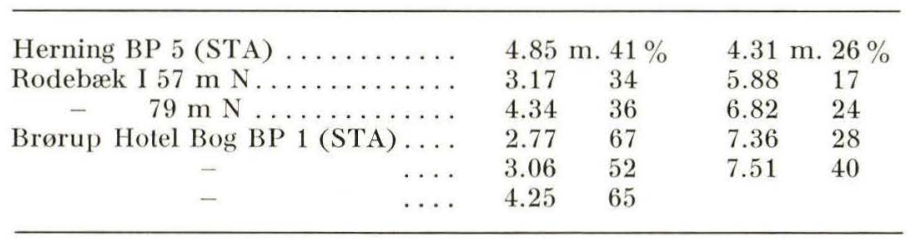

The lowermost line in each size-frequency distribution curve in fig 4 shows frequencies of the pollen occurring in the various size classes in per cent of the pollen total. The latter curve gives a certain idea of the frequency changes in the two species mentioned in relation to the pollen total. Thus it appears that the frequencies for the Betula nana pollen at Brørup Hotel Bog are rather constant in the zones W 1-W 3, and that the frequencies for the Betula pubescens pollen vary considerably. Hence, the changes in the Betula curve seen in the pollen diagram (plate VI) are due mainly to changes in the frequencies for Betula pubescens pollen.

The Betula pollen found in the subzones W $2 \mathrm{~b}$ and d at Brørup Hotel Bog was not suited for measurements, and the pollen of the genus occurring in the zones W 4-W 5 at that site was too scarce for extensive measurements. Measurements from the peak for Betula pollen in subzone W 5b (BP 2 (STA), see p. 60) suggest dominance of B. pubescens pollen.

\section{Empetrum.}

The pollen tetrads of Empetrum have often been identified in fossil state (sca, C short and irregular). A substantial difference in average size between the pollen tetrads of the diploid $E$. nigrum and the tetraploid $E$. hermaphroditum was mentioned by F ÆGRI (1936) and by ERDTMan $(1938,1943)$. FagRi (1945) demonstrated the presence of 
Table 10. Measurements of modern and fossil pollen tetrads of Empetrum. $\mathrm{M}=$ mean size. Målinger af recente og fossile pollen-tetrader af Empetrum. $\mathrm{M}=$ middelstørrelse.

\begin{tabular}{|c|c|c|c|}
\hline \multirow{2}{*}{ Source } & \multirow{2}{*}{ Treatment } & \multicolumn{2}{|c|}{$\mathrm{M}, \mu$} \\
\hline & & nigrum & herm. \\
\hline Overbeck 1934, modern $\ldots \ldots \ldots \ldots \ldots$ & $\mathrm{KOH}$ & 28.4 & \\
\hline Erdtman 1943 , modern $\ldots \ldots \ldots \ldots \ldots \ldots$ & acetolyzed & 27.9 & 40.7 \\
\hline FAGRI 1945 , modern $\ldots \ldots \ldots \ldots \ldots \ldots \ldots$ & $\mathrm{KOH}$ & & 34.0 \\
\hline$-1945, \quad-\quad \ldots \ldots \ldots \ldots \ldots \ldots \ldots \ldots \ldots \ldots \ldots$ & acetolyzed & & 39.4 \\
\hline$-\quad 1945$, Postglacial $\ldots \ldots \ldots \ldots \ldots$ & $\mathrm{KOH}$ & & 34.7 \\
\hline Jessen 1949 , modern $\ldots \ldots \ldots \ldots \ldots \ldots \ldots$ & - & 31.0 & 40.3 \\
\hline - 1949, Late-Glacial $\ldots \ldots \ldots \ldots \ldots \ldots$ & - & 31.0 & \\
\hline Brørup Hotel Bog, zone W 1 (BP 1) . . . . . . . & HF, acetolyzed & 32.5 & ca. 41 \\
\hline 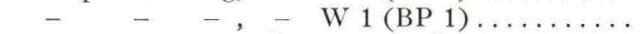 & - & 32.8 & ca. 40 \\
\hline -, all other samples ........... & - & 33.1 & ca. 42 \\
\hline$-\quad-\quad-$, zone W 5 (BP 2) ......... & - & 33.4 & \\
\hline Rodebæk I, zone h $(79 \mathrm{~m}.) \ldots \ldots \ldots \ldots \ldots$ & - & 32.5 & \\
\hline$-\quad, \quad-h(57 \mathrm{~m}.) \ldots \ldots \ldots \ldots \ldots$ & - & 35.4 & \\
\hline,$\quad-W 1(79 \mathrm{~m}.) \ldots \ldots \ldots \ldots$ & - & 35.0 & ca. 44 \\
\hline,$\quad-$ W $1(57 \mathrm{~m}.) \ldots \ldots \ldots \ldots$ & - & 33.6 & ca. 44 \\
\hline$-\quad, \quad-$ W $2 \mathrm{c}(57$ m. $) \ldots \ldots \ldots \ldots$ & - & 34.0 & ca. 41 \\
\hline
\end{tabular}

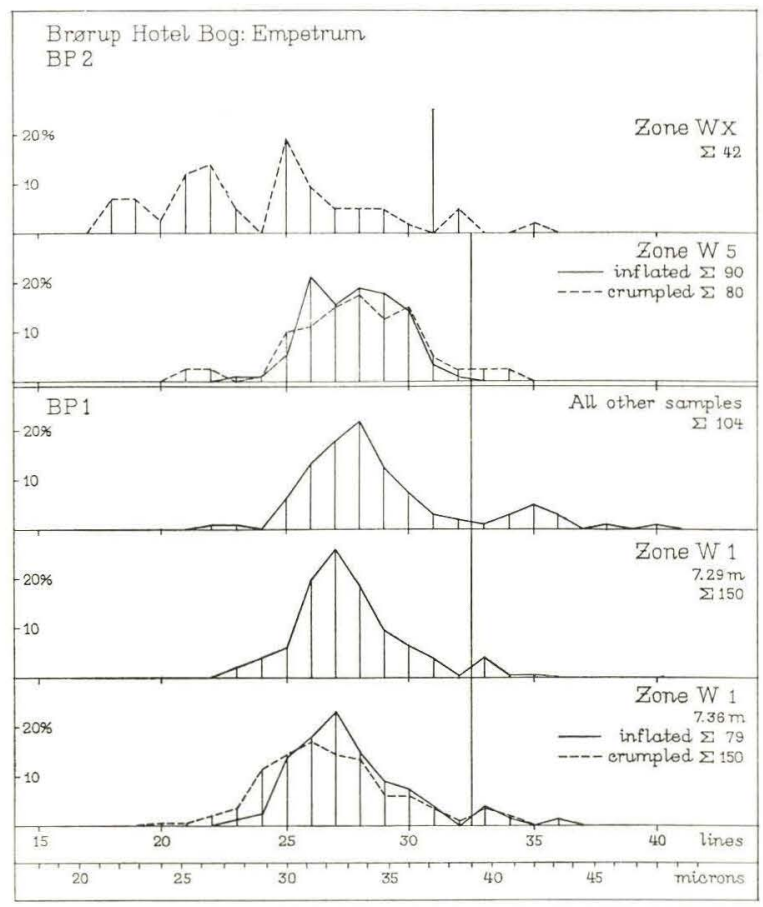

Fig. 5. Size-frequency distribution in fossil Empetrum pollen tetrads, Brørup Hotel Bog.

Størrelsesfordeling hos fossile Empetrum pollen tetrader, Brørup Hotel Mose. 


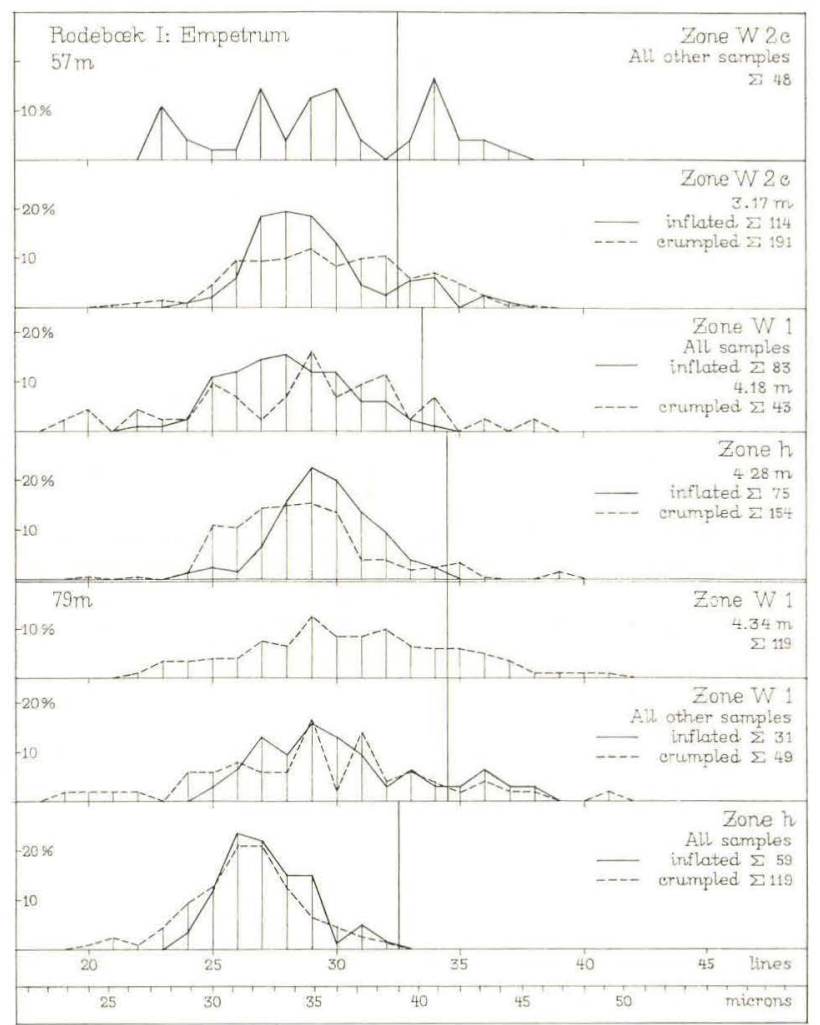

Fig. 6. Size-frequency distribution in fossil Empetrum pollen tetrads, Rodebæk I.

Størrelsesfordeling hos fossile Empetrum pollen tetrader, Rodebæk I.

fossil pollen tetrads of E. hermaphroditum in a subalphine bog in Southern Norway, and JESSEN (1949) demonstrated the presence of E. nigrum in Ireland in the LateGlacial. Size measurements from the literature are compared with figures reached from the present material (see below) in table 10.

Size-frequency distribution curves for fossil Empetrum pollen tetrads from the present investigation are shown in fig. 5 and 6 . The largest diameter of the tetrads was measured in all cases (size class value $1.20 \mu$ ). Measurements of inflated and crumpled tetrads are shown separately. It appears that the difference between inflated and crumpled tetrads is small. The largest diameter is always smaller in the crumpled tetrads than in the inflated ones. The inner walls of the tetrads form a rigid structure, and crumpling produced usually a caving in of the single grains causing a slight decrease of the size of the whole tetrad (pressure causes often an increase in one of the dimensions in single pollen grains).

The size-frequency distribution curves from zone W 1 at Brørup Hotel Bog (fig. 5) are skewed with principal modes at $31.2-32.4 \mu$, and small secondary ones at ca. $40-41 \mu$. It appears that both $E$. nigrum and $E$. hermaphroditum are represented, and that E. nigrum pollen was dominant. A curve for all inflated Empetrum tetrads found at $\mathrm{BP} 1$ is also shown in fig. 5 . The size-frequency distribution curve is similar to the 
curves from zone W 1 with a slight, but obvious representation of $E$. hermaphroditum pollen. All tetrads (inflated ones as well as crumpled ones) larger than the $38.4 \mu$ size class (indicated by a vertical line in fig. 5 ) have been included in the curve for $E$. hermaphroditum shown in the pollen diagram from BP 1 (plate VI). At BP 2 Empetrum pollen occurred in the zones W $3 \mathrm{e}, \mathrm{W} 4$, W 5 and W $\mathrm{x}$. In the zones W $3 \mathrm{e}$ and W 4 the Empetrum tetrads were too scarce for a size-frequency distribution curve. Only one tetrad (zone W 4) was larger than $38.4 \mu$, and it may belong to $E$. hermaphroditum. The measurements from zone W 5 (see fig. 5) show that there is only a slight, if any, representation of $E$. hermaphroditum (tetrads larger than $38.4 \mu$ ). In pollen zone W x only crumpled pollen tetrads occurred, and the number of tetrads measured is small, still it may appear from the curve shown in fig. 5 that some tetrads larger than $37.2 \mu$ may be referred to $E$. hermaphroditum.

At Rodebæk I the Empetrum pollen was less well preserved. It appears from the curves shown in fig. 6 that $E$. nigrum and $E$. hermaphroditum are represented, $E$. hermaphroditum pollen was apparently rare or absent in zone $\mathrm{h}$, and the pollen of the species was rather common in the zones W 1 and W $2 \mathrm{c}$. The vertical lines in fig. 6 indicate an approximate lower size limit for $E$. hermaphroditum pollen tetrads in the various cases.

At Herning and at Norbølling the numbers of Empetrum tetrads were too small for size-studies. However, presence of E. nigrum alone is indicated.

\section{Plantago.}

Plantago pollen grains in the present material have been identified with $P$. lanceolata, $P$. maritima s. I. and P. media. The characters used for the identifications is shown in table 11. The pollen of the species represented in the table falls into two major groups according to the presence or absence of a pore annulus (cp. IvErSEN 1941). The pollen grains of Littorella uniflora resemble those of P. tenuiflora (see table 11), but they are considerably larger.

$P$. lanceolata. The pollen grains of the species have annulate and usually operculate pores. They are rather similar to the pollen of $P$. coronopus, but differ as the scabrate elements are more distinct, and in pore number. Pore number-frequency distribution in $P$. lanceolata and $P$. coronopus, and in 39 fossil pollen grains referred to $P$. lanceolata are shown in the tables $12-13$ and in fig. 7. It can be seen that the pollen of $P$. coronopus and $P$. lanceolata differ essentially as to pore number, and that the fossil grains are comparable with the modern $P$. lanceolata pollen. The fossil pollen grains have been found in the interglacial deposits, and in the zones W 1 and W 2 (see plate III). Reich (1953) and West (1957) mention the occurrence of pollen of $P$. lanceolata in deposits from the Eemian Interglacial in Germany and England.

The pollen grains of $P$. lanceolata found in the zones W 1 and W 2 in the present material occur in such a manner that they may be considered to be rebedded from the interglacial layers (see p. 54). The species is not represented in the climatically favorable zones W 3-W 5, and it appears that the species became extinct in Jutland during the zones W 1-W 2. Finds of the species are very rare in the Late-Glacial and in the early Postglacial (Iversen 1941, 1954, Godwin 1956). Iversen (I. c.) considered the Danish Late-Glacial finds to be unreliable, and it is suggested that $P$. lanceolata became extinct in a wide area in Europe during the Weichselian Glacial.

P. maritima s.l. Genetic relationships and differentiation within this interesting complex have been the object of a thorough study by GrEGor (1939 and earlier). According to that author plants from North America, Greenland and North and Central Europe corresponding to the conventional species $P$. juncoides Lam., P. decipiens 
Table 11. Characteristies for pollen of Plantago species (as seen with ordinary optics, unless otherwise stated).

Karakterer for pollen af Plantago arter (set med almindelig optik, medmindre andet er nævnt).

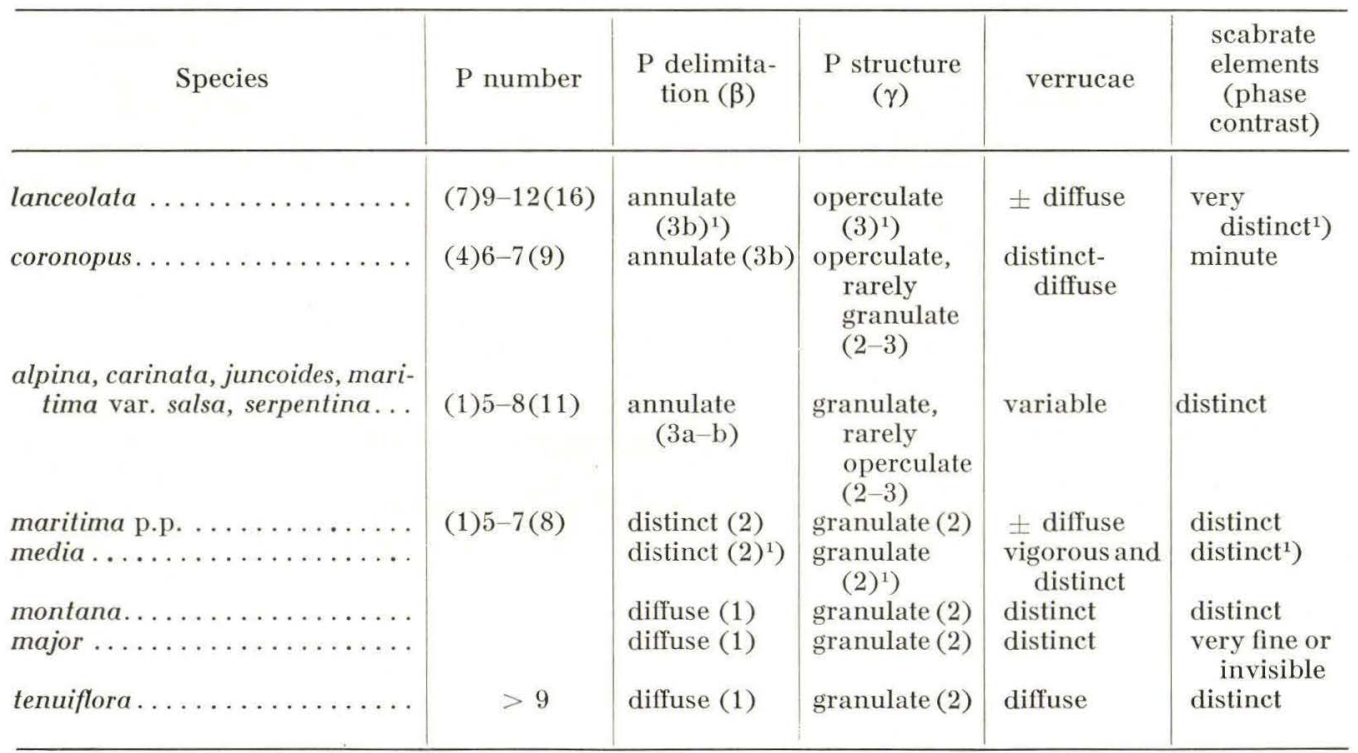

1) cp. Bradley 1958.

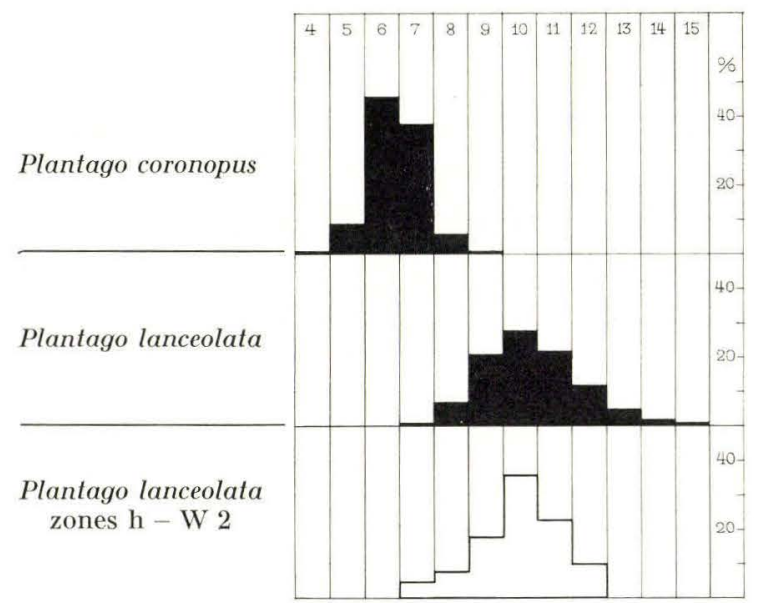

Fig. 7. Pore number-frequency distribution in modern pollen of Plantago coronopus and $P$. lanceolata (black), and in fossil pollen of $P$. lanceolata (white, $\mathrm{cp}$. the tables 12-13).

Fordeling af pore-antal hos recent pollen af Plantago coronopus og $P$. lanceolata (sort) og hos fossilt pollen af $P$. lanceolata (hvid, sml. tabel 12-13). 
Table 12. Pore number-frequency distribution in modern pollen of Plantago coronopus. $\mathrm{M}=$ mean number. $\sigma=$ standard deviation.

Fordelingen af pore-antal hos recent pollen af Plantago coronopus. $\mathrm{M}=$ middeltal. $\sigma=$ standardafvigelse.

\begin{tabular}{|c|c|c|c|c|c|c|c|c|c|c|c|}
\hline \multirow{2}{*}{$\begin{array}{c}\text { Ref. } \\
\text { no. } \\
\text { DGU }\end{array}$} & \multirow{2}{*}{ Source } & \multirow{2}{*}{$\begin{array}{l}\text { No. of } \\
\text { plants }\end{array}$} & \multirow{2}{*}{$\begin{array}{c}\text { Pollen } \\
\text { total }\end{array}$} & \multicolumn{6}{|c|}{ Pore number } & \multirow{2}{*}{ M } & \multirow{2}{*}{$\sigma$} \\
\hline & & & & 4 & 5 & 6 & 7 & 8 & 9 & & \\
\hline 2535 & N Sjælland, Denmark. . . & $>1$ & 100 & 2 & 21 & 64 & 11 & 2 & & 5.90 & \pm 0.69 \\
\hline- & Achill Island, Ireland. . . & $>1$ & 100 & & 15 & 64 & 21 & & & 6.06 & \pm 0.60 \\
\hline 2836 & Surrey, England . . . & 2 & 100 & & 8 & 51 & 37 & 4 & & 6.37 & \pm 0.69 \\
\hline 2841 & Cannes, France.... . & 1 & 100 & & 3 & 40 & 56 & 1 & & 6.55 & \pm 0.57 \\
\hline \multirow[t]{2}{*}{2534} & S Sjælland, Denmark... & $>1$ & 100 & & & 9 & 62 & 24 & 5 & 7.25 & \pm 0.68 \\
\hline & Total. . & & 600 & 2 & 47 & 228 & 187 & 31 & 5 & 6.43 & \pm 0.64 \\
\hline
\end{tabular}

Barnéoud, $P$. borealis Lge., $P$. maritima L., $P$. alpina L. and $P$. carinata Schrad. are diploid and interfertile forming a coeno-species, $P$. coeno-maritima, which contains widely varying ecologic types and clines. In the Alps tetraploid populations occur, which are cross-incompatible with the diploids. Their taxonomic relationship is not very clear (cp. Gregor 1. c., Earnshaw 1942), but it appears that the tetraploids occur mainly in $P$. serpentina All., which is restricted to the Alpine area.

The morphologic characteristics of pollen from species within the $P$. maritima complex will appear from table 11. In a large material from the species mentioned pollen grains with annulate and non-annulate pores occur. The study of this material will be continued on a more comprehensive basis. So far all plants examined from Northern Europe (including specimens from Iceland, northernmost Norway and the Scottish Highlands) and the lowlands of Central Europe outside of the Alps have

Table 13. Pore number-frequency distribution in modern and fossil pollen of Plantago lanceolata. $\mathrm{M}=$ mean number. $\sigma=$ standard deviation.

Fordelingen af pore-antal hos recent og fossilt pollen af Plantago lanceolata. $\mathrm{M}=$ middeltal. $\sigma=$ standardafvigelse.

\begin{tabular}{|c|c|c|c|c|c|c|c|c|c|c|c|c|c|c|c|}
\hline \multirow{2}{*}{$\begin{array}{c}\text { Ref. } \\
\text { no. } \\
\text { DGU }\end{array}$} & \multirow{2}{*}{ Source } & \multirow{2}{*}{$\begin{array}{l}\text { No. of } \\
\text { plants }\end{array}$} & \multirow{2}{*}{$\begin{array}{c}\text { Pollen } \\
\text { total }\end{array}$} & \multicolumn{10}{|c|}{ Pore number } & \multirow{2}{*}{ M } & \multirow{2}{*}{$\sigma$} \\
\hline & & & & 7 & 8 & 9 & 10 & $\mid 11$ & 12 & & $\mid 14$ & 15 & 16 & & \\
\hline 2812 & Genoa, Italy & 1 & 100 & & 25 & 38 & 29 & 5 & & & & & & 9.08 & \pm 0.92 \\
\hline 2813 & Sommerset, S England... & $>1$ & 100 & & 17 & 44 & 25 & 11 & 1 & & & & & 9.29 & \pm 0.97 \\
\hline - & Stockholm, Sweden . . & ? & 100 & & 9 & 40 & 34 & 13 & 4 & & & & & 9.64 & \pm 0.96 \\
\hline 1615 & Götaland, Sweden. & ? & 100 & 2 & 8 & 22 & 47 & 17 & 4 & & & & & 9.81 & \pm 1.01 \\
\hline 2786 & S Sjælland, Denmark.... & $>1$ & 100 & & 3 & 16 & 33 & 28 & & 10 & 1 & 2 & & 10.64 & \pm 1.41 \\
\hline 2811 & Cluj, Romania. . . . . . . & 1 & 100 & & & 7 & 22 & 44 & 21 & 5 & 1 & & & 10.98 & \pm 1.00 \\
\hline 1633 & W Sjælland, Denmark... & 1 & 100 & & 2 & 9 & 26 & 25 & 29 & 4 & 5 & & & 11.02 & \pm 1.30 \\
\hline 2838 & Wien, Austria $\ldots \ldots \ldots$. & 1 & 100 & & 3 & 6 & 27 & 25 & 16 & 9 & 8 & 3 & 3 & 11.37 & \pm 1.77 \\
\hline \multirow[t]{3}{*}{2824} & Galicia, Spain . . . . . . . . & 1 & 100 & & & 3 & 12 & 30 & & 20 & 4 & 3 & & 11.74 & \pm 1.27 \\
\hline & Total... & & 900 & 7 & 67 & 185 & 255 & 198 & 110 & 48 & 19 & 8 & 3 & 10.40 & \pm 1.51 \\
\hline & Fossil, zones h-W $2 \ldots$. & & 39 & 2 & 3 & 7 & 14 & 9 & 4 & & & & & 9.95 & \pm 1.26 \\
\hline
\end{tabular}


pollen grains with non-annulate pores. Plants from maritime and inland habitats in Denmark (cp. Iversen 1936 b) differ slightly also as to pollen, and the material suggests mixing (introgression) between two types. Pollen grains with annulate pores dominate in plants from Eastern North America and Greenland (corresponding to the conventional $P$. juncoides).Such a result corresponds to the result of Gregor (1. c.) that a major discontinuity occurs in the North Atlantic populations of the coeno-species between North America-Greenland and Iceland-North Europe. The annulate pollen type dominates also in plants from the Alps corresponding to $P$. alpina, $P$. serpentina and $P$. carinata, and in plants from Southern Russia and Asia belonging to $P$. maritima var. salsa (Pallas) Pilger.

By courtesy of Professor J. W. Gregor pollen from arteficial hybrids of diploid P. alpina and diploid North European P. maritima, have been examined. It proved that the hybrids produce both annulate and non-annulate pollen with predominance for pollen of an intermediate type.

Table 14. Pore number-frequency distribution in modern pollen of Plantago maritima and allied species, and in fossil pollen of P. maritima s. 1 .

$\mathrm{M}=$ mean number. $\sigma=$ standard deviation.

Fordelingen af pore-antal hos recent pollen af Plantago maritima og beslægtede arter $0 g$ hos fossilt pollen af $P$. maritima s. 1. $\mathrm{M}=$ middeltal. $\sigma=$ standardafvigelse.

\begin{tabular}{|c|c|c|c|c|c|c|c|c|c|c|c|c|c|c|}
\hline \multirow{2}{*}{ Source } & \multirow{2}{*}{$\begin{array}{c}\text { Pollen } \\
\text { total }\end{array}$} & \multicolumn{11}{|c|}{ Pore number } & \multirow{2}{*}{ M } & \multirow{2}{*}{$\sigma$} \\
\hline & & $1 \mid$ & 2 & 3 & 4 & 5 & 6 & 7 & 8 & 9 & 10 & 11 & & \\
\hline P. maritima, N Europe ... . & 3300 & & 1 & & 40 & 915 & 1598 & 637 & 107 & 2 & & & 5.96 & \pm 0.82 \\
\hline $\begin{array}{l}\text { Fossil, non-annulate, } \\
\text { zones W 1-W } 5 \ldots . . .\end{array}$ & 52 & & & & 2 & 12 & 22 & 14 & 1 & 1 & & & 6.06 & \pm 0.95 \\
\hline 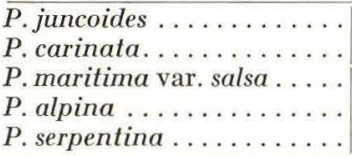 & $\begin{array}{r}1000 \\
200 \\
600 \\
1100 \\
600\end{array}$ & 1 & 6 & $\begin{array}{r}11 \\
2\end{array}$ & $\begin{array}{r}68 \\
7 \\
6 \\
26 \\
8\end{array}$ & $\begin{array}{r}248 \\
48 \\
106 \\
122 \\
40\end{array}$ & $\begin{array}{r}387 \\
97 \\
290 \\
333 \\
134\end{array}$ & \begin{tabular}{r|}
203 \\
40 \\
145 \\
365 \\
180
\end{tabular} & \begin{tabular}{|r|}
$\mid 66$ \\
6 \\
40 \\
193 \\
101
\end{tabular} & $\begin{array}{l}10 \\
\\
10 \\
42 \\
30\end{array}$ & $\begin{array}{r}1 \\
11 \\
5\end{array}$ & \begin{tabular}{l|}
2 \\
2 \\
1
\end{tabular} & $\begin{array}{l}5.92 \\
6.11 \\
6.25 \\
6.67 \\
6.73\end{array}$ & $\begin{array}{l} \pm 1.14 \\
\pm 0.85 \\
\pm 0.76 \\
\pm 1.19 \\
\pm 1.10\end{array}$ \\
\hline $\begin{array}{l}\text { Fossil, annulate, } \\
\text { zones W 1-W } 5 . .\end{array}$ & 28 & & & & & 4 & 12 & 11 & 1 & & & & 6.32 & \pm 0.77 \\
\hline
\end{tabular}

Fossil pollen referred to $P$. maritima s. 1 . occurred quite frequently, especially in zone W 2. Both the annulate and the non-annulate type occur and are rather well distinguished (see plate IV). Among 65 pollen grains counted in the pollen analyses 53 grains belonged to the non-annulate type and 12 grains to the annulate type. The nonannulate pollen grains belong no doubt to the North European $P$. maritima, a species of wide distribution and highly variable habitat preferences. They most closely resemble pollen from plants from inland habitats. The identity of the annulate pollen grains is not quite clear. As all diploid plants interbreed freely it seems unlikely that a diploid species with such pollen could have "survived" mixing with the much larger population of plants with pollen of the non-annulate type. It thus seems to be more likely that the fossil pollen of annulate type represents tetraploid plants. As mentioned above the chromosome numbers of the alpine species are not known very well, but it appears that tetraploids occur only rarely in P. alpina (cp. Gregor l. c.). Hence, it is suggested that the fossil pollen grains of annulate type belong rather to $P$. serpentina, but a clear identification is not possible at the present. Pore number frequency distribution in various modern types and in the fossil pollen grains is shown in table 14 and fig. 8 . 


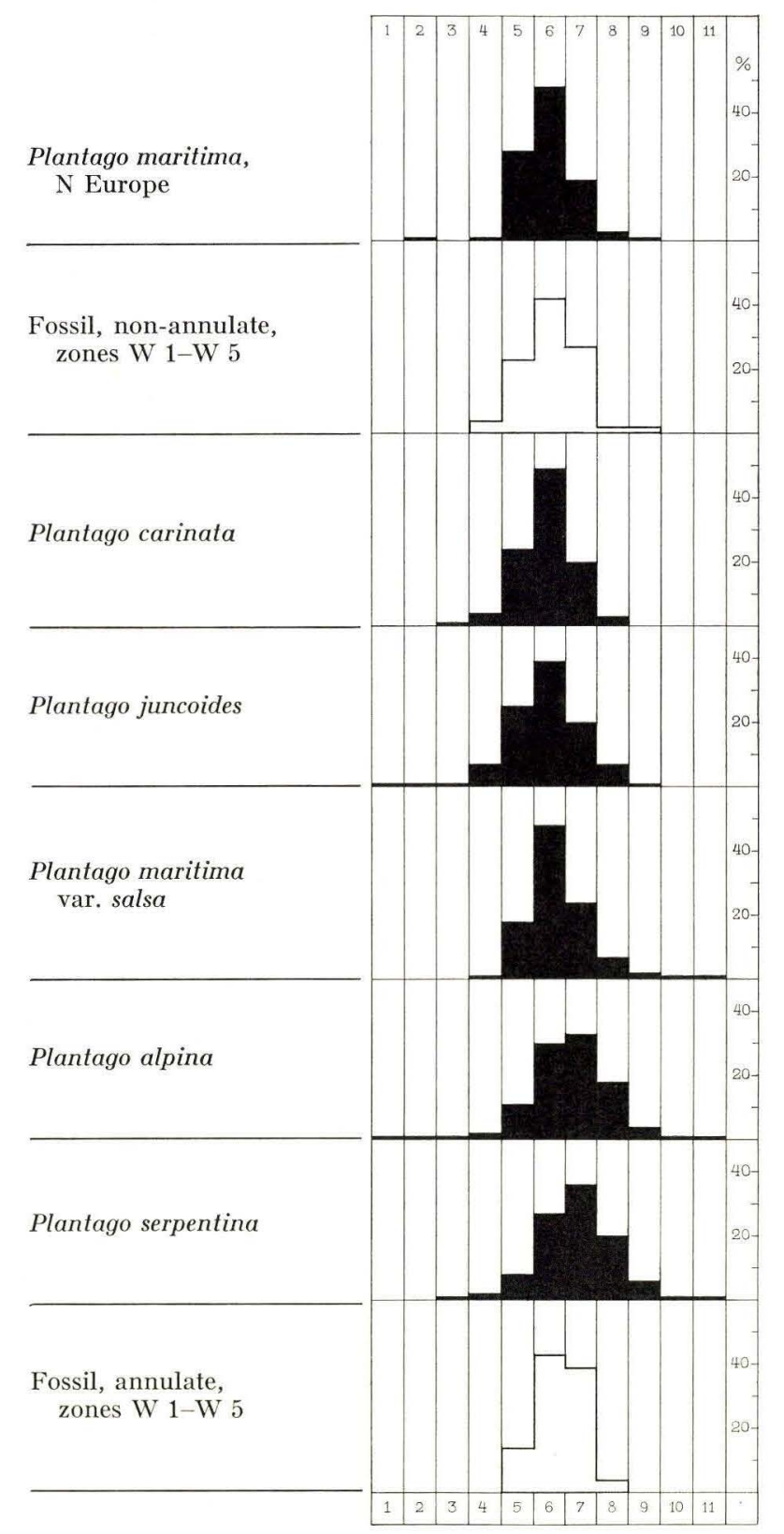

Fig. 8. Pore number-frequency distribution in modern pollen of Plantago species related to $P$. maritima (black), and in fossil pollen of $P$. maritima s. 1 . (white, cp. table 14).

Fordeling af pore-antal hos recent pollen af Plantago arter beslægtede med $P$. maritima (sort) $o g$ hos fossilt pollen af $P$. maritima s. 1 . (hvid, sml. tabel 14). 
It may be seen that the modern material is rather uniform, but small differences may exist. The fossil material is small. Still it may be seen that the pore numbers of the fossil grains compare favourably with the corresponding modern types.

The pollen of non-annulate type occurred in all pollen zones. The 12 pollen grains of annulate type counted within the pollen analyses occurred in zone W 2 (7), W 3 (3), W 4 (1) and Wx (1). van der Hammen (1951) and Iversen (1954) referred LateGlacial pollen grains of a similar type tentatively to $P$. alpina. The reasoning given above also holds true for that material.

Plantago media. Pollen grains referred to the species were recorded from all the pollen zones. 


\title{
IV. DESCRIPTIONS OF THE SITES AND \\ THE POLLEN DIAGRAMS
}

\author{
Brørup Hotel Bog
}

\begin{abstract}
After the investigations of $\mathrm{N}$. Hartz (Hartz 1909) the name of Brørup has become classic in the study of interglacial fresh-water deposits in Jutland because of the great number of peat bogs from the Eemian Interglacial found within the town and in the surrounding area (see also Jessen, Madsen, Mrlthers and Nordman 1918). J \& M (1928) found some new sites in that neighbourhood, among which was the one named after Brørup Hotel, in the garden of which it was located. Later on the grounds came into the possession of the Sports Club of Brørup, and a football field was established on top of the interglacial bog. The Sports Club of Brørup has generously allowed borings on the football field, but the existence of the field has put certain limitations to the new geologic activities.
\end{abstract}

\section{Sediments.}

The Brorup Hotel Bog and Brørup itself are situated on a high plateau, which forms a divide between the rivers Kongeån and Holsted $\AA$ (see the maps, fig. 2 in J\&M (l. c.) and fig. 11 p. 123). The site was not reached by the Weichselian glaciation, but according to the map of Milthers (1948) the outermost position of the glacier was found only a few hundred meters northeast of the site. J\&M (1928) constructed a transect of the Eemian Interglacial deposit and its covering layers from borings and excavations (l. c., plate XIII), and their profile is referred to as for the general conditions of the bog. The basin is remarkable for its small size (ca. 50 meters across) and its deepness (up to 10 meters, see also J\& M, l. c., p. 88).

In 1954 a new boring (BP 1, STA) was carried out near the position of BP 3 (J \& M). The sequence of sediments is similar to that found by $J \& M$, but a more detailed sequence could be distinguished due to the improved sampling method (p. 12). In 19572 borings (BP $1 \mathrm{a}$ and BP 2, STA) were made, their main purpose being to obtain a better representation of the youngest layers, and to oblain larger samples for enriched C 14 measurements (p. 131). The boring BP 1 a (STA) was nearly identical to BP 1 (STA). BP 2 (STA) is located near BP 4 (J\&M). In the descriptions below the strata have been designated with capital letters corresponding to those used by $\mathrm{J} \& \mathrm{M}$. The transitions between the strata are gradual, if not otherwise stated.

BP 1 (STA)

$0.00-0.70 \mathrm{~m}$. Made ground.

A $\quad 0.70-1.40 \mathrm{~m}$. Agricultural soil.

B C $1.40-2.69 \mathrm{~m}$. Grey sand, lowermost some stones. Lower limit sharp.

E $32.69-2.80 \mathrm{~m}$. Humified herbaceous and mossy peat with some dy? $\left(\mathrm{Th}^{3} 2\right.$, Sh 2). Strongly stratified. Leaf epidermis of Larix $(2.79 \mathrm{~m}$.). 
E $42.80-3.12 \mathrm{~m}$. Argillaceous coarse-detritus gyttja. Coarse-detritus occurring especially at the uppermost and the lowermost parts of the stratum (Dg 1, Ld $\mathrm{Ld}^{2}$, A 1).

E $53.12-3.74 \mathrm{~m}$. Non-humified herbaceous peat $\left(\mathrm{Th}^{1} 4\right)$. A catkin scale of Betula pubescens $(3.20 \mathrm{~m}$.) and seeds of Menyanthes trifoliata $(3.50 \mathrm{~m}$.).

F $1 \quad 3.74-3.89 \mathrm{~m}$. Coarse-detritus gyttja (Dg 2, $\left.\mathrm{Ld}^{2} 2\right)$.

F $23.89-4.24 \mathrm{~m}$. Argillaceous coarse-detritus gyttja (Dg 1, $\mathrm{Ld}^{2} 2, \mathrm{~A} 1$ ). Fruits of Betula pubescens and Carex sp. (4.00 m.). The lower limit sharp.

H $14.24-5.89 \mathrm{~m}$. Silt and clay with some sand and fine-detritus $\left(\mathrm{Ld}^{2} 1, \mathrm{~A} 2\right.$, $\mathrm{Ga}+\mathrm{s} 1$ ). Above $4.35 \mathrm{~m}$. the deposit consisted of small, angular lumps. Dopplerite occurred between the lumps.

H $25.89-6.00 \mathrm{~m}$. Clay or silt with a little fine-detritus ( $\left.\operatorname{Ld}^{2} 0-1, \mathrm{~A} 4\right)$.

J $16.00-7.41 \mathrm{~m}$. Coarse-detritus gyttja ( $\mathrm{Ld}^{2} 2$, Dg 2), below $7.20 \mathrm{~m}$. rather much humified substance and some drifted fragments of herbaceous plants $\left(\mathrm{Ld}^{3} 2\right.$, Dh 1, Dg 1$)$. Leaves of Betula nana $(6.60 \mathrm{~m}$.$) .$ The lower limit sharp.

J $27.41-7.46 \mathrm{~m}$. Rather humified herbaceous peat $\left(\mathrm{Th}^{3} 4\right)$.

J $3 \quad 7.46-(7.79) \mathrm{m}$. Wood peat with much \pm dissolved wood $\left(\mathrm{Tl}^{4} 4\right)$. Above $7.55 \mathrm{~m}$. charred wood of Picea. 7.64-7.68 m. a horizontal branch or trunk of Alnus glutinosa. The interglacial deposits extend to $9.60 \mathrm{~m}$.

In the terms of J\&M (1928), stratum J constitutes the "lower mud bed", stratum H the "middle bed", the strata E and F the "upper mud horizon", and the strata A-D the covering deposits. The equivalent of layer G described by J\&M (1. c.) as sandy mud has not been refound with certainty. It corresponds probably to a part of layer $\mathrm{H}$, as described here.

BP 2 (STA)

$0.00-0.65 \mathrm{~m}$. Made ground.

A C $0.65-2.50 \mathrm{~m}$. Sand.

D $\quad 2.50-2.60 \mathrm{~m}$. Argillaceous sand with some fine-detritus $\left(\mathrm{Ld}^{2} 1, \mathrm{Ga}+\mathrm{s} 2, \mathrm{~A} 1\right)$. The lower limit sharp.

E $12.60-3.07 \mathrm{~m}$. Humified herbaceous peat, strongly stratified $\left(\mathrm{Th}^{4} 4\right)$. Uppermost some fine sand. Roots of Calluna vulgaris (2.64-2.91 m.). Especially below $2.91 \mathrm{~m}$. many remains of Eriophorum vaginatum.

E $23.07-3.22 \mathrm{~m}$. Wood peat with many thin tree roots $\left(\mathrm{Tl}^{4} 4\right)$. Twigs of Calluna vulgaris and Betula ef. pubescens, wood of Pinus.

E $3 \quad 3.22-3.30 \mathrm{~m}$. Humified herbaceous peat, strongly stratified $\left(\mathrm{Th}^{4} 4\right) .1$ seed of Carex $(3.26 \mathrm{~m}$.$) and severa] seeds of Menyanthes trifoliata$ (3.29 m.).

E $4 \quad 3.30-(3.49) \mathrm{m}$. Argillaceous coarse-detritus gyttja, coarse-detritus especially at the uppermost part (Dg 1, $\left.\mathrm{Ld}^{2} 2, \mathrm{~A} 1\right)$.

Below this level the large sampler did not work satisfactorily, and the boring was discontinued.

\section{Chemical Analyses.}

Ash content was analyzed in three samples (BP 1). The results are shown in table 15.

It can be seen from table 15 that silicates completely dominate the ash content. Carbonates and ferrosulfides have been insignificant, as the content of $\mathrm{CaO}$ and $\mathrm{Fe}_{2} \mathrm{O}_{3}$ is very low. 
Table 15. Brørup Hotel Bog. Analyses of ash content. The figures indicate percentages of the dry weight.

Brørup Hotel Mose. Analyser af aske-indhold. Tallene angiver procenter af tørvægten.

\begin{tabular}{|c|c|c|c|c|c|c|c|}
\hline \multirow{2}{*}{ Stratum } & \multirow{2}{*}{ Depth (BP 1) } & \multicolumn{4}{|c|}{ Soluble in warm, diluted $\mathrm{HCl}$} & \multirow{2}{*}{$\begin{array}{l}\text { Insoluble } \\
\text { residue }\end{array}$} & \multirow{2}{*}{$\begin{array}{c}\text { Total ash } \\
\text { content }\end{array}$} \\
\hline & & $\mathrm{Fe}_{2} \mathrm{O}_{3}$ & $\mathrm{CaO}$ & $\mathrm{MgO}$ & $\mathrm{Al}_{2} \mathrm{O}_{3}$ & & \\
\hline E 5 & $3.49-3.60 \mathrm{~m}$. & 0.3 & 0.6 & 0.1 & 1.7 & 16.3 & 19.5 \\
\hline H 1 & $5.58-5.70$ & 0.8 & 0.2 & 0.2 & 2.2 & 75.0 & 79.0 \\
\hline J 1 & $6.08-6.20$ & 0.5 & 0.5 & 0.2 & 3.2 & 49.4 & 54.4 \\
\hline
\end{tabular}

Values for loss on ignition and "humus" content (p. 13) are shown in table 16, and in fig. 9 (right side, hatched area and black bars). It may be seen that the organic content varies highly. Thus the organic content is very high in the peaty layers (loss on ignition in layer E 3: 97\%, E 5: 90\%, J 1 (below $7.20 \mathrm{~m}$. ): $82 \%$ ). In the detritus gyttjas (layers E 4, F 2, J 1) the values for loss on ignition vary from 64 to $24 \%$. In the strata $\mathrm{H} 1$ and $\mathrm{H} 2$ the organic content is low (loss on ignition down to $7 \%$ ).

Table 16. Brorup Hotel Bog. Determinations of organic content. The figures indicate percentages of the dry weight. Brorup Hotel Mose. Bestemmelser af organisk indhold.

Tallene angiver procenter af tørvægten.

\begin{tabular}{c|l|c}
\hline Stratum & $\begin{array}{c}\text { Depth } \\
\text { (BP 1) }\end{array}$ & $\begin{array}{c}\text { Loss on } \\
\text { ignition }\end{array}$ \\
\hline E 3 & $2.71 \mathrm{~m}$. & $97.2 \%$ \\
& 2.79 & 57.2 \\
\hline E 4 & 3.00 & 40.2 \\
\hline E 5 & 3.53 & 80.5 \\
& 3.70 & 90.0 \\
\hline F 1 & 3.85 & 44.5 \\
\hline F 2 & 4.00 & 23.9 \\
\hline H 1 & 4.25 & 47.3 \\
& 4.40 & 12.5 \\
& 5.27 & 16.4 \\
& $5.58-5.70$ & 21.0 \\
& 5.72 & 20.4 \\
H 2 & 5.86 & 24.4 \\
\hline J 1 & 5.96 & 7.2 \\
\hline & 6.15 & 45.5 \\
& 6.46 & 64.3 \\
& 7.26 & 64.0 \\
\hline
\end{tabular}

\begin{tabular}{c|l|c}
\hline Stratum & $\begin{array}{l}\text { Depth } \\
\text { (BP 1) }\end{array}$ & $\begin{array}{c}\text { "Humus" } \\
\text { content }\end{array}$ \\
\hline E 4 & $2.98 \mathrm{~m}$. & $27.1 \%$ \\
\hline E 5 & $3.49-3.60$ & 73.2 \\
& 3.70 & 83.5 \\
\hline H 1 & $4.46-4.57$ & 8.1 \\
& $5.08-5.19$ & 11.4 \\
& $5.58-5.70$ & 14.3 \\
H 2 & 5.86 & 22.0 \\
\hline J 1 & $5.89-5.95$ & 6.8 \\
\hline
\end{tabular}

Organogenic minerals (lime, cp. above, diatom shells and sponge spicules) are virtually absent, and the curve for the loss on ignition and the "humus" determinations thus offer good measures for the changes in the balance between influx of allochtonous mineral matter, and sedimentation of organic matter. Thus it may be seen in fig. 9 that the mineral content increases strongly in the uppermost part of layer $J 1$. The mineral content is high in the layers $\mathrm{H} 2$ and $\mathrm{H} 1$, generally, with a small increase for organic content in the lowermost part of layer $\mathrm{H}$ 1. The sedimentation of allochtonous mineral matter had apparently increased strongly. This change was probably due to a cooling of the climate (cp. p. 14). 
The organic content increases again in the layers F and E. It is especially high in the peat layers (E 3, E 5). The climate improved presumably. As discussed later, the small maxima for mineral content in the layers F 2 and E 4 correspond to rises in the local water level in connection with minor climatic oscillations.

\section{Pollen Analyses.}

The pollen diagram published by J\&M (1928) was based on rather few analyses. Still it shows clearly enough that the lower mud bed corresponds to the Eemian Interglacial. Pollen diagrams from BP 1 and BP 2 (STA) are shown on the plates VI and VII (cp. the tables 28-29). In the curves for local plants (at BP 1) the values for Elisma and Callitriche have been summarized in a special curve (Limnophytes II). The reason is that their values follow the curve for Telmatophytes rather than the curve for the other Limnophytes (Limnophytes I, see also p. 99).

\section{Rebedded Pollen.}

J \& M (1928) noticed that the mineral layers, which constitute the "middle bed" (layer H) contained rolled fragments of wood of Picea and lumps of mud, which contained fruits and leaves of Ajuga reptans, Alnus glutinosa and Picea abies. They ascribed these remains to re-deposition from the interglacial bed below (l. c., p. 85). Hence, it is obvious that rebedded interglacial pollen and spores also must be suspected to occur.

The frequency for the pollen from the most thermophilous trees and shrubs was calculated for each sample ( $\Sigma$ "thermophilous trees and shrubs", which comprises the pollen of Alnus, Carpinus, Corylus, Fraxinus, Ilex, Quercus, Taxus, Tilia, and Ulmus). All of these trees and shrubs are known to have occurred in the Eemian Interglacial, and it was considered that their pollen must certainly be secondary in the layers from the cool intervals, if any rebedded pollen occurs there. A curve for the pollen of the "thermophilous trees and shrubs" is shown in fig. 9 (black silhouette), and it may be compared with the values for mineral and organic content (cp. above). Its values are high in the peat from zone $\mathrm{h}$ (up to above $25 \%$ ), but this pollen disappears almost completely in the course of the zone, and it is very rare in zone W 1, presumably due to decreased temperature. This result corresponds to the opinion of J\&M (l. c.), that the interglacial stage was followed by a cold stage. The curve for "thermophilous trees and shrubs" rises again in zone W 2, but the pollen of these plants becomes rare again in zone W 3. The pollen from the "thermophilous trees and shrubs" is thus most frequent in the highly mineral layers of the "middle bed". This fact shows clearly enough that their pollen must be secondary there.

It appears from fig. 9 that there is an intimate relationship between the curve for $\Sigma$ "thermophilous trees and shrubs" and the amount of mineral matter occurring in the sediments from zone W 2. Hence, it may seem clear that the incidence of that pollen was connected with erosion, and that it had been washed into the lake together with the allochtonous mineral matter. The rebedded pollen is also present in the samples from the beginning of zone W 3 , but only in very small amounts. The erosion was apparently less intensive at that time, but the frequencies of the secondary pollen may also have become depressed somewhat due to a high pollen production from the contemporaneous Betula forests.

As the samples from zone W 2 are contaminated with older pollen, they give, of course, rather uncertain information about the composition of the contemporaneous vegetation. The pollen of the "thermophilous trees and shrubs" must certainly be 


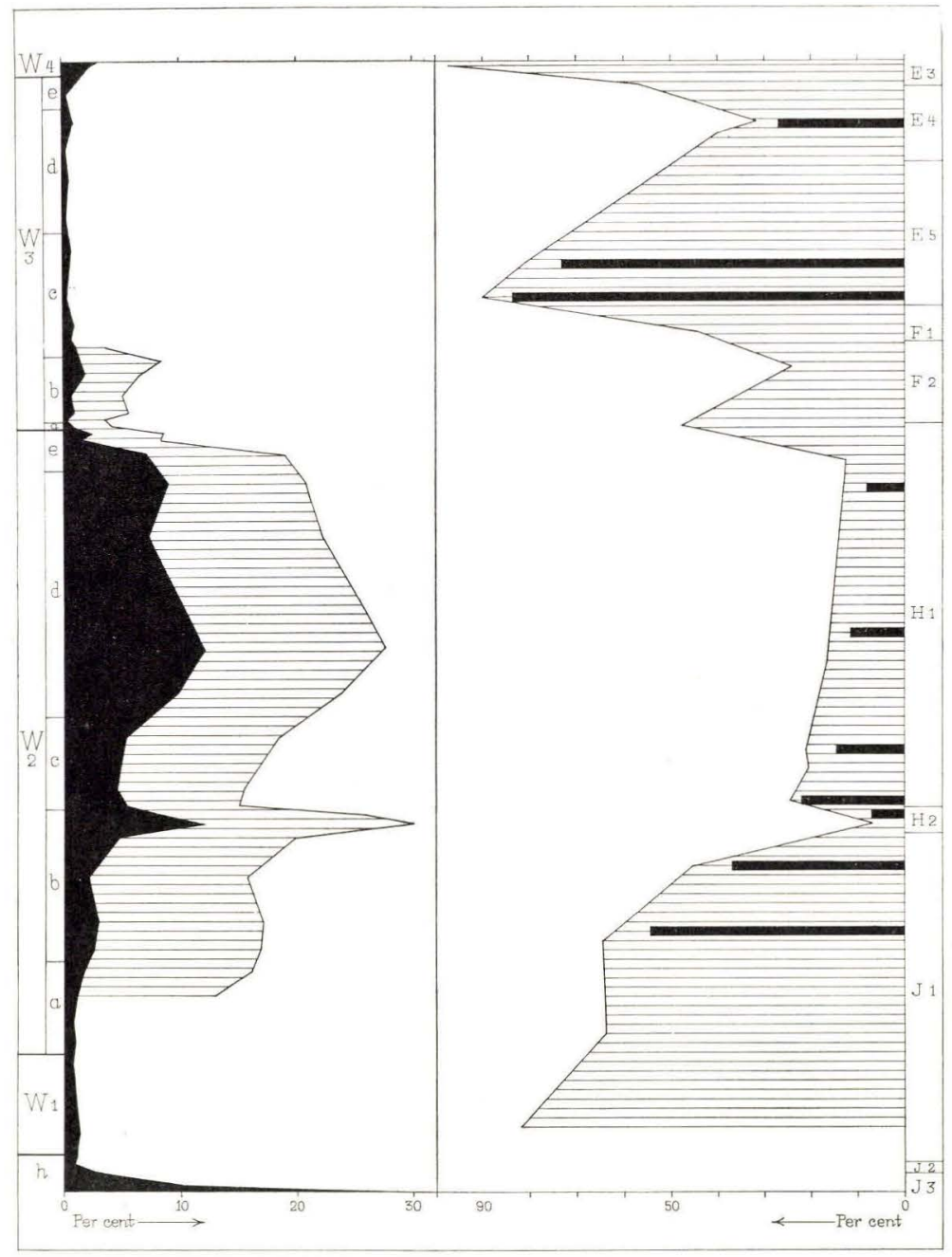

Fig. 9. Relationship of rebedded pollen to mineral and organic content of the sediments, Brorup Hotel Bog, BP 1. Left side: Pollen zones, total of pollen of "thermophilous trees and shrubs" (black silhouette, percentages of the pollen totals), and "all secondary pollen" (hatched silhouette, percentages of the pollen totals). Right side: Sediments, "humus" content (black bars, percentages of the dry weight), and loss on ignition (hatched silhouette, percentages of the dry weight).

Forekomst af omlejret pollen i forhold til mineralindhold og organisk indhold i sedimenterne, Brorup Hotel Mose, BP 1. Venstre side: Pollenzoner, summen af pollen fra "varmekrævende træer og buske" (sort silhouet, i procent af pollensummen), og "alt sekundært pollen" (skraveret silhouet, procent af pollensummen). Højre side: Sedimenter, "humus" indhold (sorte søjler, i procent af torvægten), og glødetab (skraveret silhouet, i procent af tørvægten).

considered to be rebedded, but some doubt must remain as to the origin of the other pollen and spore types found in zone W 2. The source of the rebedded pollen cannot be explored, as it must be assumed that such layers were destroyed by the erosion, and it can only be said that those deposits must have been older than zone W 2. Absence of Tertiary pollen, which usually characterize the tills in Western Jutland, suggests 
that most of the secondary pollen had been derived by erosion of pollen-bearing deposits from the Eemian Interglacial and from zone W 1. Such deposits would certainly have been immediately available for erosion, and it may be expected that other pollen and spore types from these deposits may occur as rebedded too. However, pollen from plants characteristic of forestless conditions may be primary.

3 groups of components may, accordingly, occur in the pollen flora of the highly mineral sediments from zone W 2:

(1) Pollen belonging to the "thermophilous trees and shrubs". Its secondary origin seems to be rather clear,

(2) Pollen from other plants, which are likely to have been represented in deposits from the Eemian Interglacial, and from zone W 1, such as Picea, Betula, Calluna, Empetrum, Arctostaphylos,

(3) Pollen from plants characteristic of forestless conditions such as Salix, Gramineae, Cyperaceae, Artemisia, Rumex, Plantago maritima etc. There is a chance that the pollen from such plants came from the contemporaneous vegetation and is primary.

As mentioned above, the curve for $\Sigma$ "thermophilous trees and shrubs" shows a very intimate relationship to the erosion activity. It may thus be used as a measure for the degree with which the samples are contaminated with derived pollen. A preliminary glance at the pollen diagram from BP 1 (plate VI) will show that the curves for the genera mentioned in group (2) above are actually parallel to the curve for $\Sigma$ "thermophilous trees and shrubs" in zone W 2. The curves for the plants from group (3) show an opposite trend. Thus, the curves for the plants from group (3) decrease sharply in the clay layer $\mathrm{H} 2$ (subzone $\mathrm{W} 2 \mathrm{~b}$ ), where the curve for rebedded pollen reaches maximum values, and their values increase immediately above that layer, in correspondance with a minimum for secondary pollen (subzone W $2 \mathrm{c}$, see especially the curves for Salix (17) $)^{1}$, Gramineae (19), Cyperaceae (20), Rumex acetosella type (21), Potentilla (22), Galium type (23), Tubuliflorae (24), Liguliflorae (25), Artemisia (26), Astragalus alpinus (31), Lotus (32), Plantago maritima (34). Hence, the pollen types mentioned can hardly belong to the rebedded group.

The correlation with the curve for $\Sigma$ "thermophilous trees and shrubs" has been calculated for some characteristic curves, see table 17.

The smallest significant numerical value of $\mathrm{r}$ for $\mathrm{P}=0.05$ are indicated according to Fisher (1944).

Table 17 shows that there is a close direct correlation between the incidence of the pollen belonging to $\Sigma$ "thermophilous trees and shrubs" and the pollen of Picea, Calluna, Empetrum and Pinus (r significantly larger than 0). Little doubt can remain that at least the main proportion of the pollen from these plants belongs to the rebedded fraction too. For Arctostaphylos uva-ursi the significance of the correlation is somewhat doubtful, and it is suggested that primary pollen of the species may occur (especially in subzone W 2c). The Artemisia pollen shows negative correlation ( $\mathrm{r}$ significantly smaller than 0 ). The pollen of the genus is thus unlikely to have been associated with the re-deposited material, and it may be safely considered to be primary. The Plantago maritima pollen shows negative correlation too, but the significance of the correlation is a little doubtful. However, the curve for the species is correlated positively with the Artemisia curve in a significant way (see table 17).

1) The figures in brackets indicate the curves in the pollen diagram (plate VI). 
Table 17. Brørup Hotel Bog. Correlation with $\Sigma$ "thermophilous trees and shrubs".

$\mathrm{N}=$ number of pairs, $\mathrm{r}=$ coefficient of correlation. $\sigma=$ standard deviation. Brørup Hotel Mose. Korrelation med $\Sigma$ "thermofile træer og buske". $\mathrm{N}=$ antal par. $\mathrm{r}=$ korrelationskoefficient. $\sigma=$ standardafvigelse.

\begin{tabular}{|c|c|c|c|c|c|c|}
\hline & $\begin{array}{l}\text { Samples } \\
\text { (BP 1) }\end{array}$ & Zones & $\mathrm{N}$ & $\mathrm{r}$ & $\sigma$ & $\begin{array}{l}\text { Smallest } \\
\text { value of } r \\
\quad \text { for } \\
\mathrm{P}=0.05\end{array}$ \\
\hline Picea .............. & $6.90-2.77 \mathrm{r}$ & $W 2 a-3 e$ & 38 & +0.89 & \pm 0.03 & 0.32 \\
\hline Calluna ............. & $6.90-3.97$ & $2 a-3 b$ & 27 & +0.70 & \pm 0.10 & 0.38 \\
\hline Empetrum ........... & $6.90-3.97$ & $2 a-3 e$ & 27 & +0.69 & \pm 0.10 & 0.38 \\
\hline Arct. uva-ursi. . . . . . . & $6.90-3.97$ & $2 a-3 b$ & 27 & +0.22 & \pm 0.18 & 0.38 \\
\hline Pinus . . . . . . . . . . & $6.02-3.97$ & $2 a-3 b$ & 20 & +0.89 & \pm 0.05 & 0.44 \\
\hline Artemisia . . . . . . . . & $6.02-4.28$ & $2 b-2 e$ & 14 & -0.65 & \pm 0.15 & 0.53 \\
\hline Plantago maritima . . . . . & $6.02-4.28$ & $2 b-2 e$ & 14 & -0.45 & \pm 0.21 & 0.53 \\
\hline \multicolumn{7}{|c|}{ Correlation with Artemisia } \\
\hline Plantago maritima ..... & $7.99-2.69$ & W1 -4 & 45 & +0.49 & \pm 0.08 & 0.29 \\
\hline Astragalus alp. . ....... & $6.90-2.83$ & $2 \mathrm{a}-2 \mathrm{e}$ & 38 & +0.27 & \pm 0.15 & 0.32 \\
\hline
\end{tabular}

Some curves may represent both primary and secondary pollen, and they constitute, accordingly, cases of uncertainty.

Thus the curve for the Betula pollen is parallel to the curve for the re-deposited pollen in zone W 2, and unlike the curves for the pollen types assumed to be primary. Hence, it seems rather certain that some of the Betula pollen from zone W 2, and especially from the subzones $\mathrm{b}, \mathrm{c}$ and $\mathrm{d}$, is rebedded. According to the size-statistical data $B$. pubescens and $B$. nana are represented (p. 37). In zone W 1 and in $W 2 \mathrm{a}$ the Betula pollen, mostly $B$. nana, must be primary, as the secondary pollen is rather insignificant there. The pollen of $B$. nana found in subzone $W 2 \mathrm{c}$ is presumably primary too, but the increased amount of $B$. pubescens pollen in subzone $\mathrm{c}$ is presumably secondary. Most of the Betula pollen from the subzones b and d is probably rebedded pollen from $B$. pubescens. In the samples from zone W $2 \mathrm{e}$ and $\mathrm{W} 3 \mathrm{a}$ secondary pollen is scarce again, and most of the Betula pollen must be primary. Both $B$. pubescens and $B$. nana are represented there.

The curve for the pollen of Juniperus (18) contains uncertain points too. In zone W $2 \mathrm{a}-\mathrm{c}$ the curve is parallel to the curves for the pollen of Artemisia and other genera assumed to be primary (with a minimum in subzone $b$, and a maximum in subzone c), and the Juniperus pollen found there is presumably primary. In zone W $2 \mathrm{~d}-\mathrm{W} 3 \mathrm{~b}$ this curve resembles the curve for the $\Sigma$ "thermophilous trees and shrubs", and some of the Juniperus pollen found there may be secondary (see also p. 95).

The Sphagnum curve (76) resembles the curve for Juniperus. It has a minimum at the increase for secondary pollen in zone W 2b, and the Sphagnum spores may be assumed to be primary there. In zone W $2 \mathrm{~d}-3 \mathrm{~b}$ their origin is more uncertain, and they may be secondary.

According to the observations just mentioned the pollen grains and spores from the following plants occur in zone W 2 and W $3 \mathrm{a}-\mathrm{b}$ in such a way that all of them or most of them may be considered to be secondary with a reasonable certainty (cp. the pollen diagram from BP 1, plate VI and table 28), 
proportion of the samples as reflected by the values for loss on ignition and "humus" content. In the pollen diagram on plate VI the parts of the curves which are assumed to represent mainly secondary pollen are marked in a special manner (striation and punctuation of the curves). However, the error introduced by the secondary pollen should be kept in mind at a consideration of the curves for the presumed primary types.

Average frequencies for certain pollen and spore types in the various zones are shown on plate XV. For the subzones W $2 \mathrm{~b}-\mathrm{d}$ the percentages have been based on a pollen sum, which omits all secondary types mentioned on p. 54 and half of the Betula pollen (assumed to represent secondary Betula pubescens pollen).

In the deposits from zone W 3 the influence of rebedded pollen is restricted to the subzones $\mathrm{a}$ and $\mathrm{b}$, and here it is of small importance. A large number of the plants represented there do not occur or are very rare in zone W 2. Such finds can hardly be derived and are quite certain to be of primary origin.

\section{Pollen Zones.}

Zone h (BP 1, 7.39-7.79 m.).

During the Eemian Interglacial the local hydrosere led to formation of a forest peat ( $\mathrm{J} 3$ ). This peat contains wood of Alnus glutinosa and Picea abies, and reflects an interglacial low water level. J \& M (1928) did not distinguish this stratum, but from the upper part of the interglacial layer they mention macroscopic remains of Alnus glutinosa, Picea abies, Betula, Carpinus betulus and Ajuga reptans. The burned wood of Picea indicates a local forest fire.

The pollen spectra are dominated completely by pollen and spores from the local vegetation and reflect mainly the local succession.

Alnus (6) and Picea pollen (10) dominate the pollen analyses in the lowermost part of the pollen diagram. Carpinus (1), Quercus (2), Fraxinus (5), Corylus (7) and Taxus (8) are represented with rather low frequencies. The plants mentioned were probably rather common on upland soil. The herbaceous plants represented with highest frequencies are Pteridium (9), Rumex acetosa (16), Polypodium (29), Thelypteris dryopteris (41), Urtica dioica (44), Melampyrum (54), Thelypteris cf. palustris (57) Osmunda cf. cinnamomea (58), Callitriche (62) together with Gramineae (19) and Cyperaceae (20).

At $7.55 \mathrm{~m}$. the values for the pollen of Betula (cf. pubescens) increase suddenly. The development reflects presumably successional stages that followed upon the fire (or fires?) indicated by the charcoal layer. In the layer of herbaceous peat (J 3) the values for pollen from local herbaceous plants increase considerably.

At the top of the zone Pinus pollen becomes dominant within the tree pollen. At the same level the values for Calluna (12), Empetrum (13), Arctostaphylos uva-ursi (15) and Sphagnum (76) begin to increase.

The overrepresentation of local pollen and spores obscures the picture of the general conditions somewhat, but a decrease of temperature is suggested by the decrease for the most thermophilous plants. At the same time traces of a beginning rise in the local water table occur, and the local vegetation seems to have become more oligotrophic.

\section{Zone W 1 (BP 1, 7.00-7.36 m.).}

The sediment is gyttja with coarse plant detritus, the proportion of which decreases upwards. Hence, it must be assumed that the pollen spectra give a better reflection of the general vegetation. In a layer, which corresponds to the zone, J\&M (l. c.) found a fruit of Betula nana and seeds of Andromeda polifolia (at BP 4, J\&M).

A slight re-deposition activity may haven taken place (? pollen grains and spores of Ilex, Stellaria holostea, Pteridium). The pollen of Carpinus (1), Quercus (2), Ulmus (3), Alnus (6) and Corylus (7) may have been due to long distance transport. Betula nana contributed apparently most of the Betula pollen. The most frequent pollen types are thus Betula nana, Pinus (11), Juniperus (18), Calluna (12), Empetrum nigrum and E. hermaphroditum (13-14, p. 40), Arctostaphylos uva-ursi (15), Gramineae (19), Cyperaceae (20), Rumex acetosella type (21) and $R$. acetosa (16).

The frequencies for the Pinus pollen reach $10-13 \%$. Such values indicate that the species cannot have been common in the neighbourhood. Betula pubescens seems to have been 
rare too. Picea (10) may have occurred rarely. It appears that the trees had become scarce, and that the vegetation was dominated by a shrub community of Betula nana, Juniperus and the heath shrubs with many herbs.

Sphagnum spores (76) are common, and pollen of Limnophytes such as Myriophyllum alterniflorum (60) and Eu-Potamogeton (61) appear.

Zone W 2 (BP 1, 4.28-6.90 m.).

Subzone W 2 a (BP 1, 6.59-6.90 m.).

The mineral proportion of the sediment is rising, and at the end of the subzone the influence of re-deposition becomes obvious. A sample, in which J\&M (1. c.) found fruits of Betula nana and nuts of Myriophyllum alterniflorum together with remains of the bryophytes Drepanocladus revolvens and Scorpidium scorpidioides (BP $3 \mathrm{~J} \& \mathrm{M}$ ) belongs presumably to this subzone. Leaves of Betula nana occurred at $6.60 \mathrm{~m}$. (BP 1 STA).

Secondary as well as primary pollen seems to occur, but the proportion of rebedded pollen is still low.

Tree pollen is scarce, and most of it is likely to be secondary. Some primary pollen of Pinus and Betula pubescens may occur, presumably due to long distance transport.

Pollen of Betula nana is dominant within the Betula pollen (p. 37)., and the only other woody plants of some importance were apparently Juniperus (18), the curve of which reaches a maximum in the subzone, and Salix (17). Pollen from herbaceous plants dominates. The pollen of Gramineae (19), Cyperaceae (20) and Rumex acetosella (type 21, in the zone presumably $R$. acetosella s. 1., cp. p. 37) is the most frequent.

Limnophyte pollen is abundant, the pollen of Myriophyllum alterniflorum (60) being most frequent. Others represented are Eu-Potamogeton (64), and Isoëtes echinospora (65). The pollen referred to Ranunculus trichophyllus type (63) probably represents aquatic species. Rubus chamaemorus (75) and Sphagnum (76) are also represented.

\section{Subzone W 2b (BP 1, 5.92-6.50 m.).}

The mineral content reaches a maximum value in the clay layer $\mathrm{H} 2$ (loss on ignition $7 \%$ ). The proportion of rebedded pollen is also high (in layer $\mathrm{H} 2$ up to $12 \%$ ).

The occurrence of secondary pollen makes it difficult to get a clear picture of the vegetation during the period, quantitatively as well as qualitatively. There is no evidence as to the representation of the Betula species. An increasing amount of rebedded Betula pollen seems to occur.

It seems that the most frequent primary pollen types were Salix (17), Juniperus (18), Gramineae (19), Cyperacceae (20) and Rumex acetosella s. l. (21). The flora of terrestrial plants is rather poor.

Remains of aquatic plants are very rare. The Sphagnum spores (76) and the pollen of Rubus chamaemorus (75) are presumably primary.

\section{Subzone W 2c (BP 1, 5.59-5.88 m.).}

The lower border of the subzone corresponds in the sediment column to the transition from the clay layer $\mathrm{H} 2$ to the sandy stratum $\mathrm{H} 1$. The sediment from the subzone has an increased organic proportion (loss on ignition up to $24 \%$, "humus" content $22 \%$ ). There is a sharp decrease in secondary pollen, and the curves for a series of plants, especially herbaceous plants, have characteristic maxima.

Some of the macroscopic plant remains found by J \& M (l. c.) in layer H must be considered to be derived (p. 50). Others may be primary, but primary and secondary finds cannot be distinguished.

Picea and Pinus may be represented by small amounts of primary pollen due to long distance transport. Small amounts of the Ericales pollen, especially that of Arctostaphylos uva-ursi, may also be primary (see p. 52).

The transition to the subzone is marked by a sharp decrease of the Betula curve (from $33 \%$ in subzone b to $17 \%$ in this subzone). Pollen of $B$. nana and B. pubescens occurs in equal proportions. It is likely that a part of the $B$. pubescens pollen is rebedded (p. 53), and the species must have been rare, if present at all. The most common primary pollen types are Salix (17), Juniperus (18), Gramineae (19), Cyperaceae (20), Rumex acetosella s. 1. (21), Potentilla (22), Galium type (23), Tubuliflorae (24), Liguliflorae (25), Artemisia (26), Astragalus alpinus (31), Lotus (32), Plantago maritima (34). A great number of other terrestrial plants, mostly heliophytes, are represented. 
The frequencies for the Limnophyte pollen increase to high values at the transition to the subzone. Myriophyllum alterniflorum (60, maximally 18\%) and Eu-Potamogeton (64, maximally $6.2 \%$ ) are represented abundantly, and the pollen of $M$. spicatum (61), Callitriche (62), Ranunculus trichophyllus type (63) and Typha Sparganium (68) is also rather common. The pollen curves suggest that the fruits of Myriophyllum alterniflorum, Potamogeton natans, P. pusillus, Ranunculus aquatilis (coll.) and Sparganium minimum recorded by J\&M (1. c.) from layer $\mathrm{H}$ belong to the subzone.

\section{Subzone W 2 d (BP $14.50-5.40 \mathrm{~m}$.).}

The organic content is very low (loss on ignition $13 \%$, "humus" content $8 \%$ ) and the influence of secondary pollen is strong. The frequency for definitely rebedded pollen reaches $12 \%$.

Like subzone W 2b the subzone is clearly unfavourable to plant life, but the secondary pollen makes it difficult to get a clear picture of the vegetation. The pollen of Juniperus is somewhat rarer than in the preceding subzone. The occurrence of Betula species is uncertain.

The most frequent pollen of terrestrial plants of presumed primary origin belongs to Salix (17), Gramineae (19), Cyperaceae (20), Rumex acetosella type (21), Tubuliflorae (24), Liguliflorae (25) and Artemisia (26). Pollen of Lotus (32), Plantago maritima (34) and Campanula type (35) are of some importance. Altogether the terrestrial vegetation seems to have been dominated by herbs.

Limnophyte pollen became scarce. The pollen of Myriophyllum alterniflorum (60) and Eu-Potamogeton (64) together with Typha-Sparganium (68) obtain but low frequencies.

\section{Subzone W 2 e (BP $14.28-4.37 \mathrm{~m}$.).}

The proportion of mineral content is still high in the lowermost part of the subzone, but it decreases rapidly. The frequencies for rebedded pollen decrease ( $\Sigma$ "thermophilous trees and shrubs" decreases from 7.2 to $2.6 \%$ ). Some of the macrofossils reported from layer G by J \& M (l. c.) may belong to this subzone.

The measurements of Betula pollen (at $4,31 \mathrm{~m}$.) indicate the presence of pollen of $B$. pubescens and $B$. nana in an equal mixture, and most of this pollen is presumably primary (p. 53).

The frequencies for the pollen and spores of a number of terrestrial plants characteristic of zone W 3 begin to increase in this subzone already, e. g. Populus (36), Thelypteris dryopteris (41), Filipendula (43) and Urtica dioica (44). The pollen of Salix (17), Gramineae (19), Cyperaceae (20), Rumex acetosella type (21), Polentilla (22), Galium type (23), Tubuliflorae (24), Liguliflorae (25), Artemisia (26) and Plantago maritima (34) remains common.

The microspores of Isoëtes echinospora (65) and I. lacustris (66), both Limnophytes, become abundant, but the pollen of Myriophyllum alterniflorum (60) and Eu-Potamogeton (64) remain rare. Typha-Sparganium (68), Callitriche (62), Polygonum amphibium (69), Caltha palustris (73) and Rubus chamaemorus (75) are also represented.

\section{Zone W 3 (BP $12.71-4.25$ m., BP 2 3.33-3.39 m.).}

The sediments from the zone are highly organic. In the terminology of J\&M (1. c.) they correspond to the "upper mud horizon" (p. 48). New pollen analyses have shown that the marginal parts of layer $\mathrm{F}$ as shown in the section of J\&M (1. c., plate XIII) belong rather to the "middle bed", and only the following macroscopic plant remains, from the borings 3 and 4 of $\mathrm{J} \& \mathrm{M}$, can be referred to the zone with confidence, Betula pubescens (very common), B. nana (common), Juniperus communis, Arctostaphylos uva-ursi, Empetrum nigrum, Rubus idaeus, Carex lasiocarpa, C. rostrata, Elisma natans (see p. 23), Menyanthes trifoliata, Potamogeton natans, Potentilla palustris, Ranunculus aquatilis (coll.), Sparganium minimum and Viola palustris (the remains of Picea abies mentioned by J\&M were presumably carried down from the layers above during the boring, as the pollen of the species is very rare throughout the zone).

Dominance of Betula pubescens pollen characterizes the whole zone. Up to $3.74 \mathrm{~m}$. a slight amount of rebedded pollen seems to be present, but above that level the entire pollen flora must be considered to be primary (p. 55).

\section{Subzone W 3 a (BP 14.25 m.).}

The subzone is represented by one sample from the top part of layer $\mathrm{H}$ 1, which consisted of small, hard gyttja lumps. The loss on ignition is high $(47 \%)$ indicating only a slight 
influx of allochtonous material. The content of secondary pollen is correspondingly low ( $\Sigma$ "thermophilous trees and shrubs" $0.8 \%$ ).

The frequency for Betula pollen is $75 \%$. Pollen of Betula pubescens prevails, but a fair proportion of $B$. nana pollen is also present (p. 38). The surrounding area was forested. Other woody plants represented are Populus (36), Salix (17) and Juniperus (18). The pollen of Juniperus, however, is very scarce $(0.4 \%)$. Gramineae (19) and Cyperaceae (20) pollen is still abundant, but the frequencies decrease somewhat, just like those for Rumex acetosella type (21), Potentilla (22), Galium type (23) and Artemisia (26). The frequencies for a number of herbs increase, e.g. Umbelliferae (39), Thelypteris dryopteris (41), Thalictrum (42), Filipendula (43), Urtica dioica (44), Chenopodiaceae (45), Bistorta (49), Rubus saxatile (50), Geum (51) and others.

There is a decrease for the microspores and the pollen of Limnophytes (Isoëtes echinospora (65), I. lacustris (66), Eu-Potamoteton (64)), and for Typha-Sparganium (68) and Polygonum amphibium (69). The pollen of Elisma natans (70) and Telmatophytes (Lysimachia thyrsiflora (71) and a few others) begins to become rather common. It appears that the lake dried out, and that this development caused the top part of layer $\mathrm{H} 1$ to crumble (see above). It is well known that such a clay mud, if dried, contracts strongly, and cracks into hard lumps, which cannot be re-softened by addition of new moisture. The dopplerite formed presumably during the drying out of the lake.

Subzone W 3 b (BP $13.97-4.22$ m.).

The mineral content of the sediment increases slightly (loss on ignition $24 \%$ ). The frequencies for rebedded pollen increase correspondingly, but the influence of that pollen remains low. Macroscopic remains of Betula pubescens, Carex sp. and Potamogeton sp. occurred at $4.00 \mathrm{~m}$.

The subzone is characterized by a slight depression of the Betula curve. Salix (17), Populus (36) and Prunus (37) are present in the flora of woody plants. There is an increase for herb pollen, especially for that of Gramineae (19), Cyperaceae (20), Rumex acetosella type (21), Potentilla (22), Galium type (23), Umbelliferae (39), Thelypteris dryopteris (41), Bistorta (49) but the flora remains similar to the one of subzone a.

The values for the Limnophytes (Isoëtes echinospora (65), I. lacustris (66), Eu-Potamogeton (64, according to the macrofossils presumably mainly Potamogeton natans), Myriophyllum alterniflorum (60, rather rare), Nuphar luteum (67), increase again together with the values for Typha-Sparganium (68, probably Sparganium minimum, identified from macrofossils) and Polygonum amphibium (69). The pollen from Elisma natans (70) and Telmatophytes reach rather high frequencies at the lowermost part of the subzone.

\section{Subzone W 3c (BP $13.50-3.91 \mathrm{~m}$.).}

The amount of coarse-detritus increases upwards, until the sediment, at $3.74 \mathrm{~m}$., changes to a peat formed by herbaceous plant remains (layer E 5). The organic content increases strongly (loss on ignition at $3.85 \mathrm{~m} .45 \%$, at $3.70 \mathrm{~m} .90 \%$ ). Seeds of Menyanthes trifoliata occur at $3.50 \mathrm{~m}$. There is still a small amount of rebedded pollen at the lowermost part of the subzone, but above $3.74 \mathrm{~m}$. the entire pollen flora must be assumed to be primary.

Pollen of Quercus (2), Ulmus (3), Alnus (6), Corylus (7), Picea (10) and Pinus (11) occurs in the peat layers with low frequencies. It was presumably due to long distance transport.

The subzone is characterized by increase of the Betula frequencies (up to $71 \%$ ). Other woody plants represented are $B$. nana, Populus (36), which increases somewhat too, Prunus (37), Salix (17) and Juniperus (18). The pollen of Juniperus reaches values above $7 \%$. Calluna (12), Empetrum (13) and Arctostaphylos uva-ursi (15) are represented by very small amounts of pollen.

The herb pollen frequencies decrease, and especially those for Gramineae (19), Rumex acetosella type (21), Galium type (23), Artemisia (26), Plantago maritima (34), Campanula (35, Thalictrum (42), and Bistorta (49). Other pollen and spore types such as Rumex acetosa (16), Thelypteris dryopteris (41), Filipendula (43), Urtica dioica (44), Lycopodium clavatum (46) are not affected conceivably. The values for the Cyperaceae (20) decrease at first, but the curve has another peak in the telmatic peat, without doubt due to presence of purely local pollen.

The frequencies for the pollen of Limnophytes, Typha-Sparganium (68) and Polygonum amphibium (69) decrease, and the pollen of Elisma natans (70) becomes rarer. The maximum for pollen of Cyperaceae was probably due to a local vegetation (Carex rostrata and C. lasiocarpa according to the macrofossils). At a higher level Sphagnum spores (76) become 
common. At $3.50 \mathrm{~m}$. their frequency is $52 \%$. Judging from the pollen representation Menyanthes (72), Caltha (73) and Rubus chamaemorus (75) also contributed to the formation of the peat layer.

$$
\text { Subzone W } 3 \text { d (BP } 12.95-3.35 \mathrm{~m} \text {.). }
$$

The sediment changes from telmatic peat to coarse-detritus gyttja and the mineral content increases somewhat (loss on ignition $32 \%$ ). A catkin scale of Betula pubescens was found at $3.20 \mathrm{~m}$.

The lower limit of the subzone is marked in the pollen diagram by a slight decrease of the pollen of Betula, Populus (36) and Juniperus (18), and corresponding increases of Salix (17) and the herbs, especially Gramineae (19), Rumex acetosella type (21), Artemisia (26) and Bistorta (49). The curve for the Cyperaceae is influenced by the presence of pollen produced from local vegetation in the peat layer.

The transition from telmatic peat to gyttja at $3.12 \mathrm{~m}$. indicates another rise of the water level. This is reflected in the pollen diagram by a strong decrease of Sphagnum spores (76), and a re-appearance of pollen and spores of Limnophytes (Eu-Potamogeton (64), Isoëtes echinospora (65) and $I$. lacustris (66).

\section{Subzone W 3e (BP $12.71-2.83 \mathrm{~m}$., BP 2 3.33-3.39 m.).}

The sediment in both profiles is gyttja in which the amount of coarse-detritus increases upwards. The mineral content decreases. The sediment changes to herbaceous peat at $2.80 \mathrm{~m}$. at BP 1. Leaf epidermis of Larix was noticed at $2.79 \mathrm{~m}$.

The whole subzone is developed at BP 1 , to which the following description refers. The development at $\mathrm{BP} 2$ is similar.

The lower zone border is marked by a rise of the Betula curve and decreasing values for the herb pollen. The size measurements indicate dominance of Betula pubescens pollen with some representation of B. nana (p. 38). The values of Populus (36), Juniperus (18) and Frangula (38) also increase. Larix pollen (56) appears in the subzone. Calluna pollen (12) is somewhat more common.

Decreases in frequency are conspicuous for the pollen of Gramineae (19), Cyperaceae (20), Rumex acetosella type (21), Potentilla (22), Galium type (23), Tubuliflorae (24), Artemisia (26) and Bistorta (49), but others such as Thelypteris (40), Thalictrum (42), Filipendula (43) and Lycopodium clavatum are not affected noticeably. Pteridium spores (9) appear at the end of the subzone.

The curves for the pollen of Eu-Potamogeton (64) and the microspores of Isoëtes echinospora (65) and I. lacustris (66) decrease and disappear at the end of the subzone.

\section{Zone W 4 (BP 12.69 m., BP $23.06-3.29$ m.).}

In both profiles the sediment is humified peat with remains of herbaceous roots and mosses. Seeds of Menyanthes trifoliata are common (BP $23.29 \mathrm{~m}$.). The loss on ignition is very high, in $\mathrm{BP} 1$ at $2.71 \mathrm{~m}$. $97 \%$. In BP 2 the sediment changes at $3.22 \mathrm{~m}$. to forest peat with wood of Pinus and twigs of Betula and Calluna. In samples belonging to this zone and to zone W $5 \mathrm{~J} \& \mathrm{M}$ (1. c.) recorded macroscopic remains of Picea abies, Betula pubescens, B. nana (rare), Empetrum nigrum, Potentilla palustris, Sparganium minimum, Carex rostrata, C. lasiocarpa, Potamogeton natans and Menyanthes trifoliata. They also mention remains of the moss Drepanocladus exannulatus and sclerotia of Cenococcum geophilum (BP 3 and $4 \mathrm{~J} \& \mathrm{M}$ ). A leaf fragment was re-identified to Larix sp. (p. 22).

Due to the peat formation the pollen analyses are influenced strongly by pollen produced by the plants, which took part in the local succession, a fact, which is conspicuous from the sudden changes and irregular course of most of the curves.

At BP 1 the record is obviously truncated (cp. p. 47). The zone is better developed at BP 2 and the following description refers to the pollen diagram from there. No clear distinction between pollen derived from plants that grew locally and from the general vegetation is possible.

The curve for $\Sigma$ "thermophilous trees and shrubs" rises at the beginning of the zone. The rise is conspicuous for Carpinus (1), Quercus (2), Ulmus (3), Fraxinus (4), Corylus (5), and Alnus (6), but the frequencies remain low, usually below $1 \%$, and this pollen may have been due to long distance transport.

Picea (7) reaches values of up to $32 \%$. The size statisties (p. 35) indicate that Picea abies alone is represented at the lower part of the zone, and that both Picea abies and Picea omoricoides were present at the upper part. The Pinus values reach $39 \%$. The curve for 
Larix (8) rises also. The macroscopic remains of Picea abies, Pinus and Larix indicate that these trees occurred locally.

Pollen of Frangula (9) becomes exceedingly common (frequencies up to $66 \%$ ). There can be no doubt that its pollen was produced by local populations. Pollen of Calluna (10), Empetrum nigrum (11), Arctostaphylos (12), Vaccinium type (13) and Myrica (14) also occurs.

Pollen of Betula, no doubt mainly B. pubescens, is frequent during most of the zone, and the pollen of Populus (15), Juniperus (16) and Salix (17) becomes rare. The same is the case for Gramineae (18), Rumex acetosella type (20), R. acetosa (21), Artemisia (23), Thelypteris dryopteris (24), Thalictrum (25) and other herbaceous plants, the pollen of which was rather common in zone W 3 . A few herbaceous plants such as Filipendula (28), Urtica dioica (29), Chenopodiaceae (30) and Pteridium (31) remained apparently common.

The curve for Cyperaceae (19) pollen reaches a maximum at the base of the zone. A similar trend is shown by the curves for the spores of Thelypteris palustris type (36, probably representing the species T. palustris) and the pollen of Menyanthes (37). A little later Sphagnum spores (39) become very common (values around $100 \%$ ), at first together with the rhizopods Amphitrema flava (40) and Assulina sp. (41). Rubus chamaemorus pollen becomes frequent near the top of the zone.

The pollen curves reflect to a high degree a local succession, which moved towards drier conditions. From aquatic conditions in zone W 3 the hydrosere passed into a wet telmatic phase (Cyperaceae, probably Carex rostrata and C. lasiocarpa, cp. above, Thelypteris palustris and Menyanthes, the macrofossils of Sparganium minimum, Potamogeton natans and Potentilla palustris probably belong here) to a moist Frangula-Calluna-Sphagnum community with rhizopods, and on to a rather dry stage with Picea abies, Pinus, Larix, Betula pubescens, Frangula, Calluna, Empetrum nigrum, Rubus chamaemorus and Sphagnum.

It can be assumed that Picea and Pinus expanded in the more general vegetation, and replaced the open Betula forest, where Juniperus, Populus and herbs were common.

\section{Zone W 5 (BP $22.61-3.04 \mathrm{~m}$.).}

The zone is represented by humified herbaceous peat. Remains of Eriophorum vaginatum were common especially in the lower part, and roots of Calluna vulgaris occurred at 2.64$2.91 \mathrm{~m}$.

Subzone W 5 a (BP $22.72-3.04 \mathrm{~m}$.).

The frequencies of Carpinus (1), Quercus (2) and Alnus (6) remain rather constant during the subzone, but those of Ulmus (3), Fraxinus (4), and Corylus (5) have decreased. All of the pollen just mentioned may have been due to long distance transport. The find of one Ilex pollen grain seems a little surprising (secondary?).

Pinus pollen dominates in the subzone, reaching $62 \%$, and the frequencies for the pollen of Betula and Picea (7, representing both P. abies and P. omoricoides, see p. 35) have decreased to near $10 \%$. Pollen of Larix (8), Frangula (9) and Myrica (14) is also present. Pollen of Juniperus (16) and Salix (17) occurs especially near the top of the subzone. Calluna pollen (10) is very common with frequencies up to $32 \%$. Empetrum nigrum (11) and Arctostaphylos uva-ursi (12) were apparantly somewhat rarer.

Herb pollen is rather scarce. Gramineae (18), Cyperaceae (19), Filipendula (28) and Rubus chamaemorus (38) are the most common ones. Artemisia pollen (23) has re-appeared. Sphagnum spores (39) are exceedingly common (up to $443 \%$ ), and Amphitrema flava (40) and Assulina (41) are frequent.

The local vegetation seems to have been a Calluna-Eriophorum vaginatum community with some Rubus chamaemorus. The vigorous growth of Sphagnum and the abundance of Amphitrema and Assulina indicate a stage, which was considerably wetter than the preceding one.

Subzone W 5 b (BP $22.67-2.69 \mathrm{~m}$.).

The subzone is characterized by maxima of the pollen of Betula (cf. pubescens, p. 38) and the herbs, and a decrease of Pinus (to $27 \%$ ).

The frequencies of Quercus (2) and Alnus (6) have decreased. The values of Picea (7), Larix (8) and Calluna (10) also decrease. The most common herb pollen types are Gramineae (18), Cyperaceae (19), Rumex acetosella type (20), R. acetosa (21), Plantago maritima (22) and Artemisia (23). Their maxima are accompanied by small maxima for Frangula (9), Juniperus (16) and Salix (17).

Increased wetness and less overrepresentation of local pollen may explain these changes (see p. 104). 
Subzone W 5 c (BP 2 2.61-2.65 m.).

A revertence to conditions similar to subzone W 5 a takes place. This is apparent from the high values of Pinus pollen (up to $64 \%$ ). There is also a slight increase of Quercus (2) and Alnus (6), but the pollen of Picea (7) and Larix (8) remains rare. Calluna (10) increases somewhat, and pollen of Empetrum nigrum (11) and Vaccinium type (13, probably $V$. oxycoccus) are also common. Juniperus (16), Salix (17) and most of the herbs decrease again.

Upwards the record is obviously truncated. J\&M (1. c.) noticed that the surface of the upper peat layer was very uneven. It seems thus, that the youngest layers became disturbed by erosion.

\section{Zone W x (BP $22.51-2.59 \mathrm{~m}$.).}

The sandy clay layer D overlies the peat layer E 1 with an abrupt transition. In its lower part the layer contained some coarse-detritus, probably drifted material. Allochtonous mineral matter predominates, and the layer was thus formed as a result of erosion activity. Hence, the pollen flora is presumably contaminated with rebedded pollen. Layers from the zones W 5 and W 4 are likely to have been exposed to erosion, but older layers may also have been eroded.

The pollen zone is known only fragmentarily, and an unknown interval separates it from the youngest known part of zone W 5 . The pollen flora appears to be highly contaminated with older pollen, and a separation of primary and secondary elements is not attempted.

The erosion activity indicates that a climatic deterioration had taken place, and a more or less tree-less vegetation prevailed presumably. For that reason the rather frequent pollen of plants such as Juniperus (16), Salix (17), Gramineae (18), Cyperaceae (19), Rumex acetosella type (20), R. acetosa (21), Plantago maritima (22), Artemisia (23), Thalictrum (25), Filipendula (28) and Chenopodiaceae (30) may be considered to be primary. This may also be the case for the finds of Ephedra distachya, Sanguisorba officinalis, Armeria maritima and Plantago media. The frequencies of Plantago maritima pollen $(1.0-1.2 \%)$ are the highest ones known for that species at the site, a fact, which justifies a belief that its pollen is primary together with the other herb pollen.

The clay layer contains also remains of aquatic plants, such as microspores of Isoëtes lacustris and pollen of Littorella uniflora $(0.4 \%$ at $2.51 \mathrm{~m}$.). The Isoëtes microspores may be secondary. Littorella pollen was very rare in the earlier pollen zones at the site, and the finds at this level are probably primary.

On top of layer D only mineral layers (B-C) occur. J\&M (l. c.) observed that the stony sand (C), which extends almost to the centre of the basin indicates that solifluction took part in the final filling in of the depression.

\section{RODEBAK I}

The interglacial sites called Rodebæk I-III were discovered during the survey of J \& M (1928). They are situated in Western Jutland $17 \mathrm{~km}$. southeast of Varde (see the maps, fig. 2 in J\&M 1. c., and fig. 11, p. 123), and they are still visible as three low depressions only a few hundred metres apart. Rodebæk I is the largest of the three depressions. It is up to $150 \mathrm{~m}$. across and its original depth was up to 11-12 $\mathrm{m}$. below the present level of the surroundings.

At the time when $J \& M$ carried out their investigations most of the depression was filled by a postglacial bog, which contained a small pond produced by peat cutting. To-day the depression has been drained, and only a few remnants of the postglacial peat exist.

\section{Sediments.}

J \& M (l. c.) established three transects of the basin. Their profile B directed WNWESE is the most complete one. In 1954 new borings and excavations were carried out establishing a transect of the upper layers in the direction NNW-SSE (parallel to the northeastern fence of the field, see the map of J\&M l. c.). The section is shown on Plate VIII. It proved to be almost identical to section B of J\&M. 
Detailed descriptions of two of the new borings are given below. Capital letters used by $\mathrm{J} \& \mathrm{M}$ (l. c.) have been applied to identical strata. The borings are numbered according to their distance from the SE fence of the field.

BP $57 \mathrm{~m}$.

A $\quad 0.00-0.45 \mathrm{~m}$. Sandy agricultural soil or peat, disturbed.

C $1 \quad 0.45-2.89 \mathrm{~m}$. Sand. At 2.53-2.69 m. a little gravel. Between $2.69-2.89 \mathrm{~m}$. thin argillaceous layers (A $1, \mathrm{Ga}+\mathrm{s} 3$ ).

C $22.89-2.93 \mathrm{~m}$. Argillaceous sand with a little fine-detritus $\left(\mathrm{Ld}^{2} 0-1, \mathrm{~A} 2, \mathrm{G} \mathrm{a}+\mathrm{s} 2\right)$.

D $\quad 2.93-3.27 \mathrm{~m}$. Brown argillaceous gyttja $\left(\mathrm{Ld}^{2} 2\right.$, A 2). Slightly stratified.

E $\quad 3.27$ - ca. $3.46 \mathrm{~m}$. Clay with a little fine-detritus (Dg $0-1, \mathrm{Ld}^{2} 0-1, \mathrm{~A} 4$ ).

F 1 ca. $3.46-4.04 \mathrm{~m}$. Sand $(\mathrm{Ga}+\mathrm{s} 4)$. Transition to the layer below sharp.

F $24.04-4.10 \mathrm{~m}$. Slightly argillaceous sand with a little fine-detritus $\left(\mathrm{Ld}^{2} 0-1\right.$, A $1, \mathrm{G} \mathrm{a}+\mathrm{s} 3)$.

G $\quad 4.10-4.16 \mathrm{~m}$. Humified herbaceous peat with some sand $\left(\mathrm{Th}^{3} 3, \mathrm{Ga}+\mathrm{s} 1\right)$. Strongly stratified.

H $\quad 4.16-(4.81) \mathrm{m}$. Wood peat $\left(\mathrm{Tl}^{4} 4\right)$. Much wood and bark. Horizontal branches of Picea. The interglacial deposits continue till $9.36 \mathrm{~m}$.

BP $79 \mathrm{~m}$.

A $\quad 0.00-0.35 \mathrm{~m}$. Sandy agricultural soil or peat, disturbed.

B $\quad 0.35-0.80 \mathrm{~m}$. Slightly argillaceous sand with a few small stones.

E $1 \quad 0.80-0.95 \mathrm{~m}$. Sand with windworn stones, up to $15 \mathrm{~cm}$. across.

E 20.95 - ca. $2.36 \mathrm{~m}$. Clay and silt with a little sand and with stones up to $5 \mathrm{~cm}$. across. Below $1.10 \mathrm{~m}$. irregular sandy layers ground into the deposit.

F ca. $2.36-4.30 \mathrm{~m}$. Sand.

G $14.30-4.36 \mathrm{~m}$. Humified herbaceous peat with some sand $\left(\mathrm{Th}^{3} 3, \mathrm{Ga}+\mathrm{s} 1\right)$. Strongly stratified.

G $24.36-4.48 \mathrm{~m}$. Humified peat with remains of Eriophorum vaginatum and Calluna vulgaris $\left(\mathrm{Th}^{3} 4\right)$.

$\mathrm{H} \quad 4.48-\left(4.50 \mathrm{~m}\right.$.) Wood peat $\left(\mathrm{Tl}^{4} 4\right)$. The interglacial deposits continue till $9.87 \mathrm{~m}$.

According to the profiles of $J \& M$ the surface of the interglacial peat layers ( $G$ and $H$ ) is conformable with the original shape of the basin. The peat layers are strongly compressed, a process which probably took place as the mineral layers were deposited. The surface of the interglacial peat showed traces of erosion at the margins.

The sand layer (F) deposited on top of the interglacial peat is lacustrire. During its deposition the basin was almost filled in, and the clay and mud layers E-D formed in a shallow bowl only $45 \mathrm{~m}$. across and $1-2 \mathrm{~m}$. deep. Layer $\mathrm{F}$ is thickest at the northern part, and the basin in which the layers E-D formed lies south of the centre of the depression (see plate VIII). The main transportation of material obviously took place from the north.

The stony clay (E) is almost $1.5 \mathrm{~m}$. thick at BP $79 \mathrm{~m}$., and it was deposited by solifluction from the north. An equivalent layer of stoneless clay was deposited in the shallow pool (at BP 35, 45 and $57 \mathrm{~m}$., see plate VIII). Layer E is not represented north of BP $79 \mathrm{~m}$. At that point windworn stones were found on top of layer E, and it is probable that the layer has been removed by wind erosion north of that point. Closely packed windworn stones were found at the point $125 \mathrm{~m}$., at $1.30-1.40 \mathrm{~m}$. below the 
surface (see plate VIII). They probably represent an erosional residue from the solifluction deposit $\mathrm{E}$.

As the sedimentation of the clay decreased, the clay gyttja D was deposited in the small pool. The sandy layers C 1-2 completed the filling in of the basin. They are lacustrine equivalents of the stony sand $\mathrm{B}$, which extends from the northern and southern margins of the basin to the edge of the small pool.

\section{Pollen Analyses.}

The pollen diagram published by J\&M (l. c., plate XXXVI) demonstrates clearly that the lower peat and gyttja layers (the layers $\mathrm{G}-\mathrm{K}$ ) represent the entire Eemian Interglacial. Pollen diagrams from the post-Eemian sequences at BP $57 \mathrm{~m}$. and $79 \mathrm{~m}$. are shown on plate IX (cp. table 30). The pollen diagram at $57 \mathrm{~m}$. is the more complete one, as it represents the pollen zones h-W $2 \mathrm{~d}$. At BP $79 \mathrm{~m}$. in the main only zone W 1 is represented.

\section{Rebedded Pollen.}

The post-Eemian sequence at Rodebæk I is less complete than the one at Brørup Hotel Bog. Except for the interval, during which the upper gyttja layer was deposited, mineral sedimentation was strong, and the pollen record is interrupted in the sand layers. The pollen content of the argillaceous layers is influenced strongly by redeposited pollen. In the pollen diagrams the curve for $\Sigma$ "thermophilous trees and shrubs" (total of Carpinus, Quercus, Tilia, Ulmus, Fraxinus, Alnus, Corylus, Ilex) gives a measure of the influx of rebedded pollen. Its values are high in the predominantly mineral layers corresponding to the pollen zones $\mathrm{W} 2 \mathrm{a}-\mathrm{b}$ and $\mathrm{d}$ but they are low in the gyttja layer D (W 2c). The following pollen types with similar curves are also considered to be secondary (in the pollen diagram at BP $57 \mathrm{~m}$. marked by striation and punctuation of the curves): Picea (11), Erica tetralix (13), Gentiana amarella type (17), Plantago lanceolata (19), Tubuliflorae (22), Calluna (24), Empetrum nigrum (25, in part), Arctostaphylos uva-ursi (27) and Thelypteris palustris type (43). A few rare types may also be considered to be secondary in the zones W 1 and W 2,

Buxus sempervirens

Fagus silvatica

Frangula alnus

Myrica gale

\section{Populus tremula \\ Mercurialis perennis \\ Stellaria holostea \\ Myriophyllum verticillatum}

\section{Pollen Zones.}

Zone h (BP 57 m. 4.28-4.81 m., BP 79 m. 4.43-4.50 m.).

In the wood peat (layer H) J\&M (l. c.) found macrofossils of the following plants: Ajuga reptans, Alnus glutinosa, Betula pubescens, Calluna vulgaris, Carex pseudocyperus, Cirsium palustre, Picea abies, Pinus silvestris, Potentilla palustris, Ranunculus repens, R. sceleratus, Rubus idaeus, Sparganium minimum, Viola palustris and Cenococcum geophilum.

The pollen of the following plants is most frequent in the lower part of the zone, Alnus (6), Picea (11), Pinus (23), Salix (28), Gramineae (30), Cyperaceae (31) and Thelypteris palustris type (43, cf. Thelypteris palustris). Upwards there is an increase for pollen of Betula, Calluna (25), Empetrum nigrum and E. hermaphroditum (25, 26), Arctostaphylos uva-ursi (27), Rubus chamaemorus (53) and Sphagnum (54). Woody plants represented in the whole zone with low pollen frequencies are Carpinus (1), Quercus (2), Ulmus (3) and Corylus (7). Pollen of Fraxinus (5), Taxus (8) and Abies (12) is rare or missing in the uppermost samples. 
During the zone a local succession from an Alnus-Picea community to an open heath stage took place, and the local vegetation seems to have become more oligotrophic.

In the pollen diagram from BP $79 \mathrm{~m}$. only the heath stage is represented.

Zone W 1 (BP 57 m. 4.12-4.18 m., BP 79 m. 4.30-4.40 m.).

The sediment at the two profiles is humified herbaceous peat (layer G) with a content of sand, which increases upwards. From that layer J\&M (l. c.) recorded macrofossils of the following plants: Betula nana, B. pubescens, Calluna vulgaris, Carex caespitosa, Empetrum nigrum, Myriophyllum alterniflorum, Potentilla sp., Rubus idaeus and Sparganium minimum.

The pollen analyses are much less influenced by strictly local pollen. Pollen of Pinus $(23,11)$ occurs with frequencies around $10 \%$. Betula pollen is rather frequent. $B$. nana was dominant, probably with some representation of $B$. pubescens (p. 38). Other woody plants of importance were Juniperus $(29,17)$, Salix $(28,16)$, Calluna $(24,12)$, Empetrum nigrum and E. hermaphroditum $(25,13$ and 26,14). Pollen of Gramineae $(30,18)$ and Cyperaceae $(13,19)$ is common too, the frequencies rise together with those for Rumex acetosa $(16,8)$, $R$. acetosella type $(32,20)$, Artemisia $(33,21)$ and some other herbs (e. g. Filipendula $(37,22)$, Armeria maritima $(40,-)$, Plantago maritima $(41,23)$. An open heath vegetation with many herbs characterized the vegetation.

A few aquatic plants occurred (Isoëtes echinospora $(47,25)$, Myriophyllum alterniflorum (49, -, cp. also the macroscopic remains mentioned above). A rise of the water level took obviously place. At BP $79 \mathrm{~m}$. the increased moisture caused a vigorous growth of Sphagnum, the spores of which reached frequencies above $100 \%(27)$.

\section{Zone W 2 (BP 57 m. 2.84-4.05 m.).}

The zone is only represented at BP $57 \mathrm{~m}$. The beginning of the zone corresponds probably to the strong increase for mineral sedimentation and rebedded pollen, and the whole development is not differentiated clearly in the pollen diagram.

\section{Subzone W 2 ab (BP 57 m. 3.34-4.05 m.).}

The pollen analyses from the argillaceous layers E and F 2 are influenced strongly by secondary pollen. A few pollen types may be primary, such as Juniperus, Salix, Gramineae, Cypéraceae and Rumex acetosella type. Juniperus pollen becomes quite rare.

A sample from the solifluction earth E at BP $79 \mathrm{~m}$. contained $32 \%$ of "thermophilous trees and shrubs", and only $28 \%$ of herb pollen. Secondary pollen apparently also prevailed there.

The macroscopic flora from the layers E-F recorded by J\&M (1. c.) contained Armeria maritima, Betula nana, Carex caespitosa, C. pseudocyperus (derived?), Empetrum nigrum, Myriophyllum alterniflorum, Ranunculus aquatilis (coll.), Rubus idaeus (derived?) and Sparganium minimum.

Pollen and spores from aquatic plants are very rare.

\section{Subzone W 2 c (BP $57 \mathrm{~m} .2 .90-3.27 \mathrm{~m}$.).}

The subzone is represented mainly by the gyttja layer D. From that stratum J \& M (l. c.) recorded macroscopic remains of Arctostaphylos uva-ursi, Betula nana, B. pubescens (found only at BP 17 near the marginal part, where it may be rebedded), Carex cf. caespitosa, Empetrum nigrum, Myriophyllum alterniflorum, Ranunculus aquatilis (coll.), R. sceleratus, Sparganium angustifolium, S. minimum, Viola palustris and the mosses Amblystegium stellatum, Calliergon giganteum, C. stramineum, Drepanocladus exannulatus, Polytrichum strictum and Rhacomitrium canescens. The mineral content of the sediment increases upwards, and the topmost part of the zone is represented by a layer of argillaceous sand (C 2).

The influence of secondary pollen is rather insignificant. Judging from the pollen curves some of the Pinus pollen (23) is probably primary and due to long distance transport. The pollen of heath shrubs (Calluna (24), Empetrum (25), Arctostaphylos uva-ursi (27), Erica tetralix (13), Vaccinium type (14)) occurs with low frequencies. Most of it seems secondary, but some pollen of $E$. hermaphroditum (26) may be primary, and the same may be the case for pollen of Arctostaphylos uva-ursi, which is represented by macrofossils.

Betula nana was the dominant Betula species (p. 38), but pollen of $B$. pubescens may be present (p. 38). Besides B. nana the most frequent plants apparently were Juniperus (29), 
Gramineae (30) and Cyperaceae (31). Pollen of Salix (28), Rumex acetosella type (32), Artemisia (33), Geum (36), Filipendula (37), Potentilla (38), Armeria (40), Plantago maritima (41), Campanula type (42) and a few others is quite frequent. The contemporary vegetation apparently consisted of open shrub communities with rich representation of herbs.

Microspores of Isoëtes echinospora (47) and pollen of Myriophyllum alterniflorum (49) are very common (up to $200 \%$ and $81 \%$ ), and Isoëtes lacustris (48), Myriophyllum spicatum (50) and Ranunculus trichophyllus type (51) are also represented. In the middle of the zone the curve for Limnophytes has a minimum, corresponding to maxima for the curves for Sphagnum (54), Typha-Sparganium (52, according to the macrofossils presumably S. angustifolium and $S$. minimum) and Rubus chamaemorus (53). This indicates a low water level at the middle of the zone, during which a bog community developed. Empetrum hermaphroditum (26), some of the Cyperaceae, Drosera, Menyanthes and the moss Calliergon stramineum were probably members of that community. The water level apparently rose again at the top of the subzone.

Subzone W 2 d (BP 57 m. 2.84 m.).

A sample from the sand layer C 1 belongs to subzone W $2 \mathrm{~d}$. Secondary pollen is frequent again, and the aquatic plants have almost disappeared.

\section{Herning}

The interglacial site west of the town of Herning in Western Jutland (see the maps fig. 1 in J \& M 1928 and fig. 11, p. 123) is the largest lake deposit of the Eemian Interglacial known in Denmark. According to the survey of J\&M (l. c.) the largest extent of the basin in the direction north-south is about $800 \mathrm{~m}$., and in east-west about $300 \mathrm{~m}$.

Open sections of the interglacial deposits have been visible in the pit of Herning Brickworks, and a north-south profile was surveyed by J\& M in 1914. In 1919 to 1924 $J \& \mathrm{M}$ carried out a large number of borings in the area north of the brickworks to determine the extent and stratigraphy of the lake deposits.

As follows from the investigation of J\&M (1. c.), the deposits covering the interglacial gyttja are predominantly mineral and often coarse grained. Sampling of such deposits by borings is difficult, and they are not suited for pollen analyses. Gravelly layers occur especially in the northern part of the basin, and the "upper mud horizon" (layer G) is not well developed there, according to the transects established by J\&M (l. c.). For such reasons the new investigations in 1954 and 1955 were confined to the southern part of the basin, which was also more accessible.

\section{Sediments.}

During the new investigations 5 borings were carried out in the southern half of the basin (BP 1-5, STA). Their position will appear from the map fig. 10. It may be seen that BP 1-4 follow the north-south transect of $\mathrm{J} \& \mathrm{M}$, and that BP 5 is situated about $20 \mathrm{~m}$. to the east of that line. The sediment columns are shown on plate $\mathrm{X}$. The layers have been designated with capital letters corresponding to those used by $\mathrm{J} \& \mathrm{M}$ (l. c.), although some subdivisions have been necessary. Proportions of sediment components are indicated at BP 1,3 and 5 (STA), where pollen diagrams have been worked out.

$$
\text { BP } 1 \text { (STA) }
$$

A $\quad 0.00-0.65 \mathrm{~m}$. Sandy agricultural soil.

D $\quad 0.65-0.80 \mathrm{~m}$. Stony sand.

G $1 \quad 0.80-2.88 \mathrm{~m}$. Sand. At $1.20 \mathrm{~m}$. argillaceous layer. Lowermost a few small stones. 


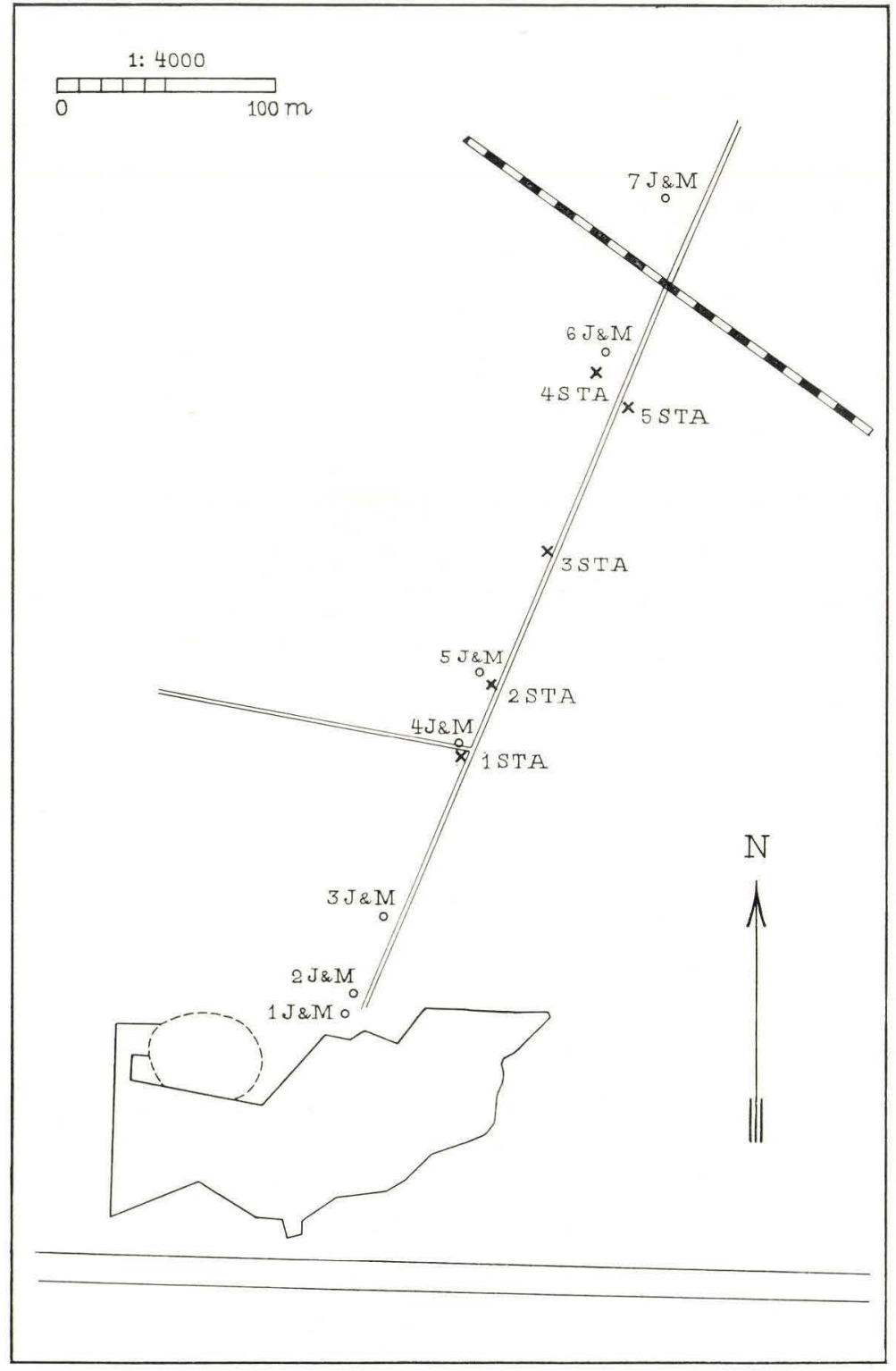

Fig. 10. Herning. Borings from 1954-55 (1-5, STA) compared with the borings $1-7$ of Jessen and Milthers 1928 (1-7, J\& M). Detail redrawn from the map on plate II in $\mathbf{J} \& \mathbf{M}$ (1928).

Herning. Boringer fra 1954-55 (1-5, STA) sammenlignet med JessEN og MiLthers' boringer 1-7, 1928 (1-7, J\&M). Udsnit af kortet på plate II i Jessen og Milthers (1928).

G $22.88-3.56 \mathrm{~m}$. Fine sand with numerous thin detritus layers $(\mathrm{Dg} 1, \mathrm{Ga}+\mathrm{s} 2$, A 1). In the layers fragments of wood of Pinus silvestris.

J $13.56-4.47 \mathrm{~m}$. Sandy clay with some fine-detritus $\left(\mathrm{Ld}^{2} 1, \mathrm{Ga}+\mathrm{s} 1, \mathrm{~A} 2\right)$.

J $24.47-7.10 \mathrm{~m}$. Brownish grey to bluish grey, very stiff clay (A 4). 
K $1 \quad 7.10-7.70 \mathrm{~m}$. Brown clay-gyttja (Ld² 1, A 3).

K $27.70-9.44 \mathrm{~m}$. Gyltja with some clay $\left(\mathrm{Ld}^{2} 2, \mathrm{~A} 2\right)$.

BP 2 (STA)

A $\quad 0.00-0.35 \mathrm{~m}$. Sandy agricultural soil.

B $\quad 0.35-0.85 \mathrm{~m}$. Sand.

D $\quad 0.85-1.40 \mathrm{~m}$. Stony sand.

G 1 1.40-1.95 m. Sand with a few small stones. At $1.88 \mathrm{~m}$. argillaceous layer.

G $2 \quad 1.95-2.86 \mathrm{~m}$. Fine sand with numerous thin detritus and argillaceous layers. Wood of Pinus silvestris.

J $1 \quad 2.86-3.33 \mathrm{~m}$. Sandy clay.

$\mathrm{J} 2 \quad 3.33-4.85 \mathrm{~m}$. Very stiff clay.

K $1 \quad 4.85-5.35 \mathrm{~m}$. Brown clay-gyttja.

K $2 \quad 5.35-6.00 \mathrm{~m}$. Gyttja.

BP 3 (STA)

A $\quad 0.00-0.25 \mathrm{~m}$. Sandy agricultural soil.

B $\quad 0.25-1.00 \mathrm{~m}$. Sand.

D $\quad 1.00-1.95 \mathrm{~m}$. Stony sand. Stones up to $10 \mathrm{~cm}$. across.

F $\quad 1.95-2.03 \mathrm{~m}$. Sandy and argillaceous gyttja $\left(\mathrm{Ld}^{2} 1, \mathrm{Ga}+\mathrm{s} 2, \mathrm{~A} 1\right)$.

G $1 \quad 2.03-2.31 \mathrm{~m}$. Sand $(\mathrm{Ga}+\mathrm{s} 4)$.

G $22.31-3.14 \mathrm{~m}$. Argillaceous sand with numerous thin detritus layers (Dg 1, $\mathrm{Ga}+\mathrm{s} 2, \mathrm{~A} 1$ ).

$\mathrm{H} \quad 3.14-4.21 \mathrm{~m}$. Sand. At $4.10 \mathrm{~m}$. a thin detritus layer $(\mathrm{Ga}+\mathrm{s} 4)$.

J $1 \quad 4.21-5.31 \mathrm{~m}$. Sandy clay. Sand content variable $(\mathrm{Ga}+\mathrm{s} 1, \mathrm{~A} 3)$.

J $2 \quad 5.31-8.81 \mathrm{~m}$. Brownish grey to bluish grey very stiff clay (A 4).

K $1 \quad 8.81-9.23 \mathrm{~m}$. Brown clay-gyttja $\left(\operatorname{Ld}^{2} 1, \mathrm{~A} 3\right)$.

K 2 9.23-10.64 m. Gyttja with some clay $\left(\mathrm{Ld}^{2} 2, \mathrm{~A} 2\right)$.

BP 4 (STA)

A $\quad 0.00-0.40 \mathrm{~m}$. Sandy agricultural soil.

B $\quad 0.40-1.35 \mathrm{~m}$. Sand.

D $1 \quad 1.35-1.98 \mathrm{~m}$. Stony sand. At $1.90 \mathrm{~m}$. argillaceous layer.

D $2 \quad 1.98-2.00 \mathrm{~m}$. Sandy clay-gyttja.

D $3 \quad 2.00-2.60 \mathrm{~m}$. Sand with a few stones.

F $1 \quad 2.60-2.95 \mathrm{~m}$. Gyttja.

F $2 \quad 2.95-3.49 \mathrm{~m}$. Argillaceous gyttja. Broken into small hard lumps.

G $13.49-5.40 \mathrm{~m}$. Sand with coarse plant fragments. At $4.90 \mathrm{~m}$. wood of Alnus glutinosa. At 4.26 and $4.34 \mathrm{~m}$. detritus layers.

G $25.40-5.91 \mathrm{~m}$. Sand with numerous thin detritus layers.

H $\quad 5.91-7.50 \mathrm{~m}$. Sand with stones up to $9 \mathrm{~cm}$. across. At 6.80 and $7.00 \mathrm{~m}$. thin argillaceous detritus layers.

J $1 \quad 7.50-9.40 \mathrm{~m}$. Sandy clay. A few thin detritus layers.

J 2 9.40-14.85 m. Stiff clay. A few detritus layers.

K 1 14.85-(15.90) m. Brown clay-gyttja. The boring was not carried through the deposit.

BP 5 (STA)
A $\quad 0.00-0.40 \mathrm{~m}$. Sandy agricultural soil.
B $\quad 0.40-0.95 \mathrm{~m}$. Sand.
D $1 \quad 0.95-2.95 \mathrm{~m}$. Stony sand. Stones up to $3 \mathrm{~cm}$. across. 
D $22.95-3.15 \mathrm{~m}$. Sandy clay-gyttja $\left(\mathrm{Ld}^{2} 1, \mathrm{Ga}+\mathrm{s} 1, \mathrm{~A} 2\right)$.

D $33.15-4.62 \mathrm{~m}$. Sand $(\mathrm{Ga}+\mathrm{s} 4)$. At $3.33 \mathrm{~m}$. wood of Alnus glutinosa. Lower limit very sharp.

F $14.62-4.82 \mathrm{~m}$. Coarse-detritus gyttja. A few moss and Sphagnum leaves and a little sand. In the lowest part less coarse-detritus. (Dg 1, $\operatorname{Ld}^{2} 3$ ).

F $24.82-5.68 \mathrm{~m}$. Argillaceous gyttja $\left(\mathrm{Ld}^{2} 2, \mathrm{~A} 2\right)$. Broken into small hard lumps. Between the lumps yellow substance rich in ochre.

G $15.68-9.85 \mathrm{~m}$. Sand $(\mathrm{Ga}+\mathrm{s} 4)$. Below $8.35 \mathrm{~m}$. some stones up to $3 \mathrm{~cm}$. across. Thin argillaceous detritus layers at $7.20,7.32,8.85$ and $9.75 \mathrm{~m}$.

J 1 9.85-12.32 m. Sandy clay. Sand content variable, decreasing downwards $(\mathrm{Ga}+\mathrm{s} 1, \mathrm{~A} 3)$.

J 2 12.32-(16.35) m. Very stiff clay (A 4). Above $14.90 \mathrm{~m}$. several thin detritus layers. At $12.90 \mathrm{~m}$. a leaf of Betula nana. The boring was not carried through the deposit.

The position of the new borings relative to those of $\mathrm{J} \& \mathrm{M}$ will appear from the map fig. 10. It may be seen that BP 1 (STA) equals BP 4 (J\&M), BP 2 (STA) $=$ BP 5 $(\mathrm{J} \& \mathrm{M})$ and $\mathrm{BP} 4(\mathrm{STA})=\mathrm{BP} 6(\mathrm{~J} \& \mathrm{M})$. The depths of the main strata have been compared in table 18 .

Table 18. Herning. Depth of the main strata, in J \& M (1928) and the present investigation (STA), compared.

Herning. Dybde af hovedlagene hos J \& M (1928) sammenlignet med den nærværende undersøgelse (STA).

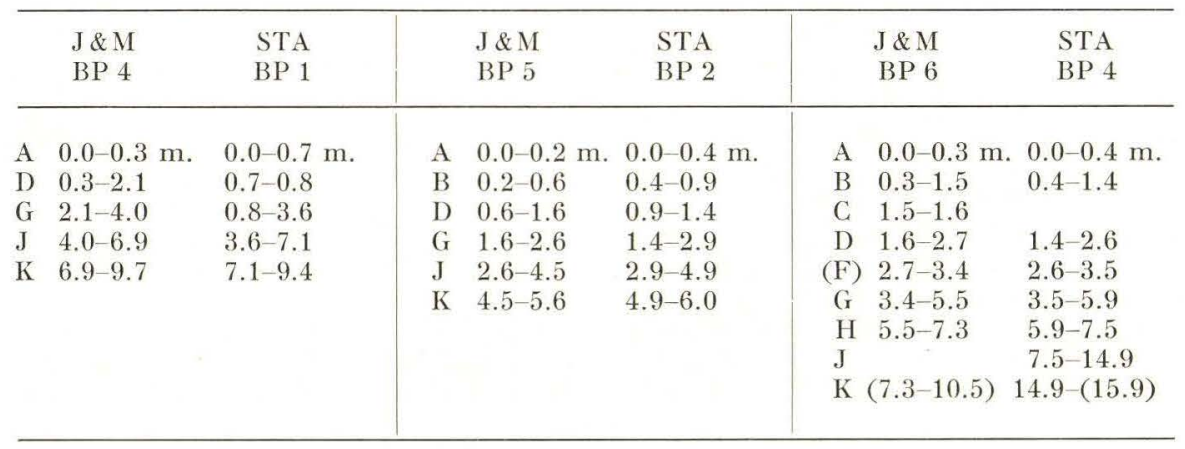

Layer $\mathrm{K}$ constitutes the Eemian Interglacial deposit. In the terminology of $\mathrm{J} \& \mathrm{M}$ (l. c.) the strata J and H constitute the "middle bed", and the strata G and F the "upper mud horizon". It appears from the comparison above that these layers can be exactly recognized in the new borings. Layer $G$, which was described by $J \& M$ (1. c.) as sandy mud or muddy sand, appeared in the new borings as fine sand with many thin detritus layers (found especially in the lowermost part of the stratum (G 2)).

The layer at 2.7-3.4 m. at BP $6(\mathrm{~J} \& \mathrm{M}=\mathrm{BP} 4$, STA) was designated $\mathrm{E}$ by $\mathrm{J} \& \mathrm{M}$ (l. c.). In the section (J\&M 1. c., plate VIII), however, this layer corresponds rather to layer $\mathrm{F}$ in the other borings. In the same boring (BP $6, \mathrm{~J} \& \mathrm{M}$ ) the layer at $7.3-10.5 \mathrm{~m}$. was taken to be the interglacial gyttja (K) by J \& M. However, in the new boring (BP 4, STA) the interglacial gyttja appeared at $14.9 \mathrm{~m}$., and the layer at $7.5-14.9 \mathrm{~m}$. is stratum J (clay and sandy clay). From this it follows that the "middle bed" is not lacking at BP 6 (J\&M), as shown in the section of J\&M (1. c., plate VIII), and that the original lake basin was just as deep at this point as it was in its northern part, and not more 
shallow, in the way the section of $\mathbf{J} \& \mathbf{M}$ shows it. The profile from BP 5 (STA) indicates that the deepest part of the basin was found east of the north-south transect (see the map, fig. 10 , and plate $\mathrm{X}$ ).

The layers $\mathrm{G}$ and J occur at all of the new borings (BP 1-5, STA, see plate X). The gyttja layer $\mathrm{F}$ was found only at BP $3-5$ (see plate $\mathrm{X}$ ), as a considerable part of the original basin had become filled in with the mineral layers $\mathrm{G}-\mathrm{J}$. The ensuing layer D is thickest in the central parts of the basin, and it must also be lacustrine, filling in most of the remainder of the original lake basin.

\section{Chemical Analyses.}

3 analyses of ash content are shown in table 19. As was the case at Brorup Hotel Bog (p. 48), silicates dominate the ash content of the samples from Herning.

Table 19. Herning. Analyses of ash content. The figures indicate percentages of the dry weight.

Herning. Analyser af askeindhold. Tallene angiver procenter af tørvægten.

\begin{tabular}{|c|c|c|c|c|c|c|}
\hline \multirow[b]{2}{*}{ Stratum } & \multirow[b]{2}{*}{$\mathrm{BP}$} & \multirow[b]{2}{*}{ Depth } & \multicolumn{2}{|c|}{ Soluble in warm diluted $\mathrm{HCl}$} & \multirow{2}{*}{$\begin{array}{l}\text { Insoluble } \\
\text { residue }\end{array}$} & \multirow{2}{*}{$\begin{array}{c}\text { Total ash } \\
\text { content }\end{array}$} \\
\hline & & & $\begin{array}{l}\mathrm{Fe}_{2} \mathrm{O}_{3} \\
+\mathrm{Al}_{2} \mathrm{O}_{3} \\
\end{array}$ & $\mathrm{CaO}$ & & \\
\hline J 1 & \multirow[t]{3}{*}{3} & $8.14-8.24 \mathrm{~m}$. & $5.0 \%$ & $1.0 \%$ & $82.6 \%$ & $90.9 \%$ \\
\hline K 1 & & $8.90-8.95$ & 2.0 & 0.7 & 78.4 & 83.0 \\
\hline K 2 & & $9.24-9.35$ & 2.9 & 0.8 & 64.4 & 69.2 \\
\hline
\end{tabular}

All determinations of organic content are shown in table 20. From the table it appears that the highest organic proportions occur in the interglacial gyttja ( $\mathrm{K} 2$, loss on ignition $31 \%$, "humus" content $24 \%$ ) and in the gyttja layer F 1 (loss on ignition $49 \%$, "humus" content $32 \%$ ). The organic proportion of the layers $\mathrm{G}-\mathrm{J}$ is variable ("humus" content $1.2-16 \%$ ).

Table 20. Herning. Determinations of organic content.

The figures indicate percentages of the dry weight. Herning. Bestemmelser af organisk indhold. Tallene angiver procenter af torvægten.

\begin{tabular}{c|c|c|c|c}
\hline Stratum & BP & Depth & $\begin{array}{c}\text { "humus" } \\
\text { content }\end{array}$ & $\begin{array}{l}\text { loss on } \\
\text { ignition }\end{array}$ \\
\hline F 1 & 5 & $4.74 \mathrm{~m}$. & $31.8 \%$ & \\
& 5 & 4.78 & & $48.6 \%$ \\
\hline F 2 & 5 & $5.25-5.35$ & 5.9 & \\
\hline G 1 & 4 & $4.35-4.46$ & 0.6 & \\
\hline G 2 & 1 & $3.38-3.45$ & 15.6 & 23.7 \\
& 3 & $2.71-2.78$ & 2.1 & \\
\hline H & 4 & $5.93-6.00$ & 1.2 & \\
\hline J 1 & 1 & $3.56-3.66$ & 12.2 & 22.0 \\
& 3 & $5.06-5.12$ & 2.5 & \\
& 5 & $10.08-10.20$ & 4.0 & \\
\hline J 2 & 5 & $11.09-11.20$ & 3.4 & \\
& 3 & $4.73-4.83$ & 1.9 & \\
\hline K 1 & 3 & $8.06-7.17$ & 1.5 & 9.1 \\
\hline K 2 & 3 & $8.90-8.24$ & 1.4 & 17.9 \\
\hline
\end{tabular}




\section{Pollen Analyses.}

The gyttja layer K represents the Eemian Interglacial (see J \& M 1928, plate XXXVI).

Pollen diagrams from the post-Eemian sequences at BP 1, 3 and 5 (STA) are shown on the plates XI-XIII and in table 31. A part of the pollen diagram from BP 5 is shown in more detail on plate XIV (BP 5, diagram 2, cp. table 32).

\section{Rebedded Material.}

In the pollen diagrams (plates XI-XIII) values for the $\Sigma$ "thermophilous trees and shrubs" are shown. As at Brørup Hotel Bog, this group comprises the pollen types representing the most warmth-demanding woody plants (Alnus, Carpinus, Corylus, Fraxinus, Hedera, Ilex, Quercus, Taxus, Tilia and Ulmus), which are most likely to have been rebedded from the interglacial layers.

In the pollen diagrams from BP 1 and 3 (STA) the clay-gyttja $\mathrm{K} 1$ represents the last part of the Eemian Interglacial. In the clay above it ( $J$ 2) the organic content is very low ("humus" content decreases to less than $2 \%$, see table 20). Hence, sedimentation of allochtonous mineral matter was completely dominant. The frequencies for the $\Sigma$ "thermophilous trees and shrubs" increase from $10-20 \%$ to values above $50 \%$. It is thus suggested strongly, that this pollen was derived by erosion, and was washed into the lake together with the allochtonous mineral matter. All the plants within this group were common during the Eemian Interglacial, and it is not surprising that an abundance of such pollen should be carried into the lake due to erosion of interglacial peat. The change of sediment and the increased herb pollen percentages suggest a climatic deterioration. Such a development could hardly be reconciled with the increased abundance for thermophilous trees and shrubs. J\&M (1. c.) were also of the opinion that the layer $\mathrm{J}$, the "middle bed", corresponded to a stage with a cool climate and treeless conditions.

The values of interglacial pollen types remain high in layer G. Hence, there is no

Table 21. Herning. The figures indicate minimum and maximum percentages of the pollen totals.

Herning. Tallene angiver minimum og maximum procenter af pollensummen.

\begin{tabular}{|c|c|c|c|c|c|c|}
\hline & BP 1 & & BP 3 & & BP 5 & \\
\hline Stratum & $\mathbf{J}$ & G & $\mathrm{J}$ & G & $J$ & G \\
\hline Carpinus........... & $1.1-3.6$ & $1.6-3.8$ & $1.2-3.0$ & $0.5-3.6$ & $0.6-2.9$ & $1.8-1.9$ \\
\hline Quercus.......... & $0.3-4.1$ & $2.4-8.5$ & $0.5-7.9$ & $2.7-5.1$ & $0.8-3.3$ & $2.7-4.6$ \\
\hline Tilia . . . . . . . & $0-0.3$ & - & $0-0.5$ & $0-0.2$ & $0-0.2$ & - \\
\hline Fraxinus . . . . . . & $0-0.7$ & $0-0.7$ & $0-0.6$ & $0-0.3$ & $0-0.5$ & $0.2-0.3$ \\
\hline Ulmus. . . . . . . . . & $0-1.1$ & $0-0.6$ & $0-0.9$ & $0-0.3$ & $0-1.1$ & $0.3-0.4$ \\
\hline Alnus . . . . . . . . . & $8.0-23$ & $15-28$ & $6.5-25$ & $13-23$ & $8.9-15$ & $8.0-13$ \\
\hline Corylus........... & $4.8-18$ & $7.2-15$ & $3.4-25$ & $7.7-9.0$ & $2.1-14$ & $3.9-7.6$ \\
\hline $\begin{array}{l}\text { Ilex............... } \\
\Sigma \text { "therm. trees and }\end{array}$ & $0.2-0.6$ & $0.2-0.7$ & $0-1.3$ & $0.4-1.5$ & $0-0.7$ & $0-0.4$ \\
\hline shrubs"...... & $18-54$ & $34-55$ & $13-53$ & $25-42$ & $15-36$ & $17-28$ \\
\hline Picea $\ldots \ldots \ldots \ldots$ & $1.5-4.0$ & $1.6-4.0$ & $1.8-7.9$ & $2.2-3.3$ & $3.0-5.9$ & $2.2-3.6$ \\
\hline Pinus ............ & $7.2-24$ & $2.7-6.3$ & $4.3-33$ & $3.1-8.1$ & $5.7-13$ & $8.3-9.5$ \\
\hline Betula ........... & $8.6-22$ & $19-33$ & $7.0-26$ & $25-34$ & $17-24$ & $18-33$ \\
\hline$\Sigma$ Ericales. & $5.5-12$ & $2.9-9.0$ & $3.4-18$ & $4.7-8.1$ & $6.2-14$ & $7.7-8.4$ \\
\hline$\Sigma$ Herbs . . . . . . & $13-38$ & $11-26$ & $9.4-39$ & $19-26$ & $23-37$ & $31-31$ \\
\hline Osmunda spp. ..... & $0-1.9$ & $0.2-0.8$ & $0-1.4$ & $0.4-1.0$ & $0-0.6$ & $0-0.4$ \\
\hline
\end{tabular}


essential difference between the pollen content of layer $J$, which corresponds to the "middle bed" and layer G, which represents the "upper warmth horizon" of J\&M. The similarity between the pollen content of the layers $J$ and $G$ appears from table 21, which shows minimum and maximum values for the most frequent pollen types in the two layers. It is apparent, accordingly, that these strata were deposited under the same conditions, and that the majority of the pollen content of layer G was also derived by erosion, and deposited together with allochtonous mineral matter. The pollen analyses from the thin detritus layers from layer G (BP $13.40 \mathrm{~m}$., BP $33.13 \mathrm{~m}$., see the plates XI-XII) are especially rich in interglacial pollen showing that these thin layers consist mainly of rebedded interglacial material. Due to the detritus layers the "humus" content of layer G may be up to $16 \%$ (table 20 ).

The macroscopic plant remains from layer $J$ identified by $J \& M$ (l. c.) represent a poor flora of aretic and sub-arctic species. In layer G a rich flora of plants typical of the interglacial bed was represented by such remains. It appears that the water movement at the deposition of the sand layer $(\mathrm{G})$ was more violent, and that macroscopic material derived from interglacial shore deposits also was carried into the basin.

Frequencies of pollen and spore types of Tertiary age are also shown in the pollen diagrams (comprising Carya type, Coryloid type (Engelhardtia, Platycarya and others), Liquidambar type, Nyssa type, Pinus haploxylon type, Pterocarya type, Rhus type, Sciadopitys type, Seqoia type, Tsuga type, and unidentified Prequaternary spores). The boulder clays found around the site are rich in Tertiary lignites, in which the pollen types mentioned are common (cp. INGWERSEN 1954), and even the interglacial layer $(\mathrm{K})$ contains such derived pollen in low frequencies. The frequencies for the Tertiary pollen increase strongly in the clay $(J)$ indicating an increased influence of derived material. Upwards these values decrease somewhat. This may show, that some of the allochtonous material in layer $J$ was derived from deposits rich in Tertiary material, probably glacial deposits, and that later on more interglacial material was deposited.

It may be seen from the pollen diagram at BP 5 (diagram 1, plate XIV), that the values for "thermophilous trees and shrubs" have decreased to about $10 \%$ in the clay-gyttja F 2, and that the amount of such pollen is very low ("thermophilous trees and shrubs" $0.8 \%$ ) in the gyttja layer F 1 , which has a low mineral content. In this layer J\&M (l. c.) found no macroscopic remains of temperate plants.

The frequencies for Calluna and Empetrum are rather high in the layers G-J, but they decrease to insignificant values in layer F 2 (BP 5). The pollen of these plants found in the layers G-J is no doubt secondary. The high frequencies indicate, that some of the eroded material probably was acid peat with an overrepresentation of pollen from heath plants.

Because of the overwhelming amount of secondary pollen it seems impossible to distinguish the primary pollen, and the vegetational development can be followed only in broad outline, except for the part represented by layer F at BP 5 (corresponding to the pollen zones W $2 \mathrm{e}$, and W $3 \mathrm{a}$ and $\mathrm{d}$ ). The pollen analyses shown in the pollen diagram 2 at BP 5 (plate XIV) have been re-calculated after deduction of all pollen believed to be secondary (p. 73).

\section{Pollen Zones.}

Zone h (BP $17.10-7.31$ m., BP $38.83-8.98$ m.).

The pollen diagrams show only the topmost part of the zone. In both borings it is represented by the clay-gyttja K 1 .

The pollen of Pinus and Alnus is the most frequent, and the pollen of Carpinus' Quercus, and Corylus is quite rare. The values for Picea, Alnus and Pteridium decrease, indicating a 
decrease of the temperature. Some rebedded pollen may be present in the topmost samples (Ilex?).

Microspores of Isoëtes echinospora are very common.

\section{Zone W 1 (BP 1 6.50-6.90 m., BP 3 8.33-8.80 m.).}

The transition from zone $\mathrm{h}$ is accompanied by an increase of mineral content (transition from the clay-gyttja $K{ }_{1}$, to the clay $J 2$ ). The frequencies for Tertiary pollen increase, reaching $12 \%$ at $\mathrm{BP} 1$, and the curve for $\Sigma$ "thermophilous trees and shrubs" also rises, indicating that re-deposited interglacial material occurs in considerable quantities.

The picture of the vegetational conditions becomes obscured by the rebedded pollen. Still the zone seems to be distinguished in the pollen diagrams in contrast to zone $\mathrm{h}$ by increased values for Juniperus, Calluna, Empetrum, and the herbs, especially Gramineae and Cyperaceae. Pollen of Pinus is rather frequent, and pollen of Picea is present. Betula pollen also occurs with rather low values. Some of the rare pollen finds may be primary, especially those of Arctostaphylos, Armeria, Artemisia, Botrychium, Ophioglossum, Plantago maritima, P. media, Rumex acetosa, Selaginella, but many obviously secondary pollen and spore types are represented.

Isoëtes echinospora is represented with very high frequencies ( $297 \%$ at BP 3 ), and microspores of $I$. lacustris are quite common.

Zone W 2.

(BP 1 1.20-6.00 m., BP 3 2.11-8.25 m., BP 5 5.00-14.91 m.).

The zone corresponds to the predominantly mineral layers $\mathrm{J}, \mathrm{H}$ and $\mathrm{G}$, and a majority of the pollen is secondary. Although the picture of the vegetational development is obscured by the secondary pollen, the subzones a-e may be recognized in a very indistinct way.

\section{Subzone W $2 \mathrm{ab}$ (BP $14.67-6.00 \mathrm{~m}$., BP 3 6.00-8.25 m.).}

The transition to the subzone may be distinguished by a decrease of Pinus and Juniperus pollen to low values. The frequencies for $\Sigma$ "thermophilous trees and shrubs" reach a maximum of $54 \%$. The values for Isoëtes echinospora and I. lacustris decrease. Both species obtain highest frequencies in the lowermost half of subzone W $2 \mathrm{ab}$ (corresponding to subzone a?). Upwards they decrease to insignificant values (subzone b?).

The flora of higher plants identified from macrofossils by $\mathrm{J} \& \mathrm{M}$ (1. c.) is rather poor. Many bryophytes are listed by J\&M (I. c.). Some of these remains may be primary, but remains of secondary origin may also occur.

Subzone W 2c.

(BP $13.52-4.49$ m., BP 3 4.60-5.80 m., BP 5 11.19-14.91 m.).

The subzone may be distinguished by a slight decrease of the content of secondary pollen. $\Sigma$ "thermophilous trees and shrubs" decreases to 19,13 and $15 \%$ in the 3 pollen diagrams. At the same point there are - rather indistinct - maxima for the pollen of Juniperus, Gramineae, Cyperaceae and Rumex acetosella type. The changes are similar to the features, which characterize the subzone at Brørup Hotel Bog and at Rodebæk I.

Some of the spores and pollen grains found rarely may be primary, e. g. those of Ephedra cf. strobilacea, Armeria, Artemisia, Gypsophila, Lotus, Lycopodium selago, Parnassia, Plantago maritima, P. media, Rumex acetosa, Sanguisorba officinalis, Selaginella and Thalictrum, which constitute a flora very similar to the one found in the subzone at the two other sites just mentioned.

The high frequencies for Isoëtes echinospora and $I$. lacustris are worthy of note. The values are especially high at BP 3 (32 and $13 \%$ for the species respectively) and at BP 5 (144 and $18 \%$ ). As the high values of Isoëtes microspores are restricted to a narrow horizon, they are presumably primary, and show that conditions allowed an aquatic vegetation to develop at that time, as was the case at Brørup and Rodebæk I.

The transition to subzone c coincides roughly with the transition from layer $\mathrm{J} 2$ to $\mathrm{J} 1$ at BP 1 and at BP 3. The organic content is slightly higher at BP 1 . The sand content also increases at that transition. At BP 5, where the basin was considerably deeper, the transition $\mathrm{J} 2-\mathrm{J} 1$ took place at a somewhat later point of time (at the end of subzone $\mathrm{c}$ ). The increase in the sand content may be ascribed to a lower water depth as a result of the filling in of the lake basin. 
Subzone W $2 \mathrm{~d}$.

(BP 1 1.20-3.40 m., BP 3 2.11-4.23 m., BP 5 7.20-10.02 m.).

The subzone is represented mainly by the sand layers H, G 2 and G 1 . The thin detritus layers in layer $\mathrm{G}$ are most numerous in the shallow part of the basin (BP 1, BP 2 and BP 3), becoming diffuse in the deepest part (BP 5), where the three layers merge into a single unit (see plate X). Most of the macroscopic material was apparently deposited near the shore. During the subzone the main parts of the large basin were filled in.

The content of secondary pollen is high ( $\Sigma$ "thermophilous trees and shrubs" $55 \%$ ). Most of the macrofossils from these layers must have been derived from interglacial deposits.

\section{Subzone W 2 e (BP $55.00-5.67$ m.).}

The subzone is represented at BP 5 by the argillaceous gyttja F 2, which consisted of small, hard lumps. The lumps may have formed during a lowering of the water level in zone W 3 a (cp. p. 58). From layer F, which also comprises subzone W 3 a, J \& M recorded macroscopic remains of the following plants: Betula nana, B. pubescens, Empetrum nigrum, Hippuris vulgaris, Selaginella selaginoides, Viola palustris and Ranunculus aquatilis (agg.).

Corresponding to the decrease of mineral content the values of "thermophilous trees and shrubs" decrease (to $10-15 \%$ ). A similar trend is shown by the curve for Tertiary types. In analogy with conditions at Brorup Hotel Bog it is assumed that the pollen of Picea, Pinus, Juniperus and the Ericales is rebedded. They all become rarer in zone W 3 a, where the values for secondary pollen are very low (cp. BP 5 diagram 1, plate XIII).

The pollen diagram BP 5 diagram 2 (plate XIV) shows the zones W $2 \mathrm{e}-3 \mathrm{~d}$ in greater detail. Here an attempt has been made to obtain a better quantitative picture by omittance of the pollen of "thermophilous trees and shrubs", Picea, Pinus, Juniperus (except for subzone W $3 \mathrm{~d}$ ) and the Ericales from the pollen totals. As it may be seen from the pollen diagram the curve comprising "all secondary types" is completely parallel to that for "thermophilous trees and shrubs", which certainly are secondary.

In pollen diagram 2 the Betula values are very low (10\%) at the lowest part of the subzone, but they rise steadily (to $45 \%$ ). Otherwise the subzone is characterized by high values of Salix (1), Gramineae (2), Cyperaceae (3), and frequent occurrence of other herbs such as Rumex acetosella type (4), Artemisia (5), Chenopodiaceae (6), Thalictrum (7), Cruciferae (8), Plantago maritima (11), P. media (12), Filipendula (19), Rumex acetosa (20), Urtica dioica (23), all of which characterize this subzone at Brørup Hotel Bog.

Pollen of Eu-Potamogeton (27), Myriophyllum spicatum (28), M. alterniflorum (29) and a few other aquatics is present. The values for $M$. alterniflorum increase to $23 \%$.

\section{Zone W 3.}

Subzone W 3 a (BP 3 1.98-2.02 m., BP 5 4.63-4.91 m.).

At BP 5 the sediment changes to the detritus gyttja F 1 at $4.82 \mathrm{~m}$. At BP 3 the subzone is represented by the sandy gyttja F, which seems to have been deposited near the shore of the former lake.

Betula seems to have dominated. However, this becomes obscured a little by a peak for Cyperaceae pollen, which presumably is quite local (see below). The size measurements (cp. p. 38) showed that $B$. pubescens pollen dominates, and $B$. nana pollen seems to have been rare, although the species was represented by macrofossils.

There is a definite decrease of the herb pollen, especially Gramineae (1), Rumex acetosella type (4), Artemisia (5), Chenopodiaceae (6) and a few others, and there is a clear increase of pollen of Populus (17), Filipendula (19), Rumex acetosa (20) and Thelypteris dryopteris (21). The birch forests thus resemble those found at Brørup Hotel Bog.

Pollen of Myriophyllum alterniflorum (28) is still common, and microspores of Isoëtes echinospora (34) and I. lacustris (35) have re-appeared. Their values increase strongly, I. lacustris reaching $31 \%$. In the middle of subzone W 3 a there is a sharp minimum of the curve for Limnophytes, and correspondingly an increase for that for Telmatophytes (Caltha (37), Lysimachia thyrsiflora (38) and Menyanthes trifoliata (39)). At the end of the subzone Limnophytes reach high values again. The maximum of Cyperaceae pollen (cp. above) corresponds to the minimum for Limnophytes. This development undoubtedly reflects the formation of a local swamp vegetation probably as the result of a lowering of the water level. A rise of the water level is certainly indicated at the transition to the cooler subzone $b$. Desiccation during the low water level probably caused the crumbling of the subjacent deposit F 2.

At BP 3 the layer F contains high amounts of Cyperaceae pollen, a fact, which makes it likely that the deposit was formed during this subzone. 
Subzone W $3 \mathrm{~d}$ (BP 5 2.95-3.14 m.).

Above layer $F$ the sand layer D is found. It contains a layer of sandy clay-gyttja (D 2), which is referred to subzone W $3 \mathrm{~d}$. The subjacent part of layer D (D 3) formed probably during the rise of water level in subzone b. Mineral sedimentation was apparently strong, probably because the large lake had become rather shallow, and no trace of the favourable subzone W $3 \mathrm{c}$ was left.

Layer D 2 seems to represent a fragment of subzone d at the transition to subzone e (BP 5, diagram 2). The content of secondary pollen has increased somewhat. The Juniperus curve (25) is of interest, as the values increase to $12 \%$. This feature shows that the deposit must be younger than subzone $\mathrm{c}$ from Brørup, where the Juniperus curve starts rising, and as the Betula values are rather low (ca. $30 \%$ ) and the herb pollen values high, it appears that the layer belongs to the slightly cooler subzone $d$, at the transition to subzone e.

The lake basin had become rather shallow. It was filled in by the sand layer D 1, and no traces of the zones W 4-5 were found.

\section{NørbøLling}

The site Norbølling (Field) is situated about $1000 \mathrm{~m}$. southwest of Brørup Hotel Bog (see the maps fig. 2, J\&M 1928, and fig. 11, p. 123). According to the survey of J\&M, the basin is rather shallow being up to $200 \mathrm{~m}$. across with a maximum depth at about $11 \mathrm{~m}$. In 1954 a new boring was carried out in the deepest part of the basin (near the borings $5-6$, J\&M).

\section{Sediments.}

The sequence of strata encountered in the new boring was as follows (the strata have been designated with capital letters corresponding to those used by $\mathrm{J} \& \mathrm{M}$ ).

A $\quad 0.00-0.55 \mathrm{~m}$. Humified herbaceous peat.

B $\quad 0.55-1.11 \mathrm{~m}$. Argillaceous gyttja.

C $\quad 1.11-2.20 \mathrm{~m}$. Sand, lowermost some small stones.

D $1 \quad 2.20-2.64 \mathrm{~m}$. Sandy clay with irregular sand layers and stones (A 2, Ga $+\mathrm{s} 2)$.

D $22.64-2.72 \mathrm{~m}$. Sandy clay with some fine-detritus and humus $\left(\mathrm{Ld}^{3} 1, \mathrm{~A} 2\right.$, $\mathrm{Ga}+\mathrm{s}$ 1). The lower limit irregular.

E $12.72-2.83 \mathrm{~m}$. Dy with a little humified herbaceous peat $\left(\mathrm{Th}^{3} 1, \mathrm{Ld}^{3} 3\right)$.

E $22.83-3.10 \mathrm{~m}$. Dy with a little clay and silt $\left(\mathrm{Ld}^{3} 3, \mathrm{~A} 1\right)$. The deposit somewhat lumpy.

F $\quad 3.10-4.53 \mathrm{~m}$. Clay and silt with some fine-detritus ( $\left.\operatorname{Ld}^{2} 1, \mathrm{~A} 3\right)$.

G $\quad 4.53-5.80 \mathrm{~m}$. Sand.

H $\quad 5.80-6.99 \mathrm{~m}$. Sandy clay-gyttja.

J $\quad 6.99-7.73 \mathrm{~m}$. Humified herbaceous peat with remains of Calluna vulgaris and Eriophorum vaginatum. The interglacial deposits continued down to $10.91 \mathrm{~m}$.

\section{Pollen Analyses.}

The lower mud and peat beds (the layers $\mathrm{H}, \mathrm{J}, \mathrm{K}$ and $\mathrm{L}$ ) represent the Eemian Interglacial, according to the pollen diagram of J \& M (1. c., plate XXXVII). New pollen analyses show that the clay, stratum F, is contaminated severely with rebedded interglacial pollen, and macroscopic remains of plants typical of the interglacial horizon were found by J\&M in the layers F and G (i. a. Brasenia schreberi, Carpinus betulus, 
Dulichium arundinaceum, Ilex aquifolium, Najas flexilis). They were presumably also derived from the interglacial deposit, in the same way as at Herning.

Detailed pollen analysis was carried out on the dy deposit E, in which mineral matter was scarce or absent. The pollen diagram is shown on plate XIV (cp. table 33).

\section{Pollen Zones.}

Zone W 3 (3.11 m.).

The topmost sample from layer $\mathrm{F}$ belongs to zone $\mathrm{W} 3$, and the deeper mineral strata (the lower part of layer F, layer G) correspond to pollen zone W 2. The erosion and the re-deposition of interglacial material thus continued during zone W 3.

The pollen spectrum at $3.11 \mathrm{~m}$. resembles subzone $\mathrm{W} 3 \mathrm{e}$ rather well. To be mentioned are the high values for Betula pollen, the rarity of Pinus and Picea pollen (7), and the abundance of pollen of Juniperus (14) and certain herb pollen types.

The common occurrence of microspores of Isoëtes echinospora (27) and I. lacustris (28) and of pollen of Elisma natans (29) is worth mentioning.

\section{Zone W 4 (2.95-3.05 m.).}

The sediment is dy (E 2) with a slight content of mineral matter. This laver corresponds only partly to layer E shown in the sections of J \& M (l. c., plate XI) as sandy clay, and some of the macrofossils recorded by $\mathrm{J} \& \mathrm{M}$ from layer $\mathrm{E}$ probably belong rather to layer $\mathrm{F}$. The pollen analyses are hardly influenced from overrepresentation of local terrestrial plants. A slight amount of rebedded pollen may be present in the lowermost sample.

Pollen of Carpinus (1), Quercus (2), Ulmus (3), Fraxinus (4), Corylus (5) and Alnus (6) is represented with low values, which increase slightly upwards. This pollen is undoubtedly primary and may be assumed to have been due to long distance transport (cp. zone W 4 at Brørup Hotel Bog).

The frequencies for Pinus pollen increase rapidly replacing Betula (cf. pubescens), and the Pinus pollen becomes dominant at the upper part of the zone.

The frequencies for Picea pollen (7) increase from an insignificant value in zone W $3 \mathrm{e}$. The size-statistics (cp. p. 35) indicate that Picea abies was the only species represented at the lower part of the zone, and that pollen of Picea omoricoides became rather frequent in the upper part.

Pollen and spores of Larix (8), Frangula (9), Calluna (10), Thelypteris dryopteris (22), Filipendula (24), Urtica (25) and Pteridium (26) are rather frequent. Pollen of Populus (13), Juniperus (14), Salix (15), Gramineae (16), Cyperaceae (17), Rumex acetosella type (18), Artemisia (20) and Thalictrum (21) is rather rare compared to the values in zone W 3.

Microspores of Isoëtes echinospora (27) and I. lacustris (28) are common.

Zone W 5 (2.73-2.90 m.).

The sediment (E 1) appears to be lacustrine. It contained a small amount of herbaceous rootlets.

Pinus pollen dominates $(40-50 \%)$ and the Betula values are rather low $(10-20 \%)$. The values for Picea (7) and Filipendula (23) decrease somewhat. The Frangula (9) and Calluna (10) values increase.

The values for Isoëtes echinospora (27) and I. lacustris (28) decrease, but the microspores do not disappear entirely. Open water was apparently present also shown by the occurrence of pollen of Nuphar luteum (38). The values of Sphagnum (33) increase together with those of Rubus chamaemorus (32).

Only the lowermost part of zone W 5 a is represented. The irregular limit to the mineral deposits above (D 1 and D 2) indicates that erosion took place before the deposition of these strata. Layer D 1 is obviously a solifluction deposit, and the pollen content of that deposit and of layer D 2 must be assumed to be dominated by rebedded pollen, probably to a certain degree derived from destroyed parts of layer E.

\section{Solsø}

J \& M (1928) discovered Eemian Interglacial deposits at a considerable depth at the site Solsø $22 \mathrm{~km}$. west of Herning (see the maps fig. 4, J\&M l. c., and fig. 11, 
p. 123). They are covered by thick mineral layers and Postglacial gyttja, and a small remnant of the lake exists still. However, no "upper mud horizon" was discovered by $\mathrm{J} \& \mathrm{M}$ (e. c.).

New borings were carried out in 1955 and 1958. The boring from 1958 was carried out at the SW edge of the present lake, approximately at the location of boring 10 of $\mathrm{J} \& \mathrm{M}$. In summary the profile was as follows:

$0.00-0.87 \mathrm{~m}$. Gyttja (Postglacial).

$0.87-1.38 \mathrm{~m}$. Clay-gyttja (Postglacial).

1.38-12.18 m. Predominantly mineral deposits (Weichselian Glacial).

12.18-17.03 m. Clay-gyttja and gyttja (Eemian Interglacial).

17.03-(17.40) m. Boulder clay.

The boring from 1955 was carried out from the ice in the centre of the small lake. Only Postglacial gyttja and mineral layers were penetrated. The boring operations were discontinued at a depth of $10.40 \mathrm{~m}$., as the heavy boring apparatus had to be removed from the ice due to its beginning to thaw. It is hoped that the boring may be repeated later.

Preliminary pollen analysis shows that redeposited pollen is present in considerable quantity already at the end of the interglacial pollen zone $h$ and that the mineral deposits above it are strongly contaminated with interglacial pollen. The uppermost clay-gyttja corresponds to the beginning of the Postglacial.

Hence the Allerød, the Bolling, and any older interstadials are not differentiated in the sections.

\section{Conclusion}

In this chapter the investigation of the post-Eemian deposits at the sites Brorup Hotel Bog, Rodebæk I, Herning, Norbolling and Solsø have been described. The records at the various sites are heterogenous as to the length of the intervals recorded, the nature of the sediments, and their value for pollen analysis.

The post-Eemian records comprise the following pollen zones (not mentioning the topmost covering deposits):

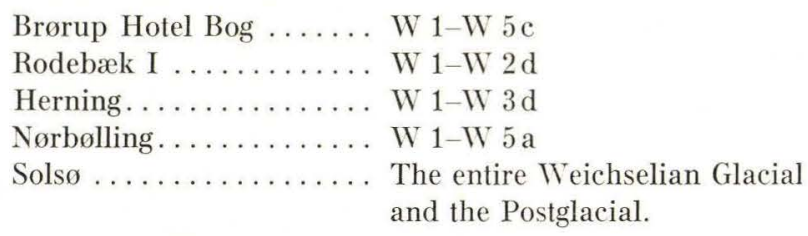

Summaries of the sediment records from the various sites are shown in table 22 . It can be seen that mineral sediments predominate especially in the lakes at Herning, Norbolling and Solsø. This was probably due to greater exposure. In subzone W $2 \mathrm{c}$ the lake at Rodebæk I was only $45 \mathrm{~m}$. at the largest diameter, and the lake at Brørup Hotel Bog was about $50 \mathrm{~m}$. across, whilst the lakes at Herning, Nørbelling and Solso in zone W 3 were still about $600 \mathrm{~m}$., $110 \mathrm{~m}$. and $150 \mathrm{~m}$. across, respectively. It may be assumed that wave erosion, especially, was rather strong in the larger lakes even in the favourable zone W 3.

Size and topography of the catchment areas, which are unknown to-day, may also have influenced the influx of mineral matter. 
Table 22. Summaries of the sediment records at the various sites. Oversigt over sedimenterne ved de forskellige lokaliteter.

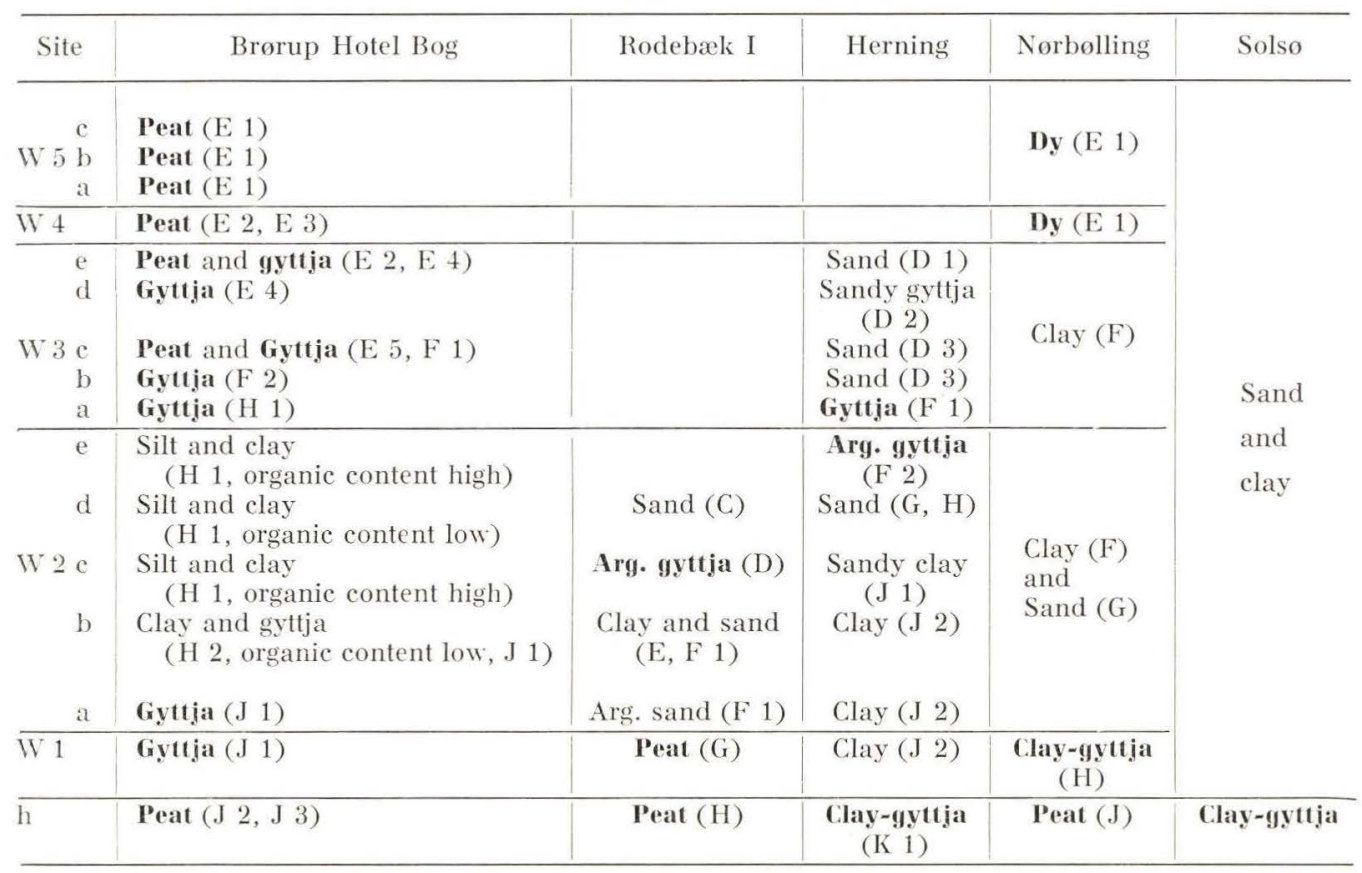

As re-deposited interglacial pollen is abundant in the mineral sediments, pollen analysis could be carried out successfully only on the sediments with a high organic content. At Brorup Hotel Bog and at Herning the predominantly mineral layers were analyzed in detail. The contamination with rebedded pollen is moderate at Brorup, and some results may be obtained, but at Herning the contamination of the mineral strata is so strong that the results are largely negative. For that reason detailed pollen analysis was applied at Norbolling only to the organic deposits, and a detailed investigation of the predominantly mineral strata was omitted. At Solsø the prospect for positive results by detailed pollen analyses was not good, and they have been neglected. It is hoped that the investigation of the interglacial layers can be continued at a later occasion. 


\title{
V. VEGETATION AND ITS ENVIRONMENT IN WESTERN JUTLAND IN THE POLLEN ZONES W 1-W 5
}

\author{
General Remarks
}

Sediments and pollen diagrams from the sites at Brørup Hotel Bog, Rodebæk I, Herning, Nørbølling and Solsø have been described in chapter IV. The data are concerned especially with the pollen zones W $1-W 5$, and the interglacial pollen zone $h$ should rather be discussed on a basis of more representative data and in connection with a study of the entire interglacial succession.

Conclusions as to the palaeoenvironment and its changes may be based on the sediment records (cp. p. 14), indications of water level changes (p. 14), the composition of the vegetation, and on information about the requirements of the plants identified in the fossil flora.

The palaeobotanist works always under the limitations induced by the fossil material. The parts of plants preserved are usually only those of greatest durability. However, the macrofossils, such as fruits, seeds and floral parts, are often of high taxonomical value. It may also be thought that only plants which grew in or near the lakes and bogs would have a chance to become represented by such remains. The literature contains, however, a large number of identifications of dry-land plants. Pollen grains and spores are dispersed more effectively, of course, but these fossils may often only be identified to taxa of a higher rank than the species.

The identifications in the present study refer primarily to the present-day flora of Northern and Central Europe. A wealth of information now exists about European Pleistocene floras, and not the least important part of it relies on a multitude of macrofossils. It appears from these studies that the last great changes in the North European floras took place at the Pliocene-Pleistocene border and during the earliest Pleistocene (see especially the investigations from the Netherlands by REID (see van DER VLerk and Florschütz 1953) and by Zagwisn (1960), and from Poland by Szafer 1953, 1954). Hence, floras from the late Pleistocene, at least, may be considered to be young from an evolutionary point of view (cp. Jentys-Szaferowa 1958). A large number of Pleistocene plant remains can be referred to present-day species, and only a limited number of species now extinct in Europe have been encountered in the late Pleistocene interglacial floras. HARTZ (1909) and JESSEN (in J \& M 1928) thus examined an extensive material of plant remains from Eemian Interglacial deposits and layers immediately ajacent to them from Jutland. Macrofossils from this material could be identified with 132 species of higher plants living in Northern Europe to-day. The remains of only two species could be shown not to belong to any species from that area to-day. These remains resemble present-day North American species (Brasenia schreberi Gmel. and Dulichium arundinaceum (L.) Britt.). Within the material examined by the present author it has proved that an Osmunda species related to the modern North American and East Asiatic O. cinnamomea L. occurred together with the European O. regalis (p. 21). It thus appears that the Eemian Interglacial flora known from Denmark did 
not differ from the modern North European flora in an essential way. If it had been otherwise, one might expect that the authors mentioned above had encountered a greater number of foreign species in their careful investigations.

In the data discussed in more detail here, macrofossils and pollen and spores derived from Eemian Interglacial deposits occur together with a flora considered to be primary and to date from the early Weichselian Glacial. This flora is compared with the LateGlacial flora from Denmark on table 23, and it can be seen that especially the floras of heliophytes resemble each other closely (see p. 106). These plants were apparently widespread in Europe in the Weichselian Glacial, and most of the species are still represented in North and Central Europe.

The species as delimited to-day comprise in many cases series of races (biotypes, ecotypes, provenances), which may vary physiologically. This problem of physiological variability within species is not new to palaeoecology (cp. Wesenberg-Lund 1906, Turesson 1922, Langlet 1935, Firbas 1949). The variability of the species during the Pleistocene has been studied only in a few cases, and plant remains have been identified to units lower than the species only rarely (e. g. Jentys-Szaferowa and Truchanowicz 1953). Hence, species identified from fossils must be considered in a broad sense. The ecological races of these species may have changed. This possibility represents a serious difficulty in the interpretation of palaeobotanical data. Thus it may be imagined that the Pleistocene glaciations caused alterations in the biotype content of the thermophilous species during their migrations to distant southern refugia. The Pleistocene plant migrations covered presumably rather long spans of time, and it is possible that they were so slow that the various ecological races found within the thermophilous species were preserved. Still, the vicissitudes of migration may have caused racial intermixing or depauperation in these species (cp. CaIn $1940 \mathrm{~b}$, Dansereau 1956, Iversen 1958, Firbas 1958, Jessen, Andersen and Farrington 1959). Heliophilous species are likely to have varied greatly due to racial hybridization with the creation of open habitats during the glacials. However, these species presumably suffered serious depauperations due to competition in the Postglacial (cp. Tutin 1953, IVERSEN 1958). It seems clear, that palaeoenvironmental conclusions must be broad, and they should be based on suggestions from more than a very limited number of species, if possible.

A number of pollen grains and spores could be identified only to species group (type), genus, or in some cases family. However, such a group of species, or even a genus, may have certain ecological preferences, although they may be of a broad nature. In cases where macrofossils have been identified with a species, it is probable that the pollen referred to the genus belongs to the same species, but one cannot assume that this was always the case.

The deposits studied serve as residues for fossil remains from the vegetation that grew locally and in an area around the sites, the size of which cannot be defined. In such a fossil flora is it only exceptionally possible to group the species into associations, and in most cases the earlier plant communities can only be delimited in a rather coarse manner.

General considerations of the interrelations between plants and their environment are mentioned in a number of well known handbooks (i. a. Warming, Clements, Livingstone and Shreve, Rubner, Dengler, Braun-Blanguet, Walter). Information about details may be obtained from the plant-geographical and the forest-botanical literature, and from literature on experimental investigations. In the following, information from such sources has been relied upon. No claim to complete references is made, but it has been attempted to obtain information from a wide range within the distribution areas of the species in question. General sources for information have 
been the works G. Hegr: Illustrierte Flora von Mitteleuropa and E. Hultén: Atlas of the Distribution of Vascular Plants in NW. Europe. These works form a basis for information in all cases, where literature references are not quoted.

In most cases the demands of plant species to their environment are known only in a coarse manner. However, their requirements may be much more precise. It will be necessary to divide environment into simple factors, although it is realized that such factors may be interrelated, and their effect often complementary.

Unfortunately, exact information about the climatic demands of the plant species is scarce in the botanical literature. The microclimate at the habitats of the plants may differ from the meteorological climate. In the present cases, however, we are concerned more with the meteorological climate. Coincidence of present-day distribution limits for plant species with meteorological border lines (isotherms, isohyetes, etc.) may not offer a direct causal explanation of these limits, but such cases suggest that the species in question cannot find suitable growing places outside the meteorological border lines (cp. FÆGRI 1960). The horizontal distribution limits of plant species may in some cases be checked by factors irrelevant to climate, e. g. deficient immigration opportunity, the vertical limits, however, less so, as in that situation dispersal must be assumed to be more effective. For that reason altitudinal distribution limits may be compared with horizontal distribution limits with advantage. However, conclusions as to the nature of the palaeoclimate reached on such a basis should be considered to be interpretations rather than facts.

According to IVERSEN (1944), it should be remembered that the occurrence of a plant species is likely to be delimited by the temperatures of the whole year, but the average temperatures for the warmest and the coldest month may be useful for a determination of its thermosphere (Iversen 1. c.). Unfortunately, indications of the winter temperature are scarce in the fossil material. Hence, summer temperatures can only be estimated rather broadly. Iversen (1954) arranged the plant species into the following groups, according to their reliability as temperature indicators, (1) trees and shrubs, (2) water plants, (3) shade tolerant herbs and dwarf shrubs, (4) heliophilous herbs and dwarf shrubs. Plant species which are highly exacting as to their habitat, e. g. basiphilous species, are the ones least likely to have climatically conditioned distribution limits to-day (SAmuelsson 1915, 1934, Iversen 1. c.). In contrast to Wesenberg-Lund (1909), Iversen (1. c.) concludes that aquatic plants may be excellent temperature indicators, and that a low sun altitude does not favour the occurrence of thermophilous aquatic plants in particular (for the high value of aquatic plants as temperature indicators, see also Glǘc (1927), Samuelsson (1934), and Szafer (1946, 1954)). Iversen's study (l. c.) of the environment of the Late-Glacial flora in Denmark demonstrates the detail with which such a picture may be reached on the basis of a comprehensive and well determined fossil material.

The polar and the altitudinal forest and tree limits constitute important plant geographical border lines. In Northern Europe Pinus silvestris, Picea abies and Betula pubescens are the most important trees along the forest border. In Scandinavia, west of the middle part of the Kola peninsula, Betula tortuosa, probably a race of B. pubescens (s. 1.), dominates the zone between the coniferous forest border and the tree line. This zone is commonly referred to as the subalpine or subaretic zone. Scattered individuals of Pinus silvestris, Picea abies and Populus tremula occur in this zone, but the plants remain dwarfed and are often sterile there (e. g. Kinlman 1890, Selander 1950 and Kilander 1955). The subarctic zone in Scandinavia corresponds to the zone with scattered trees ("forest tundra") in Northern Russia (Hustich 1952). Scattered individuals of Pinus silvestris and Picea abies also occur there (Pohle 1903, Rubner and ReInhold 1953). 
In Central Europe Picea abies is also common at the altitudinal forest border. Betula pubescens and Pinus silvestris ascend to a similar altitude there (see i. a. Gams 1927, Paul 1947). Besides Picea, Larix decidua and Pinus cembra are frequent at high altitudes in the Central Alps. The upper Picea forest border may be compared with the North European coniferous forest border, and the Pinus montana-Alnus viridis zone in the Northern Alps, and the Larix-Pinus cembra zone in the Central Alps correspond thus approximately to the North European subaretic-subalpine zone (Gams 1921, 1923, DU Rietz 1924, Regel 1924, Iversen 1954).

Information from sediment records, finds of macrofossils, and the distribution of the fossil pollen and spores will be referred to below. The details of pollen distribution in the pollen zones W 1-W 5 will appear from the pollen diagrams, plates VI, VII, IX, and XI-XIV, and the tables 23 (pp. 107-111) and 28-33 (pp. 138-149). A survey of the most significant features in the occurrence of the various pollen and spore types is shown on plate XV. The histograms indicate for each zone or subzone the numbers of species belonging to certain ecological categories (the curves $\mathrm{A}$ and $\mathrm{B}$ ), and average frequencies for various significant pollen and spore types. The species entering the curves $\mathrm{A}$ and $\mathrm{B}$ will be listed below at the descriptions of the various zones (the Ericales were not included, as presence or absence of their species cannot be determined exactly for the subzones, in which secondary pollen occurs). The pertentages are based on the pollen record from Brørup Hotel Bog (for the zones W 1-W 3) and Norbølling (zones W 4-W 5). In that manner the various zones are represented by records from lacustrine sediments, which are rather free from overrepresentation of pollen from local vegetation.

The curves for pollen and spore frequencies shown on plate $\mathrm{XV}$ are intended to illustrate the mode of occurrence of each species. For that reason it has not been attempted to keep the percentage scales uniform. Dominance and subdominance may be judged more readily from the pollen diagrams themselves. The percentages are based on the pollen totals used for the pollen diagrams (see p. 15), except for the zones W 2 b-e and W $3 \mathrm{a}-\mathrm{b}$, in which "all secondary pollen" was omitted (see p. 55). The curves on plate XV are somewhat easier to read than the pollen diagrams. On the other hand, details may sometimes have become obscured, and may appear more clearly in the pollen diagrams themselves.

The curves on plate XV have been divided into 3 groups in the following manner:

I. Plants occurring mainly in zone W 2.

II. Plants occurring mainly in zone W 3 .

III. Plants occurring mainly in the zones W 1 or W 4-5.

\section{ZONE W 1}

The pollen spectra at Brørup Hotel Bog and at Rodebæk I from zone h, the last zone of the Eemian Interglacial sequence, represent quite local vegetation, which apparently consisted of Alnus-Picea-Betula pubescens swamp forests with frequent occurrence of heath shrubs.

The pollen spectra from zone $\mathrm{h}$ at Herning from aquatic sediments indicate that Picea, Pinus and Alnus predominated in the general vegetation. The presence of pollen of Buxus, Taxus, Ilex, Hedera and Lonicera periclymenum (Brørup Hotel Bog, Rodebæk I and Herning) suggests that the climate was warm and oceanic, at least in the early part of the zone. It is remarkable that Picea abies was rather common at that time (see also J \& M 1928, Iversen 1944). This may suggest that this species was richer in oceanic biotypes formerly than at present (cp. Jessen, Andersen and Farrington 1959). 
This problem may be returned to on basis of a more adequate material including the whole Eemian Interglacial.

The transition to zone $\mathrm{W} 1$ is indicated in the pollen diagrams at Herning by decreases of Picea, Alnus and Pteridium, and increases of Juniperus, Calluna, Empetrum and herb pollen, but the zone border is not developed clearly at that site due to rebedded interglacial pollen. The sediments from zone W 1 at Brørup and Rodebæk I are also aquatic, and at these sites the general vegetation is better represented than in zone $\mathrm{h}$. At Brørup the sediment from zone $\mathrm{W} 1$ contains practically no secondary pollen, and at Rodebæk I only a slight influence from re-deposition is apparent.

\section{Sediments.}

$\mathrm{J} \& \mathrm{M}$ (1928) noticed indications of a rise of water level at the uppermost part of a number of bogs dating from the Eemian Interglacial. As mentioned before, the present investigations have shown that the rise of water level took place at the transition to zone W 1 at Brørup Hotel Bog and at Rodebæk I. The sediment changes, and remains of water plants appear at both sites. At Herning the transition to the zone is accompanied by an increase in the amount of mineral matter in the sediment.

\section{Temperature.}

Trees. The pollen from temperate trees and shrubs occurs at Brorup with such low frequencies that it may be assumed that this pollen was due to long distance transport by wind.

It may be presumed that most of the Pinus pollen belongs to Pinus silvestris. The pollen occurs at Brørup and at Rodebæk I with values at $10-13 \%$, and it is rather frequent at Herning $(20-30 \%)$. Such frequencies suggest that the tree occurred at that time with scattered individuals.

Pollen referred to Picea abies, Betula pubescens and Populus tremula occurs in small amounts (Brørup Hotel Bog), and it is suggested that these trees may have occured occasionally.

It is interesting to notice that the tree birch decreased together with Pinus and Picea at the end of the Eemian Interglacial. It is suggested, accordingly, that the Betula species present at that time had climatic demands similar to those of Pinus silvestris and Picea abies, and the species was, accordingly, B. pubescens (s. str.) rather than B. tortuosa (cp. p. 80). The size-statistical data suggest a similar conclusion (p. 37).

Shrubs. Shrub communities characterized the zone.

The pollen of Betula nana dominates within the birch pollen (p. 37).

The pollen referred to Juniperus communis is quite common with frequencies up to $6 \%$ (at Rodebæk I).

Pollen of Calluna vulgaris and Empetrum nigrum occurs with frequencies at $5-10 \%$, and pollen referred to Empetrum hermaphroditum and Arctostaphylos uva-ursi is rather frequent. Heaths with Betula nana, Juniperus and ericaceous dwarf shrubs were apparently widespread. Similar communities characterize the subalpine-low alpine zones in Scandinavia, the mountains of the British Isles, and the Faeroes and Iceland to-day. It appears that Empetrum nigrum was more common than $E$. hermaphroditum in Jutland in zone W 1. The species does not occur above the forest limit to-day, but is replaced by E. hermaphroditum at that altitude (ARwidsson 1935, WATt and JonES 
1948). E. hermaphroditum is rare below the forest limit in Scotland and in Scandinavia (Metcalfe 1950, Arwidsson l. c.).

A few pollen grains were referred to Frangula alnus, Genista, Rubus idaeus, R. saxatile ${ }^{1}$ ) and Arctostaphylos alpina, and seeds of Andromeda polifolia occurred. Frangula alnus does not reach the subalpine zone to-day. The pollen referred to the species was found near the lower border of the zone. The species of Genista occur only in the southernmost part of the Scandinavian peninsula to-day, but the species G. germanica and G. tinctoria may be found above the forest limit in the Alps. Rubus idaeus is rare in the subalpine zone in Scandinavia, and $R$. saxatilis ${ }^{1}$ ) ascends into the low alpine zone (Nordhagen 1943, Selander 1950, Kilander 1955). Arctostaphylos alpina reaches the high alpine zone, and the species is rare below the forest border. Andromeda polifolia reaches the low alpine zone.

Terrestrial herbs. Pollen grains referred to Rumex acetosa and Geum were rather frequent. These plants characterize open (and moist) woods to-day.

Some of the herbaceous plants represented rather commonly by pollen indicate open habitats (e.g. Rumex acetosella (type), Armeria maritima, Plantago maritima, Artemisia), and a number of the plants identified from rare finds also indicate such habitats (Lycopodium selago, Selaginella selaginoides, Botrychium, Chenopodiaceae, Plantago media, Sanguisorba officinalis, S. minor, Campanula).

Aquatic plants. Microspores and pollen referred to Isoëtes echinospora and Myriophyllum alterniflorum are recorded at Brørup. Similar remains occurred at Rodebæk I, together with fruitstones of Sparganium minimum. Isoëtes echinospora and I. lacustris were apparently also common at Herning together with Myriophyllum alterniflorum. The Isoëtes species occur in the subalpine zone to-day. Sparganium minimum and Myriophyllum alterniflorum also occur there, but Myriophyllum is often sterile in most of the subalpine zone (Samuelsson 1934, Kilander 1955).

The summer temperature in zone W 1 must have been considerably lower than that of zone h. Pinus silvestris, Betula pubescens, Populus tremula and Picea abies may have remained with scattered individuals. The terrestrial and aquatic plants represented in the zone suggest that conditions were similar to those found in the subalpine and subarctic zones of NW Europe to-day.

The finds of Armeria maritima suggest that the winter temperature was not very low (cp. Iversen 1954). Genista species characterize oceanic heaths to-day (i. a. Tüxen 1937, Böcher 1943), but the species G. germanica and G. tinctoria are rather of a subcontinental distribution type (Meusel 1940, Böcher 1. c., Walter 1951). Species of $\mathrm{NW}$-European distribution are represented in the aquatic flora, but their occurrence is probably related to edaphic conditions rather than to winter temperature. Information about the winter temperature in zone W 1 is thus scarce. However, it is suggested that the climate was oceanic.

\section{Precipitation.}

As mentioned above heaths similar to those found in zone W 1 are widespread in the subarctic and subalpine zones of NW Europe to-day. According to NordHaGen (1943) Calluna and Empetrum are most common in the coastal mountains in Norway, and these species dominate the mountain heath vegetation of the British Isles (WATT and Jones 1948) and the Faeroes (Böcher 1940) too. Both species seem to depend on high air humidity during the summer, and snow protection during the winter is essential

1) and R. arcticus, 
for them too (Nordhagen 1. c., Hedberg et al., 1952). Betula nana and Juniperus communis also require some snow protection in the subalpine zone, and are slightly chionophilous. Arctostaphylos uva-ursi, on the other hand, is chionophobous. The three last mentioned species are common in the continental parts of Scandinavia and seem to require less air humidity during the summer (Nordhagen l. c.).

Rumex acetosa requires snow protection and some moisture. Plantago maritima and Armeria maritima occur to-day frequently in mountain vegetation in the British Isles, the Faeroes and Iceland, and they even tolerate long snow cover (Böcher 1940, Steindorsson 1945), but other herbs represented in zone W 1 are chionophobous (Rumex cf. acetosella, Artemisia, Sanguisorba spp.).

It thus appears that air moisture was high and snow cover rich, but not excessive during zone W 1. Locally, on slopes facing south or exposed to wind, snow cover may have been scarce.

Soil.

The composition of the vegetation in zone W 1 indicates that acid soils were of wide occurrence. Calluna and the Empetrum species cover to-day large areas on acid substrate in the subalpine zone in NW Europe together with Betula nana, Juniperus and Arctostaphylos uva-ursi. The sites investigated here are situated in the "hill islands" of Western Jutland in tills left from the glaciation, which preceded the Eemian Interglacial, and in which boulder clays with a high lime content predominate. Leaching began probably during the Interglacial, and it seems that this process had become so general in zone W 1 that acidophilous heath vegetation became prevalent. This development was probably encouraged by formation of an acid terrestrial humus layer due to a humid climate.

The flora of terrestrial plants from zone W 1 contains besides Calluna and the Empetrum species a few other plants, which are acidophilous to-day (Arctostaphylos alpina, Thelypteris dryopteris, Lycopodium clavatum). A few of the plants represented (Filipendula, Geum, Urtica dioica, Rumex acetosa, Trollius europaeus) occur in subalpine tall herb communities to-day, and require a rather nutritious soil (NordHageN 1943, Kotilainen 1951).

Some plants represented in zone W 1 characterize open soil (Artemisia, Chenopodiaceae, Plantago maritima, Rumex cf. acetosella), and a few species which are neutro-basiphilous to-day are recorded (Ophioglossum vulgatum, Plantago media, Sanguisorba minor, S. officinalis, Selaginella selaginoides). It is suggested that areas with bare, mineral soil existed, probably due to some erosion activity. The finds of basiphilous species are rare; they may represent patches of calciphilous vegetation, which survived the Interglacial.

The local vegetations at Brørup Hotel Bog and at Rodebæk I became oligotrophic already during zone $\mathrm{h}$, as heath vegetation developed. Wet local communities with Sphagnum, Eriophorum vaginatum and Rubus chamaemorus developed at the transition to zone W 1, but the aquatic species appeared soon. Isoëtes echinospora and I. lacustris characterize lakes with acid or neutral water to-day. Myriophyllum alterniflorum does not occur in decidedly acid water, but the species is rare in lakes with a rich aquatic vegetation (Iversen 1929, Samuelsson 1934, Iversen and Olsen 1943, Olsen 1950).

No aquatic species, which is basiphilous to-day, is recorded. This fact is quite interesting, as the lakes apparently were basic in the Interglacial. Impoverishment of the lake water is suggested, probably due to leaching of the soils in the areas surrounding the lakes. A similar development is known from Postglacial lakes (Samuelsson 1934, IVERSEN 1954). 


\section{ZONE W 2}

The subzones a, c and e appear to have been relatively warm, and the subzones b and $d$ seem to represent the coldest parts of the sequence studied. The entire zone is well developed at Brørup Hotel Bog, and the five subzones are well distinguished in the composition of the sediments, and their pollen content. The subzones a- $\mathrm{d}$ are represented at Rodebæk I, but only the deposits from subzone c are suitable for pollen analysis. The entire zone is represented at Herning, but the sequence is not clearly differentiated. Subzone c may be recognized in an indistinct way, and subzone e is well developed there.

Remains from 170 taxa of higher plants have been identified to genus or species level. 60 of them are considered to be rebedded from the interglacial layers (cp. table 23, pp. 107-111). The layers at Brørup from the subzones a, $\mathrm{c}$ and e are relatively free from that source of error, and the same is true for subzone $\mathrm{c}$ at Rodebæk I and for subzone e at Herning.

\section{Sediments.}

It can be seen from table 22 (p. 77), that the sediments from zone W 2 are predominantly mineral, but that there is some local variation. The mineral sedimentation was strongest at Herning, Nørbølling and Solsø, presumably because these lakes were larger than the lakes at Brørup Hotel Bog and at Rodebæk I (p. 76). Mineral content predominates in the sediments from the subzones $b$ and $d$ at all of the sites. At the end of the zone, lakes still existed at Brørup, Herning, Nørbølling and Solsø, but the lake at Rodebxk I became filled in almost completely already during the subzones $\mathrm{a}-\mathrm{b}$, except for a small pool, and this basin was nearly oblitterated in subzone d, so that no deposits could form in zone W 3. Most of the many Eemian Interglacial sites known in Western Jutland (cp. the list in J \& M 1928, pp. 245-246) were apparently filled in by mineral deposits already during an early part of zone W 2 (the subzones a-b). It is suggested, accordingly, that a major part of the cryoplanation of the Western Jutland landscape took place at an early time after the Eemian Interglacial.

The erosion in zone W 2 was apparently considerable. At Brørup Hotel Bog the maximum thickness of the layers dating from zone W 2 is $2.70 \mathrm{~m}$., at Rodebæk I $3.50 \mathrm{~m}$., at Nørbølling about $3 \mathrm{~m}$., and at Herning no less than $14 \mathrm{~m}$. (at BP 11 of $\mathrm{J} \& \mathrm{M})$. At the interglacial sites listed by $\mathrm{J} \& \mathrm{M}$ (l. c.) as having no organic horizons in the covering deposits, the thicknesses of the upper mineral strata vary between 1.15$10.00 \mathrm{~m}$.

The various erosion activities mentioned earlier (wave erosion, surface run-off, solifluction, cp. p. 13 and 76) will produce the same type of sediment in the deepest part of the lakes, i. e. water-sorted clay, sand or gravel. However, it is suggested that at least a part of the material was brought to the margins of the lakes by solifluction. At Brørup Hotel Bog J \& M (l. c.) characterize the marginal part of layer $\mathrm{H}$ ("the middle bed") as stony sand with rolled fragments of wood and lumps of interglacial mud (BP 5, J\&M), and at Herning the marginal parts of layer $J$ (corresponding to the subzones $a-b$ ) was described by those authors as "stony clay, moraine like in the southern-most part" (see the description of the brickworks pit profile, l. c., p. 17). At Rodebæk I a solifluction deposit dated to subzone b (layer E, see the profile, plate VIII) reached almost to the centre of the basin from the north, and the covering deposit of stony sand (C), which postdates the clay-gyttja from subzone c, was also soliflucted. This layer reaches from the north and south almost to the centre of the basin, where its equivalent is stratified sand. 
The observations just mentioned agree with the results of A. Jessen, Madsen, Milthers and Nordmann (1918), in their investigation of the covering deposits at a number of Eemian Interglacial sites in Western Jutland. These authors found above the Eemian Interglacial layers, marginal solifluction deposits replaced in the central parts of the basins by lacustrine sediments, and they noticed disturbances of the surface of the interglacial peat at the margins of the basins. Similar results were reached by J \& M (1928). Nørvang (1943) in his investigation of the covering deposits of some Eemian Interglacial bogs (Høllund Søgård, Emmerlev Klev) found mainly layers of stratified sand, a result which is not inconsistent with the observations mentioned above. Hence, it is indicated that mineral material was brought to the edges of the lakes largely by solifluction, and became water-sorted during deposition in the central parts of the lakes.

The solifluction deposits from Western Jutland appear to have formed by amorphus solifluction, which implies that an undifferentiated mass of soil moved or crept down the slopes. This solifluction type was described originally by ANDERsson (i. a. 1906, cp. Sernander 1905, Нögbom 1913). Later authors (Sørensen 1935, Gripp 1939, Troll 1944, 1947, Bryan 1946, CaIlleux and Taylor 1954) include structured soils (polygons, stone stripes) within the solifluction phenomena. Fossil structured soils have also been observed in Western Jutland (see Nørvang 1946), but they cannot be dated exactly within the Weichselian Glacial, and they may have formed at a later point of time than the phenomena mentioned here. At any rate, there is no evidence that structured soils formed during zone $\mathrm{W} 2$. According to observations from the present day, the most intensive mass transportation is caused by amorphus solifluction, as the movement in structured soils results mainly in a sorting of the material in situ (cp. Sørensen l. c., "Hangsolifluktion" versus "Microsolifluktion" according to TroLl 1. c.). According to RUdBerg (1958) water-saturated solifluction soil, poor in vegetation, may move up to $6.5 \mathrm{~cm}$. a year on a slope of only $5^{\circ}$, and transportation may be effective even on slopes of only $2^{\circ}$ (BüDEL 1948). Amorphous solifluction was apparently a main agent in the cryoplanation of the West Jutland landscape, a result, which agrees with the opinion of J\&M (l. c., see also A. Jessen 1905, Нӧgвom 1913, Salomon 1916, A. Jessen, Madsen, Milthers and Nordman 1918, Gripp 1924, Büdel 1944, Troll 1948).

Structured soils characterize the High Arctic to-day, and amorphus solifluction occurs especially in low arctic and subarctic regions (BESKOw 1930, SøRENSEN 1935, Büdel 1948, Cailleux and Taylor 1954). Sernander (1905) and Högbom (1913), in their classic descriptions, referred also to solifluction phenomena of this type from low alpine and even subalpine regions in Scandinavia. Most authors consider oversaturation with water to be an important reason for amorphous solifluction. A perennial pergelisol is not a necessity, as other conditions may cause excess of water. Some authors (Andersson 1906, Sernander 1. c., Büdel 1944, Dahl 1956. Hedberg et al. 1952) mention the importance of melting water from large snow accumulations, and oversaturation by formation of ice crystals during freezing in the autumn may also be important (Beskow 1930, Sørensen l. c., Dücker 1937, Büdel 1948). A moist climate, especially one with much snow, a long melting period, and a high ground water level, are thus favourable for amorphous solifluction, which characterizes areas with oceanic climate within the arctic and subarctic regions (cp. especially BEskow 1930, Paterson 1940, Troll 1944, 1948, Büdel 1944, 1948, Dahl 1956). Fine grained soils such as those found in the glacial landscape of Western Jutland would be especially suited for this solifluction type.

The sediment records show that the soil erosion in zone W 2 was especially strong in the subzones b and d. Traces of solifluction can be referred to these subzones, 
especially. Organic sedimentation in the lakes was strongest in the subzones a, c and e. The differences between the sediment columns from the various sites must be due to variations in the local conditions, probably especially size of the lakes, exposure to wind, and topography of the catchment areas. The solifluction was presumably due to oversaturation of the surface layers with water in connection with an arctic or subaretic climate, and a high ground water level. Perennial pergelisol may have been present, but no indications of this phenomenon can be dated to zone W 2 .

\section{Temperature.}

Trees. As discussed earlier most pollen of trees found in zone W 2 appears to be secondary.

The frequencies for Picea pollen decrease at the lower zone border at Brørup to very low values. The curve rises later on due to deposition of secondary pollen.

The percentage values for the Pinus pollen remain around $10 \%$ in subzone a at Brørup. Most of that pollen was probably due to long distance transport by wind. The Pinus pollen occurring in the later subzones is probably secondary, but a proportion of wind transported pollen may occur, especially in subzone c (see especially the pollen diagram from Rodebæk I, plate IX).

A few pollen grains referred to Populus tremula occur in subzone a, and may be primary. The few finds from the subzones $b$ and d may be secondary.

Primary pollen of Betula pubescens may be present in subzone a at Brørup (p. 53). Much of the Betula pollen from the subzones b d at Brorup is presumably secondary (p. 53), and the pollen of the species was rare in subzone $\mathrm{c}$ at Rodebæk I, according to the size-frequency distribution curve (p. 38). In subzone e, however, the species was apparently present at Brørup (p. 53).

One pollen grain from subzone a may be referred to Prunus cf. padus. The tree occurs in the subalpine zone in Scandinavia to-day.

Shrubs and heliophilous herbs. Pollen from various shrubs is rather frequent in the zone, and a rich element of heliophilous herbaceous plants appeared.

Salix pollen is quite frequent in most of the zone, but its species identity is unknown. Pollen of Salix herbacea was found only once (subzone c), and no pollen referable to $S$. polaris (cp. FÆGRI 1953) was noticed. A few leaves of S. herbacea and a fragment of a leaf of S. cf. phylicifolia were recorded at Herning by J\&M (1928). Salix scrub occurs most commonly in the low arctic and low alpine zones in Scandinavia to-day.

Betula nana was apparently quite common in the subzones a (Brørup), c (Brørup, Rodebæk) and e (Brørup). As mentioned earlier the species ascends into the low arctic and low alpine zones in Scandinavia to-day.

Juniperus communis was common at least in the subzones a and c.

Ericales. The pollen of the ericaceous dwarf shrubs is rare in the pollen analyses from subzone a at Brørup Hotel Bog (cp. plate XV). In subzone b the frequencies increase again, but the majority of the Ericales pollen is secondary, and these plants must have been rare, if present at all. The various species are common in the low alpine and subalpine zones in NW Europe to-day (p. 82), and their decline at the beginning of zone W 2 can hardly have been caused by too low summer temperature.

Pollen of Gramineae and Cyperaceae is very common throughout the zone, indicating that vegetation of herbaceous plants prevailed. Heliophilous shrubs (except Ericales) and herbaceous plants identified from pollen and spores are listed below. Most of the plants are represented only by scattered finds, but a few of them have continuous curves in the pollen diagrams (Artemisia, Rumex acetosella, Plantago maritima). The letters in brackets indicate the subzones from which the finds are recorded. 

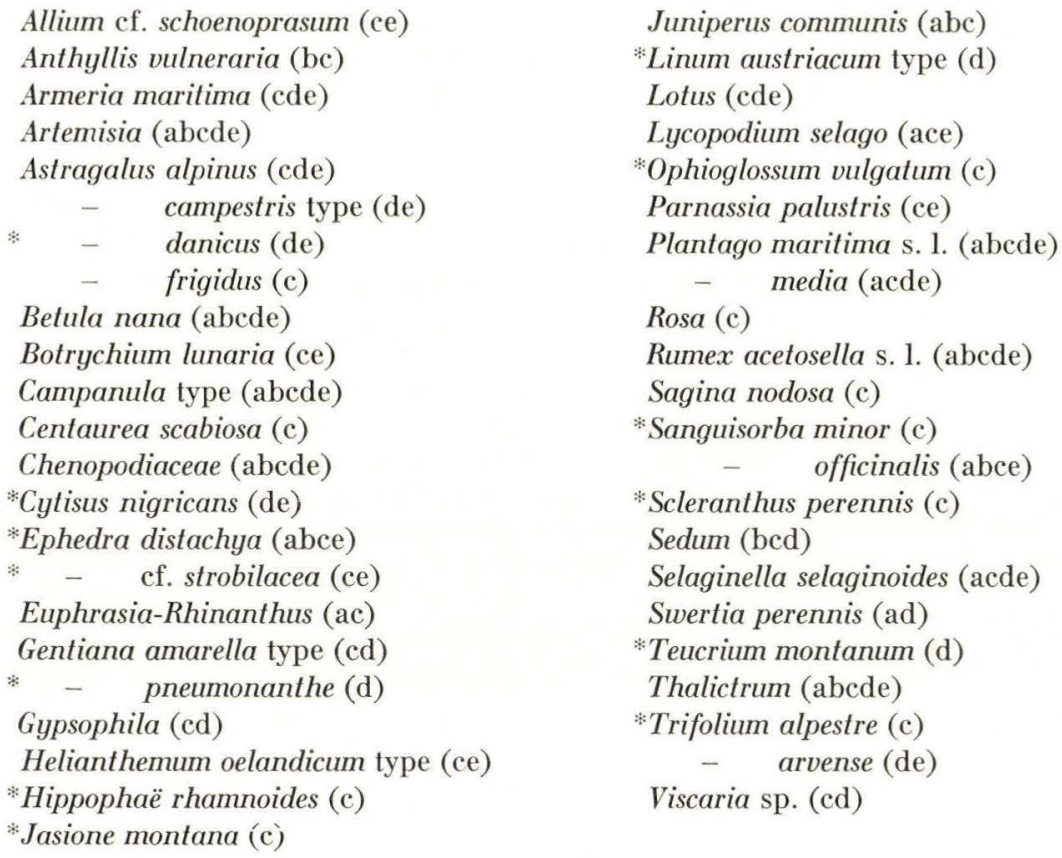

The pollen from several of the genera and species listed is almost certainly primary (p. 54). Curve A on plate XV shows that plants of this ecological type were represented most commonly in subzone c (37 taxonomic groups), where the amount of rebedded pollen is at minimum at Brørup Hotel Bog and at Rodebæk I. This suggests strongly that the heliophilous plants belong to the primary flora.

Higher summer temperature in subzone c may have contributed to the general concentration of heliophytes there. The Artemisia curve at Brørup Hotel Bog shows maxima in the warmer subzones a, $\mathrm{c}$ and $\mathrm{e}$, and minima in the subzones b and $\mathrm{d}$ (see curve 26 on plate VI, and plate XV). VAN DER HAMmen (1951) found that the Artemisia values were particularly low in the Pleni-Glacial of the Netherlands, and ascribed this to low summer temperature. Hence, it is possible that the plant was favoured by higher summer temperature in the subzones a, c and e, and that deficient summer temperature caused its minima in the subzones $b$ and $d$ (for the influence of soil conditions, see p. 92).

The plants marked with asterisks in the list above are not represented above the forest limit in Europe to-day. However, they will not be considered reliable temperature indicators here (cp. IvERSEN 1954 and p. 79), as such plants may be limited to-day rather by competition or historical factors than by temperature. Still, some of the finds may suggest a rather high summer temperature, especially in subzone c (Ephedra spp., Hippophaë, Jasione montana, Scleranthus perennis, Teucrium montanum (found at the transition subzone $\mathrm{c}-\mathrm{d})$ ).

Shade tolerant herbs. Plants, which characterize subalpine tall herb communities to-day (cp. i. a. Böcher 1938, Hustich 1936, Nordhagen 1943, Selander 1950), were not common in zone W 2. Thus pollen grains and spores of Filipendula, Rumex acetosa, Urtica dioica, Geum, Thelypteris dryopteris, Melampyrum and Lycopodium clavatum were rare in most of the zone (see the curves in group II on plate XV). In some cases, their frequencies begin to increase in subzone e. 
The summer temperature can hardly have been too low for these plants, at least not in the warmer subzones, and it appears to be more likely that soil conditions were unfavourable for them (cp. p. 91).

Pollen referred to Mercurialis perennis was recorded from subzone a at Brørup and subzone c at Rodebæk I, and pollen referred to Stellaria holostea from subzone c at Brørup. These finds are rather surprising. A secondary origin might be possible.

Aquatic plants. The sequences at Brørup Hotel Bog, Rodebæk I and Herning were lacustrine during zone $\mathrm{W} 2$, and pollen and spores from aquatic plants are rather abundant in certain subzones.

The pollen and spores of the following species of higher aquatic plants are quite certainly primary (the letters in brackets indicate the sites at which the plants are represented. $\mathrm{B}=$ Brørup Hotel Bog, $\mathrm{R}=$ Rodebæk I, H = Herning),
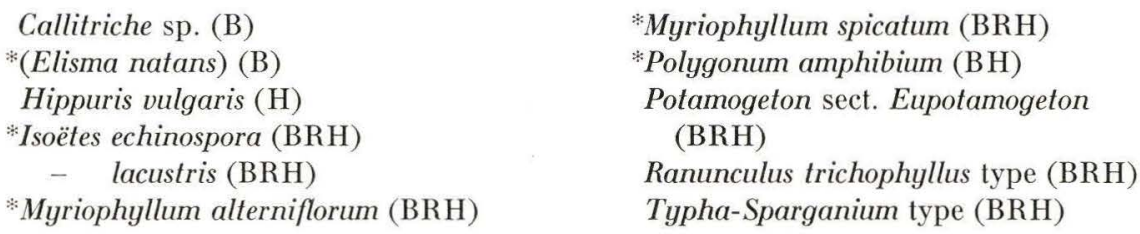

The following macrofossils ( $\&$ M 1928) are presumably primary too,

*Potamogeton natans (B)

$$
\text { - pusillus (B) }
$$

Ranunculus aquatilis (coll.) (BRH)

\author{
Sparganium angustifolium $(\mathrm{R})$ \\ * $\quad-\quad$ minimum $(\mathrm{BR})$
}

The pollen of Elisma natans was found just at the transition to zone W 3 . Its significance will be discussed later (p. 98).

The plants marked with asterisks are not represented in the lists of species occurring in the alpine zone in Europe to-day given by Iversen (1954). One species (Myriophyllum spicatum) is basiphilous to-day, and its present distribution may be restricted by edaphic factors rather than by temperature (SAMuelsson 1934, Iversen 1. c.). Two species (Myriophyllum alterniflorum, Sparganium minimum) are sterile in the upper part of the subalpine zone to-day (Samuelsson 1934, Kilander 1955).

The distribution within the zone of the aquatic plants is best illustrated by the pollen diagrams. At Brørup Hotel Bog (plate VI) the curve for Limnophytes shows very clear maxima in the subzones a, $\mathrm{c}$ and e, and the values are low in the intervening subzones $\mathrm{b}$ and d. The following plants are represented in the three subzones, subzone a: Myriophyllum alterniflorum, Sparganium, subzone c: Myriophyllum alterniflorum, M. spicatum, Potamogeton, Sparganium, Ranunculus, Callitriche, subzone e: Isoëtes echinospora, I. lacustris, Potamogeton, Sparganium, Callitriche, Polygonum amphibium. The following plants are represented at Rodebæk I, in subzone c: Isoëtes echinospora, I. lacustris, Myriophyllum alterniflorum, M. spicatum, Ranunculus, Sparganium. At Herning the curves are less clear. The subzones a and c contain indistinct maxima for Isoëtes echinospora and I. lacustris. A richer aquatic flora developed at the site in subzone e with maxima for Myriophyllum alterniflorum, M. spicatum, Potamogeton, Ranunculus, Sparganium and Hippuris vulgaris.

It may be seen that the aquatic plants occurred richly in the subzones a, $\mathrm{c}$ and $\mathrm{e}$, and the lakes were nearly sterile in the subzones $b$ and $d$. The subzones $b$ and $d$ coincide with the maxima for influx of allochtonous mineral matter. Livingstone 
(1957) has shown that strong mineral sedimentation may cause a depletion of nutrients, especially phosphorus, in the lake water, sufficiently to prevent a development of certain plankton organisms. In the present case there is no reason to believe that the mineral sedimentation was unfavourable for the aquatic plants. Most of the species in question do not depend on the concentration of nutrient ions in the lake water, as they may derive such ions from the bottom deposits, and some of the species (Sparganium angustifolium, S. minimum, Myriophyllum alterniflorum, Isoëtes echinospora and I. lacustris) require very little phosphorus (Lohammer 1938, Iversen and Olsen 1943). It may accordingly be considered to be fairly certain that temperature was the most important factor governing the abundance (or flowering intensity) of the aquatic plants in the profiles just mentioned.

It may be concluded from the occurrence of higher aquatic plants that the summer temperature was relatively high during the subzones a, $\mathrm{c}$ and e, and that it did not differ substantially from that of zone W 1. As Myriophyllum alterniflorum is sterile in most of the subalpine zone in Scandinavia to-day, the common occurrence of pollen grains referred to the species in the subzones a, c and e suggests that the summer temperature at those times was hardly substantially lower than the summer temperature found at the coniferous forest border in Scandinavia to-day. This agrees with the finds of Potamogeton natans, Sparganium minimum (subzone c) and Polygonum amphibium (subzone e), which also are rather thermophilous.

Some other plants from local habitats indicate probably also rather favourable summer temperatures in subzone c. Pollen grains referred to Rumex aquaticus or $R$. hydrolapathum are recorded at Rodebæk I. Both species are of lowland distribution to-day, and do not occur above the coniferous forest limit in Scandinavia. This is also the case for Drosera intermedia, recorded at Rodebæk I too. Drosera anglica or D. rotundifolia is recorded from the subzone at Rodebæk I and at Herning. D. rotundifolia, which ascends the highest to-day, occurs only rarely above the subalpine zone.

A minimum for Limnophytes in subzone $\mathrm{c}$ at Rodebæk I corresponds to maxima for Sphagnum, Rubus chamaemorus and other bog plants (p. 65). A lowered water level during the subzone is indicated. It was probably due to a slightly increased climatic dryness, which coincided with the temperature maximum.

The disappearance of the aquatic plants in the subzones $b$ and $d$ suggests that the summer temperature was low, perhaps of high arctic character.

It may be seen that the terrestrial and the aquatic floras offer similar pictures of the changes of the summer temperature in zone W 2. The summer temperature in the subzones a and e presumably corresponded to that of the subarctic and the subalpine zones in Scandinavia to-day. This was presumably also the case during the warm oscillation in subzone c, which separated the two cold subzones b and d. The climate in the subzones b and $d$ was most probably arctic. Such a result explains the conclusions reached from the sediment records, according to which solifluction and other erosion especially prevailed during the subzones $\mathrm{b}$ and $\mathrm{d}$.

The vegetation was nearly treeless in the subzones a-d. In subzone e, Betula pubescens and Populus tremula were apparently present, but Pinus, Picea and Juniperus did not react to the temperature rise in this subzone.

Only a few indications as to the winter temperature exist. The rareness of the ericaceous heath shrubs may have been due to edaphic conditions (cp. below) rather than to too low winter temperature. The finds of plants of present-day atlantic or sub-atlantic distribution, such as Jasione montana, Scleranthus perennis and Armeria maritima suggest that the winter temperatures cannot have been very low, and the climate apparently was at least moderately oceanic. 


\section{Soil and Precipitation.}

The decrease for the Ericales pollen at the beginning of the zone was a significant event. As mentioned above the decline of these heath plants can hardly have been due to temperature changes, and there is no reason to believe that the climate became too dry. It seems to be much more likely that the decrease of the Ericales resulted from soil changes. It is well known from the present day that solifluction may destroy a humus layer and turn up unleached subsoil, thus preventing podsolization. Acidophilous heath plants are absent from such places (see descriptions from the Scandinavian mountains by Sernander 1905, Frödin 1918, Hedberg et al. 1952, GJerevoll 1956, and especially the detailed description by DAHL 1956). Hence, it may be assumed that the solifluction destroyed the acid, podsolized land surface in zone W 2, and brought unleached subsoil to the surface.

As mentioned on p. 71, the high frequencies for rebedded pollen of Calluna and Empetrum found at Herning indicate that acid humus with much local heath shrub pollen was eroded.

Calluna and Empetrum may have occurred occasionally in places not affected by the solifluction. Empetrum hermaphroditum was probably a member of a local bog community at Rodebæk I in subzone c (p. 65), and it appears that Arctostaphylos uva-ursi may have occurred in subzone c (p. 52 and 64). The species may occur on a wide variety of soils to-day.

Juniperus was apparently fairly common at least in the subzones a and c. The species has a wide soil range to-day. Betula nana was common at least in the subzones a, c and e. This species may grow on wetter and more acid soils, but otherwise its soil range is similar to that of Juniperus.

It was mentioned on p. 88 that herbaceous plants common in subalpine tall herb communities to-day were rare in zone W 2. As it is indicated that the summer temperature was rather high in certain subzones, it appears that this probably was due to insufficient humus formation. The frequencies of some of these plants begin to increase in subzone e, and the soil became probably more favourable for them at that time.

It may be assumed that the soil erosion in zone W 2 brought unleached mineral soil to the surface. Finds of plants considered to indicate neutral-basic soils are listed below (the letters in brackets indicate the subzones from which the finds are recorded),

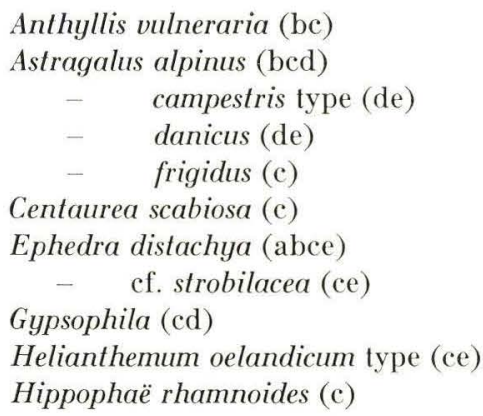

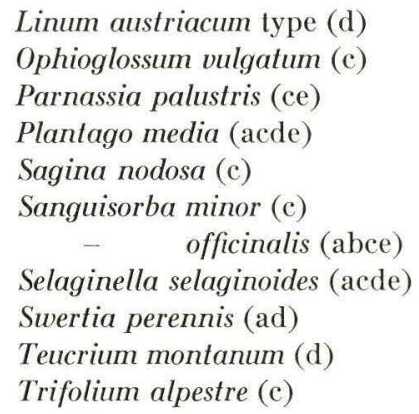

Only 5 species of this type were represented in zone W 1 (p. 84, and curve B on plate XV). Similar numbers occur in the subzones a and b. After subzone b, during which the solifluction may be presumed to have been especially strong, their number had increased to 19 (in subzone c). None of the heliophilous plants listed on p. 88 are distinctly acidophilous to-day. Jasione montana, Rumex acetosella s. 1. and Scleranthus perennis may be considered to be acidophilous (VoLK 1931, WaLTER 1951), but 
these species have wide $\mathrm{pH}$ ranges. Rumex acetosella $\mathrm{s}$. 1 . thus occurs frequently on basic soils (i. a. Volk l. c., Olsen 1921, Mølholm Hansen 1930, Nordhagen 1943, Albertsson 1950, Böcher 1954), and this is also the case for Jasione and Scleranthus (Volk l. c., Braun-Blanquet 1955, Böcher 1. c.). It is suggested, accordingly, that neutral-basic soils became of wide occurrence in zone W 2 .

Some of the heliophilous plants belong rather to closed meadow or grassland communities to-day (e.g. Gentiana pneumonanthe, Ophioglossum vulgatum and Trifolium alpestre), but the majority of these plants occur often in habitats with open mineral soil, such as young moraines, solifluction areas, mountain screes and land slides, beaches, dunes, flood zones of rivers, flat rock areas with seasonal flooding, steep dry slopes and deserts (for examples containing the plants mentioned, see especially Aichinger 1951, Albertsson 1950, Andersson and Birger 1912, O. Andersson 1950, Braun-Blanguet 1936, 1955, Braun-Blanguet and Jenny 1926, Böcher 1937, 1945, 1954, Cajander 1903, 1908, 1909, F ÆGri 1934, Gams 1927, Mølholm Hansen 1930, Jalas 1950, Jenny-Lips 1929, Klika 1931, 1936, 1939, Lüdi 1921, 1945, 1958, Meusel 1939, 1940, Nordhagen 1943, Salisbury 1925, Steffen 1928, Steindorsson 1945, Sterner $1922 \mathrm{a}, 1922 \mathrm{~b}$, Tüxen 1937, Volk 1931, 1940). It is interesting to notice that pioneer plants were so prominent in zone W 2. Prevalence of open habitats with mineral soil apparently formed a background for the rich flora of these plants.

It has been stressed that snow cover and soil moisture were high in zone W 2 . This may explain that the Artemisia frequencies remain rather low, in the warmer subzones only exceptionally above $2 \%$, whilst in the Late-Glacial Artemisia frequencies above $10 \%$ are often met with (see i. a. Firbas 1949, 1951, Iversen 1954, van DER Hammen 1951, Godwin 1956). As Iversen (1. c.) pointed out, most European Artemisia species are xerophilous. Thus the plant may have been favoured by decreased moisture in the subzones a, $\mathrm{c}$ and e, but snow and soil moisture probably prevented it from becoming more common.

As mentioned on p. 88, heliophilous plants were especially common in subzone c. As these plants may not be particularly thermophilous, they may rather have been favoured in subzone c by decreased moisture (see the curves for Rumex acetosella s. 1., Plantago maritima, Lotus, Astragalus alpinus and Thalictrum on plate XV).

Wet solifluction soils of the amorphous type may carry practically speaking no vegetation to-day (see descriptions by Böcher 1954 b. Dahl 1956, GJerevoll 1949, 1956, Frödin 1918, Hedberg et al., 1952, Nordhagen 1943, Seidenfaden 1931, Selander 1950, Sernander 1905, Steindorsson 1945). Even Salix herbacea, S. polaris and Polygonum viviparum, which tolerate some snow cover, show reduced vitality in wet solifluction soils (GJerevoll l.c.), and species able to survive such conditions (e. g. Phippsia spp., Poa alpina, Luzula confusa and other Luzula species, Cerastium cerastoides, Ranunculus glacialis, $R$. pygmaeus, $R$. nivalis, Cardamine bellidifolia, Saxifraga rivularis, Cassiope hypnoides, Gnaphalium supinum a. o.) may produce very little pollen because of reduced flowering intensity, and they may not become recognized in pollen analysis.

Very little can be said about the composition of the vegetation in the subzones $b$ and $\mathrm{d}$, and the vegetation from the solifluction soils seems to be represented poorly in the pollen analyses. Salix herbacea is represented with one pollen grain (subzone c, at Rodebæk I), and one pollen tetrad belongs probably to Cassiope hypnoides (subzone b, at Brørup Hotel Bog). The pollen of Cerastium-Stellaria type cannot be identified sufficiently closely, and the pollen of Ranunculus belonged rather to aquatic species. The curves for Liguliflorae, Galium type, Campanula and Bistorta show highest frequencies in the subzones $\mathbf{b}$ or $\mathbf{d}$. These finds may be primary, but the species identity of the pollen is uncertain. The Bistorta pollen may belong to Bistorta (Polygonum) 
viviparum, and the pollen of Campanula to C. rotundifolia. A sample from the solifluction layer E 2 at Rodebæk I (BP $79 \mathrm{~m}$., depth $1.90 \mathrm{~m}$., from subzone b) had the following pollen spectrum: "thermophilous trees and shrubs" (Carpinus, Quercus, Acer, Fraxinus, Alnus, Corylus, Ilex, Viscum) $32 \%$, Picea $0.4 \%$, Pinus $5.0 \%$, Betula $23 \%$, Salix $1.3 \%$, Juniperus $0.7 \%$, Calluna $7.3 \%$, Empetrum 1.5\%, Gramineae 17\%, Cyperaceae $8.6 \%$, Pteridium $0.2 \%$, Rumex acetosella type $0.5 \%$, Rumex acetosa $1.1 \%$, Plantago maritima $0.2 \%$, Sphagnum $3.8 \%$, Isoëtes lacustris $0.9 \%$, Thelypteris palustris type $0.4 \%$, Typha-Sparganium $0.4 \%$, Myriophyllum alterniflorum $0.5 \%$. It may be seen that the pollen spectrum is dominated by interglacial pollen and pollen from plants which were common in zone W 1 . Only a small proportion of the pollen may be assumed to be primary, and no species particularly characteristic of solifluction soils is represented.

Macroscopic remains of such plants were also rare. J\&M (1928) recorded two leaves of Salix herbacea from the "middle bed" at Herning, and among the 37 species of bryophytes listed from that layer by J\&M (l. c.) two species (Meesia triquetra and Paludella squarrosa) may be found in snow beds, and only four other species (Bryum ventricosum, Catosporium nigritum, Ceratodon purpureus and Ditrichum flexicaule) may grow on wet solifluction soils to-day (according to kind information from cand. mag. K. Holmen).

It seems, indeed, that the remains of terrestrial plants found in the lake sediments represent mainly the vegetation that occurred on well drained slopes exposed to sun and wind, and, in the warmer subzones, also on dried out solifluction soils. Such habitats harboured a flora rich in plants able to grow on barren mineral soil, truly the "tramps" of the plant world (cp. Erdtuan 1946), which spread from their interglacial refugia, as an opportunity was offered.

It can be seen from the pollen diagram from Brørup Hotel Bog (BP 1, plate VI) that Cyperaceae pollen is most frequent in the subzones a-c, and that spores of Sphagnum and pollen of Rubus chamaemorus are common there. These remains represent probably vegetation in boggy habitats not yet affected by the solifluction. The Cyperaceae pollen is less common in the subzones d-e, and it is suggested that the bog habitats became destroyed.

The local bog community that developed at Rodebæk I in subzone c apparently contained Empetrum hermaphroditum, Cyperaceae, Rubus chamaemorus, Drosera spp. and Sphagnum (p. 65). Such a community is distinetly acidophilous. The moss Caliergon stramineum noticed in the same layer (p. 65) presumably also belonged to that community. The species occurs mainly in acid Sphagnum bogs to-day (Kivinen 1935, Sørensen 1948).

The flora of higher aquatic plants from the zone is listed on p. 89. The species Myriophyllum alterniflorum, Potamogeton pusillus and Hippuris vulgaris are neutrobasiphilous to-day (Iversen 1929, Iversen and Olsen 1943, Olsen 1950, Meijer and DE WIT 1955), and the moss Scorpidium scorpidioides, recorded at Brørup Hotel Bog (p. 56), belongs to that category of plants too. Sørensen (l. c., cp. Iversen l. c., Kivinen l. c.) found the species only in neutral and basic water, and he found that it grows best at $\mathrm{pH} 7.5-8.0$. Calliergon giganteum, recorded from subzone $\mathrm{c}$ at Rodebæk I (p. 64), occurs in weakly acid and neutral water to-day, but the species is most common at neutral conditions (Kivinen l. c., Sørensen l. c.). The occurrence of the higher plants and the bryophytes mentioned suggests, that the water of the lakes at Brørup Hotel Bog, Rodebæk I and Herning cannot have been acid in zone W 2.

The remains of Potamogeton filiformis and other basiphilous species found especially at Herning do not occur in such a manner that it can be assumed that they are primary. The finds referred to Myriophyllum spicatum, however, must be considered to be reliable. The pollen grains occur quite commonly in subzone $\mathrm{c}$ at Brorup Hotel Bog and at 
Rodebæk I, and in subzone e at Herning, where the occurrence of rebedded pollen is at minimum, and it can hardly be doubted that the species grew in the lakes at those times. The aquatic floras from zone W 1 contained no basiphilous species, and the appearance of Myriophyllum spicatum may be considered to indicate that the water received by the lakes from the surroundings contained carbonates, presumably due to solifluction, which brought unleached subsoil to the surface (see above).

The aquatic vegetation found in the warmer subzones of zone W 2 was not exceedingly rich. Still, competition from Myriophyllum and Potamogeton was apparently too strong for the Isoëtes species at Brorup Hotel Bog in the subzones a and c, and at Herning in subzone e. The Isoëtes species replaced Myriophyllum and Potamogeton at Brørup Hotel Bog in subzone e, and at Herning at the transition to zone W 3, presumably because the lake water became poorer again.

\section{Zone W 3}

The entire zone is developed in detail in the pollen diagram from Brørup Hotel Bog (BP 1, plate VI), but only subzone a and a fragment of subzone d are represented by pollen bearing deposits at Herning (BP 5, plate XIV).

Rebedded pollen occurs only in the subzones a and b at Brørup Hotel Bog, and the amount of rebedded pollen is insignificant. The influence of rebedded material is a little stronger in the layers at Herning, but a rather clear picture of the contemporaneous vegetation can still be reached (p. 73).

\section{Sediments.}

The sediments at Brørup Hotel Bog indicate a climatic improvement. The organic content is high, generally (see fig. 9, p. 51), and the water level was low during most of the zone. The sediments also reflect minor oscillations in the water level within the zone. The lake dried out in subzone a, and the lake bottom contracted into hard lumps (p. 58). The sedimentation was resumed in subzone b, and clay-gyttja (F 2) formed. During subzone c the peat layer E 5 formed, but gyttja formed in subzone d again. The reversements of the development in the subzones $b$ and $d$ were probably caused by slight climatic deteriorations, which led to higher water level (see also p. 117). Another peat deposit (E 3) began forming in subzone e.

Increased organic content (layer F 1) also marks the transition to zone W 3 , at Herning. At the transition to subzone $\mathrm{b}$ the sediment became predominantly mineral again, and mineral sedimentation continued until most of the basin was oblitterated. The large lake had apparently become so shallow that material carried out from the shores probably by wave movement dominated the sedimentation. At Nørbølling and Solsø the sediments from this zone were predominantly mineral, here too presumably due to wave erosion (see p. 76).

The sediments are lacustrine, mostly, and the pollen diagrams are influenced only slightly by locally produced pollen (see p. 58 and 73).

\section{Temperature.}

Trees and shrubs. The sediments from the subzones $\mathrm{c}$ and e at Brørup Hotel Bog contain no allochtonous material, and all their pollen is undoubtedly primary. Pollen of Carpinus, Quercus, Ulmus, Alnus and Corylus occurs there with frequencies less than $1 \%$. It was presumably due to long distance transport by wind. Pollen of Picea and Pinus occurs in a similar way. The Pinus pollen reaches maximum values at $4 \%$. 
Betula pubescens was by far the most frequent tree. The species contributed the main proportion of the large-sized pollen, and B. tortuosa, if present at all, was rare (p. 37). The Betula pollen frequencies are so high, that it must be assumed that the area was forested. The abundance of Betula pubescens indicates that the July temperature was rather high. The frequent occurrence of the light demanding Populus tremula, Betula nana and Juniperus communis (in the subzones c-e), and the high herb pollen frequencies show that the birch forest cannot have been dense. The Betula values decrease in the subzones $\mathrm{b}$ and $\mathrm{d}$, and the herb pollen frequencies increase. The Betula forest apparently became more open in these subzones, and it is suggested that the summer temperature was lowered sufficiently to cause decreased vitality in Betula pubescens.

The Populus curve rises just below the transition to the zone. The curve follows that of Betula rather closely. As mentioned earlier Populus tremula occurs in the subarcticsubalpine zones in Scandinavia to-day, but the species is dwarfed there and often sterile. The temperature requirements of the species are probably similar to those of Betula pubescens and Pinus silvestris (see p. 80).

Prunus pollen occurs scatteredly in the subzones a, c and d. Prunus padus is the least thermophilous Prunus species in Northern Europe to-day, and occurs in the subalpine zone in Scandinavia (Holmboe 1925, Nordhagen 1943, Selander 1950, KILANDER 1955), but the species may not always reach the upper limit of that zone (Nordhagen 1927).

Pollen grains referred to Malus silvestris are recorded from the subzones a and c at Brørup Hotel Bog. The species has a rather southerly distribution in Scandinavia to-day, and it does not reach high altitudes in the Alps (Wallis at $1600 \mathrm{~m}$., Gams 1927). In view of the difficulty in reaching very certain identifications the finds should probably be considered with caution.

Betula nana was apparently rather common during the zone. This heliophilous shrub ranges widely in subarctic and temperate parts of Europe to-day.

Juniperus pollen is fairly frequent in the later part of zone W 2 at Brorup Hotel Bog $(2 \%)$. The frequencies decrease to very low values at the transition to subzone W 3 a $(0.4 \%$ at Brorup, $1.3 \%$ at Herning $)$, and the pollen is quite rare in subzone $\mathrm{b}$ too ( $0.8 \%$ at Brorup). The pollen of the species becomes common later reaching $7 \%$ in subzone c, and $12 \%$ in subzone e, and the species found obviously favourable conditions in the open Betula forest at that time. It is quite difficult to understand, why the species was so rare in the subzones a and b. Temperature, light and soil were presumably just as favourable for it as later on. One possible explanation is that this shrub disappeared from the neighbourhood of the sites in zone W 2 (subzone d), and that some of the pollen found there is secondary (cp. p. 53). Such a theory would imply that Juniperus did not re-immigrate to the area untill subzone c.

The Salix pollen becomes rarer in zone W 3. It is least common in the subzones c and e (see plate XV). The Salix scrub apparently belonged to the heliophilous element.

A few pollen grains referred to Frangula alnus occur scatteredly in the subzones a-d. The curve rises just before the transition to subzone e. The species does not exceed the $13{ }^{\circ} \mathrm{C}$ July isotherm in Scandinavia to-day, and it is rare north of that for $14^{\circ} \mathrm{C}$. Birger (1904) indicates its northern distribution limit in Norrland at $15^{\circ} \mathrm{C}$ July temperature. The species may fail to flower at its northernmost habitats in cool summers (Andersson and Birger 1912), and it does not reach the upper coniferous forest limit in Scandinavia, nor in the Alps. The species grows well on acid soil and tolerates some shade. Hence, it may be considered to be a fairly reliable temperature indicator.

Pollen grains referred to species of Rubus ( $R$. idaeus, $R$. saxatilis, $R$. arcticus, $R$. cf. fruticosus) were found repeatedly. Seeds of $R$. idaeus occur too (p. 57). The pollen grains referred to that species occur in the subzones $\mathrm{c}$ and $\mathrm{e}$. The species is rather rare 
above the forest border in Scandinavia to-day. $R$. arcticus (subzone b) and $R$. saxatilis (subzones b, c and d) ascend somewhat higher, into the low alpine zone (NordHaGEN 1943, Selander 1950, Kilander 1955, Hedberg et al. 1952). The species belonging to $R$. fruticosus s. l. are rather southern in Scandinavia to-day, but the pollen cannot be identified with great certainty.

Pollen referred to Lonicera xylosteum is recorded from subzone e at Brørup Hotel Bog. The species is rare north of the July isotherm for $15^{\circ} \mathrm{C}$ in Scandinavia to-day, and it does not reach the upper coniferous forest limit. The species occurs also in Picea woods in the Alps (LüDI 1921, GaMs 1927).

The remains of Larix discovered in subzone e do not allow an identification with one of the North European species, Larix decidua Mill. or L. sibirica Ledeb. Larix decidua found closest to Denmark to-day is the species most likely to have occurred. It grows naturally in southern Poland and in the Carpathians (var. polonica (Racib.) Ostenfeld and Syrach Larsen), the Sudeten, Hohe Tatra, and in the Alps (Ostenfeld and LARSEN 1930). The species reaches high altitudes in the Central Alps, where it is common at the upper tree limit. In the Sudeten the species does not reach high altitudes, but in Hohe Tatra it ascends to the forest border (RUBner 1934). Larix decidua is susceptible to attacks from canker (Dasyscypha Willkommi (Hart.) Rehm) when planted in regions with oceanic climate (RUBNer l. c., Robak 1948). This is the case for plants of Alpine and Carpathian provenance especially, but plants from the Polish lowlands may be quite resistant to such attacks (GøHRN 1956). The light requirements of the species vary somewhat. The species has high light requirements in the Alps, and is a weak competitor, but the Sudetian larch seems to be less demanding. At any rate, the open birch forest of zone W 3 must have suited the species well.

Shade tolerant herbaceous plants. Plants of this type became rather frequent in zone W 3. A number of rather thermophilous species are represented.

Filipendula cf. ulmaria pollen is quite frequent in the zone. The pollen frequencies decrease slightly in the subzones $b$ and $d$ (see plate XV). The species is rare and usually sterile in the low alpine zone to-day (Nordhagen 1943, Selander 1950, Kilander 1955). Pollen referred to the species was common in Denmark in the Allerød and in the Pre-Boreal, but was rare in the cold Younger Dryas (Iversen 1954).

Other rather thermophilous herbs identified from pollen grains are Urtica dioica, the pollen of which is common in most of the zone, Fragaria (subzone a) and Solanum dulcamara (subzones a and c). Iversen (1954) mentions the occurrence of the latter species from the Allerød Interstadial, and emphasizes its importance as an indicator of a rather high summer temperature $\left(14^{\circ} \mathrm{C}\right.$ in July).

Pteridium spores appear in subzone e (see plate XV). The species appears to be quite thermophilous. It is rare north of the $15^{\circ} \mathrm{C}$ July isotherm in Finland and in Sweden, but it is common south of the $13^{\circ} \mathrm{C}$ July isotherm at the West coast of Norway. The distribution of the species is rather similar to that of Alnus glutinosa, and it does not reach the upper coniferous forest limit in the Scandinavian mountains. The altitudinal limit of the species in the Alps is similar to that of Corylus avellana (maximum at $1800 \mathrm{~m}$.).

Finally, the finds of pollen referred to Mercurialis perennis are to be mentioned. One pollen grain is recorded from subzone a and one from subzone e, both of them from Brørup Hotel Bog. The distribution of the species in Scandinavia is quite southern to-day. Its northern limit touches southernmost Finland, Middle Sweden and southern Norway (corresponding to the $15-16^{\circ} \mathrm{C}$ July isotherm), but the species has a few peculiarly isolated outposts in Western Norway (cp. FAgri 1960). In the Alps, the species ascends to about the same altitude as Pteridium aquilinum. A few pollen grains are recorded from zone W 2 (secondary?, see p. 89). The find from subzone W 3 a 
at Brørup Hotel Bog may not be quite reliable, but the find from subzone e is undoubtedly primary.

Plants from open habitats. The abundance of herb pollen in zone W 3 illustrates that the forest remained open. The pollen of several herbaceous plants, which were prominent in zone W 2, remained rather common in this zone (Gramineae, Cyperaceae, Rumex acetosella type, Galium type, Tubuliflorae, Liguliflorae, Artemisia, Plantago maritima and Campanula, see also group I on plate XV). Their frequencies decrease as a rule during the zone, and they are especially low in the subzones c and e, presumably because the forest was more dense in these subzones. A few light-demanding plants became more common in zone W 3 (e.g. Thalictrum, Chenopodiaceae, Sanguisorba officinalis, Allium cf. schoenoprasum, see group II on plate XV).

Besides some of the shrubs mentioned above (Juniperus, Belula nana, Salix), the following plants from open habitats are represented in the zone:
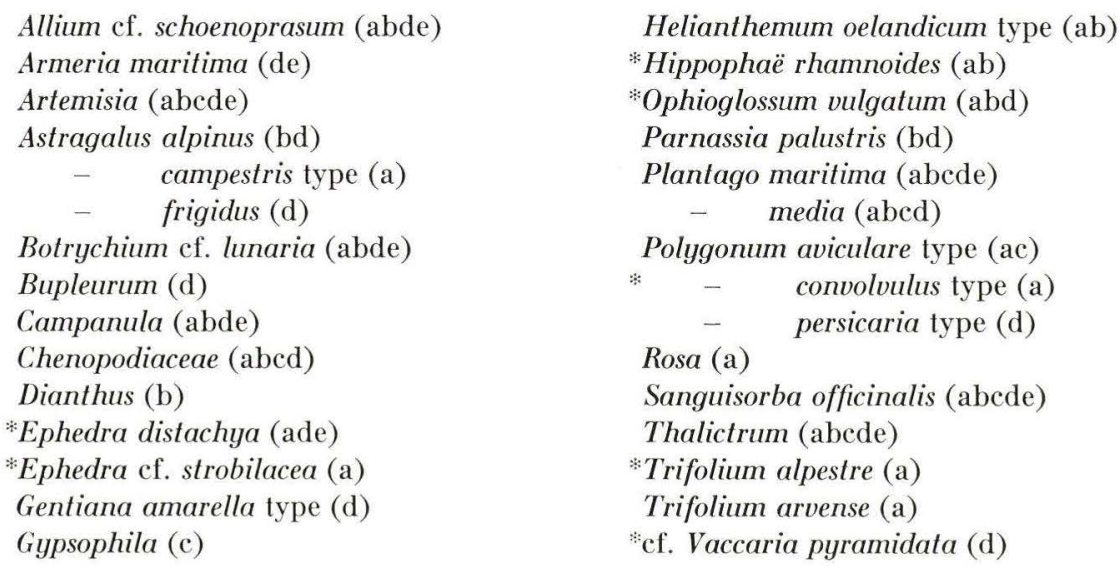

32 plants from this category are represented. Compared with the corresponding figure for zone W 2 (45) it may be seen that the total number of such plants has decreased somewhat. The occurrence of heliophilous plants within the zone will appear from curve $\mathrm{A}$ on Plate XV. It can be seen that the numbers found in the subzones $\mathrm{c}$ and e are lowest, presumably due to shade.

The plants marked with asterisks are not represented above the forest zone in Europe to-day. Their occurrence in zone W 3 is not surprising. The Bistorta pollen probably represents Polygonum bistorta here, a species, which is most common below the forest border in the Alps to-day, and is rather shade tolerant (see also plate XV).

The Betula forest of zone W 3 was apparently sufficiently open for a rather rich flora of heliophilous plants. It is indicated that the shade was strongest in the subzones $\mathrm{c}$ and $\mathrm{e}$.

Local plants. The floras of local plants from zone W 3 were quite rich. Several of the species appear to be rather thermophilous. The following species do not occur above the coniferous forest border in Scandinavia to-day:
Elisma natans (abcde)
Nuphar luteum (abc)
Littorella uniflora (b)
Typha latifolia (de)
Lobelia dortmanna (acd)
Valeriana dioica (b)
Lysimachia thyrsiflora (acd)

The pollen of Elisma natans is rather frequent at Brørup Hotel Bog. One pollen grain occurred in subzone a at Herning, and the species is represented at Norbolling (sub- 
zone e) too. Elisma natans occurs only in Western Europe to-day (from NW. Spain to Western Poland, Southern Scandinavia and the British Isles). The occurrences are very scattered. In Scandinavia the species occurs in westernmost Denmark, at two localities near Oslo in Norway, and it was discovered recently at one locality in SW. Värmland in Sweden (Hylander 1953). GlücK (1905) suggested that the scattered distribution of the species may be due to difficulties of spreading, as its seeds do not float well (RAvn 1895), but competition may be a more decisive factor. The species thrives well when cultivated outside of its natural range (SAMUELSSON 1934), and its present distribution can hardly be limited by temperature alone (cp. Firbas and Grahmann 1928). However, the species may still be considered to be rather thermophilous.

Typha latifolia appears to be rather thermophilous, and Iversen (1954) considers the species to be a reliable temperature indicator. The species belongs to SAMUELSSON's Bothnian group, the species of which do not exceed the $15^{\circ} \mathrm{C}$ July isotherm in Scandinavia (SAMuelsson 1934, see also Birger 1904). Lobelia dortmanna, Littorella uniflora and Nuphar luteum belong to SAMUELSson's Laplandish group, the species of which do not exceed the $14^{\circ} \mathrm{C}$ July isotherm. None of the species mentioned are basiphilous. Nuphar luteum does not reach the upper Picea forest limit in the Alps.

Pollen referred to Lysimachia thyrsiflora was quite common at Brørup Hotel Bog. The northern and altitudinal limits of the species in Scandinavia are similar to those of Nuphar luteum. Its altitudinal limit in the Alps is rather low $(1100 \mathrm{~m}$.). The species is not basiphilous.

Valeriana dioica is quite southern in Scandinavia and probably rather thermophilous (cp. FÆGRI 1960). The species ascends to $1800 \mathrm{~m}$. in the Alps.

It may be seen that the vegetation in zone W 3 appears to be distinctly thermophilous.

The subzones a, c and e appear to be the most favourable ones. The forests of Betula pubescens were rather dense, but not strongly shading. According to Iversen (1954) the very similar birch forests from the Allerød Interstadial indicate that the July temperature was at least $12^{\circ} \mathrm{C}$. The common occurrence of Filipendula ef. ulmaria is also significant (cp. Iversen l. c.).

From subzone a the finds referred to Prunus cf. padus, Fragaria and Solanum dulcamara are worth mentioning. Among the local plants the occurrences of Elisma natans, Lysimachia thyrsiflora, Nuphar luteum and Lobelia dortmanna should be mentioned. A rather high summer temperature is indicated.

From subzone c we may mention the finds referred to Prunus cf. padus, Rubus idaeus, Solanum dulcamara, Elisma natans, Lysimachia thyrsiflora and Nuphar luteum. Here too the summer temperature was presumably rather high.

From subzone e we may notice the finds of Frangula alnus, Lonicera xylosteum, Rubus idaeus, Pteridium, Mercurialis perennis, Elisma natans, Lysimachia thyrsiflora and Typha latifolia.

It seems to be indicated that the summer temperature was lowered slightly in the subzones b and d. The Betula curve was depressed and increases in the herb pollen values show that the forest became more open. Populus and Filipendula decreased in these subzones, and even the Juniperus curve is depressed somewhat in subzone d.

The floras of these subzones are poor in thermophilous terrestrial plants, but the floras of local plants do not differ appreciably. Hence, the temperature oscillations cannot have been large.

Indications of the winter temperature are few. The occurrence of Larix and Lonicera xylosteum may suggest that the climate was not strongly oceanic. Several atlantic species are represented in the flora of aquatic plants (Isoëtes echinospora, I. lacustris, Elisma 
natans, Myriophyllum alterniflorum, Littorella uniflora, Lobelia dortmanna). However, their value as indicators of winter temperature may be questioned (p. 83).

The local successions give information about changes in water level, which probably reflect climatic changes. They reflect in detail the changes in water level indicated by the sediment columns.

Limnophytes (Isoëtes echinospora, I. lacustris, Potamogeton) were common at Brørup Hotel Bog at the end of zone W 2 (see the pollen diagram on plate VI). Their values decrease strongly at the transition to zone W 3 corresponding to a drying out of the lake, and they reach another maximum in subzone b. The Limnophytes disappear in subzone c, but their curve reaches another maximum in the course of subzone d, reflecting another rise of the water level. The curve for Typha-Sparganium is similar, it represents probably Sparganium minimum, another Limnophyte. The curve for Polygonum amphibium, an Amphiphyte, is also similar to that for the Limnophytes.

The curve for Elisma natans is similar to that for the Telmatophytes, suggesting that the species was associated with these plants. The species flowers and fruits well on dry ground, but then its vegetative parts become reduced (GLücK 1905).

The curve for the Telmatophytes (Lysimachia thyrsiftora, Menyanthes trifoliata, Caltha palustris) rises in subzone a. The species mentioned apparently colonized the lake bottom as the lake dried out. The curve for Umbelliferae has a similar course. The generic or specific identity of the pollen is unknown, but it is suggested that it represents an Amphiphyte or a Telmatophyte from that family.

In subzone $\mathrm{c}$ the lake was overgrown by another community of bog plants especially Cyperaceae (presumably Carex rostrata and C. lasiocarpa, p. 58) and Sphagnum. This community was flooded in subzone d, but in subzone e the lake was overgrown again by a similar community with much Sphagnum.

The local succession at Brorup Hotel Bog in zone W 3 contained thus 3 telmatic stages (in the subzones a, c and e) and two aquatic stages (in the subzones b and d).

A similar development took place at Herning. Limnophytes (mainly Potamogeton, Myriophyllum alterniflorum, Isoëtes echinospora, I. lacustris), Ranunculus spp. and Typha-Sparganium show a minimum at the middle of subzone a. The values for Cyperaceae and Telmatophytes (Caltha palustris and Menyanthes trifoliata) increase at the same level. The succession indicates that the water level was low in subzone a, and that it rose again at the transition to subzone b. Limnophytes (Potamogeton, Myriophyllum, Isoëtes a. o.) were also common in subzone d.

The local developments thus give detailed information about changes in water level. The water level at both sites was apparently lowered at the transition to zone W 3, and it remained rather low during the zone. The water level rose slightly in the subzones $\mathrm{b}$ and $\mathrm{d}$. Hence, the rises in the water level correspond to the minima in the Betula curve. These water level changes were presumably related to changes in the summer temperature (see chapter VI).

\section{Precipitation.}

Information about the precipitation in zone W 3 is scarce. It may be mentioned that the lowerings of the water level in the lakes suggest that evaporation was higher and the climate in general drier than in zone W 2. The climate probably became slightly more moist in the subzones $\mathrm{b}$ and $\mathrm{d}$. The decline in Betula in these subzones cannot have been due to increased dryness, and it seems quite certain that the precipitation was ample for the growth of trees. 
Myriophyllum alterniflorum remained rare in subzone b, and the other plants represented there (Isoëles echinospora, I. lacustris, Potamogeton natans, Sparganium minimum, Nuphar luteum, Polygonum amphibium, Littorella uniflora, Elisma natans, Lysimachia thyrsiflora, Menyanthes trifoliata and Caltha palustris) indicate that the lake water probably was circum-neutral or slightly acid.

The communities of swamp plants from subzone c and e appear to be somewhat acidophilous. They consisted apparently mainly of Cyperaceae (Carex rostrata and C. lasiocarpa), Sphagnum, Menyanthes trifoliata, Caltha palustris and Rubus chamaemorus. Some of these species do not occur in pure raised bog communities to-day (e. g. Carex rostrata, C. lasiocarpa, Caltha, Menyanthes), but, on the other hand, no species characteristic of rich fen vegetation to-day are represented (cp. DU RIETZ 1954, Sjörs 1950, MaLmer and SJörs 1955).

The community of aquatic plants represented in subzone d was quite similar to the one found in subzone b.

The community of aquatic plants found at Herning at the end of zone W 2 consisted mainly of Myriophyllum alterniflorum, M. spicatum, Potamogeton, Ranunculus spp., Typha-Sparganium and Hippuris vulgaris. The frequencies for the pollen referred to the Myriophyllum species, Hippuris and Ranunculus spp. decrease at the transition to zone W 3, and the frequencies for Isoëtes echinospora, I. lacustris and Polygonum amphibium increase. This succession suggests that the lake became acid. Other local species represented in zone W 3 are Caltha palustris, Lysimachia thyrsiflora, Menyanthes trifoliata, Lobelia dortmanna, Elisma natans and Callitriche sp. This flora is quite similar to the one, which occurred at Brørup Hotel Bog.

It appears that the lakes became acid in zone W 3. As mentioned on p. 100 it is indicated that the zone was characterized by consolidation of the soil and initial formation of an acid humus layer. The vegetation from the lakes apparently also reflects such a development.

\section{ZONE W 4}

\section{Sediments.}

Deposits from the zone occur at Brorup Hotel Bog and Nørbølling. The deposit at Brorup is telmatic peat and forest peat, and it is not possible to distinguish pollen produced locally from pollen derived from the general vegetation. The deposit is free from contamination with rebedded pollen. At Norbolling the sediment is lacustrine (dy), and the pollen composition gives a better picture of the general vegetation. A slight amount of rebedded pollen may be present at the lowermost part of the zone at this site (p. 75).

\section{Temperature.}

Trees and shrubs. The frequencies for Carpinus, Quercus, Fraxinus, Corylus and Alnus increase slightly (see the pollen diagram from BP 2 at Brorup Hotel Bog, plate VII and the curves on plate XV), but there is no reason to believe that these trees occurred in the neighbourhood of the sites. However, it seems to be suggested that they had immigrated to an area closer to the sites.

The upland forest apparently consisted mainly of Betula pubescens, Pinus (silvestris), Picea abies and Larix. Picea omoricoides appeared later. 
The immigration of Picea abies and Pinus cannot have been due to increased summer temperature. The climate of zone W 3 was also favourable for these trees (p. 98).

Picea omorica is restricted to a very small distribution area in Yugoslavia to-day. The species occurs there at altitudes at $700-1500 \mathrm{~m}$., most frequently together with Fagus silvatica, Abies alba, Picea abies, Acer pseudoplatanus and Pinus nigra (Fukarek 1951). As Picea omoricoides was widely distributed, the species presumably varied considerably, and its requirements may have differed from those of the present rather small populations of Picea omorica (WEBER 1898).

The pollen referred to Frangula alnus is rather common and it is suggested that the summer temperature was rather high. Also Lonicera xylosteum (p. 96), Erica tetralix and Myrica gale appear to be rather thermophilous to-day. Erica tetralix does not usually extend beyond the July isotherm for $15^{\circ} \mathrm{C}$ in Scandinavia. In the most oceanic part of Norway the species may occur above the coniferous forest limit, and in areas with a July temperature down to $12^{\circ} \mathrm{C}$ (see F ÆGRI 1960). Myrica gale does not ascend to the coniferous forest limit; it also reaches the $12^{\circ} \mathrm{C}$ isotherm for July in westernmost Norway.

The forest had probably become denser. The frequencies for Gramineae and Cyperaceae decrease, and a number of the light-demanding plants, which were rather common in zone W 3, decrease in frequency, or disappear (e. g. Salix, Rumex acetosella (type), Artemisia, Populus, Chenopodiaceae, Juniperus, see the curves on plate XV). The finds of plants from open habitats are restricted mainly to the lowermost part of the zone, later on only a few are represented (Plantago media, P. maritima, Jasione). Calluna became increasingly common.

Shade tolerant herbs identified from pollen and spores are Filipendula ef. ulmaria, Urtica dioica, Thelypteris dryopteris, Pteridium aquilinum, Linnaea borealis, Symphytum and Mercurialis perennis. The four species mentioned first were apparently rather common (see the curves on plate XV). Pteridium aquilium and Mercurialis perennis are rather thermophilous to-day (p. 96). Symphytum is represented in Scandinavia only by introduced species. S. officinale and S. tuberosum may be native in Central Europe. They spread easily from culture, and the northern and western limits of their spontaneous distribution areas cannot be determined. $S$. officinale is rather southern in Scandinavia, but the species may ascend to the Picea zone in the Alps.

Local plants. Thermophilous species of local occurrence identified from pollen grains are Typha latifolia and Nuphar luteum.

It seems obvious that the summer temperature in zone W 4 was just as favourable as that of subzone e in zone W 3. A rise of temperature in zone W 4 is not indicated.

The finds of Erica tetralix suggest that the winters were rather mild (see GranLund 1925, F ÆGRI 1958). Such a conclusion may seem to be contradicted by the presence of Picea abies, as this species does not thrive at high winter temperatures to-day. The species grows well in Denmark at an average winter temperature for January at $-1^{\circ} \mathrm{C}$, but at a higher winter temperature it is in danger of attacks from parasitic fungi (especially Polyporus radiciperda, Oppermann 1922). Hence, Picea abies may still grow well in a moderately oceanic climate (cp. HaGEm 1947).

\section{Precipitation.}

The presence of Picea abies in zone W 4 may indicate a rather humid climate, as the species requires moisture and is susceptible to summer drought to-day (OPPERManN 1922, RuBner 1934). Also the finds of Erica tetralix and Myrica gale suggest that the climate was rather humid (cp. Kotilainen 1933, FEGRI 1958, 1960). 
Soil.

The pollen diagram from Nørbølling indicates increasing abundance of the pollen and spores referred to acidophilous species, especially Frangula alnus, Calluna vulgaris, and Sphagnum. Spores of Pteridium aquilinum and Thelypteris dryopteris were also rather frequent (cp. plate XV), and pollen grains and spores referred to the acidophilous Empetrum nigrum, Erica tetralix, Myrica gale, Linnaea borealis, Lycopodium annotinum, L. clavalum and Melampyrum occur. It seems that an acid humus layer became increasingly widespread, in continuation of the development initiated in zone W 3.

Finds referred to neutro-basiphilous species are correspondingly rare (Lonicera xylosteum, Mercurialis perennis, Sanguisorba officinalis, Plantago media). The pollen of Filipendula cf. ulmaria and Urtica dioica, both of which are rather requiring, remained quite common, however (see plate XV). Symphytum is of a similar type to-day. The species mentioned on p. 102 occur in tall herb communities e. g. on consolidated river alluvia to-day (Klika 1936, Wendelberger-Zelinka 1952).

The absence of macrofossils of Picea omoricoides from the peat at Brørup Hotel Bog suggests that the species may have occurred mainly on upland soils. Picea omorica occurs mostly on limestone to-day, and the species is accompanied by a great number of neutro-basiphilous species (Lonicera xylosteum is very common, i. a., see FUKarek 1950). However, the floras recorded together with Picea omoricoides at Lüneburg and at Aue (p. 126) include acidophilous species.

The local succession at Brørup Hotel Bog was described on p. 60. The hydrosere from a wet telmatic stage to a rather wet Frangula-Calluna-Sphagnum community, and to a Picea forest stage with Pinus, Betula, Frangula, Calluna, Empetrum, and Rubus chamaemorus suggests increased dryness and acidity.

The local aquatic community at Norbolling was apparently dominated by Isoëtes echinospora and I. lacustris. Other plants identified are Nuphar luteum, Polygonum amphibium, Typha latifolia, Menyanthes trifoliata and Drosera. It appears that the lake was neutral or somewhat acid at that time. Finds referred to neutro-basiphilous species (Myriophyllum alterniflorum, M. spicatum and $M$. verticillatum) are very rare. They are restricted to the lowermost sample, and the pollen is presumably secondary (p. 75).

\section{ZoNe W 5}

\section{Sediments.}

Peat resembling raised bog peat formed at Brørup Hotel Bog, but the sediment at Nørbølling is lacustrine (dy), and the best picture of the general vegetation is obtained from the pollen diagram at that site. The sequence from Brørup is the more complete one, as the subzones a-c are represented. Only subzone a is represented at Nørbolling. The record is truncated upwards at both sites.

\section{Temperature.}

There are no definite indications of temperature changes at the transition to the zone. The values for the pollen of Carpinus, Quercus, Ulmus, Fraxinus, Corylus and Alnus decrease a little, and a slight temperature decrease may be suggested. The frequencies 
for these plants decrease to a minimum in subzone b, which may indicate a cooler climate for a short interval.

The arboreal flora remained rather unchanged in subzone a. Pinus pollen dominates and the values for Betula and Picea decrease somewhat. The forest was probably rather dense, and plants such as Juniperus, Gramineae, Cyperaceae, Rumex acetosella (type), Artemisia and Thelypteris dryopteris were apparently rare. Pollen and spores of Frangula alnus, Calluna vulgaris, and Pteridium aquilinum were rather common, (see especially the pollen diagram from Norbølling, and plate XV).

The values for Pinus are somewhat higher at Brørup (about 60\%) than at Nørbølling $(40-50 \%)$. It is suggested that some of the Pinus pollen from the peat deposit at Brørup was produced by individuals, which grew on the bog itself.

The curves in the pollen diagram from Brørup change rather suddenly in subzone $\mathrm{b}$ (minima for Pinus, Picea, Larix and Calluna, maxima for Betula (cf. pubescens, cp. p. 38), Frangula, Juniperus, Salix, Gramineae, Cyperaceae, Rumex acetosella type). These changes cannot have resulted from a decrease in temperature directly, as e. g. Frangula is more southern than Pinus to-day (p. 95). It seems to be more likely that the bog became too wet for local populations of Pinus silvestris and other local plants for a short time, and that the overrepresentation of Pinus, Picea etc. in the pollen spectra was reduced. The pollen spectra from subzone b probably offer a rather good picture of the general vegetation which apparently consisted of Pinus-Betula forest with some representation of Picea, shrubs (Frangula alnus, Calluna vulgaris, Juniperus communis) and herbaceous plants (Gramineae, Cyperaceae, R. acetosa, Thelypteris dryopteris, Filipendula ef. ulmaria, Urtica dioica, Pteridium aquilinum and Mercurialis perennis). A few plants typical of open habitats were represented (Ephedra cf. strobilacea, Rumex acetosella (type), Artemisia, Plantago maritima, P. media, Chenopodiaceae, Thalictrum, Sanguisorba officinalis, Lotus).

It may be concluded that the climate was rather uniform in zone $\mathrm{W} 5$. The summer temperature was rather high, as indicated by the occurrence of thermophilous species (Frangula alnus, Myrica gale (subzone a), Erica tetralix (subzone a), Pteridium aquilinum (subzones a and c), Mercurialis perennis (subzone b)). The summer temperature decreased probably slightly in subzone $\mathbf{b}$.

The winter temperature also appears to have been similar to that of zone W 4 .

\section{Soil and Precipitation.}

The pollen diagram from Nørbølling indicates increasing frequency of pollen referred to Frangula alnus, Calluna vulgaris and other plants, which are acidophilous to-day. It is suggested that acid humus accumulated and acidophilous vegetation expanded. The increase in the frequency of Pinus was probably also due to such a change. The frequencies of Picea, Filipendula and Urtica dioica decrease somewhat, and finds referred to neutro-basiphilous species are rare (e. g. Ephedra ef. strobilacea, Mercurialis perennis, Sanguisorba officinalis, Plantago media). These features were presumably due to increased soil leaching and development of an acid humus layer.

The local vegetation at Brørup Hotel Bog developed into a Calluna-Eriophorum vaginatum-Sphagnum community. Rubus chamaemorus and rhizopods were common. It seems that the bog had reached a stage which resembled a raised bog, and the centre of the bog was apparently rather wet. The moss Drepanocladus exannulatus (Gümb.) Warnst. probably belonged to such a community. The species is neutro-acidophilous and may occur in Sphagnum bogs according to Sørensen (1948). Pinus silvestris may have grown in certain parts of the small bog. A few fully illuminated individuals might have produced sufficient pollen to account for the overrepresentation of the species 
in the pollen analyses. The pollen of Picea and Frangula alnus becomes somewhat rarer than in zone $\mathrm{W} 4$. The bog had apparently become too poor for them. Pollen referred to Arctostaphylos uva-ursi was found at the transition to the zone. It probably indicates quite dry conditions at its very beginning. The pollen of the species is rare in the upper part of the zone. The species did certainly not belong to the raised bog vegetation.

It may be concluded that the development of bog vegetation at Brorup Hotel Bog in zone W 5 was a part of a local succession, and that the peat became increasingly poor and acid.

The re-immigration history of the forest trees in the zones W $3-\mathrm{W} 5$ is rather remarkable. Betula pubescens and Populus tremula reacted quite readily to the temperature rise, and these trees were common from the beginning of zone W 3. Larix immigrated in a late part of zone W 3, and Pinus and Picea in zone W 4. It is suggested that the summer temperature in zone W 3 was sufficiently high for these trees, and as the Betula forests were quite open, competition can hardly have delayed the immigration of Pinus, Picea and Larix. The soil can hardly have been unfavourable in zone W 3 for the trees mentioned, especially not for Pinus and Larix, and it appears that Pinus, Picea and Larix were absent rather because of incomplete immigration. These trees were probably found at a considerable distance to the south during the cold zone W 2, whilst Betula pubescens and Populus tremula survived nearer, or they migrated faster.

It is also suggested that Alnus glutinosa and probably also Quercus robur, Tilia cordata, Ulmus glabra and Corylus avellana might have found favourable conditions during the zones W 3-W 5. Pollen of Quercus, Ulmus, Alnus and Corylus occurs, but there is reason to believe that this pollen was due to long distance wind transport, and that the plants themselves were absent from the area. These thermophilous trees and shrubs survived probably zone $\mathrm{W} 2$ at a considerable distance to the south, and they apparently migrated quite slowly. Thermophilous terrestrial herbs and aquatic plants already occurred at an early part of zone W 3. The great migration speed of such plants is known from parallel cases (see i. a. Iversen 1954, Środoń 1954, Jessen, ANDERSEN and Farrington 1959).

A very similar case of delayed immigration of forest trees occurred in the Allerød Interstadial. Forests of Betula pubescens (s. str.) prevailed in Denmark at that time (Iversen 1954). Pinus silvestris occurred in Holland and North Germany, but this species was rare or absent from most of Denmark. According to Iversen (1. c.) the slow progress of the species was hardly due to the climate, and Iversen's results (l. c.) suggest that more thermophilous trees and shrubs (Alnus, Corylus, Tilia cordata) also were absent from North and Central Europe due to a slow immigration rather than to the climate (cp. also Firbas 1949).

\section{ZONE W $\mathrm{x}$}

The upper limit of the peat from zone W 5 at Brorup Hotel Bog gives evidence of erosion (cp. p. 61), and an interval of unknown length elapsed before the sandy clay layer (D) was deposited. However, that interval was presumably not very long.

The probable composition of the vegetation at the time when layer D was deposited is discussed on p. 61. The vegetation seems to have been unforested and the climate must have been considerably colder than that of zone W 5 . The common occurrence of Filipendula and Littorella uniflora indicates that the climate was probably subarctic.

Juniperus, Salix and herbs seem to have been common, and several plants from open habitats are represented (Ephedra cf. distachya, Rumex acetosella type, Artemisia, 
Plantago maritima, P. media. Thalictrum, Sanguisorba officinalis, Armeria maritima, Campanula type). Several of these plants are basiphilous (Ephedra, Plantago media, Sanguisorba).

The topmost deposits at Brørup Hotel Bog contain evidence of solifluction (cp. p. 61). They were apparently formed in a cold period.

\section{The Flora List}

Higher plants identified either from macrofossils, or pollen and spores from the zones W 1-W 5 are listed in table 23. 194 taxa of various ranks are listed. 180 taxa were identified to genus, species group or species, but 44 of these are represented only by rebedded remains or pollen considered to be due to long distance transport by wind. The corresponding figures for species identified with a reasonable certainty are 145 and 40.56 of the species identifications rely mainly on macrofossils, mainly from the investigation of $J \& M(1928)$. The dating of the remains within the pollen zones W 1W 5 was discussed in chapter IV. The macrofossils identified by J\&M (l. c.) have only been listed if they could be dated with some certainty.

The list of identifications has been compared with the list of remains of higher plants from the Danish Late-Glacial published by IvERSEN (1954). It should be remembered that the chances for preservation and identification of the species vary considerably, and the material is too heterogenous for comparison on an exact basis. It may be seen from the list that 88 of the 136 genera, species groups or species considered to be primary re-appear in the list of Late-Glacial finds. 4 plants not represented in the list of Late-Glacial finds (Larix, Picea abies, P. omoricoides, Symphytum sp.) did not reach Denmark after the Weichselian Glacial. 2 species (Lonicera xylosteum, Mercurialis perennis) are rather southern to-day, and may not have found sufficiently high temperatures during the Late-Glacial. 16 acidophilous species are missing from the Late-Glacial list. This may be understood if it is considered that heath and bog vegetation occurred widely in the zones W 1 and W 4-5. As Iversen (l. c.) pointed out, the boulder clays left from the last glaciation in Denmark were not subjected to severe leaching during the Late-Glacial, and acid soils were of limited occurrence. Only 3 of the finds of neutro-basiphilous plants (Linum austriacum type, Teucrium montanum, Trifolium alpestre) are absent from the Late-Glacial list, whilst the Late-Glacial flora (see IVERSEN l. c.) contained a number of basiphilous species, which are not represented in the present material with primary finds (i. a. Dryas octopetala, Helianthemum nummularium, Salix polaris, S. reticulata, Saxifraga aizoides, S. hirculus, S. oppositifolia, Silene acaulis, and the aquatics Ceratophyllum demersum, Myriophyllum verticillatum, Potamogeton filiformis). This suggests that the mineral soil produced by the solifluction in zone W 2 may have been poorer in lime than the raw boulder clays from the LateGlacial. This is also suggested by the fact that Isoëtes echinospora, I. lacustris and Myriophyllum alterniflorum were rather common in the lakes from the zones W 1-3, and only one basiphilous species (Myriophyllum spicatum) was represented. During the Late-Glacial the Isoëtes species and Myriophyllum alterniflorum did not occur, or they were exceedingly rare in the lakes from the glaciated part of Denmark, due to competition from more demanding and rapidly growing aquatic plants.

50 genera or species of heliophytes and plants from open habitats were identified in the present material. 40 of these plants re-appear in the Late-Glacial list. This suggests that the pioneer floras from the early and the late Weichselian Glacial were alike. Their relationship to present-day vegetation types on unstable soils was pointed out by Iversen (1. c.) and above (p. 92). Truly aretic-alpine species were rare, as in the Late-Glacial. 
Table 23. Flora list.

Flora liste.

W: Pollen probably transported from long distance

*: Species identification fairly reliable reliable
( ): All remains likely to be secondary

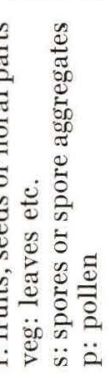

B: Brørup Hotel Bog

R: Rodebæk I

$\mathrm{H}$ : Herning.

$\mathrm{N}$ : Norbølling

+ : certainly primary find

+ : probably primary find

$(+)$ : probably secondary find

$[+]$ : certainly secondary find

\begin{tabular}{|c|c|c|c|c|}
\hline W 1 & W 2 & W 3 & W 4 & W 5 \\
\hline R H & B $\mathrm{R} \quad \mathrm{H}$ & B H & $\mathrm{N}$ & B \\
\hline
\end{tabular}

\section{PTERIDOPHYTA}

(Azollaceae)

(Azolla filiculoides Lam.)

Isoëtaceae

Isoëtes echinospora

$$
\text { lacustris }
$$

\section{Lycopodiaceae}

Lycopodium alpinum-complanatum ..... . annotinum .............. clavatum.............. complanatum ssp. cham. ... inundatum ............. selago .....................

Ophioglossaceae

Botrychium lunaria................

Ophioglossum vulgatum . . . . . . . . . . (Osmundaceae)

(Osmunda ef. cinnamomea L.). . . . . . . . ( regalis)

\section{Polypodiaceae}

Polypodium vulgare.

Pteridium aquilinum

Thelypteris dryopteris. . . . . . . . . . . . palustris type.............

Selaginellaceae

Selaginella selaginoides.

\section{GYMNOSPERMAE}

Cupressaceae

Juniperus communis

Ephedraceae

Ephedra distachya L...............

cf. strobilacea Bunge. .........

\section{Pinaceae}

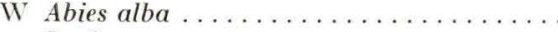

Larix sp. . . . . . . . . . . . . . . . .

Picea abies.....................

omoricoides Weber............

Pinus silvestris..................

Taxaceae

W Taxus baccata..................

\section{ANGIOSPERMAE}

(Aceraceae)

$$
\text { (Acer campestre) }
$$

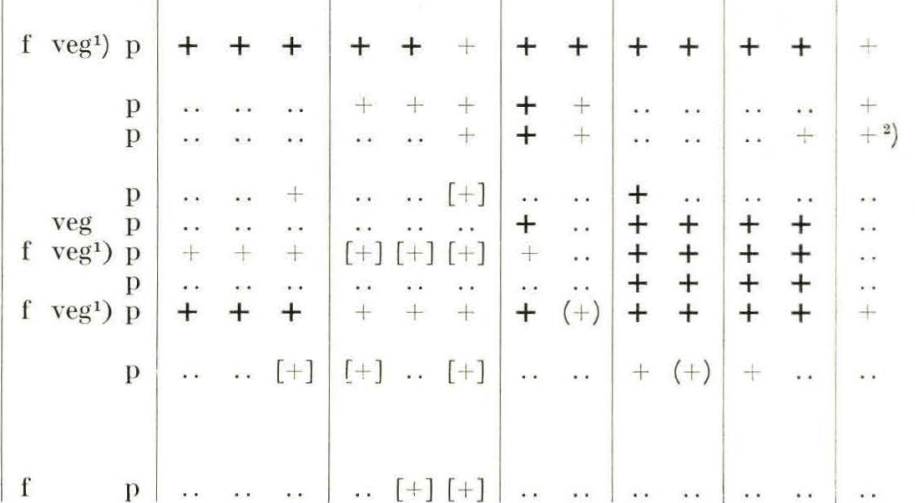




\begin{tabular}{|c|c|c|c|c|c|c|c|c|c|c|c|c|c|c|c|}
\hline & & & \multicolumn{3}{|c|}{ W 1} & \multicolumn{3}{|c|}{ W 2} & \multicolumn{2}{|c|}{ W 3} & \multicolumn{2}{|c|}{ W 4} & \multicolumn{2}{|c|}{ W 5} & \\
\hline (Aquifoliaceae) & & & & & & & & & & & & & & & \\
\hline $\begin{array}{l}\text { (Ilex aquifolium) } \ldots \ldots \ldots \ldots \ldots \ldots \ldots \\
\text { Alismaceae }\end{array}$ & & $\mathrm{p}$ & $(+)$ & {$[+]$} & {$[+]$} & & {$[+]$} & {$[+]$} & & {$[+]$} & .. & . & $(+)$ & . & . \\
\hline $\begin{array}{l}\text { Elisma natans................... } \\
\text { (Araliaceae) }\end{array}$ & f & $\mathrm{p}$ & .. & .. & .. & + & .. & & + & + & .. & .. & .. & .. & .. \\
\hline $\begin{array}{l}(\text { Hedera helix) } \ldots \ldots \ldots \ldots \ldots \ldots \ldots \ldots \\
\text { (Balsaminaceae) }\end{array}$ & & $\mathrm{p}$ & .. & . & .. & {$[+]$} & .. & {$[+]$} &.. & .. & .. & . & .. & . & .. \\
\hline $\begin{array}{l}\text { (Impatiens sp.) } \ldots \ldots \ldots \ldots \ldots \ldots \ldots \ldots \\
\text { Betulaceae }\end{array}$ & & $\mathrm{p}$ & .. & . & .. & .. & .. & {$[+]$} & .. & . & .. & .. & .. & .. & .. \\
\hline W Alnus glutinosa . . . . . . . . . . . . ** & $\left.\mathbf{f}^{1}\right)$ & $\mathrm{p}$ & + & {$[+]$} & + & {$[+]$} & {$[+]$} & {$[+]$} & + & {$[+]$} & + & + & + & + & .. \\
\hline Betula nana....................** & f $\left.\operatorname{veg}^{1}\right)$ & $\mathrm{p}$ & + & + & . & + & + & + & + & + & + & . & + & .. & + \\
\hline 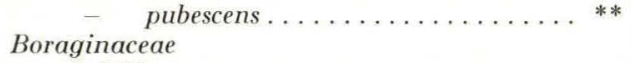 & f & $\mathrm{p}$ & + & + & .. & + & + & + & + & + & + & + & + & + & + \\
\hline cf. Lithospermum arvense. . . . . . . . . . & & $\mathrm{p}$ & $\cdots$ & . & .. & + & .. & & $\ldots$ & . & .. & . &.. & .. & . \\
\hline $\begin{array}{l}\text { Symphytum sp....................... } \\
\text { (Buxaceae) }\end{array}$ & & $\mathrm{p}$ & .. & .. & .. & .. & .. & .. & .. & .. & + & .. & .. & .. & .. \\
\hline $\begin{array}{l}\text { (Buxus sempervirens) } \ldots \ldots \ldots \ldots \ldots \ldots \\
\text { Callitrichaceae }\end{array}$ & & $\mathrm{p}$ & .. & {$[+]$} & {$[+]$} & .. & .. & .. & .. & . & . & .. & .. & .. & .. \\
\hline $\begin{array}{l}\text { Callitriche sp. } \ldots \ldots \ldots \ldots \ldots \ldots \ldots \ldots \\
\text { Campanulaceae }\end{array}$ & & $\mathrm{p}$ & . & .. & .. & + & .. & .. & + & + & .. & .. & .. & . & + \\
\hline Campanula sp. ................. & & $\mathrm{p}$ & + & + & .. & + & + & t & + & + & . & .. &.. & .. & + \\
\hline $\begin{array}{l}\text { Jasione montana. . . . . . . . . . . . } \\
\text { Caprifoliaceae }\end{array}$ & & $\mathrm{p}$ & .. & .. & .. & + & .. & .. & .. & .. & + & .. & .. & .. & + \\
\hline Linnaea borealis . . . . . . . . . . . . . & & $\mathrm{p}$ & $\ldots$ & . & .. & .. & .. & & $\ldots$ & . & . & + &.. & .. & .. \\
\hline (Lonicera periclymenum) ............ * & & $\mathrm{P}$ & . & . & .. & .. & .. & {$[+]$} & .. & . & .. & .. & .. & .. & .. \\
\hline$-\quad x y l o s t e u m \ldots \ldots \ldots \ldots \ldots \ldots$ & & $\mathrm{p}$ & .. & .. & . & .. & .. & & + & .. & .. & + & .. & .. & . \\
\hline (Sambucus nigra) ................ ** & $\left.f^{1}\right)$ & & .. & .. & .. & .. & .. & {$[+]$} & .. & .. & .. & . & .. & . & .. \\
\hline $\begin{array}{l}\text { (Viburnum opulus) } \ldots \ldots \ldots \ldots \ldots \ldots \ldots \\
\text { Caryophyllaceae }\end{array}$ & & $\mathrm{p}$ & . & . & .. & .. & .. I & {$[+]$} & .. & .. & .. & . & .. & . & .. \\
\hline Dianthus sp. ............... & & $\mathrm{p}$ & $\ldots$ & . & . & .. & .. & . & + & . & . & . &.. & . & . \\
\hline Gypsophila sp................ & & $\mathrm{p}$ & .. & . & .. & + & + & + & .. & . & .. & .. & .. & .. & + \\
\hline Melandrium sp............... & & $\mathrm{p}$ & .. & + & .. & .. & .. & $\cdots$ & .. &.. & .. & .. & .. & .. & .. \\
\hline Sagina nodosa................. * & & $\mathrm{p}$ & .. & . & .. & + & .. & .. & .. & .. & .. & .. & .. & . & .. \\
\hline Scleranthus perennis............... ** & $\left.f^{1}\right)$ & $\mathrm{p}$ & .. & .. & & + & .. & & .. & .. & .. & .. & .. & .. & . \\
\hline (Stellaria holostea) ................. ** & & $\mathrm{p}$ & $(+)$ & {$[+]$} & {$[+]$} & $(+)$ & .. I & {$[+]$} & .. & .. & .. & .. & .. & .. & . \\
\hline cf. Vaccaria pyramidata............ & & $\mathrm{p}$ & .. & .. & .. & .. & .. & .. & + & .. & .. & . & .. & .. & . \\
\hline 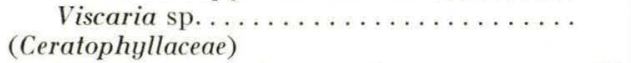 & & $\mathrm{p}$ & .. & .. & .. & + & .. &.. & .. & .. & .. & . & .. & . & + \\
\hline (Ceratophyllum demersum) ...........*** & $\left.\mathrm{f}^{1}\right)$ & & & $\cdots$ & .. & . & .. & {$[+]$} & $\because$ & . & $\because$ & .. & . & .. & + \\
\hline $\begin{array}{l}\text { Chenopodiaceae } \ldots \ldots \ldots \ldots \ldots \ldots \ldots \ldots \\
\text { Cistaceae }\end{array}$ & & $\mathrm{p}$ & + & + & + & + & .. & + & + & + & + & .. & + & .. & + \\
\hline $\begin{array}{l}\text { Helianthemum oelandicum type......... } \\
\text { Compositae }\end{array}$ & & $\mathrm{p}$ & $\ldots$ & . & .. & + & .. & .. & + & + & .. & . & .. & .. & + \\
\hline Artemisia sp. . & & $\mathrm{p}$ & + & + & + & + & + & + & + & + & + & + & + & + & + \\
\hline Cirsium & & $\mathrm{p}$ & .. & .. & + & .. & .. & + & .. & .. & .. & .. & + & .. & + \\
\hline Centaurea scabiosa & & $\mathrm{p}$ & .. & . & .. & .. & + & & .. & .. & .. & . & .. & .. & + \\
\hline $\begin{array}{l}(\text { Hypochoeris radicata }) \ldots \ldots \ldots \ldots \ldots \ldots \text { * } \ldots * \\
\text { Corylaceae }\end{array}$ & $\left.\mathbf{f}^{1}\right)$ & & . & & .. & .. & .. & $(+)$ & .. & .. & .. & .. &.$\cdot$ & .. & .. \\
\hline W Carpinus betulus . . . . . . . & $\left.\mathbf{f}^{1}\right)$ & $\mathrm{p}$ & + & $(+)$ & $(+)$ & {$[+]$} & {$[+]$} & {$[+]$} & + & {$[+]$} & + & + & + & + & . \\
\hline $\begin{array}{l}\text { W Corylus avellana .................. } \\
\text { Crassulaceae }\end{array}$ & $\left.\mathbf{f}^{1}\right)$ & $\mathrm{p}$ & + & $(+)$ & $(+)$ & {$[+]$} & {$[+]$} & {$[+]$} & + & {$[+]$} & + & + & + & + & .. \\
\hline $\begin{array}{c}\text { Sedum sp. . . . . . . } \\
\text { Cyperaceae }\end{array}$ & & $\mathrm{p}$ & $\ldots$ & . & .. & + & . & + & .. & .. & .. & . & .. & .. & + \\
\hline Carex caespitosa & $\left.f^{1}\right)$ & & $\ldots$ & + & .. & .. & + & & $\cdots$ & . & .. & . &.. & .. & . \\
\hline - lasiocarpa & $\left.f^{1}\right)$ & & . & .. & .. & . & .. & $(+)$ & + & . & + & .. & .. & .. & . \\
\hline ( - pseudocyperus)... & $\left.\mathbf{f}^{1}\right)$ & & .. & . & .. & . & $(+)$ & $(t)$ & .. & . & .. & .. & .. & .. & . \\
\hline - rostrata........ & $\left.\mathbf{f}^{1}\right)$ & & . & . & .. & . & .. & $(+)$ & + & . & + & .. & .. & .. & + \\
\hline$(-\quad$ vesicaria $) \ldots \ldots \ldots \ldots \ldots \ldots \ldots \ldots \ldots$ & $\left.f^{1}\right)$ & & .. & . & .. & .. & .. & $(+)$ & .. & .. & .. & . &.$\cdot$ & .. & + \\
\hline
\end{tabular}




\begin{tabular}{|c|c|c|c|c|c|c|c|c|c|c|c|c|c|c|c|c|}
\hline & & & & & W 1 & & & W 2 & & W & 3 & W & 4 & W & & \\
\hline & & & & $\mathrm{B}$ & $\mathrm{R}$ & $\mathrm{H}$ & $\mathrm{B}$ & $\mathrm{R}$ & $\mathrm{H}$ & $\mathrm{B}$ & $\mathrm{H}$ & $\mathrm{B}$ & $\mathrm{N}$ & & $\mathrm{N}$ & \\
\hline (Cladium mariscus). & $* *$ & $\left.\mathrm{f}^{1}\right)$ & & .. & . & $\ldots$ & .. & $\ldots$ & {$[+]$} & . & .. & .. & $\ldots$ & . & .. & .. \\
\hline (Dulichium arundinaceum (L.) Britt.). ... " & $* *$ & $\left.\mathrm{f}^{1}\right)$ & & .. & . & .. & .. & .. & {$[+]$} & .. & .. & .. & .. & .. & .. & .. \\
\hline Eriophorum vaginatum. ........... & $* *$ & veg & & .. & + & .. & .. & .. & & .. & . & .. & . & + & .. & + \\
\hline (Scirpus lacustris) $\ldots \ldots \ldots \ldots \ldots \ldots$ & $* *$ & $\left.\mathrm{f}^{1}\right)$ & & .. & .. & .. & .. & .. & {$[+]$} & .. & . & .. & .. & . & .. & + \\
\hline Droseraceae & & & & & & & & & & & & & & & & \\
\hline Drosera anglica-rotundifolia........... & & & $\mathrm{p}$ & .. & .. & . & . & + & + & .. & .. & . & + & . & $\ldots$ & .. \\
\hline $\begin{array}{l}-\quad \text { intermedia } \ldots \ldots \ldots \ldots \ldots \ldots \ldots \\
\text { Elaeagnaceae }\end{array}$ & $*$ & & $\mathrm{p}$ & . & .. & . & .. & + & .. & .. & . & . & . & . & .. & .. \\
\hline $\begin{array}{l}\text { Hippophaë rhamnoides.............. } \\
\text { Empetraceae }\end{array}$ & & & $\mathrm{p}$ & .. & .. & . & .. & + & . & + & + & . & . & . & . & + \\
\hline Empetrum hermaphroditum . . . . . . . . . & $* *$ & & $\mathrm{p}$ & + & + & $\ldots$ & + & + & & + & .. & $\ldots$ & $\ldots$ & + & .. & $\ldots$ \\
\hline - nigrum.............. & ** & $\mathrm{f}$ & $\mathrm{p}$ & + & + & + & + & + & $(+)$ & + & {$[+]$} & + & + & + & + & \\
\hline Ericaceae & & & & & & & & & & & & & & & & \\
\hline Andromeda polifolia .............. & $* *$ & $\left.f^{1}\right)$ & & + & . & .. & . & .. & .. & .. & .. & .. & . & . & .. & $\ldots$ \\
\hline Arctostaphylos alpina ............. & * & & $\mathrm{p}$ & .. & + & .. & .. & .. & & .. & .. & .. & . & . & .. & + \\
\hline$-\quad$ uva-ursi........... & $* *$ & $\left.f^{1}\right)$ & $\mathrm{p}$ & + & + & + & + & + & $(+)$ & + & {$[+]$} & + & + & + & + & + \\
\hline Calluna vulgaris ................. & & & $\mathrm{p}$ & + & + & + & $(+)$ & $(+)$ & $(+)$ & + & {$[+]$} & + & + & + & + & + \\
\hline Cassiope hypnoides . ............... & & & $\mathrm{p}$ & . & .. & .. & + & & & .. & . & .. & . & . & .. & .. \\
\hline 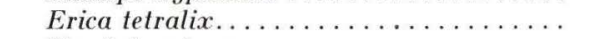 & * & & $\mathrm{p}$ & .. & $(+)$ & .. & & $(+)$ & $(+)$ & .. & .. & + & . & + & .. & .. \\
\hline Vaccinium type ................ & & & $\mathrm{p}$ & + & + & .. & $(+)$ & + & $(+)$ & + & .. & + & .. & + & + & + \\
\hline Euphorbiaceae & & & & & & & & & & & & & & & & \\
\hline $\begin{array}{l}\text { Mercurialis perennis . . . . . . . } \\
\text { (Fagaceae) }\end{array}$ & $* *$ & & $\mathrm{p}$ & .. & .. & .. & $(+)$ & $(+)$ & .. & + & .. & .. & + & + & .. & .. \\
\hline (Fagus silvatica) . . . . . . . . . . & & & $\mathrm{p}$ & .. & & & & & {$[+]$} & .. & & . & .. & $\ldots$ & $\ldots$ & .. \\
\hline $\begin{array}{l}\text { W Quercus robur .................................. } \\
\text { Gentianaceae }\end{array}$ & $* *$ & $\left.\mathrm{f}^{1}\right)$ & $\mathrm{p}$ & + & $(+)($ & $(+)$ & {$[+]$} & {$[+]$} & {$[+]$} & + & {$[+]$} & + & + & + & + & .. \\
\hline Gentiana pneumonanthe............. & * & & $\mathrm{p}$ & .. & $\therefore$ & .. & + & & .. & .. & .. & . & .. & . & $\cdots$ & + \\
\hline Gentianella amarella type............ & & & $\mathrm{p}$ & .. & $(+)$ & .. & + & $(+)$ & + & + & .. & .. & . & . & . & + \\
\hline $\begin{array}{l}\text { Swertia perenne L. . . . . . . . . . . . . } \\
\text { Geraniaceae }\end{array}$ & & & $\mathrm{p}$ & . & .. & . & + & .. & .. & .. & .. & . & .. & . & .. & + \\
\hline $\begin{array}{c}\text { Geranium sp. } \ldots \ldots \ldots \ldots \ldots \ldots \ldots \ldots \\
\text { Haloragaceae }\end{array}$ & & & $\mathrm{p}$ & .. & + & .. & $(+)$ & .. & .. & + & .. & + & .. & .. & .. & + \\
\hline Myriophyllum alterniflorum . . . . . . . . . & ** & $\left.\mathrm{f}^{1}\right)$ & $\mathrm{p}$ & + & + & + & + & + & + & + & + & $\ldots$ & + & $\ldots$ & .. & + \\
\hline - $\quad$ spicatum & $* *$ & $\left.\mathrm{f}^{1}\right)$ & $\mathrm{p}$ & .. & .. & .. & + & + & + & .. & ... & .. & $(+)$ & .. & .. & + \\
\hline 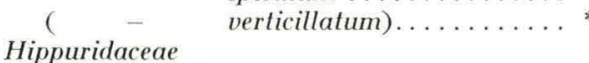 & $* *$ & $\left.\mathrm{f}^{1}\right)$ & $\mathrm{p}$ & .. & $(+)$ & .. & . & .. & {$[+]$} & .. & .. & .. & $(+)$ & .. & .. & + \\
\hline $\begin{array}{l}\text { Hippuris vulgaris } \ldots \ldots \ldots \ldots \ldots \ldots \ldots \\
\text { Labiatae }\end{array}$ & * & $\left.f^{1}\right)$ & $\mathrm{p}$ & .. & .. & .. & .. & .. & + & + & + & .. & .. & .. & .. & + \\
\hline$\ldots \ldots \ldots \ldots \ldots$ & ** & $\left.\mathrm{f}^{1}\right)$ & & .. & .. & .. & {$[+]$} & .. & {$[+]$} & .. & .. & $\ldots$ & . & .. & .. & $\ldots$ \\
\hline Mentha type $\ldots \ldots \ldots \ldots \ldots \ldots$ & & & $\mathrm{p}$ & .. & + & .. & + & .. & . & + & .. & .. & .. & .. & .. & + \\
\hline Teucrium montanum. . . . . . . . . . & * & & $\mathrm{p}$ & .. & . & . & .. & + & . & .. & $\ldots$ & .. & .. & . & . & .. \\
\hline Anthyllis vulneraria $\ldots \ldots \ldots \ldots \ldots \ldots$ & & & $\mathrm{p}$ & $\ldots$ & .. & $\ldots$ & + & + & .. & .. & .. & $\ldots$ & $\ldots$ & $\ldots$ & .. & + \\
\hline Astragalus alpinus. .............. & * & & $\mathrm{p}$ & .. & .. & .. & + & .. & .. & + & .. & .. & .. & . & .. & + \\
\hline - $\quad$ campestris type $\ldots \ldots \ldots \ldots \ldots$ & & & $\mathrm{p}$ & .. & .. & .. & + & .. & .. & + & .. & .. & .. & .. & .. & + \\
\hline danicus $\ldots \ldots \ldots \ldots \ldots \ldots$ & * & & $\mathrm{p}$ & .. & .. & .. & + & .. & .. & .. & .. & .. & .. & .. & .. & + \\
\hline$-\quad$ frigidus ............... & * & & $\mathrm{p}$ & .. & .. & .. & + & . & .. & .. & + & .. & $\cdots$ & .. & .. & + \\
\hline Cytisus nigricans................ & & & $\mathrm{p}$ & .. & .. & .. & + & .. & . & .. & .. & $\ldots$ & .. & . & .. & .. \\
\hline Genista sp.. & & & $\mathrm{p}$ & + & . & .. & .. & .. & .. & .. & .. & .. & .. & + & .. & .. \\
\hline Lotus ef. corniculatus . . . . . . . . . . . & & & $\mathrm{p}$ & .. & .. & .. & + & .. & + & + & + & .. & .. & .. & + & + \\
\hline Trifolium alpestre ................ & . & & $\mathrm{p}$ & .. & .. & .. & + & .. & .. & .. & + & .. & .. & .. & .. & .. \\
\hline arvense ......... & * & & $\mathrm{p}$ & .. & . & .. & + & .. & .. & + & .. & $\ldots$ & .. & .. & .. & .. \\
\hline $\begin{array}{l}\text { Vicia-Lathyrus } \ldots \ldots \ldots \ldots \ldots \ldots \ldots \ldots \\
\text { Liliaceae }\end{array}$ & & & $\mathrm{p}$ & .. & .. & + & + & .. & + & + & .. & .. & . & .. & .. & .. \\
\hline $\begin{array}{l}\text { Allium cf. schoenoprasum............. } \\
\text { Linaceae }\end{array}$ & & & $\mathrm{p}$ & .. & .. & .. & + & .. & .. & + & + & .. & .. & .. & .. & + \\
\hline $\begin{array}{l}\text { Linum austriacum type ... } \\
\text { Lobeliaceae }\end{array}$ & & & $\mathrm{P}$ & .. & . & .. & + & .. & .. & .. & .. & .. & .. & . & . & .. \\
\hline Lobelia dortmanna ............... & & & $\mathrm{p}$ & $\ldots$ & .. & .. & $\ldots$ & .. & . & + & $\ldots$ & $\ldots$ & .. & .. & . & .. \\
\hline
\end{tabular}




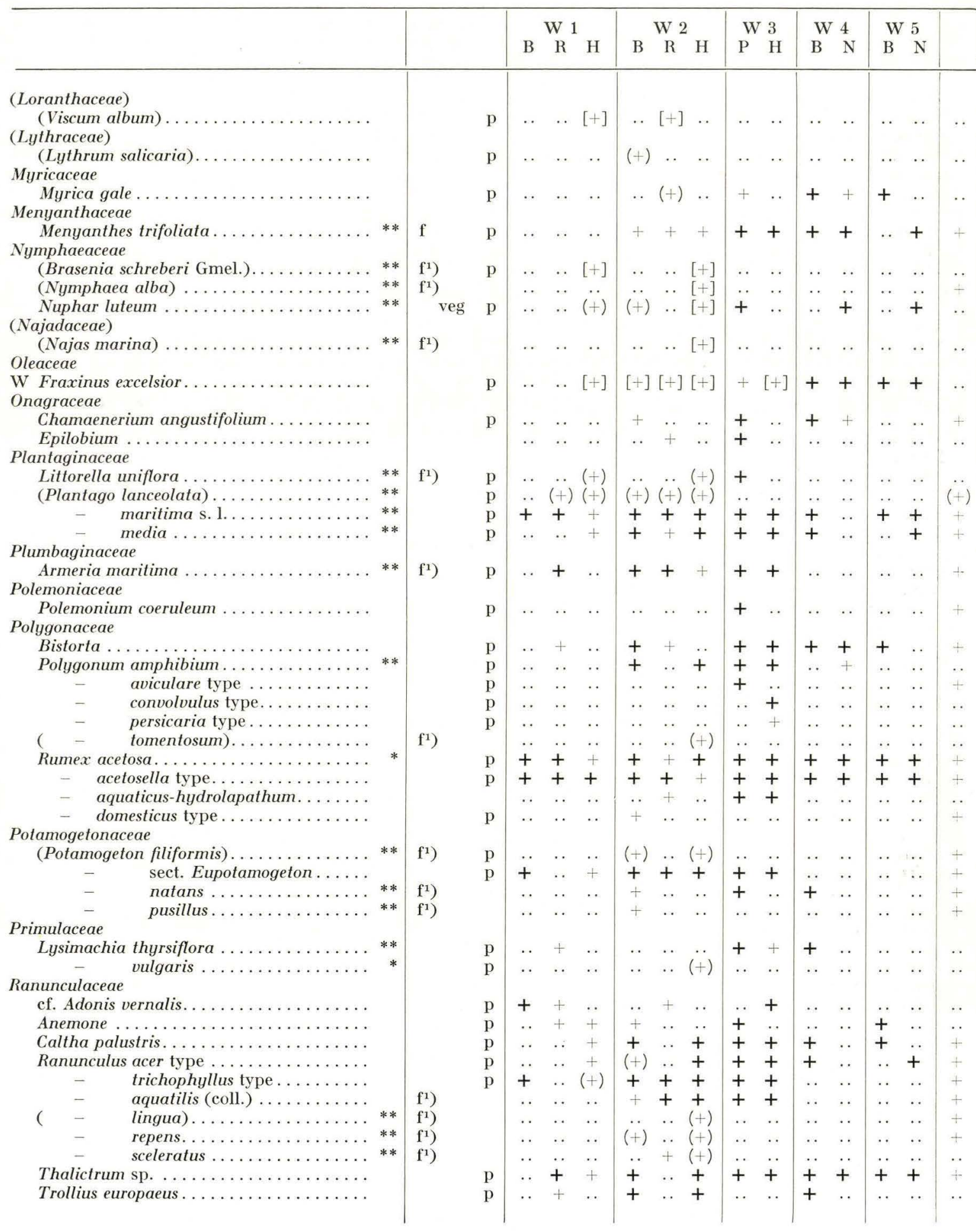




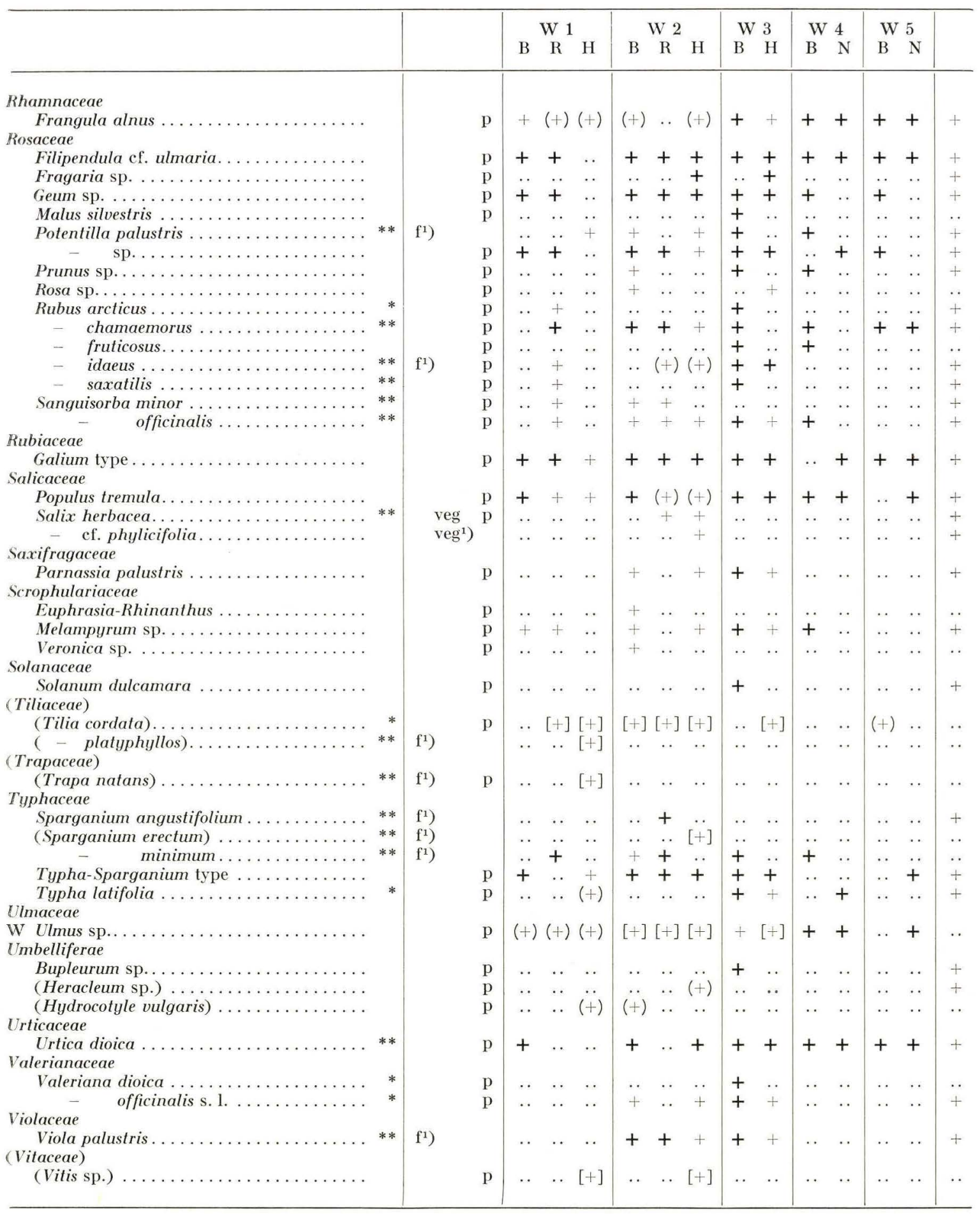

1) According to Jessen and Milthers (1928).

2) cp. p. 22 . 


\section{CLIMATE AND CHRONOLOGY OF THE EARLY WEICHSELIAN GLACIAL IN WESTERN JUTLAND}

\section{Terminology}

The geologic phenomena of the Pleistocene present a multitude of variations, and as most of them may be compared with present-day parallels in a detailed manner, studies of the Pleistocene lead almost inevitably to conclusions as to the palaeoenvironment, especially as to the former climatic conditions. Palaeoclimatic conclusions do not ordinarily form a basis for stratigraphic divisions (HEDBERG 1954). However, the Pleistocene climatic changes were of a large amplitude, and the interpretations as to climatic change are in many cases rather safe. The stratigraphic evidence, moraine stages and till sequences, river terrace systems, löss profiles, cave deposits, beach lines, invertebrate and vertebrate palaeontology, and vegetational history, present a multitude of divisions of litho-stratigraphic or bio-stratigraphic nature, but very few local sequences represent a complete development. Hence, the only hope for a common chrono-stratigraphy relies on climatic change (cp. VAN DER VLERK 1959).

Palaeobotanical evidence may be useful for a distinction of Pleistocene stratigraphic units. As discussed in chapter I, J\&M and later Gams, Woldstedt, van der Vlerk, FlorschüTz, and other authors have pointed out, that the vegetational successions may be important for a distinction of late Pleistocene interglacials. Features of the vegetational developments may also be useful for a delimitation of glacials and interglacials. Thus glacials in Northern Europe may be characterized by occurrence of non-forest vegetation in the peri-glacial area (SELle $1953 \mathrm{a}, Z_{\text {AGwiJn } 1957 \mathrm{a}, 1960 \text {, ANdersen }}$ 1957), and interglacials by successions of temperate forest stages. ZaGwiJn (l. c.) has shown that similar principles may also be applied to early Pleistocene stratigraphic units. However, the stages of the vegetational history represent bio-stratigraphic units. Their limits may not always coincide exactly in a wide area, and the dominant vegetation may not always express the climate exactly.

It may be preferred, accordingly, to delimit the time units of the Pleistocene by climatic change (cp. Woldstedt 1953, $1954 \mathrm{a}$ and b, 1958, Flint 1957, van der Vlerk 1957, 1959, Gross 1958, Andersen, de Vries and ZaGWIJn 1960). The glacials and the interglacials may be considered the main stages of the Pleistocene. The interglacial stages contain characteristic long-time progressive vegetational successions. They are delimited by relatively large climatic changes, and are separated by the glacial stages.

Stadials and interstadials may be considered to be substages within the glacial stages. The interstadial substages constitute minor warm intervals within the glacial stages (cp. J\&M 1928, p. 376).

At present the following main stages have been recognized in Northern Europe (ZaGWidn 1957 a, 1960, van der Vlerk 1957, 1959, ZonNeveld 1957), 


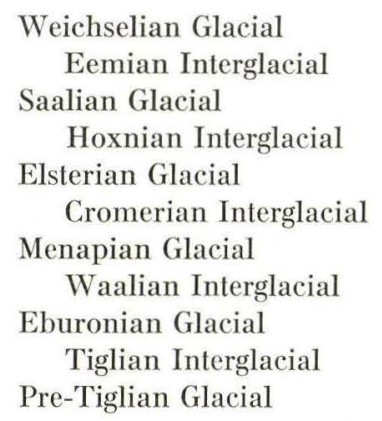

These stages may be distinguished lithologically or palaeontologically, and their limits may be assumed to correspond roughly to major climatic changes.

The Weichselian Glacial may be considered to be the lapse of time which separated the Eemian Interglacial from the Postglacial (cp. Andersen, de Vries and Zagwisn 1960). The Late-Glacial is now usually included in that Glacial (VAN DER VLERK and Florschütz 1950, 1953, van der Hammen 1952, Selle 1953 a, Woldstedt 1956 , Gross 1956, 1958), and the upper limit of the Weichselian Glacial is, accordingly, the fini-glacial temperature rise in Scandinavia, which corresponded to the end of the last major advance of the Scandinavian ice sheet. In the vegetational history of Northern Europe that limit corresponded to the transition pollen zone III to IV in Scandinavia and the Netherlands (Donner 1951, Iversen 1953, van der Hammen 1957), at which point of time forest vegetation became dominant, and the long-time progressive succession of forest stages of the Postglacial was initiated. However, the zone border may be slightly younger than the main temperature rise (VAN DER HAMMEN 1951, Iversen 1954). The radiocarbon age of the zone border is 10300 years before present (IvERSEN 1953, Anderson, Levi and Tauber 1953, de Vries, Barendsen and Waterbolk 1958, Godwin and WiLLis 1959).

Below, the lower limit of the Weichselian Glacial, and a subdivision of its early part in Western Jutland will be discussed in more detail.

\section{Temperature}

A summary of the stages of the vegetational history and the climatic development of the post-Eemian sequences mentioned in the present study is shown in table 24 (see also chapter V).

As mentioned on p. 80 , it is desirable to know the temperatures of the whole year. Winter temperatures could hardly be determined very well in the present cases. However, as the climate of the intervals studied seems to have been generally rather oceanic, it may be assumed that the length of the vegetative season varied with the temperature for the warmest month. Whereas the trends of the changes in summer temperature may be detected with a good degree of certainty, average temperatures may only be inferred from the biological data with some doubt, although they are suggested by various sources, and they should be considered to be interpretations rather than facts (see also p. 80).

A major decrease in the summer temperature initiated in the late Eemian Interglacial. It continued at the transition subzone W $2 \mathrm{a}-\mathrm{b}$, and a minimum was reached in subzone W $2 \mathrm{~b}$. It appears that this entire development was gradual. It is not possible to say exactly how low the summer temperature became, but there are reasons to believe that the average July temperature was considerably lower than $10^{\circ} \mathrm{C}$ in subzone $\mathrm{W} 2 \mathrm{~b}$. 
Table 24. $\mathrm{B}=$ Brørup Hotel Bog. $\mathrm{R}=$ Rodebæk I. $\mathrm{H}=$ Herning. $\mathrm{N}=$ Nørbølling. (Tabellen er gengivet paa dansk paa side 160).

\begin{tabular}{|c|c|c|c|c|c|c|c|}
\hline \multicolumn{3}{|r|}{ Bio-stratigraphy } & \multirow[b]{2}{*}{ Soil } & \multirow{2}{*}{$\begin{array}{l}\text { July } \\
\text { temp. }\end{array}$} & \multirow{2}{*}{$\begin{array}{l}\text { Local water } \\
\text { level }\end{array}$} & \multicolumn{2}{|c|}{ Local chronology } \\
\hline \multicolumn{2}{|c|}{ Zones } & Vegetation & & & & Substages & $\begin{array}{l}\text { Main } \\
\text { stages }\end{array}$ \\
\hline \multicolumn{2}{|c|}{$W x$} & $\begin{array}{l}\text { Betula pubescens? B. nana, } \\
\text { Juniperus, herbs }\end{array}$ & Soil erosion & $10-12^{\circ}$ & $\begin{array}{l}\text { Rising water } \\
\text { level (B) }\end{array}$ & & \multirow{17}{*}{$\begin{array}{l}\text { Weich- } \\
\text { selian } \\
\text { Glacial }\end{array}$} \\
\hline \multicolumn{6}{|c|}{ Hiatus } & \multirow{11}{*}{$\begin{array}{l}\text { Brorup } \\
\text { Inter- } \\
\text { stadial }\end{array}$} & \\
\hline \multirow{3}{*}{ W 5} & $\mathrm{c}$ & \multirow{3}{*}{$\begin{array}{l}\text { Forests of Pinus, Picea, Betula pubesc- } \\
\text { ens, Larix, Frangula. } \\
\text { Calluna, Empetrum. }\end{array}$} & \multirow{3}{*}{$\begin{array}{l}\text { Acid humus } \\
\text { layer prevalent }\end{array}$} & $13-15^{\circ}$ & $\begin{array}{l}\text { Low water level } \\
\text { (B) }\end{array}$ & & \\
\hline & $\mathrm{b}$ & & & Ca. $13^{\circ}$ ? & $\begin{array}{l}\text { Slightly higher } \\
\text { water level (B) }\end{array}$ & & \\
\hline & a & & & $13-15^{\circ}$ & $\begin{array}{l}\text { Low water } \\
\text { level }(B, N)\end{array}$ & & \\
\hline \multicolumn{2}{|c|}{ W 4} & $\begin{array}{l}\text { Forests of Betula pubescens, Picea, Larix, } \\
\text { Frangula. Pinus increasing }\end{array}$ & $\begin{array}{l}\text { Acid humus } \\
\text { layer increasing }\end{array}$ & $13-15^{\circ}$ & $\begin{array}{l}\text { Low water level } \\
\text { (B) }\end{array}$ & & \\
\hline \multirow{5}{*}{ W 3} & e & $\begin{array}{l}\text { Forests of Betula pubescens, Populus, } \\
\text { Larix, Frangula. B. nana, Juniperus } \\
\text { and herbs common. Calluna increasing }\end{array}$ & $\begin{array}{l}\text { Increasing devel- } \\
\text { opment of acid } \\
\text { humus layer }\end{array}$ & $13-15^{\circ}$ & $\begin{array}{l}\text { Low water level } \\
\text { (B) }\end{array}$ & & \\
\hline & $\mathrm{d}$ & Tree vegetation more open & $\overline{\text { Slight erosion }}$ & Ca. $12^{\circ}$ & $\begin{array}{l}\text { Rise of water } \\
\text { level (B) }\end{array}$ & & \\
\hline & $\mathrm{c}$ & $\begin{array}{l}\text { Forests of Betula pubescens, Populus. } \\
\text { B. nana, Juniperus and herbs common }\end{array}$ & $\begin{array}{l}\text { Stabilization } \\
\text { Humus forma- } \\
\text { tion }\end{array}$ & $13-15^{\circ}$ & $\begin{array}{l}\text { Low water level } \\
\text { (B) }\end{array}$ & & \\
\hline & $\mathrm{b}$ & Tree vegetation more open & Slight erosion & Ca. $12^{\circ}$ & $\begin{array}{l}\text { Rise of water } \\
\text { level }(B, H)\end{array}$ & & \\
\hline & a & $\begin{array}{l}\text { Forests of Betula pubescens, Populus. } \\
\text { Betula nana and herbs common }\end{array}$ & $\begin{array}{l}\text { Stabilization } \\
\text { Humus } \\
\text { formation }\end{array}$ & Ca. $13^{\circ}$ & $\begin{array}{l}\text { Low water level } \\
(\mathrm{B}, \mathrm{H})\end{array}$ & & \\
\hline \multirow{5}{*}{ W 2} & e & $\begin{array}{l}\text { Betula nana and herbaceous vegetation } \\
\text { prevalent. Betula pubescens and Populus } \\
\text { present }\end{array}$ & $\begin{array}{l}\text { Stabilization } \\
\text { Raw soil. Initial } \\
\text { humus forma- } \\
\text { tion }\end{array}$ & $\begin{array}{l}\text { In- } \\
\text { creasing. } \\
\text { Ca. } 12^{\circ}\end{array}$ & \multirow[t]{2}{*}{ High water level } & & \\
\hline & d & Bare solifluction areas widespread & $\begin{array}{l}\text { Slope wash and } \\
\text { solifluction }\end{array}$ & $<10^{\circ}$ & & & \\
\hline & $\mathrm{c}$ & $\begin{array}{l}\text { Betula nana, Juniperus and herbaceous } \\
\text { vegetation prevalent }\end{array}$ & $\begin{array}{l}\text { Stabilization } \\
\text { Raw soil }\end{array}$ & $10-12^{\circ}$ & $\begin{array}{l}\text { Low water level } \\
\text { (R) }\end{array}$ & $\begin{array}{l}\begin{array}{l}\text { Rodebæk } \\
\text { Inter- } \\
\text { stadial }\end{array} \\
\end{array}$ & \\
\hline & $\mathrm{b}$ & Bare solifluction areas widespread & $\begin{array}{l}\text { Slope wash and } \\
\text { solifluction }\end{array}$ & $<10^{\circ}$ & \multirow[b]{2}{*}{ High water level } & & \\
\hline & a & $\begin{array}{l}\text { Betula nana, Juniperus and herbaceous } \\
\text { vegetation prevalent }\end{array}$ & $\begin{array}{l}\text { Increasing } \\
\text { soil erosion }\end{array}$ & $10-12^{\circ}$ & & & \\
\hline \multicolumn{2}{|c|}{ W 1} & $\begin{array}{l}\text { Scaltered individuals of Pinus, Picea, } \\
\text { Betula pubescens. Heath with Juniperus, } \\
\text { B. nana, Calluna, Empetrum. Herbs } \\
\text { common }\end{array}$ & $\begin{array}{l}\text { Acid humus } \\
\text { layer and pod- } \\
\text { solization } \\
\text { prevalent }\end{array}$ & $\begin{array}{l}\text { De- } \\
\text { creasing. } \\
10-12^{\circ}\end{array}$ & $\begin{array}{l}\text { Rising water } \\
\text { level }(B, R)\end{array}$ & & \\
\hline \multicolumn{2}{|c|}{$\mathrm{h}$} & $\begin{array}{l}\text { Forest dominated by Picea, Pinus, } \\
\text { Betula pubescens. Alnus rather common }\end{array}$ & & $\begin{array}{l}\text { De- } \\
\text { creasing }\end{array}$ & $\begin{array}{l}\text { Low water level } \\
(\mathrm{B}, \mathrm{R})\end{array}$ & & $\begin{array}{l}\text { Eemian } \\
\text { Inter- } \\
\text { glacial }\end{array}$ \\
\hline
\end{tabular}

Assuming a July temperature at above $18^{\circ} \mathrm{C}$ in the Eemian Interglacial (J\&M 1928, p. 336) the summer temperature decreased with at least $10^{\circ} \mathrm{C}$ in total.

The vegetation reflects a definite increase in the summer temperature in subzone W 2 c. The July temperature was probably about $10-12^{\circ} \mathrm{C}$. Subzone W $2 \mathrm{~d}$ reflects 
another temperature minimum, which was just as low, or lower, than that of subzone W $2 \mathrm{~b}$. After that minimum, the summer temperature increased again. It is not indicated when exactly this development began, but the temperature rise was reflected by the vegetation in subzone $\mathrm{W} 2 \mathrm{e}$, and Betula forest prevailed in zone W 3 . The summer temperature probably increased by at least $6^{\circ} \mathrm{C}$.

The summer temperature remained high during the zones W 3, W 4 and W 5 . The July average temperature was probably about $13-15^{\circ} \mathrm{C}$ or more. Minima in the summer temperature are reflected by the development in the subzones $\mathrm{W} 3 \mathrm{~b}$ and $\mathrm{d}$. In these subzones the summer temperature probably decreased by $2-3^{\circ} \mathrm{C}$.

The record does not illustrate the further development in detail. A temperature decrease later than zone W 5 is indicated by traces of erosion activity at Brørup Hotel $\mathrm{Bog}$, and the vegetation from zone $\mathrm{W} x$ reflects such a change too. The temperature decrease was probably separated from the uppermost peat at Brørup by a short span of time only. The solifluction deposit found at the top of the sequence at Brørup Hotel Bog indicates that the temperature decrease was continued.

A temperature curve based on these data and on the radiocarbon dates mentioned in chapter VIII is shown in fig. 12 (p. 133).

\section{Humidity}

The palaeobotanical material does not give much information about the precipitation during the intervals studied. It is quite certain, that the precipitation was ample for the development of forest vegetation in the warmer intervals, and that the changes in the herb pollen frequencies were due to changes of the temperature alone. Snow cover seems to have been abundant, and many hygrophilous plants were present. The solifluction in zone W 2 indicates abundant moisture.

The heath vegetation found in zone W 1 was conditioned by a rather moist-oceanic climate and by the existence of an acid humus layer. The heath disappeared in zone W 2 because the humus layer was destroyed by solifluction (p. 91), and the ericaceous heath shrubs also remained rare in zone W 3 , presumably because an acid humus layer had not had time to develop. Hence, the lack of Ericales in zone W 3 does not indicate a dry climate. The frequencies of the Ericales increase in the zones W 4W 5, apparently due to progressive formation of an acid humus layer. It may thus be seen that it cannot be assumed that large changes of precipitation and air humidity took place.

Information about minor changes of air humidity may be obtained from the local changes of water level (see the discussion in chapter II).

A reversement of the hydrosere to wetter conditions indicates definitely that the local water level rose. Such cases are listed below $(B=$ Brørup Hotel Bog, $\mathrm{R}=$ Rodebæk I, H = Herning, $\mathrm{N}=$ Nørbølling).

$$
\begin{aligned}
& \text { Dry } \rightarrow \text { wet stage } \quad \text { Corresponding change } \\
& \text { in summer temperature } \\
& \text { Zone h-W 2b: B, R ........ Decrease } \\
& \text { - W 2c-d: R......... - } \\
& \text { - W } 3 \mathrm{a}-\mathrm{b}: \mathrm{B}, \mathrm{H} \ldots \ldots \ldots \text {. - } \\
& \text { - W 3c-d: B......... - } \\
& \text { - W 5-W x: B....... - }
\end{aligned}
$$

A rise of water level may not always become reflected by the local vegetation, depending on the immediate local stage. The list above shows, nevertheless, that each 
decrease in the summer temperature was accompanied by a rise in the water level at least at one of the sites. Hence, it seems to have been a very general rule that a decrease in the summer temperature resulted in higher local water levels.

A lowering in the local water level may be more difficult to detect from changes in the local vegetation, as its effect on the vegetation cannot always be distinguished from the normal hydrosere, which led to stages of increased dryness. A lowering in the water level may have accelerated this succession. Such changes are listed below.

$$
\text { Wet } \rightarrow \text { dry stage } \quad \text { Corresponding change }
$$

in summer temperature

Zone $\mathrm{h}: \mathrm{B}, \mathrm{R}$ (low water level) ....... High summer temperature

- W $2 \mathrm{~b}-\mathrm{c}: \mathrm{R} \ldots \ldots \ldots \ldots \ldots \ldots$ Increase

- W $2 \mathrm{e}-\mathrm{W} 3 \mathrm{a}: \mathrm{B}, \mathrm{H} \ldots \ldots \ldots \ldots$.

- W $3 \mathrm{~b}-\mathrm{c}: \mathrm{B} \ldots \ldots \ldots \ldots \ldots \ldots \ldots$ -

- W $3 \mathrm{~d}-\mathrm{e}: \mathrm{B} \ldots \ldots \ldots \ldots \ldots \ldots \ldots$ -

- W 4-W 5: N............ None

The list shows that most increases in the summer temperature corresponded to a drier vegetational stage in at least one of the local basins. This can hardly have been accidental, and it seems that increases in summer temperature usually resulted in lower local water levels. Evidence of a drying out of the lake bottom was found at the transition zone W 2-W 3, especially at Brørup Hotel Bog (p. 58).

It appears to have been a general rule that intervals with a high summer temperature were reflected by low water levels in the lakes, and intervals with a low summer temperature by high water levels. The lowest water level occurred in the Eemian Interglacial, where the summer temperature was highest, and the highest water levels corresponded to the subzones $\mathrm{W} 2 \mathrm{~b}$ and $\mathrm{d}$, which had the lowest summer temperatures within the sequence studied. It is thus suggested that the changes of water level were due to the changes in summer temperature, presumably because of its influence on the evaporation.

As mentioned above, the air humidity was rather high during the warm intervals, and the climate became accordingly very moist in the cold intervals, and especially in the subzones $\mathrm{W} 2 \mathrm{~b}$ and $\mathrm{d}$. This assertion explains the strong erosion activity in these cold intervals, and it corresponds well to the assumptions mentioned earlier, that snow cover was excessive, the ground water level high, and that wet solifluction areas bare of vegetation prevailed at those times (p. 92).

\section{Chronology. The Rodebek and the Brørup Interstadials}

From the above it appears that changes in the summer temperature were the most significant climatic changes in the post-Eemian sequence in Western Jutland. These changes may be useful for a delimitation of chrono-stratigraphic units.

Some of the temperature changes may have been rather sudden, but a difficulty may exist, nevertheless, deciding which points of the falling or rising temperature curve should be chosen for delimiting the time units. For that reason the chronostratigraphic limits cannot be defined very sharply, in contrast to the bio-stratigraphic limits (pollen zone limits), which may be defined for a certain area with a great clearness.

The post-Eemian climatic development described above and in table 24 contains several temperature changes, which may be useful for chrono-stratigraphic limits (see also fig. 12, p. 133). 
(1) the temperature decrease zone $\mathrm{h}-\mathrm{W} 2 \mathrm{~b}$.

(2) the temperature oscillation zone W $2 \mathrm{~b}-\mathrm{c}-\mathrm{d}$.

(3) the temperature increase zone W $2 \mathrm{~d}-\mathrm{W} 3 \mathrm{a}$.

(4) the temperature oscillations zone W $3 \mathrm{a}-\mathrm{b}-\mathrm{c}-\mathrm{d}-\mathrm{e}$.

(1) The temperature decrease zone $\mathrm{h}-\mathrm{W} 2 \mathrm{~b}$ interrupted the vegetational succession of the Eemian Interglacial, and caused an expansion of non-forest vegetation. That transition took place at some point of time during the temperature decrease. The summer temperature decreased with at least $10^{\circ} \mathrm{C}$ in total (see above). In Western Jutland the temperature decrease was accompanied by an initiation of periglacial erosion (slope wash and solifluction). It seems that the erosion became prominent at the transition zone W 1-W 2, and solifluction was intensive in subzone W $2 \mathrm{~b}$. It can hardly be doubted that this major temperature decrease had great effects outside of Denmark, not only on the vegetational successions, but on the history of glaciers, the development of periglacial phenomena in a wide area, and changes in the ocean level. It forms a convenient boundary between the Eemian Interglacial and the Weichselian Glacial.

(2) The Rodebæk Interstadial. The temperature oscillation zone W $2 \mathrm{~b}-\mathrm{c}-\mathrm{d}$ was reflected clearly by the terrestrial vegetation and the vegetation of the lakes. The summer temperature increased and decreased substantially, and the warm interval may be considered to be an interstadial, in the local sequence the Rodebæk Interstadial, named after that site, at which the oscillation is represented by a gyttja layer intercalated between predominantly mineral strata. The interstadial was followed by the temperature minimum of subzone $\mathrm{W} 2 \mathrm{~d}$, during which periglacial erosion became intensive again.

(3) The Brorup Interstadial. The temperature increase reflected in the zones W $2 \mathrm{~d}-\mathrm{W} 3$ a constituted an important climatic change. The summer temperature increased by at least $6-8^{\circ} \mathrm{C}$, and it remained high during the zones W $3-\mathrm{W} 5$. The vegetation reacted rather slowly to this change. The first changes may be traced at the transition W $2 \mathrm{~d}-\mathrm{e}$, and Betula forest developed at the transition W $2 \mathrm{e}-\mathrm{W} 3 \mathrm{a}$, but other forest trees (Larix, Pinus silvestris, Picea abies and P. omoricoides) did not immigrate till after a considerable interval, although the summer temperature was undoubtedly favourable for them at an earlier point of time (p. 105). The temperate deciduous trees did apparently not immigrate at all, and were represented only by pollen due to long distance transport by wind.

The temperature increase during zone W $2 \mathrm{~d}-\mathrm{W} 3$ a must also have affected a wide region. The trees mentioned had apparently only survived the preceding cold interval far to the south. The climatic amelioration must have caused re-expansion of forest vegetation, extensive recession of glaciers, and a rise in the ocean level.

The upper limit of the favourable interval is not represented in detail in the pollen diagrams, but it seems clear that this warm interval terminated with another considerable temperature decrease soon after the formation of the deposits from subzone W $5 \mathrm{c}$. The entire warm interval may be considered to be a major interstadial within the Weichselian Glacial, the Brørup Interstadial.

(4) The oscillations within zone W 3, finally, deserve attention. The minima of summer temperature corresponded to the subzones $\mathrm{W} 3 \mathrm{~b}$ and $\mathrm{d}$ of the vegetational history. The summer temperature was lowered twice, and sufficiently to cause a decrease in the vitality of Betula pubescens, but the frequencies for Filipendula cf. ulmaria were affected only slightly (cp. p. 96). In the cold intervals that separated the Bolling and the Allerød Interstadials, and the Allerød from the Postglacial (the Lower Dryas and Upper Dryas intervals respectively) Filipendula disappeared almost entirely 
in Denmark (cp. Iversen 1954). The temperature minima of the subzones W $3 \mathrm{~b}$ and $d$ are, accordingly, not comparable to the Late-Glacial temperature minima. They should be considered to be minor oscillations within the Brorup Interstadial.

It thus appears that the upper limit of the Eemian Interglacial and two early Weichselian interstadials, the Rodebæk Interstadial and the Brørup Interstadial, may be recognized on the basis of the changes of summer temperature studied in the present work.

The relationship of the chronologic divisions proposed here to the stages of the vegetational history and the temperature oscillations is indicated in table 24 (p. 115). This chronology has been compared with the chronology described by J\&M (1928, pp. 334-307) in table 25. Stage II of those authors, the stage with the "lower temperate flora" corresponds to the Eemian Interglacial (p. 9). All the younger stages mentioned by J\&M (l. c.) should be considered to belong to the Weichselian Glacial. The Rodebæk Interstadial was not distinguished by J\&M (1. c.). As discussed in detail in chapter IV, Stage IV of J\&M (l. c.), the stage with the "upper temperate flora" at Herning and other sites, consists of re-deposited interglacial material with rebedded macrofossils and pollen, and it corresponds to a cold interval. Stage V of J\& M (l. c.), the stage with the "upper subarctic flora", corresponds to the Brørup Interstadial, which had a rather warm climate.

Table 25 .

(Tabellen er gengivet på dansk på side 162).

\begin{tabular}{|c|c|c|c|}
\hline \multicolumn{2}{|c|}{ Jessen and Milthers 1928} & \multicolumn{2}{|c|}{ Present investigation } \\
\hline $\begin{array}{l}\text { Last } \\
\text { Glaciation }\end{array}$ & & Cold substage & \multirow{5}{*}{$\begin{array}{l}\text { Weichselian } \\
\text { Glacial }\end{array}$} \\
\hline \multirow{6}{*}{$\begin{array}{l}\text { Last } \\
\text { Interglacial }\end{array}$} & V. Upper sub-arctic flora & Brørup Interstadial & \\
\hline & IV. Upper temperate flora & Cold substage & \\
\hline & \multirow{2}{*}{ III. Sub-arctic flora } & Rodebæk Interstadial & \\
\hline & & Cold substage & \\
\hline & II. Lower temperate flora & & $\begin{array}{l}\text { Eemian } \\
\text { Interglacial }\end{array}$ \\
\hline & $\begin{array}{l}\text { I. Lower sub-aretic and } \\
\text { arctic flora }\end{array}$ & & $\begin{array}{l}\text { Saalian } \\
\text { Glacial }\end{array}$ \\
\hline
\end{tabular}

No Weichselian ice advances can be correlated in a direct manner with the postEemian sequence from Western Jutland described here. The Scandinavian ice sheet extended almost to the site at Brørup Hotel Bog at the maximum of the Weichselian glaciation, and it seems to be quite certain that the Brørup Interstadial preceeded that substage. 


\section{REMARKS ON THE VEGETATION OF NW EUROPE DURING THE EARLY WEICHSELIAN GLACIAL, AND CORRELATION OF EARLY WEICHSELIAN DEPOSITS IN THAT AREA}

Post-Eemian sequences very similar to the ones from Western Jutland mentioned in the present report were studied recently at Amersfoort in the Netherlands by ZAGWIJN and the preliminary results from the Netherlands and Denmark were compared by Andersen, de Vries and Zagwisn (1960). The profile at Amersfoort consists of clay from the Eem marine transgression overlain by fresh-water gyttja and peat with intercalated sand layers. The sequences from the Netherlands and Denmark were correlated due to analogous vegetational successions (Andersen, De Vries and ZaGwijn, l. c.). Their main features are summarized in table 26.

At present only the correlation of the main vegetational stages in table 26 is considered to be rather certain. The differences in vegetation of the correlated stages may be due to differences in geographic location and soil texture (cp. below).

Climatic curves for the two areas based on the botanical data were compared, and the names Amersfoort Interstadial and Brørup Interstadial were suggested for the two early Weichselian warm substages in a general chronology (ANDERSEN, de Vries and ZaGwidn 1. c., cp. table 26). The climatic curves are shown in fig. 12, p. 133. Radiocarbon dates are consistent with the correlations. They will be mentioned in chapter VIII.

As stated above and on p. 118, it is believed that the disappearance of the forest and the expansion of non-forest vegetation at the end of the Eemian Interglacial were fairly synchronous in Northern Europe. An acidophilous heath stage similar to that represented in Jutland in zone W 1 prevailed apparently in Northern Europe, presumably due to soil leaching, which progressed during the Eemıan Interglacial (cp. p. 84).

During the coldest intervals in zone W 2 (subzones b and d) the vegetation in Denmark was poor and sparse with the influence of solifluction. In Scandinavia glacial advances presumably took place. Solifluction prevailed presumably for some distance south of Denmark. Thus most Eemian Interglacial sequences from Northern Germany are covered by layers of predominantly mineral material (cp. i. a. J \& M 1928). Vegetation poor in trees prevailed presumably in a wide area further to the south. A subarctic parklike vegetation prevailed in the Netherlands (see table 26). The wider occurrence of solifluction in Denmark may have been due to a somewhat lower summer temperature and to a higher clay content in the soils.

During the Amersfoort (Rodebæk) Interstadial Denmark was not forested, and similar conditions prevailed presumably in Scandinavia. Regions south of Denmark carried presumably forests of a northern type with Pinus and Betula, as was the case in the Netherlands.

In the Brørup Interstadial forests of Betula pubescens, Populus tremula, and later Larix, Pinus silvestris, Picea abies and P. omoricoides prevailed in Denmark. Larix, Pinus and the Picea species immigrated rather slowly. A thermophilous flora, especially 
Table 26.

(Tabellen er gengivet på dansk på side 105).

\begin{tabular}{|c|c|c|c|c|c|c|c|c|}
\hline & \multicolumn{6}{|c|}{ Bio-stratigraphy } & \multirow{2}{*}{\multicolumn{2}{|c|}{ Chrono-stratigraphy }} \\
\hline & \multicolumn{3}{|r|}{ Denmark (ANDERSEN) } & \multicolumn{3}{|c|}{ The Netherlands (ZAGWIJN) } & & \\
\hline $\begin{array}{l}\text { Local } \\
\text { substages }\end{array}$ & \multicolumn{2}{|c|}{$\begin{array}{l}\text { Pollen } \\
\text { zones }\end{array}$} & Vegetation & \multicolumn{2}{|c|}{$\begin{array}{l}\text { Pollen } \\
\text { zones }\end{array}$} & Vegetation & Substages & $\begin{array}{l}\text { Main } \\
\text { stages }\end{array}$ \\
\hline \multirow{5}{*}{$\begin{array}{l}\text { Brørup } \\
\text { Inter- } \\
\text { stadial }\end{array}$} & \multicolumn{2}{|c|}{ W 5} & $\begin{array}{l}\text { Forest of Pinus, Betula and } \\
\text { Picea }\end{array}$ & \multirow{4}{*}{ EW IV } & $\mathrm{c}$ & $\begin{array}{l}\text { Pinus, Betula, Picea, Alnus } \\
\text { forest }\end{array}$ & \multirow{4}{*}{$\begin{array}{l}\text { Brorup } \\
\text { Inter- } \\
\text { stadial }\end{array}$} & \multirow{11}{*}{$\begin{array}{l}\text { Weich- } \\
\text { selian } \\
\text { Glacial }\end{array}$} \\
\hline & W & & $\begin{array}{l}\text { Forest of Betula, Pinus and } \\
\text { Picea }\end{array}$ & & $\mathrm{b}$ & $\begin{array}{l}\text { Picea, Pinus, Betula, Alnus } \\
\text { forest }\end{array}$ & & \\
\hline & W & & Forest of Betula pubescens & & & & & \\
\hline & \multirow{7}{*}{ W 2} & $\mathrm{e}$ & $\begin{array}{l}\text { Betula nana, B. pubesc. } \\
\text { Populus, herbs }\end{array}$ & & a & $\begin{array}{l}\text { Open forest of Pinus and } \\
\text { Betula, Picea increasing }\end{array}$ & & \\
\hline & & d & Solifluction prevalent & EW II & & $\begin{array}{l}\text { Subarctic parklandscape } \\
\text { with Betula and Pinus }\end{array}$ & & \\
\hline \multirow{7}{*}{$\begin{array}{l}\text { Rodebæk } \\
\text { Inter- } \\
\text { stadial }\end{array}$} & & & & FWU & $\mathrm{b}$ & Pinus-Betula forest & Amers- & \\
\hline & & $\mathrm{c}$ & Betula nana Juniperus herbs & EW 11 & $\mathrm{a}$ & Betula forest & foort & \\
\hline & & & 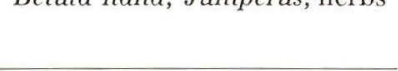 & \multirow{4}{*}{ EW I } & b & $\begin{array}{l}\text { Open forest and parkland- } \\
\text { scape, much Salix }\end{array}$ & $\begin{array}{l}\text { Inter- } \\
\text { stadial }\end{array}$ & \\
\hline & & $\mathrm{b}$ & Solifluction prevalent & & & & & \\
\hline & & $\mathrm{a}$ & Betula nana, Juniperus, herbs & & a & Subarctic parklandscape with & & \\
\hline & \multicolumn{2}{|c|}{ W 1} & $\begin{array}{l}\text { Subarctic heath with } \\
\text { scattered trees }\end{array}$ & & $\mathrm{a}$ & tula & & \\
\hline & & & Temperate forest & & & Temperate forest & & $\begin{array}{l}\text { Eemian } \\
\text { Inter- } \\
\text { glacial }\end{array}$ \\
\hline
\end{tabular}

of herbaceous terrestrial plants and water plants, indicates that the climate was warmer than suggested by the presence of the trees mentioned, and it appears that the temperate deciduous trees were absent mainly because they had not had time to immigrate. A similar vegetation may have prevailed in Scandinavia. However, species of trees (Picea?, Alnus?) may have immigrated to that area from the east. Regions to the south of Denmark were presumably reached by Pinus and Picea at an earlier point of time within the interstadial than in Jutland. Pinus, Picea and Alnus occurred in the Netherlands during most of the interstadial, and it seems that the Netherlands were more accessible for a re-immigration of trees than Denmark. This was also the case in the late Weichselian Allerød Interstadial with regard to Pinus (p. 105). The other temperate deciduous trees and shrubs represented in the Brørup Interstadial in Jutland by wind transported pollen (Carpinus, Quercus, Ulmus, Fraxinus, Corylus) occurred presumably at some not exactly known distance to the south.

Picea omoricoides and Larix are not known from the Eemian Interglacial in Denmark, and these trees may characterize the Brørup Interstadial in a limited area. However, the trees are known from Eemian or older deposits in Poland and Germany, and cannot be considered to be "type" species for the Brørup Interstadial in a wide area.

At Amersfoort the deposits from the Brørup Interstadial are overlain by deposits from the middle and the late Weichselian Glacial (ZaGwiJn, in Andersen, de Vries and ZAGwiJn 1960). According to ZAGwiJn (l. c.), a younger interstadial may be represented at Breda in the Netherlands. An interstadial of a similar age is problaby represented at Geesthacht, Northern Germany (mentioned in DE VRIEs 1958a). The vegetations of these interstadials have not yet been described. 
During the period of maximum extent of the Scandinavian ice sheet in the Weichselian Glacial, the glacier extended almost to the site at Brørup Hotel Bog (p. 47). Hence, older Weichselian moraine stages were overrun, and presumably destroyed to a wide extent, but interstadial deposits may have been preserved in the glaciated area, and may offer a possibility for a comparison and a correlation with the early Weichselian interstadials by their vegetational successions. Other post-Eemian sequences from the neighbouring countries to the south may be compared and correlated with the general sequence. The occurrence of such deposits will be discussed below (the figures in brackets refer to the map fig. 11). Relevant radiocarbon dates will be mentioned in chapter VIII.

\section{Denmark}

From the part of Denmark, which was covered by ice during the Weichselian Glacial only a few post-Eemian plant bearing deposits older than the maximum of the Weichselian glaciation are known.

Skcrumhede (6). The Skærumhede series from Northern Jutland is well known (cp. especially A. Jessen, Milthers, Nordman, Hartz and Hesselboe 1910). 123 m. of marine deposits were found below $57 \mathrm{~m}$. of glacigenous layers. The fauna differs from that of the marine Eemian deposits, and the age of the marine series is not known with certainty. J \& M (1928) correlated the Skærumhede marine series with their "Upper Temperate Stage" from the sequence at Herning. Wennberg (1949) referred the boulder clay underlying the marine series to an early post-Eemian ice advance, and referred the marine series to an interstadial. However, no definite proof of such a suggestion exists (cp. Woldstedt 1958). The uppermost marine zone (Portlandia arctica zone) contained a flora typical of forestless conditions (i. a. Betula nana, Dryas octopetala, Salix herbacea, S. polaris), and the glacigenous deposits above it a similar flora mixed with remains presumably derived from interglacial fresh-water deposits (i. a. Brasenia schreberi, Ceratophyllum demersum, Nymphoides peltatum, Najas marina, cp. A. Jessen et al. 1. c.). The plant remains suggest that the marine series is interglacial.

Wennberg (l. c.) correlated the lowermost boulder clay from the Skærumhede series with the C-moraine, which overlies Eemian marine deposits at Ristinge Klint (cp. Madsen, Nordman and Hartz 1908), and he referred the "yellow sand", which overlies the C-moraine, to a post-Eemian interstadial. The plant remains found in the sandy deposit mentioned (pollen of Pinus, seeds of Scirpus lacustris, cp. Madsen et al. 1. c.) give no information as to a possibility for a correlation with the Brørup Interstadial.

\section{Sweden}

Several plant bearing deposits covered by till from the Weichselian Glacial are known in Sweden. Their age is not known exactly. They have usually been considered to be interglacial, but their vegetational sequences do not resemble the typical Eemian Interglacial sequence (for radiocarbon dates, see chapter VII).

Öje, Kopparbergs Län (7, G. Lundouist 1955). Sandy clay found at a depth at 4-6 m. contained i. a. a Picea log. Pinus pollen occurs with frequencies at $45-70 \%$, Picea is represented with $40-50 \%$, Alnus with $1-5 \%$. In a sample from the deposit Erdtman identified scattered pollen of Quercus, Tilia, Corylus, Larix, Salix, Myrica and Calluna, and spores of Lycopodium selago and Osmunda cf. claytoniana (see G. Lundoust l. c.). If the Osmunda spores occur in a primary position, the deposit at Öje is unlikely to belong to the Brorup Interstadial. As spores of a similar type occurred in the Eemian Interglacial in Jutland (p. 21), the deposit may be of a similar age, and it is not any longer necessary to assume that it was of a greater age (G. Lundquist 1. c.). 


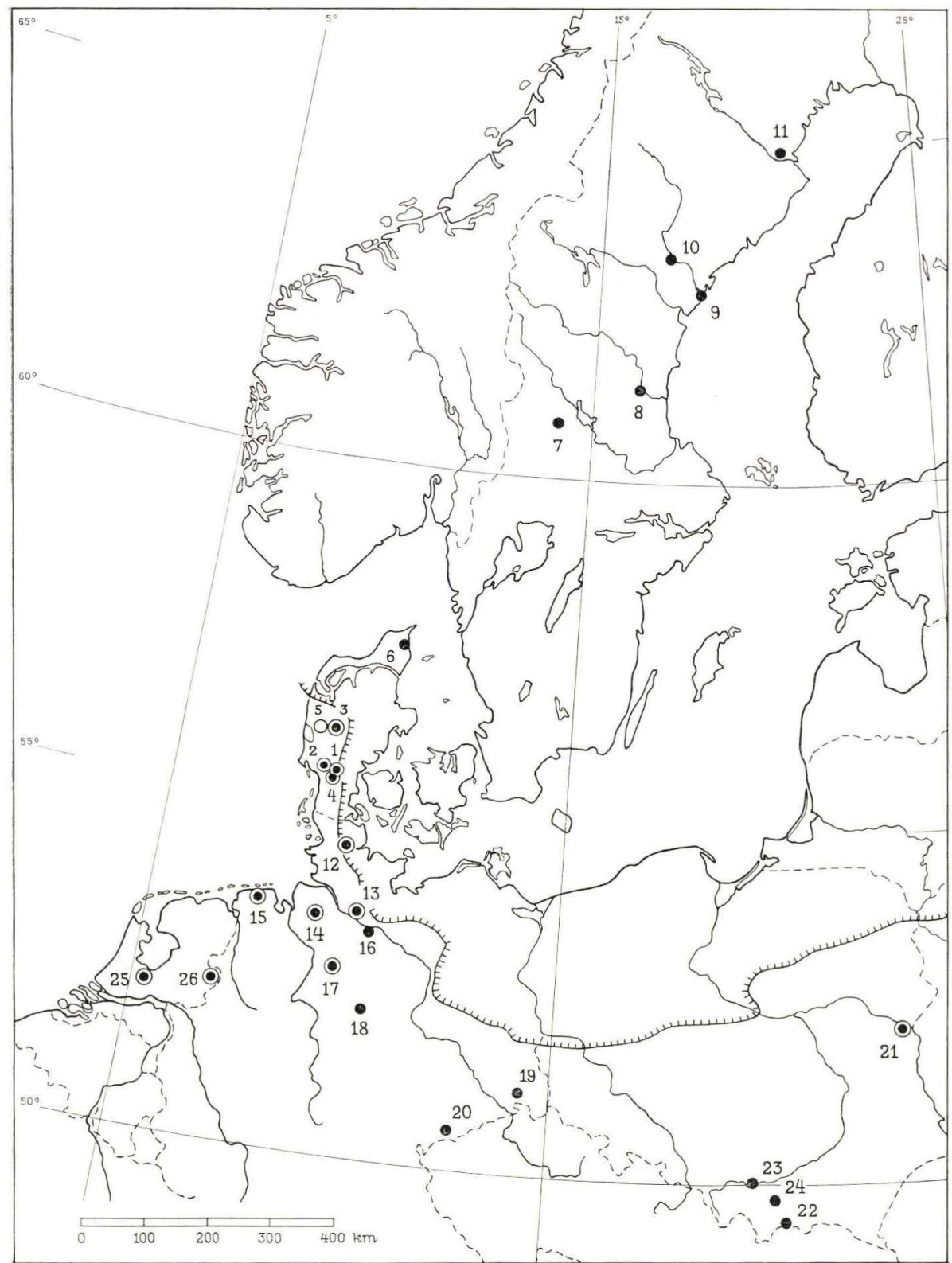

Fig. 11. Interglacial and interstadial sites mentioned in the text, chapters IV and VII. $\circ$ Eemian Interglacial deposit. • Interstadial deposit found above an Eemian Interglacial deposit. Interglacial or interstadial deposit. |||| $\mid$ Limit of the Weichselian glaciation. The deposit at Chelford, England (p. 128), is not indicated.

Lokaliteter med interglaciale og interstadiale lag omtalt i teksten, kapitel IV og VII. $\bigcirc$ aflejring fra Eem Interglacialtiden. ๑ interstadial aflejring beliggende over en aflejring fra Eem Interglacialtiden. - interglacial eller interstadial aflejring. $|+| \mid$ grænse for Weichsel-nedisningen. Aflejringen fra Chelford, England (s. 128) er ikke vist.

Denmark:

1. Brørup Hotel Bog.

2. Rodebæk I.

3. Herning.

4. Norbølling.

5. Solsø.

6. Skærumhede. Sweden:

7. Öje.

8. Bollnäs.

9. Härnö.
10. Långsele.

11. Boliden.

Germany:

12. Loopstedt.

13. Harksheide.

14. Örel.

15. North Friesland.

16. Lüneburg.

17. Nedden Averbergen.

18. Vechelde.
19. Grube Marga.

20. Aue.

Poland:

21. Horoszki.

22. Kąty.

23. Ściejowice

24. Ziembówka. Holland:

25. Amersfoort.

26. Hengelo. 
Bollnäs, Hälsingland (8). A drifted mud layer covered by $6 \mathrm{~m}$. of glacigenous deposits contained macrofossils identified with the following species of higher plants (HALdéN 1915):

\author{
Alnus glutinosa \\ - incana \\ Andromeda polifolia \\ Betula "alba" \\ Calla palustris \\ Carex pseudocyperus \\ - riparia \\ Ceratophyllum sp. \\ Empetrum nigrum \\ Frangula alnus \\ Iris pseudacorus
}

\author{
Lycopus europaeus \\ Menyanthes trifoliata \\ Najas marina \\ Nymphaea alba \\ Picea abies \\ Potamogeton praelongus \\ pusillus \\ Potentilla palustris \\ Rubus idaeus \\ Selaginella selaginoides \\ Solanum dulcamara
}

A pollen diagram from the deposit was published by Sundius and SANDEgren (1948). Betula pollen dominates, and pollen of Pinus and Picea is frequent. Pollen of Alnus cf. glutinosa (det. G. ERDtman) is present with frequencies at about $20 \%$, and that of Corylus with $5 \%$. It is unlikely that the deposit belonged to the Brørup Interstadial, and it is presumably of Eemian Interglacial age.

Härnö, Västmanland (9). A gyttja deposit found under $2.5-5 \mathrm{~m}$. of till was described by Munthe (1904). The deposit has not been re-investigated with pollen analysis. The flora contained the following species of higher plants (Munthe l. c.):

\section{Betula nana \\ - pubescens \\ Botrychium lunaria \\ Isoëtes echinospora \\ - lacustris \\ Lycopodium annotinum}

\author{
Lycopodium clavatum \\ Pinus silvestris \\ Potamogeton filiformis \\ Pteridium aquilinum \\ Selaginella selaginoides
}

The deposit is presumably interglacial or interstadial, but its age cannot be determined.

Långsele, Västmanland (10, Sundius and SAndegren 1. c.). Clay mud was found at 22-24 m. beneath the surface. The following species of higher plants occurred:

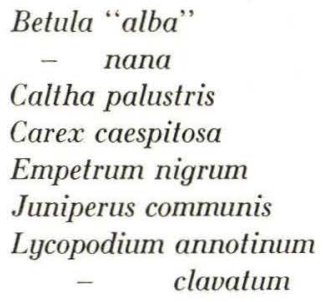

\author{
Myriophyllum verticillatum \\ Potentilla palustris \\ Ranunculus repens \\ Rubus idaeus \\ Rumex acetosella \\ Selaginella selaginoides \\ Vaccinium uliginosum
}

Pollen of Betula and Pinus dominate the pollen spectra, and about $10 \%$ of Alnus and Picea pollen occurred. The deposit may belong to the Brørup Interstadial, but an Eemian Interglacial age seems to be more likely. Heinonen (1957) found abundant rebedded pollen in the tills covering the mud deposit.

Boliden, Västerbotten (11, J. LundQuist 1955). The deposit, at $7 \mathrm{~m}$. below the surface, appears to be rather heterogenous. Remains of wood belonged to Alnus sp., Betula 
"alba", B. nana, Ledum palustre, Salix sp., Vaccinium uliginosum and V. myrtillus. Betula pollen dominates the pollen analyses together with $6-33 \%$ Pinus and 1-3\% Alnus pollen. A correlation with the Brørup Interstadial may be possible.

Other possibly interglacial or interstadial deposits were found near Frösjön (AskLund 1936), near Storsjön (Thorslund 1939) and at Pilgrimstad (Kulling 1945), all in Jämtland. Their floras of plant remains are rather poor and give no information about their age. Remains of mammoth were found at Pilgrimstad (KulLing l. c.), and the deposit may be of early Weichselian age. At Luleå in Northern Sweden a moss peat layer was found under $7 \mathrm{~m}$. of glacial deposits (Fromm 1958). Arctic or subarctic conditions are suggested, and the peat may belong to an interglacial or a Weichselian interstadial (Fromm 1. c.).

\section{Germany}

Loopstedt, near Schleswig (12). A pollen diagram from the interglacial deposit at Loopstedt was published by J\&M (1928). It shows a sequence typical of the Eemian Interglacial. Kolumbe (1955) described interstadial layers separated from the interglacial layer by mineral deposits. The interstadial deposit consisted of thin peaty layers in sand and silt, overlain by sand and boulder clay. The interstadial is thus older than the maximum of the Weichselian glaciation, during which the moraine mentioned formed (see Gripp 1940). The vegetational development was described by KoLumbe (l. c.). It seems to be very similar to the Brørup Interstadial. A Betula stage corresponds presumably to zone W $3 \mathrm{a}-\mathrm{b}$, a Betula-Pinus stage to zone W $3 \mathrm{c}-\mathrm{e}$, and a Pinus-Picea stage to the zones W 4-5. Pinus immigrated apparently to the vicinity of the site somewhat earlier than to the neighbourhood of the bogs at Brørup. Pollen from thermophilous trees was represented with frequencies up to $5 \%$. It was presumably due to long distance transport by wind, just as at Brørup and Nørbølling.

Harksheide, near Hamburg (13). HaLliK (1955) described an interstadial deposit found above an Eemian Interglacial deposit, and separated from it by $0.6 \mathrm{~m}$. of sand. The interstadial layers consisted of $0.85 \mathrm{~m}$. of peat and gyttja, and were covered by $1.75 \mathrm{~m}$. of gravelly sand. The vegetational succession illustrated by the pollen diagram published by HaLLIK (l. c.) resembles that of the lower part of the Brørup Interstadial. However, Pinus appeared earlier than Picea (in zone W 3c), just as it did at Loopstedt. A small herb pollen maximum corresponds to a wet horizon ("nasse Lage", Hallik 1. c.), and it probably reflects the temperature decrease of subzone $\mathrm{W} 3 \mathrm{~d}$. Pollen from the more thermophilous trees occurred sporadically. HaLLiK (l. c.) assumed it to be rebedded interglacial pollen. At the topmost part of the sequence that pollen may be primary, due to long distance transport by wind (cp. above). Spores of Pteridium also occurred at that level. Other identified pollen grains and spores worthy of note are Bistorta, Myriophyllum alterniflorum, Nuphar, Drosera and Scheuchzeria. A similar, but considerably shorter vegetational succession is represented in a post-Eemian interstadial deposit at Kollau, located not far from the site at Harksheide (HaLlik 1. c.).

Örel, near Bremervörde (14). Selle (1952) found three layers of peat and gyttja, at $6-8 \mathrm{~m} ., 10-12 \mathrm{~m}$., and $13.5-15.5 \mathrm{~m}$. below the surface, separated by sandy layers. The lowermost peat and gyltja represent the Eemian Interglacial. Judging from SELLE's pollen diagram (l. c.), the middle peat layer may correspond to the Amersfoort Interstadial or a part of the Brørup Interstadial (zone W $3 \mathrm{a}-\mathrm{c}$, with Pinus dominant at the top). The upper peat layer may also correspond to a part of the Brørup Interstadial (Pinus dominant, Picea still rare).

North Friesland (15). Ditrmfr (1954) mentioned a layer of Sphagnum peat covered by $3.6 \mathrm{~m}$. of melt-water sand, and $6.4 \mathrm{~m}$. of Postglacial deposits. Eemian Interglacial 
deposits were found at $11.70 \mathrm{~m}$. below the surface separated from the Sphagnum peat by $1.3 \mathrm{~m}$. of sand. Only a few pollen analyses were mentioned by DrtTMER (l. c., with Betula, Pinus and a little Picea). The deposit may correlate with the Brørup Interstadial.

Lüneburg (16). Müller and Weber (1904) mentioned a deposit of Sphagnum peat and silt with mossy layers. The Sphagnum peat was underlain by gravelly sand, with a podsol profile immediately under the peat, and it was covered by about $6 \mathrm{~m}$. of gravelly sand. Firbas and Firbas (1935) mention a pollen analysis from the deposit. HALLIK (1952) published a pollen diagram based on freshly collected material. According to the latter author, the sequence represents probably the end of the Eemian Interglacial, and the beginning of the following glacial. However, judging from the pollen diagram mentioned (with $80-90 \%$ Pinus, 5-20\% Betula, 0-10\% Picea pollen), the deposit may represent a part of the Brørup Interstadial. The following species are worthy of note, Picea omoricoides (Müller and Weber l. c., Firbas and Firbas l. c.), Larix (Firbas and Firbas l. c.), and Frangula alnus (Hallik 1. c.).

Nedden Averbergen, near Verden (17). SELLE (1952) mentions 2 peat layers found at $1.50-2.23 \mathrm{~m}$. below the surface, and above a deposit, which belongs to the Eemian Interglacial. The pollen diagram (Selde 1. c.) shows dominance of Betula and Pinus pollen, and sporadic occurrence of Picea pollen. A correlation with one of the early Weichselian interstadials is not unlikely.

Vechelde, near Braunschweig (18). According to Selle (1954), a peat deposit occurred at $9-10 \mathrm{~m}$. below the surface. No Eemian Interglacial deposit was found. Pollen of Pinus and Betula dominate the pollen spectra (Picea 0-5\%). A correlation with the Brørup Interstadial might be possible.

Grube Marga, near Senftenberg (19). Several peaty horizons were described by Firbas and Grahmann (1928). Grahmann considered the organic horizons to be younger than the Warthe stadial (Saalian Glacial), and to predate the maximum of the Weichselian glaciation, and he referred the deposits to an early part of an interglacial following the Warthe stadial. However, the pollen diagrams (Pinus and Betula dominant, Picea $0-13 \%$, Ericales increasing to high values in the upper layers, Alnus up to $7 \%$, Carpinus, Quercus, Ulmus, and Corylus sporadic) do not suggest an early Eemian age. Firbas distinguished 3 stages with dominance of Pinus pollen, which correspond to peaty horizons, and intermediate stages with dominance of Betula pollen. As Firbas pointed out, the middle peat layer contains remains of a number of thermophilous plants (Alisma plantago-aquatica, Carex pseudocyperus, Elisma natans, Glyceria fluitans, Lycopus europaeus, Oenanthe aquatica, Ranunculus lingua, Rhynchospora alba, Rumex maritimus, Sagittaria sagittifolia, Sium latifolia, Solanum dulcamara, Sparganium erectum) indicating "dass die Temperaturverhältnisse etwa jenen um den 60 . und 61. Breitengrad im heutigen Fennoskandien entsprachen". The July temperature of the area mentioned is about $16^{\circ} \mathrm{C}$. The presence of such a thermophilous flora of aquatic and swamp plants contrasts with the poorness of the woody flora, and it is suggested, that the temperate woody species had not had sufficient time to immigrate to the area, just as it was the case in Jutland in the Brørup Interstadial. The rich flora from Grube Marga is very similar to the one known from the Brørup Interstadial in Jutland. The following 28 species of the 62 species of higher plants identified from macrofossils by FinBas occurred in Jutland:

\author{
Arctostaphylos uva-ursi \\ Betula pubescens \\ - nana \\ Caltha palustris \\ Calluna vulgaris \\ Carex lasiocarpa
}

Carex rostrata

Elisma natans

Empetrum nigrum

Filipendula ulmaria

Fragaria vesca

Lysimachia thyrsiflora 


\author{
Menyanthes trifoliata \\ Myriophyllum alterniflorum \\ Myrica gale \\ Nuphar luteum \\ Picea abies \\ Pinus silvestris \\ Potamogeton natans \\ pusillus
}

\author{
Potentilla palustris \\ Rubus fruticosus \\ Rumex acetosella \\ Solanum dulcamara \\ Sparganium minimum \\ Urtica dioica \\ Vaccinium oxycoccus \\ Viola palustris
}

The occurrence of Elisma natans is particularly interesting, as the finds at Grube Marga are the only other late Pleistocene record for the species, besides the finds from Brørup, Herning and Nørbølling in Jutland.

It appears probable that the deposits belong to the Brørup Interstadial.

Aue, Erzgebirge (20). Weber (1898) identified from a peat deposit remains of Picea omoricoides, P. abies, Pinus silvestris, Betula pubescens, Menyanthes trifoliata and Potentilla palustris. The peat deposit found under $8 \mathrm{~m}$. of löss and silts is usually referred to the Eemian Interglacial (WoLdstedt 1950). It may, however, belong to a Weichselian interstadial, a suggestion, which appears to be quite likely judging from the plant remains just mentioned.

Bavarian Alps. ReIch (1953) described Eemian Interglacial deposits, above which interstadial layers occur (especially at the sites Grossweil and Ohlstadt). Pollen of Picea omoricoides was found in the post-Eemian layers (p. 33). Other interstadial peat deposits of probable post-Eemian age occur in the Alps (cp. Lüd 1953, Firbas 1958). Detailed correlations with the NW European interstadials are not possible at the present.

\section{Poland}

Horoszki, near Mielnik on the river Bug (21). At this site Bitner (1954) found an Eemian Interglacial deposit covered by $6 \mathrm{~m}$. of bituminous shales and $10 \mathrm{~m}$. of fluvioglacial deposits. In the post-Eemian sequence 2 maxima of herb pollen occur. An intermediate stage with high frequencies for Betula and Pinus pollen reflects presumably an early Weichselian interstadial. Above the second herb pollen maximum another Pinus stage occurs. Pollen of Picea and temperate deciduous trees and shrubs is very rare in the entire post-Eemian sequence. The two interstadials may be correlated with the Amersfoort Interstadial and a part of the Brorup Interstadial.

Lower Carpathians. Presumed early Weichselian interstadials occur at Ściejowice (23), Kuty (22) and Ziembówka (24, Dyakowska 1939, 1947, Środon 1952). The deposits at Kąty and ściejowice contained pollen of Pinus and Picea (dominant). Alnus pollen occurred with frequencies up to $30 \%$, and pollen of Quercus, Carpinus and Corylus was very rare (DYAKowska 1. c.). The flora of macroscopic remains of higher plants at ściejowice was rather rich in thermophilous herbaceous plants. The following species were identified:

\author{
Betula nana \\ Carex rostrata \\ Cicula virosa \\ Cladium mariscus \\ Hippuris vulgaris \\ Hypericum hirsutum \\ Larix sp.
}

\author{
Menyanthes trifoliata \\ Myriophyllum alterniflorum \\ Phragmites communis \\ Potamogeton acutifolius \\ - alpinus \\ - coloratus \\ - densus
}




\begin{tabular}{|c|c|c|}
\hline \multicolumn{2}{|c|}{ Potamogeton filiformis } & Potentilla palustris \\
\hline- & praelongus & Ranunculus flammula \\
\hline - & pusill & \\
\hline
\end{tabular}

At Katy macroscopic remains of Abies, Picea, Juniperus, Carex rostrata, Rubus idaeus, Salvia sp. and Ranunculus aquatilis occurred (Dyakowska 1. c.).

Forests of Picea, Pinus, Larix and Betula characterized the vegetation at Ziembowka, according to pollen analysis (ŚRODoń 1. c.). Pollen of Quercus, Ulmus, Alnus etc. occurred very rarely. Macroscopic remains of the following species of higher plants occurred:

\author{
Ajuga reptans \\ Betula "alba" \\ - humilis \\ Euphorbia amygdaloides \\ Frangula alnus
}

\author{
Picea abies \\ Pinus cembra \\ Sambucus racemosa \\ Thesium alpinum
}

Dyakowska (1. c.) and Środoñ (1. c.) referred the deposits mentioned to a Weichselian (Baltic Glacial) interstadial. A correlation with the Brørup Interstadial seems likely $\left.{ }^{1}\right)$.

\section{The Netherlands}

The section from Amersfoort mentioned on p. 120 represents the most detailed post-Eemian sequence from the Netherlands.

Hengelo (26). VAN DER VLERK and FloRSChütz (1953) referred two maxima for tree pollen found above Eemian Interglacial deposits in the "Oilharbour" section to interstadials. The interstadials may resemble the Amersfoort and the Brørup Interstadials. New pollen-analytical data are being collected by ZaGwiJN.

In the post-Eemian sequence at Zwartewater near Zwolle (VAN DER VLERK and Florschütz 1953), pollen of Alnus $(60 \%)$, Corylus $(20 \%)$, and Quercetum mixtum $(10 \%)$ occurred in a sand layer found between peat layers, where pollen of Pinus dominated and the pollen of the other genera mentioned was rare or absent. It appears, accordingly, that the pollen in the sand layer is rebedded.

\section{ENGLAND}

Chelford, near Manchester. SrMPSON and WEST (1958) mention interstadial peat and mud layers embedded in the "Middle Sands", which in turn are intercalated between two tills, the "Upper Boulder Clay" and the "Lower Boulder Clay" of the Manchester area. The pollen spectra from the peat and mud beds are according to Simpson and West (l. c.) dominated by Pinus and Betula pollen. The pollen diagram suggests a zone with very little or no Picea followed by a zone with Picea frequencies up to $10 \%$. A few scattered pollen grains of Ulmus, Carpinus, Alnus and Corylus occur. Simpson and West (1. c.) also recorded pollen of i. a. Hedera, Lonicera xylosteum, Calluna, Empetrum nigrum, Armeria, Filipendula cf. ulmaria, Polemonium, Valeriana dioica, V. officinalis, Helianthemum, Scleranthus perennis, Caltha and Myriophyllum alterniflorum, and spores of Botrychium, Lycopodium annotinum, Selaginella and Sphagnum.

1) In a recent survey of the "Aurignacian" Interstadial in Poland Brrkenmajer and Środoñ (1960) also refer some other deposits from Poland to an interstadial presumed to be contemporaneous with the Brørup Interstadial. At the site Konopki Leśne rebedded interglacial pollen seems to occur. 
Pinus silvestris, Picea abies, Betula cf. pubescens, B. cf. verrucosa, Rubus fruticosus and a few other species were recorded from macrofossils. The authors mentioned conclude that the mean July temperature probably was about $12-16^{\circ} \mathrm{C}$, and that the climate was rather continental, due to the presence of Picea abies. However, Picea abies may grow in a moderately oceanic climate to-day (see p. 102). The find of Hedera pollen, if reliable, suggests that the climate was oceanic indeed, and that the July temperature was rather high $\left(15-16^{\circ} \mathrm{C}\right.$ or more, cp. Iversen 1944). The finds of Lonicera xylosteum, Valeriana dioica and Rubus fruticosus also suggest a rather high summer temperature (cp. p. 98). Simpson and West (l. c.) present reasons for believing that the peat deposit at Chelford belongs to the Brorup Interstadial. The detailed data from this Interstadial in Jutland show that the vegetation recorded at Chelford was very similar to the vegetation found in Jutland in the pollen zones W 4-W 5, and the absence from Chelford of certain plants recorded at Brørup, e. g. Picea omoricoides, Larix and Frangula alnus, may be accidental. The suggestions as to the climate at that time are also consistent (cp. p. 116 and above), and the correlation mentioned seems highly probable indeed. The vegetation known from the Netherlands was similar, but Alnus occurred there (p. 121). Pinus silvestris apparently immigrated to England already at the beginning of the interstadial, as it also did in the Netherlands (p. 121), and a Betula zone is absent. A radiocarbon date from Chelford will be mentioned in chapter VIII.

It may appear from the survey above, that certainly early post-Eemian interstadial deposits occur outside of Denmark and the Netherlands at Loopstedt, Harksheide, Örel, North Friesland and Nedden Averbergen in Germany, and at Horoszki in Poland (see also fig. 11). The correlation of the interstadial deposits at Loopstedt and Harksheide with the Brørup Interstadial can be considered to be reasonably certain. At Örel, Nedden Averbergen and Horoszki two interstadials seem to be represented, and they may correspond to the Amersfoort Interstadial and a part of the Brørup Interstadial.

The other deposits mentioned above are not related to a deposit with an Eemian Interglacial succession and cannot be dated exactly by their vegetational developments. The deposits at Lüneburg, Grube Marga and Aue in Germany, at Ściejowice, Kąty and Ziembówka in Poland, and at Chelford in England may be referred to the Brørup Interstadial, due to their vegetational conditions, but this assertion cannot be considered to have been proved. 


\section{RADIOCARBON DATES}

Palaeobotanical investigations of post-Eemian sequences from Northern Europe have been mentioned in the preceding chapter. The most complete vegetational successions are the ones from Denmark described in the present work, and the sequence from the Netherlands studied by ZAGwIJN (see chapter VII). From these results it appears that the Eemian Interglacial in Denmark and the Netherlands terminated with a substantial temperature decrease. The entire interval which separated the Eemian Interglacial from the Postglacial may be considered as the Weichselian Glacial (see p. 114). The Weichselian Glacial began with two cold intervals with arctic or sub-arctic conditions, separated by a rather short interval with a somewhat warmer climate, the Amersfoort (Rodebæk) Interstadial. After the second cold interval followed a rather long, warm interval with a temperate climate, the Brørup Interstadial. The Amersfoort (Rodebæk) Interstadial and the Brorup Interstadial may also be recognized in other plant-bearing deposits in Northern Germany, Poland and England (see chapter VII).

In Denmark the record was interrupted near the end of the Brørup Interstadial, and it is only known that this interstadial was followed by the maximum of the Weichselian glaciation. In the Netherlands, the record shows that the Brørup Interstadial was followed by a cold interval.

No moraine stages from Northern Europe may be referred to the cold intervals, which preceded the Brørup Interstadial. The Weichselian moraine stages known from Denmark, Northern Germany and Poland are of a later date, and the classic Weichselian glaciation, and its correlatives in Central Europe, the Würm moraines, are younger than the Brørup Interstadial.

Attempts to date samples in the age range above 30-40 000 years ago by the radiocarbon method were carried out especially by DE VRIES in the years up to 1959 . The original activity of such samples is small, and the results are, accordingly, easily affected by contaminations of various kinds. Thus DE VRIEs (1959) stated that 1 per cent only of recent carbon added to a 37000 years old sample will make the sample 5000 years younger. The difficulties arising from contaminations of this kind will appear clearly from the works of DE VRIES $(1958,1959)$. In addition to trivial contaminants such as modern rootlets and young material admixed in other ways, infiltrated substances, especially humus, have proved to affect the results seriously (DE VRIES I. c., Tauber and de Vries 1958). For such reasons radiocarbon dates in the age range above 30 000-40 000 years may be considered rather to be minimum dates (see TAUBER and de Vries l. c., de Vries l. c.). A contamination with older material, on the other hand, is not as serious. DE VRIES (1959) states that 100 per cent of old inactive carbon are needed to make a sampl 2 of 37000 years' age 5000 years older.

Considering the facts mentioned above, it follows that radiocarbon dates in the said age range should be considered cautiously, and they should not be used for too farfetched correlations. However, if corroborated by other geologic evidence, absolute ages become of interest for an estimate of the length of the time intervals concerned.

In the present material samples from Herning, Rodebæk I and Brørup Hotel Bog have been submitted for radiocarbon assay. All the material was sampled in a manner, which excludes an admixture of younger material (p. 12). Modern roots have not been 
observed at any time, and are unlikely to have occurred, as all of the deposits in question have been covered by a layer of stagnant ground water collected in the shallow bowl formed by the peat and gyttja deposits (see e. g. the sections in J\& M 1928, plates VIII, XIII, and XIV, and the present work, plate VIII). However, the deposits are situated so close to the surface, that infiltration of humus during the Postglacial cannot be excluded. At the time of deposition, the lakes contained no carbonates, and no old carbon derived from such a source can occur. Rebedded material is insignificant or absent in the samples dated.

The dates obtained at Herning (Y-257 and Y-258-3, see below) are so inconsistent, that it must be assumed that some kind of false activity was measured in Y-257 (cp. BARENDSEN et al. 1. c., the sample was not pre-treated for removal of humus).

Non-pretreated samples from BP 1 at Brørup Hotel Bog contained a slight activity. This activity may have been due to infiltrated young humus (TAuber and dE Vries l. c.). The dates from BP 1 mentioned here were measured after a pre-treatment of the samples with acid and alcali for removal of soluble components. As the samples from BP 1 were too small for further investigations, new material was collected with a larger sampler (BP 1a and BP 2, see also p. 12), and made available to DE VRIES. Unfortunately, DE VRIEs did not communicate details about his investigation of the samples, but it must be assumed that they were subjected to a thorough pre-treatment before the dating. The activity of the samples was enriched according to the method developed by Haring, de Vries and de Vries (1958). According to this method the original activity of the samples is enriched by passage through long diffusion columns. The degree of isotopic enrichment may be measured, and in this manner the original activity of samples otherwise too old for radiocarbon assay may be measured. The method is elaborate, but it makes it possible to obtain finite dates for samples in the age range up to 70000 years ago. The dates GRO-1729 and GRO-1470 below were measured on enriched samples. These dates are considered rather reliable,

The following radiocarbon dates were obtained (indicated in years before present),

Herning:
BP 5
Pollen zone W 3 a
$(4.62-4.73 \mathrm{~m}.) \quad \mathrm{Y}-257$
$19580 \pm 730$
Pollen zone W $2 \mathrm{e}$
$(5.05-5.12 \mathrm{~m}.) \quad \mathrm{Y}-258-3$
$>30000$

Rodebæk I:

BP $57 \mathrm{~m}$. Pollen zone W 2c $\quad(2.99-3.10 \mathrm{~m}$.$) \quad Y-259-1 >30000$

See Barendsen, Deevey and Gralensky (1957).

Brørup Hotel Bog:

$\begin{array}{llrll}\text { BP 1 } & \text { Pollen zone W 3d-e } & (2.85-2.90 \mathrm{~m} .) & \text { GRO-1264 } & >50000 \\ & \text { Pollen zone W 3c-d } & (3.37-3.48 \mathrm{~m} .) & \text { GRO-1263 } & >50000 \\ & \text { Pollen zone W 3b } & (3.96-4.08 \mathrm{~m} .) & \text { K-526 } & >40000 \\ & \text { Pollen zone W 2a } & (6.81-6.91 \mathrm{~m} .) & \text { GRO-1256 } & >50000 \\ & \text { See Tauber and DE VRIEs }(1958) . & & \\ \text { BP 1 a } & \text { Pollen zone W 3c } & \text { GRO-1729 } & 58740 \pm 1000 \\ \text { BP 2 } & \text { Pollen zone W 5b-c } & (2.64-2.70 \mathrm{~m} .) & \text { GRO-1466 } & >50000 \\ & \text { Pollen zone W 4 } & (3.22-3.30 \mathrm{~m} .) & \text { GRO-1470 } & 59430 \pm 1000\end{array}$

See Andersen, de Vries and Zagwisn (1960).

Disregarding the date Y-257 (see above), it may be concluded that all of the samples dated pre-date 30-40 000 years ago. The two finite dates obtained from the enriched 
samples (zone W 3 c, $58740 \pm 1000$, and zone W 4, $59430 \pm 1000$ ) do not differ, considering the statistical error, to which must be added error induced by the enrichment and measurement of the enrichment, amounting to about 800 years (HARING et al. 1. c.). The sample from zone W $3 \mathrm{c}$ is actually the older one, but the time difference of the two samples may have been rather short only.

The pollen zones W $3 \mathrm{c}$ and W 4 belong to a medium part of the Brørup Interstadial. It appears, accordingly, that this Interstadial occurred at about 59000 years ago. The length of the whole time interval represented by the interstadial is unknown, but it can hardly have been less than a few thousand years. The next finite radiocarbon date known from Denmark derives from a lower part of the late Weichselian Allerød Interstadial, the age of which is $11880 \pm 340$ years (K-106, Anderson, Levi and TAuber 1953, Iversen 1953, Krog 1954). The Allerød Interstadial was preceded by the Bølling Interstadial, the age of which in the Netherlands is about 12300 years (DE VRIEs, BARENDSEN and WATERBolk 1958). Hence, an interval of nearly 50000 years intervened between the Brørup Interstadial and the late Weichselian interstadials. About this interval, in Denmark, we only know that it contained the maximum of the Weichselian glaciation.

Palaeotemperature curves for the Weichselian Glacial in Denmark and the Netherlands based on palaeobotanical data and on radiocarbon dates were presented in Andersen, de Vries and Zagwijn (1960). The curves are reproduced in fig. 12 (with a few corrections). In the Netherlands, the Amersfoort (Rodebæk) Interstadial was dated at $64000 \pm 1100$ years ago (GRO-1397, enriched sample). It is thus suggested that the cold substage, which separated the Amersfoort Interstadial from the Brørup Interstadial lasted for about 3000 years. The length of the cold substage, which separated the Amersfoort Interstadial from the Eemian Interglacial is unknown, but by extrapolation it may be estimated that the Eemian Interglacial ended at nearly 70000 years ago. The length of the entire Weichselian Glacial was thus probably about 60000 years.

In the Netherlands, Pleni-Glacial samples recording an arctic climate (ZAGwisn, in ANDERSEN et al. 1960) were dated at 32000-46 500 years before present (DE VRIES 1958, de Vries, Barendsen and Waterbolk 1958, Andersen et al. 1960, see fig. 12).

In Sweden radiocarbon dates at $>24000->40000$ years before present were obtained for samples from Öje, Bollnäs, Boliden, Pilgrimstad, Vålbacken near Storsjön, and Luleå (see especially LundQuist 1957, Östuund 1959). The dates indicate that the deposits in question (cp. pp. 122-125) antedate the maximum of the Weichselian glaciation.

Several radiocarbon dates from the interstadial deposit at Loopstedt, North Germany (see p. 125), proved later on to be too young due to contamination with recent rootlets (DE Vries 1958). One date, at $50000 \pm 2000$ years ago (GRO-1365), was assumed to be more reliable by DE VRIEs (I. c.). The sample corresponds presumably to the pollen zones W 4 or W 5 at Brørup (p. 125). The date appears to be too young, and it should probably be considered a minimum date, rather.

From the famous Mousterian site at Lebenstedt in Northern Germany a gyttja and humus sample was dated at $48300 \pm 2000$ years ago (GRO-1219, DE VRIEs 1958). According to Preul (1953) and Richter (1953) the find horizon, which contained the gyttja and peat layers, is included in a series deposited under cold conditions, and solifluction phenomena occur below and above the horizon, but the sequence cannot be referred to any definite substage of the Weichselian Glacial. The pollen analysis by SELLE $(1953 \mathrm{~b})$ is preliminary only. These data and the macroscopic plant remains (Pfaffenberg 1953) suggest that the vegetation of the area was aretic or subarctic. Hence, the radiocarbon date derives from a cold interval, or from an interval with a very slight temperature rise. If the date is correct, the cold intervals postdate the Brørup 


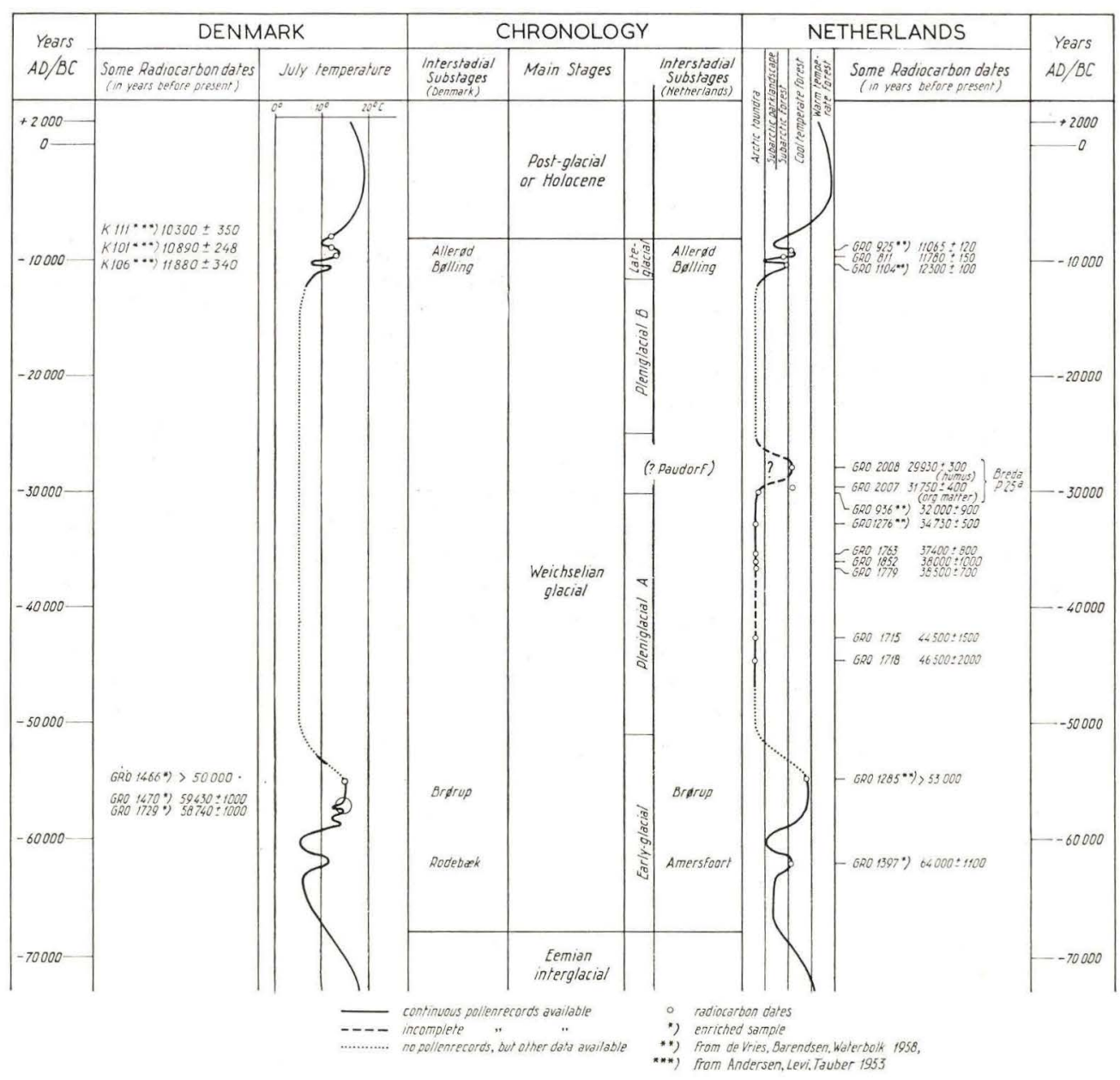

Fig. 12. Climatic curves and radiocarbon dates for the Weichselian Glacial in Denmark and the Netherlands (from Andersen, DE Vries and Zagwisn, 1960, with a few corrections). Klimakurver og C-14 dateringer for Weichsel Istiden i Danmark og Holland (fra Andersen, de Vries og Zagwisn, 1960, med enkelte rettelser).

Interstadial, and it is suggested that the Brørup Interstadial ended before about 48000 years ago. The date is slightly older than the Pleni-Glacial samples from the Netherlands just mentioned.

A wood sample from the main mud bed of the interstadial deposit at Chelford, England (p. 128), was dated at 57000 years ago by DE VRIES (enriched sample, see Simpson and West 1958). This date is consistent with the correlation of the deposit with the Brørup Interstadial mentioned on p. 129.

An interesting "old" radiocarbon date, at 65000 years ago (enriched sample), was obtained for a $\log$ of Abies alba from the Agro Pontino near Rome (Blanc 1958). In the profile from the Agro Pontino (see Blanc 1938, Tongiongi 1936, Blanc, Segre and Tongrongr 1953) a beach deposit from the Tyrrhenian II transgression (with shells of 
Strombus bubonius) is found at $5 \mathrm{~m}$. above the present sea level. Above the beach deposit fresh-water peats occur, which contain a warm-temperate forest flora (Carpinus betulus, Quercus, Taxus baccata, Fagus silvatica, Vitis vinifera i. a.), and, at a higher level, remains from an Abies forest vegetation. Abies alba occurs to-day in Italy above altitudes of $800-900 \mathrm{~m}$., and the profile reflects a climatic deterioration following upon the Tyrrhenian transgression. The radiocarbon date is older than the dates from the Brørup Interstadial and is about the same as the one obtained for the Amersfoort Interstadial. The profile from the Agro Pontino does not reflect the minor climatic oscillations, and it may be assumed that the Abies trunk derives rather from one of the early Weichselian cold intervals, which preceded the Brørup Interstadial in the Netherlands and in Denmark. At Agro Pontino a still colder interval is recorded above the Abies forest horizon. It is presumably contemporary with the maximum of the Weichselian glaciation in Northern Europe (cp. Blanc l. c.).

Emiliani (1958, and earlier) constructed a curve for Pleistocene surface temperature variations in the middle North Atlantic Ocean based on several deep-sea bottom cores distributed in that area. Various difficulties in the interpretation of the data were discussed by Emiliani (l. c.). The topmost part of the temperature curve (back to about 20000 years before present) was dated with radiocarbon measurements, but the older absolute dates indicated on the curve by Emiliani (l. c.) were extrapolated assuming a constant rate of sedimentation. The temperature minima correlated with the last glacial stage by EMILIANI (l. c.) occur between -10000 and -70000 years. If that correlation is correct, the temperature minimum between -60000 and -70000 years (EMiliani 1. c., stage 4) corresponds probably to the cold interval, that separated the Eemian Interglacial from the Brørup Interstadial. The temperature decrease from the assumed Eemian Interglacial to this temperature minimum amounts to $6-7^{\circ} \mathrm{C}$. The Brorup Interstadial is probably recorded in the temperature maximum found in Emiliani's curve between 50 000-60 000 years ago. Here the temperature increase is $5-6{ }^{\circ} \mathrm{C}$. A possible equivalent of the Amersfoort (Rodebæk) Interstadial is not apparent in Emilians's curve. Such a rather short oscillation may have become smoothed out due to mixing of the bottom sediments at the time of deposition. 
Table 27. Photo-micrographs.

Mikrofotografier.

Photo-micrographs of pollen and spore finds from the zones W 1-W 5 are on file at the Geological Survey of Denmark. 6-8 optical sections of each pollen grain or spore were photographed (LeITz apochromatic objective, n.a. 1.32), and enlarged $1000 \mathrm{x}$. Phase contrast equipment (LEITZ achromatic objective, n.a. 1.25) has been used in addition, where useful. Only a few of the photo-micrographs can be reproduced here (see the plates I-IV), and in most cases several photo-micrographs of each find will be necessary for showing the features necessary for an identification. All the finds photographed are listed below, with their DGU file numbers.

cf. Adonis.

Allium cf. schoenophrasum

Anemone. . . . . . . . . . . . . . . . . . . .

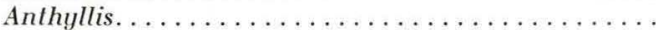

Armeria maritima .....................

Arctostaphylos alpina ..................

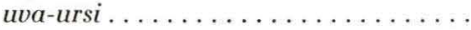

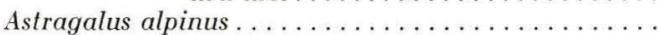

campestris type $\ldots \ldots \ldots \ldots \ldots \ldots \ldots \ldots$

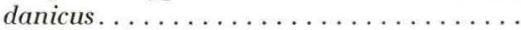

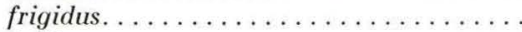

Azolla filiculoides . . . . . . . . . . . . . . . . .

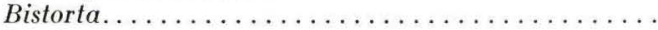

Bupleurum . . . . . . . . . . . . . . . .

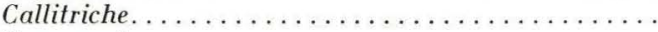

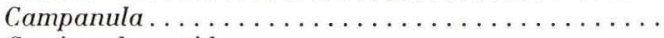

Cassiope hypnoides......................

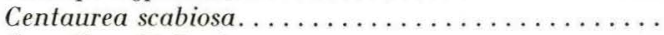

Cerastium-Stellaria

Chamaenerium angustifolium

Cytisus nigricans

Drosera intermedia.

Elisma natans . ..............

Empetrum hermaphroditum . . . . . . . . . . . .

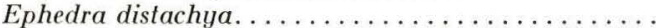

ef. strobilacea ..................

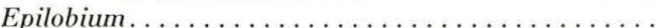

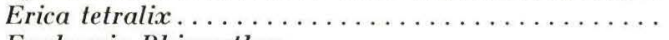

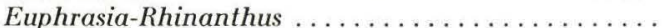

Fragaria . . . . . . . . . . .

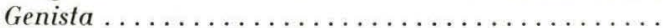

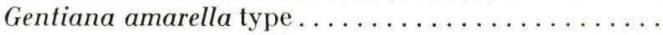

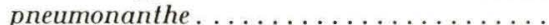

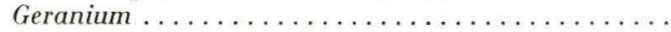

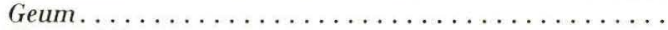

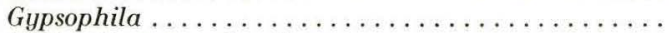

Helianthemum oelandicum type . . . . . . . . .

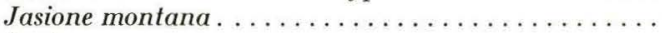

Larix . . . . . . . . . . . . . . . . . . . . . .

cf. Lithospermum arvense . ...............

Littorella uniflora .......................

Lobelia dortmanna ......................

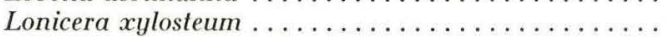

Lotus. . . . . . . . . . . . . . . . . . . . .

Lycopodium annotinum. . . . . . . . . . . . . alpinum-compl................ clavatum. .................. compl. ssp. cham.................

Lysimachia thyrsiflora.

Malus silvestris. a 1224,1544

a1201, 1202, 1601

a1011, 1221, 1251, 1384

a 1353

a1405, 1464, 1471, 1553, 1561

a1611

a1404, 1462

a1045, 1363

a1431, 1434, 1441

a1121, 1412

a1411, 1662

a 1581

a1203

a1112

a1111

a 1181,1472

a1451

a1551

a1062, 1071, 1083, 1084, 1091, 1092 ,

$1252,1351,1371,1381,1511$

a1513

a1362, 1413

a $1063,1074,1352$

a1541

a $1101,1102,1631,1641,1642,1651$

a1403

a1194

a1095

a1514

a1452, 1461

a1504, 1653

a1521

a1474

a1014, 1421, 1422, 1424, 1463

a1093

a1232

a1272, 1312, 1331

a1072, 1344, 1492

a1103, 1324

a1473

a 1613

a1264

a1123

a1322, 1574

a 1013

a1041, 1391

a1334

a1182

a1184

a1183

a1401

a1372, 1682 
Melandrium

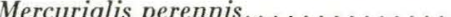

Myriophyllum spicatum. . . . . . . . . . . .

Osmunda ef. cinnamomea. .

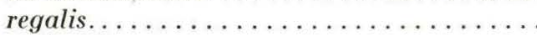

Parnassia palustris.

Plantago lanceolata.

maritima s. 1 . media

Polygonum amphibium

avicula convolvulus type.

Prunus . .

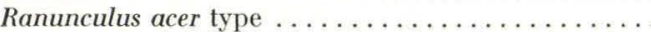

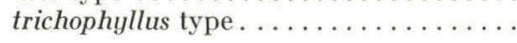

Rosa

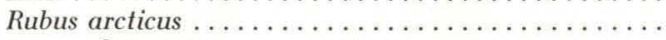

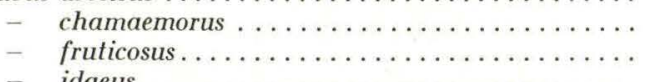

- idaeus.

.

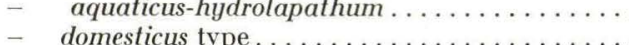

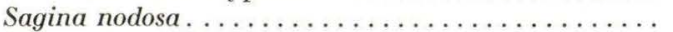

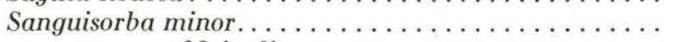

Scleranthus perennis

Sedum................

Silene-Arenaria type.

Stellaria holostea.

Swertia perennis

Symphytum ...........

Teucrium montanum

Trifolium alpestre arvense.

Typha-Sparganium type. . a1612

a1012

a1393

a1192

a1614

a1104

a1124, 1125, 1481, 1482, 1483, 1484

1563,1632

a1131, 1485, 1543, 1633, 1674

a1132

a1094

a1515

a1211

a1573

a1273, 1321

a1223, 1383

a1225, 1261, 1392

a1552

a1271, 1542

a1341, 1342

a1582

a1382

a1311, 1313

a1571

a1661

a1204

1214, 1512

a1253

a1343

a1212

a1243

a1122

a1073, 1075, 1082

a1061, 1213

a1191, 1242, 1423

a1113

a1534

a1263

a1432, 1433

a1205, 1231

a1323, 1491, 1592 
Table 28

(next page) 
Table 28. Brørup Hotel

The figures indicate numbers of pollen

Tallene angiver antal af pollenkorn og

\begin{tabular}{|c|c|c|c|c|c|c|c|c|c|c|c|c|c|c|c|c|c|c|}
\hline $\mathrm{De}_{\mathrm{I}}$ & 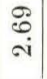 & $i$ & N & $\mathscr{\infty}$ & 18 & \begin{tabular}{l}
0 \\
\hdashline \\
$\dot{\infty}$
\end{tabular} & คิ & \begin{tabular}{|l|l}
20 \\
0
\end{tabular} & 官 & $\stackrel{R}{1}$ & $\infty$ & $\infty$ & $\sigma$ & s. & 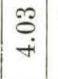 & $\stackrel{N}{\sim}$ & $\stackrel{\curvearrowright}{\sim}$ & $\underset{\sim}{\approx}$ \\
\hline : & .. & . & .. & $\cdots$ & $\cdots$ & .. & $\cdots$ & $\cdots$ & .. & - & $\cdots$ & $\cdots$ & & $\cdots$ & * & & & \\
\hline ef. Adonis.. & $\cdots$ & $\cdots$ & $\cdot$. & . & $\cdot \cdot$ & $\cdots$ & .. & $\cdots$ & $\cdots$ & $\because$ & . & $\cdots$ & $\cdots$ & . & .. & . & $\cdots$ & - \\
\hline$\ldots \ldots \ldots \ldots \ldots \ldots$ & .. & $\cdots$ & $\cdots$ & . & $\cdots$ & $\cdots$ & . & $\cdots$ & . & 1 & $\cdots$ & . & $\cdots$ & .. & .. & $\cdots$ & . & 列 \\
\hline Anthyllis vulneraria $\ldots \ldots \ldots \ldots \ldots \ldots \ldots \ldots \ldots$ & .. & . & $\cdots$ & .. & . & . & . & . & .. & $\cdots$ & . & .. & .. & $\cdots$ & . & . & $\cdots$ & $\cdots$ \\
\hline$\ldots \ldots \ldots \ldots \ldots \ldots$ & $\cdots$ & .. & + & . & .. & . & .. & $\cdots$ & .. & $\cdots$ & . & .. & $\cdot$. & $\cdots$ & .. & $\cdots$ & . & 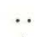 \\
\hline Astragalus & .. & .. & .. & .. & .. & . & .. & . & .. & .. & .. & . & .. & $\cdots$ & .. & . & . & + \\
\hline Astragalus danicus & .. & .. & . & . & . & . & . & . & . & .. & .. & . &.. & .. & . & . & $\cdots$ & $\cdots$ \\
\hline Astragalus frigidus & $\cdots$ & $\because$ & $\cdots$ & . & $\cdots$ & $\cdots$ & . & . & . & . & . & . & $\cdots$ & . & . & . & & - \\
\hline Botrychium lunaria... & . & 1 & .. & . & $\because$ & + & . & . & . & .. & .. & .. & $\cdot \cdot$ & $\cdots$ & + & . & $\cdot$ & . \\
\hline Bupleurum ........ & . & .. & .. & . & 1 & .. & .. & . & ... & .. & .. & . &.. & .. & . & .. & & \\
\hline $\begin{array}{l}\text { Bux } \\
\text { cf. }(\end{array}$ & . & . & .. & $\cdots$ & .. & .. & . & * & ". & . & .. & • & $\cdot$. & .. & . & .. & .. & \\
\hline -1, & . & $\cdot \cdot$ & $\cdot \cdot$ & $\ddot{*}$ & .. & .. & .. & $\ddot{1}$ & $\cdot \cdot$ & & $\cdot \cdot$ & &.$\cdot$ &. & & 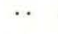 & & \\
\hline 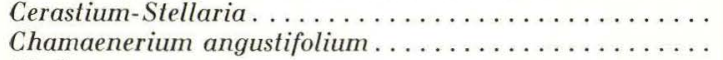 & $\cdots$ & $\cdot \cdot$ & & 3 & .. & $\ddot{1}$ & . & 1 & .. & 1 & . & . &.. & . & 2 & . & 1 & 1 \\
\hline $\begin{array}{l}\text { ifolium } \\
\ldots \ldots \ldots \ldots \\
\ldots \ldots \ldots \ldots \ldots \ldots\end{array}$ & $\cdots$ &.. & . & + & .. & 1 & .. & . & . & .. & . & .. &. & .. & 1 & .. & 1 & $\cdots$ \\
\hline 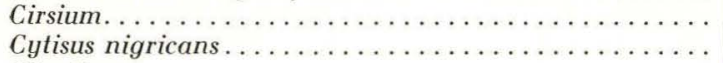 & . &.. & .. & . & . & . & .. & . & . & .. & $\cdot$. & .. & . & . & . & .. & 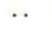 & $\cdots$ \\
\hline$\cdots \cdots \cdots \cdots \cdots$ & . &.. &.. & .. &. & . & .. & .. & .. & .. & $\cdot$. & .. & . & . & $\because$ & .. & & . \\
\hline $\begin{array}{l}\text { Dial } \\
\text { Eph }\end{array}$ & . & .. & .. & $\because$ & . & . & . & .. & .. & . & . & · & $\cdots$ & .. & 1 & .. & 2 & \\
\hline $\begin{array}{l}\text { Ephe } \\
\text { Ephe }\end{array}$ & .. & .. & $\ldots$ & + & .. & .. & . & . & . & *. & . & $\ldots$ & $\cdots$ &. & + & . & . & 1 \\
\hline $\begin{array}{l}\ldots \ldots \\
\ldots \ldots\end{array}$ & . & $\cdot$. & . & .. & .. & . & .. & 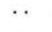 & .. & 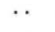 & .. & . & . & . & .. & . & $\cdots$ & . \\
\hline $\begin{array}{l}\cdots \cdots \\
\ldots \ldots\end{array}$ & $\because$ & .. & .. & + & .. & .. & .. & . & $\cdots$ & . & .. & .. & .. &.. & .. & .. & .. & .. \\
\hline $\begin{array}{l}\cdots \cdots \\
\ldots \ldots \ldots\end{array}$ & 1 &.. & .. & . & .. & $\cdots$ & . & . & .. & .. & .. & . & .. & .. & .. & .. & .. & 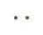 \\
\hline $\begin{array}{l}\cdots \cdots \cdots \cdots \\
\cdots \ldots \ldots \ldots \ldots\end{array}$ & . & .. & .. & . & .. & . & . & .. & .. & . & .. & .. & . &.. & .. & .. & .. & $\cdot$ \\
\hline $\begin{array}{l}\text { Genista. } \\
\text { Gentiana }\end{array}$ & $\cdots$ & .. & .. & . & . & . & .. & .. & .. & . & . & .. & .. &.. & . & . & .. & 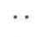 \\
\hline $\begin{array}{l}\text { Gentiana amas } \\
\text { Gentiana pneu }\end{array}$ & $\cdots$ & . & $\cdot \cdot$ & .. & . & + & .. & $\cdot \cdot$ & $\cdot \cdot$ & . & .. & $\cdot \cdot$ & $\cdot$. &.. & $\cdot \cdot$ & . & $\cdot$. & . \\
\hline$\cdots \cdot \cdots$ & $\cdots$ & .. & 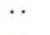 & .. & . & $\cdot$. & . & .. & . & . & .. & $\cdots$ & $\cdots$ & .. & $\cdots$ & . & . & . \\
\hline$\cdots \cdot \cdots$ & . & .. & . & .. & . & .. & .. & .. & .. & $\because$ & . & .. &. & .. & .. & $\cdot$ & . & . \\
\hline $\begin{array}{l}\text { GyI } \\
\mathrm{He}\end{array}$ & $\cdots$ & .. & . & .. & .. & . & . & . & $\cdot$ & 1 & . & 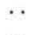 & $\cdot \cdot$ & $\cdot \cdot$ & . & $\cdot \cdot$ & . & * \\
\hline landicum. & .. & .. & $\begin{array}{l}. . \\
. .\end{array}$ & $\begin{array}{l}. \cdot \\
.\end{array}$ & .. & $\begin{array}{l}. \\
.\end{array}$ & . & .. & . & .. & . & $\cdots$ & $\cdots$ & $\cdots$ & & . & .. & $\cdot$ \\
\hline 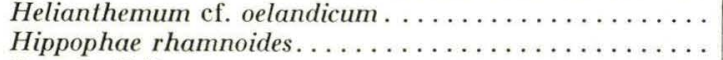 & $\begin{array}{l}. . \\
. .\end{array}$ & $\begin{array}{l}. . \\
. .\end{array}$ & $\begin{array}{l}. \\
. .\end{array}$ & $\begin{array}{l}. . \\
. .\end{array}$ & $\begin{array}{l}\cdots \\
. .\end{array}$ & $\begin{array}{l}\cdots \\
\cdots\end{array}$ & .. & $\begin{array}{l}. . \\
. .\end{array}$ & $\begin{array}{l}. \cdot \\
.\end{array}$ & $\begin{array}{l}\cdots \\
\ldots\end{array}$ & .. & .. & .. & $\ldots$ & $\begin{array}{l}1 \\
1\end{array}$ & $\ddot{x}$ & .. & $\cdot$ \\
\hline $\begin{array}{c}\cdots \cdots \cdots \cdots \cdots \cdots \cdots \cdots \cdots \\
\cdots \cdots \cdots \cdots \cdots\end{array}$ & .. & .. & .. & .. & .. & .. & .. & $\cdots$ & $\begin{array}{l}\cdots \\
. .\end{array}$ & $\begin{array}{l}\cdots \\
\cdots\end{array}$ & $\begin{array}{l}\cdots \\
\ldots\end{array}$ & $\begin{array}{l}. \\
. .\end{array}$ & $\begin{array}{l}\cdots \\
\cdots\end{array}$ & $\begin{array}{l}\cdots \\
. .\end{array}$ & $\begin{array}{c}1 \\
{[+]}\end{array}$ & $\begin{array}{l}. . \\
. .\end{array}$ & & .. \\
\hline$\ldots \ldots \ldots \ldots \ldots \ldots \ldots$ & $\cdots$ & $\cdots$ & $\cdots$ & . & . & .. & . & .. & . & .. & $\ddot{.}$ & $\begin{array}{l}\cdots \\
. .\end{array}$ & $\ddot{*}$ & $\cdots$ &.. & .. & $\begin{array}{l}\cdots \\
. .\end{array}$ & $\begin{array}{l}\cdots \\
\cdots\end{array}$ \\
\hline$\cdots \cdots \cdots \cdots \cdots \cdots \cdots$ & . & .. & .. & .. & .. & .. & .. & .. & .. & .. & . & .. & .. & $\cdots$ & .. & . & . & .. \\
\hline$\ldots \ldots \ldots \ldots \ldots \ldots$ & .. & .. & . & .. & . & . & . & .. & . & .. & . & . & . & .. & .. & $\cdots$ & .. & . \\
\hline$\ldots \ldots \ldots \ldots \ldots$ & $\cdots$ & .. & $\cdots$ & .. & . & $\cdots$ & . & . & . & . & . & . & . & .. & .. & .. & . & . \\
\hline$\ldots \ldots \ldots \ldots \ldots \ldots$ & .. & .. & + & .. & . & . & .. & .. & .. & .. & . & .. & .. & .. & .. & .. & . & .. \\
\hline$\ldots \ldots \ldots \ldots$ & .. & .. & .. & $\cdots$ & 1 & . & .. & .. & . & .. & .. & $\cdots$ & $\cdots$ & .. & .. & . & $\cdots$ & .. \\
\hline Mal & .. & .. & .. & .. & . & .. & . & . & . & . & . & $\cdots$ & 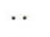 & .. & .. & . & .. & .. \\
\hline$M e$ & .. & .. & .. & .. & .. & $\cdots$ & $\cdots$ & .. & . & .. & .. & $\cdots$ & .. & .. & . & .. & .. & .. \\
\hline perenni & . & .. & .. & + & .. & .. & .. & .. & .. & .. & . & $\cdot \cdots$ & . & .. & . & . & .. & .. \\
\hline$M y$ & 1 & .. & . & . & . & .. & . & . & .. & . & + & . & $\cdot \cdot$ & $\cdot \cdot$ & $\therefore$ & .. & & \\
\hline$\cdots \ldots \ldots \ldots \ldots \ldots$ & . & $\cdots$ & .. & $\cdots$ & *. & .. & * & . & .. & $\ddot{1}$ & - & $\cdots$ & . & .. & + & . & 1 & .. \\
\hline 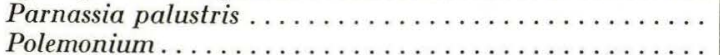 & $\cdots$ & .. & 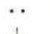 & . & . & . & . & . & .. & 1 & . & $\cdot \cdot$ & . & .. & .. & . & . & . \\
\hline $\begin{array}{l}\ldots \ldots \ldots \\
\cdots \ldots \ldots\end{array}$ & . & $\cdots$ & + & .. & .. & . & .. & . & .. & . & . & .. & . & .. & . & .. & .. & .. \\
\hline $\begin{array}{l}\text { Poly } \\
\text { Rosa }\end{array}$ & . & .. & .. & .. & .. & .. & .. & .. & .. & 1 & .. & .. & .. & .. & .. & .. & .. & .. \\
\hline $\begin{array}{l}\text { Rosa } \\
\text { Rubu }\end{array}$ & .. & .. & .. & .. & . & .. & . & .. & . & .. & .. & .. & .. & .. & . & .. & $\theta$ & . \\
\hline $\begin{array}{l}\cdots \cdots \cdots \cdots \cdots \cdots \\
\cdots \cdots \cdots \cdots \cdots\end{array}$ & .. & .. & .. & .. & .. & .. & . & .. & . & .. & .. & .. & . & .. & .. & $\cdots$ & 1 & . \\
\hline$\cdots \cdots \cdots \cdots \cdots$ & . & .. & .. & .. & .. & .. & . & .. & .. & .. & 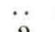 & .. & . & .. & . & . & $\cdots$ & . \\
\hline $\begin{array}{l}\ldots \ldots \ldots \ldots \ldots \ldots \\
\ldots \ldots \ldots \ldots \ldots \ldots\end{array}$ & . & .. & .. & . & .. & .. & . & . & .. & .. & 2 & .. & .. & . & . & .. & $\cdot$ & \\
\hline$\ldots \ldots \ldots \ldots$ & .. & .. & .. & $\cdots$ & .. & .. & . & . & .. & $\cdots$ & . & .. & . & .. & .. & .. & . & \\
\hline$\ldots \ldots \ldots \ldots$ & . & .. & . & .. & . & . & .. & .. & .. & .. & . & .. & . & .. & .. & - & . & \\
\hline 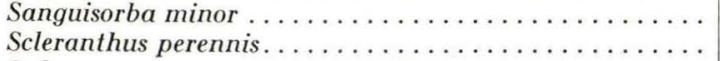 & .. & .. & .. & .. & . & .. & . & . & . & .. & . & .. & .. & .. & .. & . & .. & \\
\hline ( & .. & .. & .. & . & . & . & . & . & .. & .. & .. & .. &. & . & . & $\cdots$ & . &. \\
\hline ( & $\cdot \cdot$ & $\cdots$ & .. & . & . & . & . & . &. & .. & . & .. & . &. & .. & .. & .. & \\
\hline$\ldots \ldots \ldots$ & $\cdots$ & .. & .. & $\cdots$ & . & $\cdots$ & $\cdots$ & . & $\because$ & $\cdots$ & $\cdots$ & $\cdots$ & $\cdots$ &. & .. & $\cdots$ & .. & .. \\
\hline & & & & & & & & & 2 & .. & & . & .. & & & $\cdots$ & 1 & \\
\hline
\end{tabular}


Bog. BP 1 (STA).

grains or spores. [ ] probally derived.

sporer. [ ] sandsynligvis omlejret.

\begin{tabular}{|c|c|c|c|c|c|c|c|c|c|c|c|c|c|c|c|c|c|c|c|c|c|c|c|c|c|c|c|c|c|c|c|c|}
\hline : & $\stackrel{\infty}{\stackrel{N}{*}}$ & $\bar{\sigma}$ & $\hat{\infty}$ & 8 & $\mathfrak{i}$ & $\begin{array}{l}8 \\
i \dot{0}\end{array}$ & $\overrightarrow{\mathrm{N}}$ & \& & : & $\vec{\infty}$ & $\begin{array}{l}\infty \\
\infty\end{array}$ & $\mathfrak{g}$ & $\mathscr{1}$ & $\begin{array}{l}\mathscr{O} \\
\dot{0} \\
\dot{0}\end{array}$ & $\stackrel{2}{2}$ & $\begin{array}{l}\infty \\
\infty\end{array}$ & : & is & $R$ & ન્| & $\&$ & $\underset{i}{\stackrel{8}{1}}$ & $\stackrel{\nabla}{.}$ & $\stackrel{\mathscr{N}}{\mathrm{N}}$ & $\stackrel{\bullet}{\circ}$ & $\vec{\sim}$ & $\mathscr{F}$ & 19 & $\vec{b} \quad \overrightarrow{0}$ & \begin{tabular}{l|l}
+ \\
$\qquad$
\end{tabular} & \begin{tabular}{l|l}
$:$ & 8 \\
$:$
\end{tabular} & $\stackrel{R}{R}$ \\
\hline
\end{tabular}

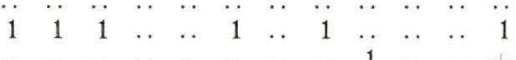

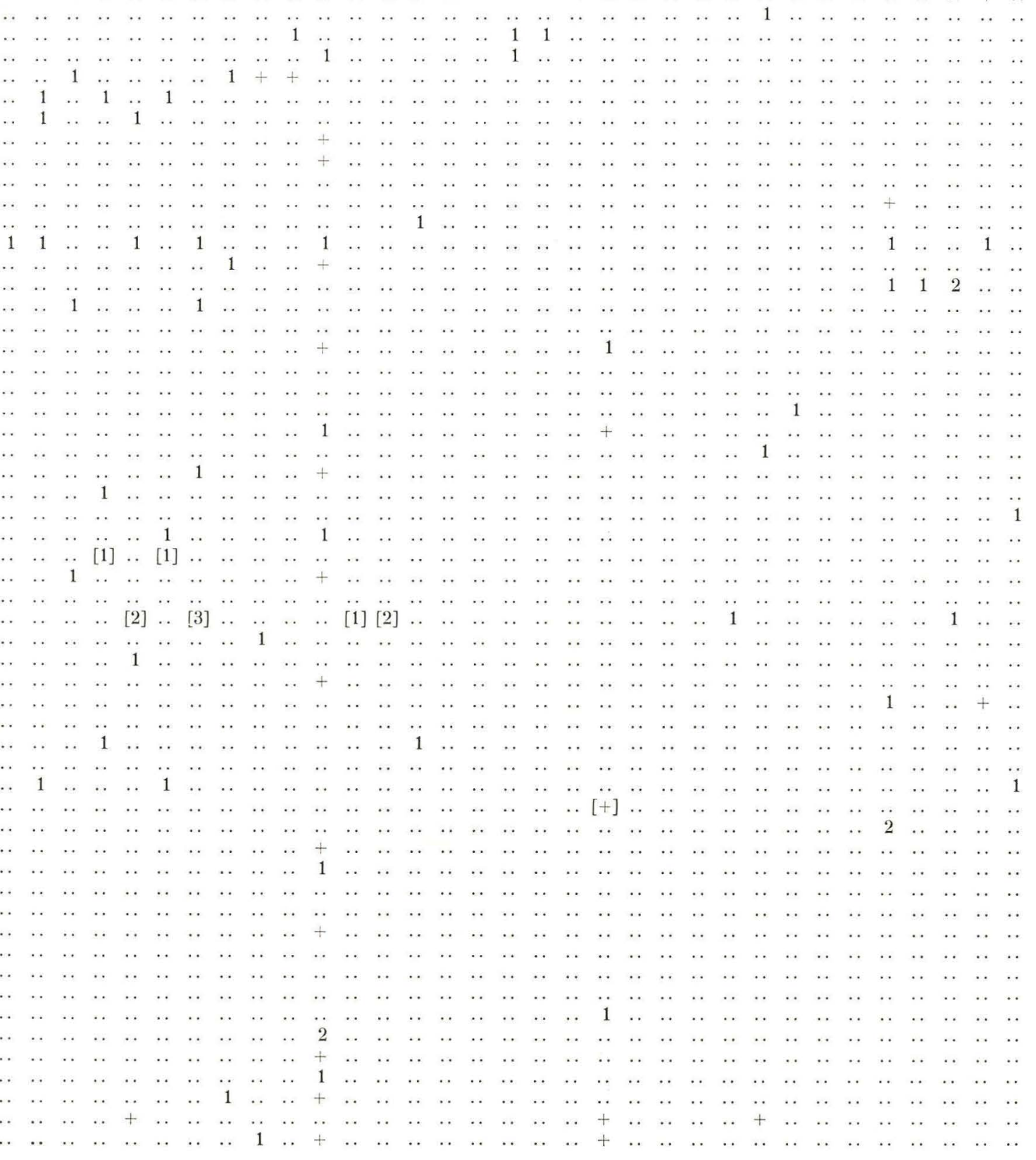


Table 28 (continued)

\begin{tabular}{|c|c|c|c|c|c|c|c|c|c|c|c|c|c|c|c|c|c|c|}
\hline Depth, m. & $\begin{array}{c}\mathscr{B} \\
\vec{i}\end{array}$ & $\approx$ & N & $\infty$ & $\stackrel{20}{\circ}$ & 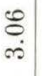 & 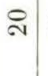 & ח2 & $\therefore$ & $\therefore$ & $\stackrel{\mathfrak{N}}{\infty}$ & $\infty$ & $\bar{\sigma}$ & S. & 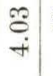 & $\stackrel{\text { I }}{\sim}$ & $\stackrel{2}{2}$ & ลี \\
\hline Solanum dulcamara $\ldots \ldots \ldots \ldots \ldots \ldots \ldots \ldots \ldots$ & $\cdots$ & .. & .. & .. &. & .. & . &.. & .. & . & . & 1 & . & . & . & .. & .. & . \\
\hline Sorbus aucuparia.......................... & . & .. & .. & .. & .. & .. & .. & .. & .. & .. & . & .. & .. & . & . & . & .. & $\cdots$ \\
\hline$\ldots \ldots \ldots \ldots \ldots \ldots \ldots \ldots \ldots \ldots \ldots \ldots \ldots \ldots$ & .. & .. & .. & .. & .. & .. & .. & .. & .. & .. & .. & .. & .. & . & .. & . & .. & . \\
\hline Stellaria holostea...................... & .. & .. & .. & .. & .. & .. & .. & .. & .. & .. & .. & .. & .. & . & .. & .. & .. & .. \\
\hline Swertia perennis . ....................... & . & .. & .. & .. & .. & .. & .. & .. & .. & .. & . & .. & .. & . & . & .. & .. & .. \\
\hline 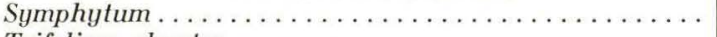 & . & 1 & .. & .. & .. & .. & .. & .. & .. & .. & .. & .. & .. & . & .. & .. & .. & .. \\
\hline$\ldots \ldots \ldots \ldots \ldots \ldots \ldots \ldots$ & .. & .. & .. & .. & .. & .. &.. & .. &.. & .. & . & .. & .. & .. & .. & .. & .. & .. \\
\hline Trifolium arvense. & .. & .. & .. & .. & .. & . & .. & .. & .. & .. & .. & .. & .. & .. & .. & .. & .. & .. \\
\hline ria $\ldots \ldots \ldots$ & $\because$ & .. & .. & .. & .. & 1 & . & $\because$ & .. & .. & . & .. & .. & .. & .. & .. & .. & $\cdots$ \\
\hline Vaccinium typ & 1 & . & .. & .. & .. & .. & .. & 2 & .. & .. & .. & $\cdot$. & .. & . & $\cdots$ & .. & .. & $\cdots$ \\
\hline Valeriana of ficir & $\cdots$ & $\cdot \cdot$ & $\cdot \cdot$ & + & $\cdots$ & .. & $\cdot \cdot$ & .. & $\cdot \cdot$ & $\cdot \cdot$ & . & .. & .. & .. & + & .. & $\cdot \cdot$ & .. \\
\hline Veronica.......... & $\cdots$ & $\cdots$ & $\cdots$ & $\cdots$ & 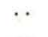 & $\because$ & $\cdot \cdot$ & $\cdots$ & $\cdot \cdot$ & $\cdot \cdot$ & . & .. & $\cdot \cdot$ & - & .. & $\ddot{1}$ & . & \\
\hline Vicia-Lathyrus . . & $\cdots$ & .. & .. & $\cdots$ & $\ldots$ & + & $\cdot \cdot$ & . & $\cdots$ & .. &.. & 1 & - & $\ldots$ & .. & + & .. & . \\
\hline$\cdots \ldots \ldots \ldots \ldots \ldots \ldots \ldots \ldots$ & $\cdots$ & . & $\cdot \cdot$ & . & $\cdot \cdot$ & $\cdot \cdot$ & $\cdot \cdot$ & $\cdot \cdot$ & $\cdot \cdot$ & *. & $\cdot \cdot$ & $\cdot \cdot$ & * & $\cdot \cdot$ & $\cdot \cdot$ & $\cdot \cdot$ & .. & - \\
\hline$\ldots \ldots \ldots \ldots \ldots$ & $\cdots$ & . & . & . & $\cdots$ & .. & $\cdot \cdot$ & $\cdots$ & .. & $\cdot \cdot$ & . & .. & $\cdot \cdot$ & .. & .. & .. & . & $\cdots$ \\
\hline Hippur & .. & .. & .. & .. & .. & + & .. & .. & .. & .. & .. & .. & .. & .. & .. & .. & .. & .. \\
\hline 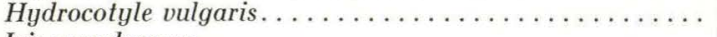 & . & .. & . & .. & .. & . & .. & .. & .. &.. & .. & .. & .. & .. & .. & .. & .. & . \\
\hline$\ldots \ldots \ldots \ldots \ldots \ldots$ & $\cdots$ & .. & . & .. & . & . & .. & .. & .. & .. & .. & .. & .. & .. & .. & .. & .. & $\because$ \\
\hline$\ldots \ldots \ldots$ & . & .. & .. & .. & .. & .. & .. & .. & .. & .. & $\because$ & .. & . & .. & .. & .. & $\cdots$ & 1 \\
\hline Lobelia dortmanna & .. & .. & .. & .. & .. & .. & .. & .. & .. & .. & 1 & .. & 1 & .. & .. & .. & .. & .. \\
\hline Lythrum salicaria. & .. & .. & . & .. & .. & .. & .. & .. & .. &.. & .. & .. & .. & .. & .. & .. & .. & .. \\
\hline Potamoget. sect. Coleoget & .. & .. & .. & .. & .. & .. & $\cdot$. & .. & .. &.$\cdot$ & .. & $\cdot \cdot$ & .. & .. & .. & .. & .. & .. \\
\hline Rumex-aquaticus-hydrolap & . & . & $\because$ & . & . & . & .. & $\cdot \cdot$ & .. & $\cdot \cdot$ & .. & .. & . & .. & . & . & .. & \\
\hline Typha latifolia ..... & $\cdots$ & .. & + & $\cdots$ & . & - & $\cdot \cdot$ & $\cdots$ & -. & .. & * & $\cdot \cdot$ & · & $\cdot$ & $\cdot \cdot$ & $\ddot{i}$ & . & \\
\hline Valeriana dioica... & $\cdots$ & & $\cdots$ & $\cdots$ & & . & .. & $\cdots$ & - & $\cdot \cdot$ & $\cdot \cdot$ & . & - & . & . & 1 & •. & 1 \\
\hline$\ldots \ldots \ldots \ldots \ldots \ldots \ldots \ldots \ldots$ & . & .. & + & .. &.. & .. & + & $\cdots$ & + & + & + & .. & .. & + & + & + & + & \\
\hline
\end{tabular}

1) Omitted from the pollen totals.

$\left.{ }^{2}\right)+$ indicates presence in the sample. 


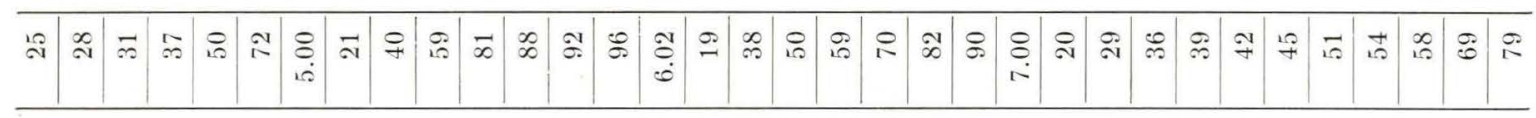

$\begin{array}{llllllllllllllllllllllllllllllllllllll}+ & \ldots & . & \ldots & \ldots & \ldots & \ldots & \ldots & \ldots & \ldots & \ldots & \ldots & \ldots & \ldots & \ldots & \ldots & \ldots & \ldots & \ldots & \ldots & \ldots & \ldots & \ldots & \ldots & \ldots & \ldots & \ldots & \ldots & \ldots & \ldots & \ldots & \ldots & \ldots & 1\end{array}$

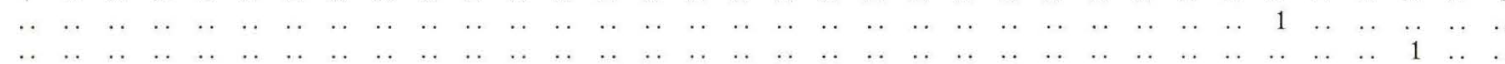

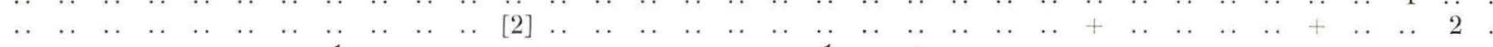

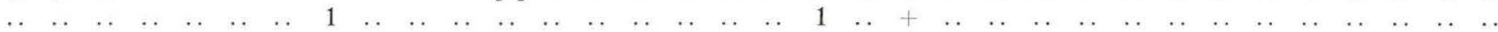

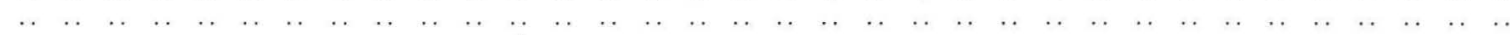

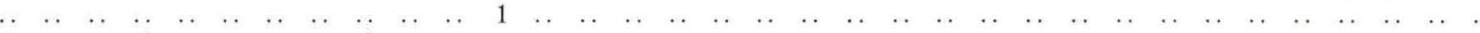

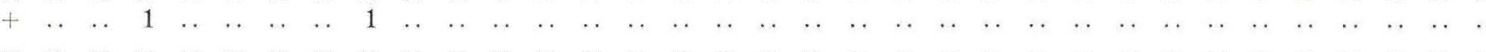

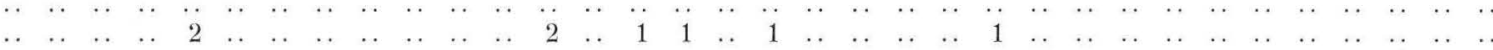

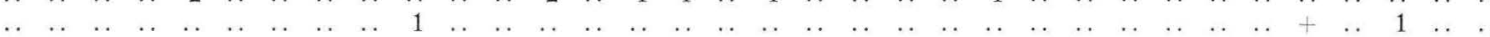

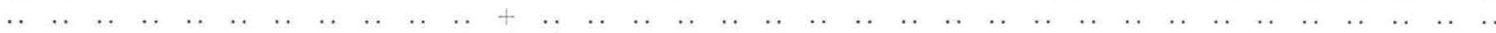

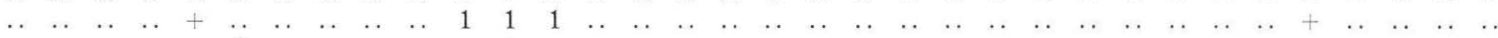

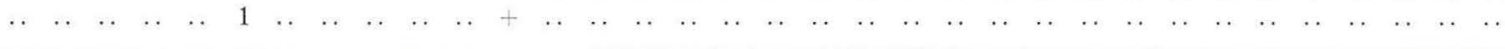

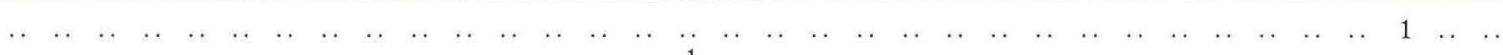

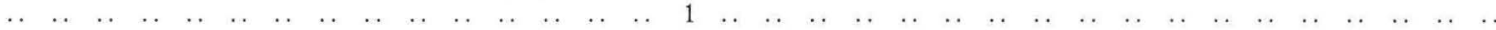

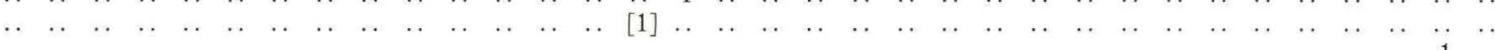

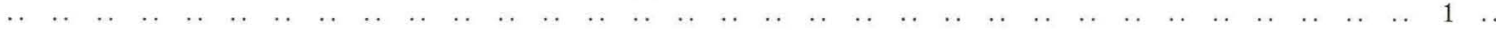

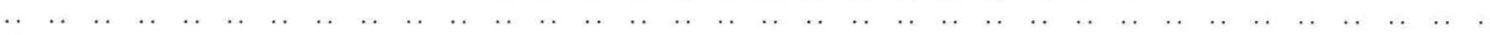

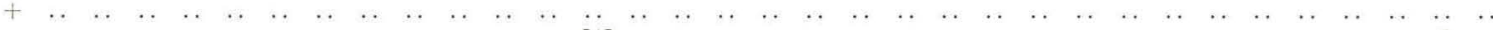

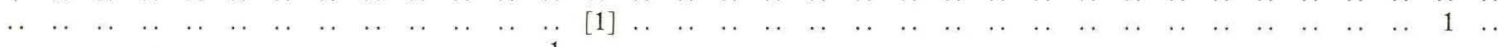

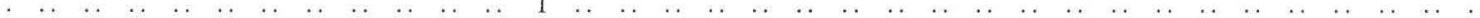

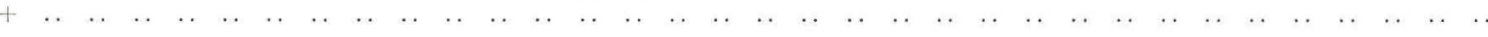

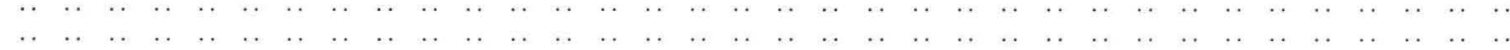

\begin{tabular}{lll}
..+ & + & + \\
\hline
\end{tabular} 
Table 29. Brørup Hotel Bog. BP 2 (STA).

The figures indicate numbers of pollen grains or spores. [ ] probably derived.

Tallene angiver antal af pollenkorn og sporer. [ ] sandsynligvis omlejret.

\begin{tabular}{|c|c|c|c|c|c|c|c|c|c|c|c|c|c|c|c|c|c|c|c|c|c|}
\hline Depth, m. & $\begin{array}{l}\infty \\
\text { sp }\end{array}$ & $\dddot{\infty}$ & ले & จ & $\overline{\mathrm{N}}$ & 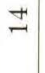 & 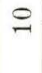 & 8 & O & 8 & $\begin{array}{l}\vec{A} \\
\stackrel{d}{i} \\
\end{array}$ & $\infty$ & $\underset{2}{\infty}$ & $\vec{\sim}$ & $\mathfrak{N}$ & $\stackrel{9}{6}$ & 6 & 8 & 6 & is & is \\
\hline$\cdots \ldots \ldots \ldots \ldots \ldots \ldots$ & $\cdot$. & . & & $\cdots$ & $\cdots$ &.. & .. & .. &. & $\cdot$. & $\cdots$ & $\cdots$ & $\cdots$ &.. & $\cdots$ & $\cdots$ &. &.. & $\cdots$ & $\cdots$ & [1] \\
\hline$\ldots \ldots \ldots \ldots$ & .. & .. & 1 & .. & . & .. & . & .. & .. & .. & . & .. & .. & .. & . & . & .. & .. & .. & .. & \\
\hline$\ldots \ldots \ldots \ldots \ldots$ & .. & $\because$ & $\cdots$ & .. & . & .. & .. & .. & .. & .. & .. & . & . & .. & $\cdots$ & . & .. & .. & .. & . & 2 \\
\hline Bistorta ..................... & $\because$ & 5 & 3 & .. & . & .. & .. & .. & .. & .. & .. & .. & . & .. & 2 & .. & .. & .. & . & 1 & .. \\
\hline Botrychium cf. lunaria. . . . . . . . . . . . . & 1 & .. & 1 & .. & . & .. & .. & .. & .. & .. & .. & . & . & .. & $\cdots$ & . & .. & .. & . & $\because$ & .. \\
\hline aria. ................ & $\because$ & .. & .. & .. & .. & .. & .. & .. & .. & $\cdot \cdot$ & . & . & . & . & .. & .. & .. & .. & .. & 1 & 2 \\
\hline Chamaenerium angust & 1 & .. & .. & . & .. & .. & .. & .. & .. & .. & .. & .. & $\cdots$ & .. & $\because$ & $\cdots$ & .. & .. & .. & . & . \\
\hline Cirsium. . . . . . . . . & .. & $\cdot \cdot$ & .. & .. & .. & .. & .. & .. & .. & .. & . & .. & .. & .. & 1 & $\cdots$ & .. & .. & .. & . & $\ddot{0}$ \\
\hline Cruciferae.... & $\cdot \cdot$ & $\cdot \cdot$ & .. & .. & $\cdots$ & .. & .. & .. & .. & .. & .. & .. & .. & .. & .. & .. & .. & .. & $\because$ & . & 2 \\
\hline Empetrum her & $\cdots$ & .. & $\cdots$ & .. & .. & $\cdots$ & . & .. & . & $\cdot \cdot$ & .. & .. & $\cdot \cdot$ & .. & .. & .. & $\cdots$ & - & 2 & 2 & 2 \\
\hline$\ldots \ldots \ldots \ldots \ldots$ & .. & .. & $\cdots$ & .. & . & $\cdots$ & .. & $\because$ & $\because$ & . & .. & .. & .. & .. & .. & .. & .. & .. & .. & . & 1 \\
\hline$x \ldots \ldots \ldots$ & .. & .. & .. & .. & .. & .. & .. & 2 & 1 & .. & .. & .. & .. & .. & .. & & .. & .. & .. & .. & $\because$ \\
\hline дре......... & 2 & 1 & .. & .. & -. & .. & .. & .. & 1 & $\because$ & .. & .. & 1 & . & .. & 2 & .. & . & .. & 1 & 1 \\
\hline$\ldots \ldots \ldots \ldots \ldots$ & .. & $\because$ & .. & . & $\cdots$ & .. & . & .. & $\cdots$ & 1 & .. & .. & $\cdot \cdot$ & . & .. & $\cdots$ & .. & .. & .. & .. & $\cdots$ \\
\hline$\ldots \ldots \ldots$ & .. & 1 & . & . & .. & .. & .. & + & . & .. & .. & $\cdots$ & .. & . & $\cdot \cdot$ & $\cdots$ & $\cdot \cdot$ & . & $\because$ & $\because$ & $\because$ \\
\hline$\cdots$ & .. & 1 & .. & .. & .. & .. & . & .. & .. & .. & . & $\cdot \cdot$ & .. & .. & .. & $\cdots$ & .. & .. & 1 & 1 & 1 \\
\hline Heder & .. & $\cdot \cdot$ & $\cdot \cdot$ & .. & .. & .. & .. & .. & .. & .. & .. & .. & .. & .. & .. & .. & .. & .. & $\cdot \cdot$ & [1] & . \\
\hline Hum & .. & $\cdot \cdot$ & .. & . & $\cdots$ & $\cdots$ & .. & .. & .. & 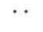 & $\cdot \cdot$ & . & $\cdot \cdot$ & .. & .. & $\therefore$ & .. & $\cdots$ & .. & $\because$ & 1 \\
\hline ifolium & $\cdots$ & $\cdot \cdot$ & $\cdots$ & . & .. & .. & .. & $\because$ & .. & .. & .. & .. & .. & .. & .. & [1] & .. & $\cdots$ & .. & {$[2]$} & .. \\
\hline . & $\because$ & . & .. & . & .. & .. & $\cdots$ & 1 & .. & . & .. & .. & .. & .. & .. & .. & .. & .. & & .. & $\because$ \\
\hline$L$ & 1 & .. & .. & .. & .. & .. & . & .. & . & 1 & .. & .. & $\cdot \cdot$ & .. & .. & .. & .. & .. & .. & $\cdots$ & 1 \\
\hline$\cdots$ & 1 & .. & .. & .. & .. & .. & . & $\because$ & .. & .. & . & .. & .. & .. & .. & .. & .. & .. & .. & $\because$ & .. \\
\hline . & $\because$ &.. & . & . & $\cdots$ & $\because$ & . & 1 & . & .. & $\because$ & $\cdot \cdot$ & $\cdot \cdot$ & . & $\cdot \cdot$ & . & .. & .. & . & 1 & $\cdot \cdot$ \\
\hline tum & 1 & 2 & .. & . & .. & 1 & $\cdots$ & .. & .. & .. & 1 & .. & $\cdot \cdot$ & .. & $\cdot \cdot$ & . & .. & .. & $\cdot \cdot$ & *. & $\cdot \cdot$ \\
\hline . & 1 & $\cdot \cdot$ & .. & . & .. & $\cdots$ & $\cdot \cdot$ & . & $\cdot \cdot$ & .. & $\cdots$ & $\cdots$ & . & . & $\cdots$ & .. &.. & .. & . & $\cdot$ & .. \\
\hline. & $\ldots$ & . & . & & $\ldots$ & $\cdots$ & . & .. & $\cdot \cdot$ & . & 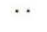 & $\cdots$ & · & $\cdot$. & 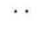 & 1 &.. & $\cdots$ & $\cdot$ & $\because$ & . \\
\hline . & $\ddot{v}$ & $\ddot{1}$ & .. & 1 & $\cdots$ & $\cdots$ & . &.. & 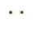 & .. & $\cdot$. & $\cdots$ & .. & $\because$ & 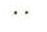 & 1 & $\ldots$ & .. & . & 1 & . \\
\hline$a \ldots \ldots \ldots$ & 2 & 1 & . & .. & $\ldots$ & .. & . &.. & .. & .. & .. & $\ldots$ &.. & 1 & .. &.. & .. & $\ldots$ & $\ldots$ & 2 &.. \\
\hline . & .. & .. & 1 & . & .. & .. & . & $\because$ & .. & .. & .. & .. & .. & .. & .. & . & .. & .. & .. & .. & .. \\
\hline . & .. & . & .. & $\cdots$ & .. & .. & . & 1 & . & .. & $\cdot \cdot$ & .. & .. & .. & .. & . & .. & .. & . & . & .. \\
\hline . & .. & 1 & .. & .. & .. & . & . &. & . & .. & .. & .. & .. & .. & $\because$ & . &.. & .. & . & $\because$ & .. \\
\hline . & .. & 2 & . & . & .. & $\cdots$ & . & .. & $\cdots$ & 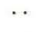 & & $\cdots$ & $\cdots$ & . & 1 & . &.. & .. & . & 2 &.. \\
\hline . & $\cdots$ & $\cdot \cdot$ & $\ddot{i}$ & $\cdot \cdot$ & $\cdots$ & $\cdots$ & . & $\cdot \cdot$ & $\ddot{i}$ & $\cdots$ & 1 & $\cdots$ & $\cdots$ & $\cdot \cdot$ & $\cdot \cdot$ & $\cdot \cdot$ & $\cdot \cdot$ & $\cdots$ & $\cdot \cdot$ & $\cdot \cdot$ & $\cdot$. \\
\hline$\cdot$ & $\cdot \cdot$ & $\cdots$ & 1 & · & $\cdot \cdot$ & $\cdot \cdot$ & 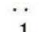 & $\because$ & 1 & $\cdots$ & $\cdot \cdot$ & $\cdots$ & . & $\cdot \cdot$ & $\cdot \cdot$ & $\cdots$ & .. & $\cdots$ & $\cdot$ & 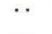 & $\cdots$ \\
\hline$\cdot$ & $\cdots$ & .. & $\cdots$ & .. & $\cdots$ & . & 1 & 1 &. & & .. &. & . & $\cdot$ & $\cdots$ & $\cdot \cdots$ & $\cdot \cdot$ & · & $\cdot$ & 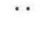 & $\cdots$ \\
\hline $\begin{array}{l}\text { Tilia........... } \\
\text { Vicia-Lathurus }\end{array}$ & 1 & $\cdots$ & $\cdots$ & $\cdots$ & $\cdots$ & .. & . & $\cdot \cdot$ & * & 1 & - & $\cdots$ & .. & $\cdot$ &.. & * &.. & . & . & $\cdots$ & .. \\
\hline Vicia-Lathyrus . & 1 & $\cdot \cdots$ & $\cdot \cdot$ & $\cdots$ & $\cdot \cdot$ & $\cdot \cdot$ & - & $\cdot \cdot$ & $\cdot \cdot$ & $\cdot \cdot$ & $\cdot \cdot$ & $\cdot \cdot$ & $\cdot \cdot$ & - & $\cdot \cdot$ & . & $\cdot \cdot$ & $\cdot \cdot$ & 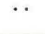 & . & . \\
\hline & 1 & . & . & . & . & $\cdots$ & .. & 1 & .. & $\cdots$ & $\cdots$ & $\cdots$ & $\cdots$ & 1 &.. & $\cdots$ &.. & $\cdots$ & $\cdots$ & .. & 1 \\
\hline Elism & 2 & . & .. & .. &. & .. & . & . &.. & . & . & $\cdots$ & .. & .. & .. & . & . & .. & 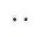 & . & . \\
\hline Litto & .. & .. & & . & . & . & . & .. & .. & . & .. & $\ldots$ & .. & . & .. & .. & $\ldots$ & $\ldots$ & . & . & 5 \\
\hline Lysit & . & . & 1 & . & .. & .. & - & .. & .. & $\cdots$ &.. & .. & .. & .. & .. & . & .. & .. & $\cdot$. & .. & $\because$ \\
\hline Ranunculus acer type........... & 1 & . & 2 &. & .. & .. & $\cdots$ & $\cdot \cdot$ & . & . & $\cdot \cdot$ & .. & .. & $\cdot \cdot$ & .. & $\cdot \cdot$ & .. & . & . & 1 & 1 \\
\hline Pediastr & & + & & $\cdots$ & $\cdots$ & . & $\cdots$ & 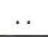 & 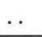 & 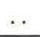 & & &. & 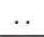 & .. & .. & .. & . &.. & + & 4 \\
\hline
\end{tabular}

1) Omitted from the pollen totals.

$\left.{ }^{2}\right)+$ indicates presence in the sample. 
Table 30. Rodebæk I.

The figures indicate numbers of pollen grains and spores. [ ] presumably derived.

Tallene angiver antal af pollenkorn og sporer. [ ] sandsynligvis omlejret.

\begin{tabular}{|c|c|c|c|c|c|c|c|c|c|c|c|c|c|c|c|c|c|c|c|c|c|c|c|c|}
\hline Depth, m. & 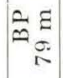 & 要 & 年 & $\dddot{F}$ & \& & के & $\stackrel{\curvearrowright}{2}$ & 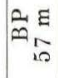 & $\begin{array}{l}\vec{\infty} \\
\dot{\pi}\end{array}$ & $\overrightarrow{0}$ & : & $\begin{array}{l}\infty \\
\infty\end{array}$ & $\stackrel{\sim}{\infty}$ & $\infty$ & $\mathscr{\theta}$ & \pm & $\stackrel{9}{\sim}$ & $\stackrel{2}{8}$ & $\begin{array}{ll}\vec{\infty} & 1 \\
\infty & \end{array}$ & 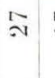 & $\cong$ & $\dot{8}$ & $\begin{array}{l}\dot{D} \\
\infty \\
i\end{array}$ & 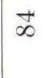 \\
\hline ef. Adonis. & & 3 & 1 & 2 & 1 & + & 1 & & $\cdots$ & .. & .. & .. & .. & .. & .. & .. & . & .. & .. & .. & + & 1 & + & .. \\
\hline Ajuga reptans. & & .. & . & . & .. & .. & .. & & . & .. & . & 1 & .. & . & . & . & . & . & .. & . & .. & .. & . & .. \\
\hline Anemone .............. & & .. & . & 1 & . & .. & . & & .. & . & . & . & .. & 1 & . & .. & . & . & . . & .. & .. & .. & .. & .. \\
\hline Anthyllis vulneraria ......... & & .. & . & . & .. & .. & . & & .. & . & . & .. & .. & . & .. & .. & . & . & . . & .. & & .. & .. & . \\
\hline rctostaphylos alpina . ........ & & .. & .. & .. & .. & .. & .. & & .. & . & .. & .. & .. & .. & 1 & . & .. & .. & .. & .. & .. & .. & . & .. \\
\hline Armeria maritima . . . . . . . & & .. & .. & . & $\cdots$ & + & .. & & & & & & & & & & & & & & & & & \\
\hline$\ldots \ldots \ldots \ldots$ & & .. & . & . & . & + & .. & & . & . & $\cdots$ & . & . & . & . & . & . & . & .. & .. & + & 2 & + & .. \\
\hline Botrychium cf. lunaria........ & & .. & .. & $\ldots$ & $\cdots$ & + & . & & . & .. & $\cdots$ & - & $\ldots$ & .. & . & . & .. & . & .. & .. & .. & . & .. & .. \\
\hline$s \ldots \ldots \ldots \ldots$ & & . & .. & .. & .. & {$[t]$} & 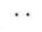 & & .. & .. & .. & .. & .. & .. & .. & .. & .. & .. & .. & .. & . & .. & . & . \\
\hline$\ldots \ldots \ldots$ & & .. & . & .. & . & .. & . & & . & .. & . & . & .. & .. & .. & .. & .. & . & .. & .. & + & . & . & . \\
\hline$a \ldots \ldots \ldots \ldots$ & & .. & .. & .. & .. & .. & . & & .. & . & . & . & . & .. & .. & .. & .. & . & . & .. & .. & .. & . & 1 \\
\hline$\ldots \ldots \ldots \ldots$ & & .. & .. & .. & 1 & .. & 1 & & . & . & . & . & . & 1 & 1 & . & .. & . & .. & .. & . & .. & . & . \\
\hline Cirsium. . . . . . . . . . . & & .. & . & $\because$ & . & $\because$ & . & & .. & . & .. & 1 & .. & .. & . & . & .. & . & . & .. & . & . & . & .. \\
\hline $\begin{array}{l}\text { Cruciferae . . . } \ldots \ldots \ldots \ldots \ldots \\
\text { Ephedra distachya } \ldots \ldots \ldots \ldots \ldots\end{array}$ & & $\begin{array}{l}\cdots \\
. .\end{array}$ & $\begin{array}{l}. \\
. .\end{array}$ & $\begin{array}{r}1 \\
\ldots\end{array}$ & $\begin{array}{l}\cdots \\
\cdots\end{array}$ & $\begin{array}{r}1 \\
\ldots\end{array}$ & $\begin{array}{l}\cdots \\
\ldots\end{array}$ & & .. & .. & .. & & & $\ldots$ & & & & & & + & & & & \\
\hline - ef. strobilacea. ....... & & .. & .. & 1 & .. & $\cdots$ & $\cdots$ & & $\cdots$ & $\ldots$ & .. & $\begin{array}{l}\cdots \\
.\end{array}$ & $\cdots$ & $\cdots$ & $\cdots$ & $\begin{array}{l}\cdots \\
\ldots\end{array}$ & $\begin{array}{l}\cdots \\
\ldots\end{array}$ & $\cdots$ & $\begin{array}{l}\cdots \\
. \\
.\end{array}$ & .. & $\begin{array}{l}\cdots \\
. .\end{array}$ & $\begin{array}{l}\cdots \\
. .\end{array}$ & $\begin{array}{l}\cdots \\
\ldots\end{array}$ & .. \\
\hline$\ldots \ldots \ldots \ldots$ & & .. & .. & .. & .. & .. & .. & & .. & .. & .. & .. & .. & .. & .. & .. & .. & . & 1 & .. & .. & .. & .. & .. \\
\hline 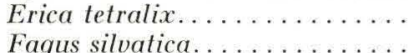 & & .. & . & .. & {$[1]$} & .. & . & & & & & & & & & & & & & & & & & \\
\hline 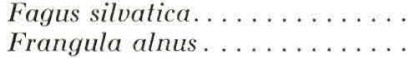 & & $\cdot \cdot$ & . & .. & $\cdots$ & .. & . & & . & .. & .. & .. & .. & .. & .. & . & .. & .. & .. & .. & + & .. & .. & .. \\
\hline $\begin{array}{l}\text { Frangula alnus } \ldots \ldots \ldots \ldots \ldots \\
\text { Genista } \ldots \ldots \ldots \ldots \ldots \ldots\end{array}$ & & .. & .. & .. & .. & .. & .. & & .. & .. & .. & .. & .. & .. & .. & 1 & .. & 1 & .. & .. & .. & .. & .. & .. \\
\hline $\begin{array}{l}\text { Genista . . . . . . . . . . . . . } \\
\text { Gentiana amarella type....... }\end{array}$ & & .. & .. & .. & $\because$ & $\because$ & .. & & . & . & .. & 2 & . & . & . & . & . & . & .. & .. & .. & .. & .. & .. \\
\hline $\begin{array}{l}\text { Gentiana amarella type. } \ldots \ldots \ldots \\
\text { Geum } \ldots \ldots \ldots \ldots \ldots \ldots \ldots \ldots\end{array}$ & & $\begin{array}{l}\cdots \\
.\end{array}$ & $\begin{array}{l}. . \\
\ldots\end{array}$ & $\begin{array}{l}\cdots \\
\ldots\end{array}$ & $\begin{array}{c}1 \\
\ldots\end{array}$ & $\begin{array}{l}1 \\
2\end{array}$ & $\begin{array}{l}\cdots \\
\cdots\end{array}$ & & & & & & & & & & & & & & & & & \\
\hline 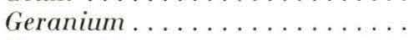 & & 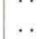 & .. & .. & .. & .. & .. & & .. & .. & .. & .. & .. &.. & 1 & .. & .. &.. & .. &.. & .. & .. & $\ldots$ &.. \\
\hline hila $\ldots \ldots \ldots \ldots \ldots$ & & .. & .. & .. & .. & .. & .. & & .. & . & .. & .. & .. & .. & .. & .. & .. & .. & $\ldots$ & . & + & .. & .. & .. \\
\hline$\ldots \ldots \ldots \ldots$ & & .. & . & .. & .. & .. & .. & & .. & 1 & .. & .. & .. & .. & .. & .. & .. & .. & .. & . & .. & .. & . & .. \\
\hline Hippophaё rhamnoides........ & & .. & . & .. & .. & . & .. & & . & . & .. & .. & .. & . & .. & .. & .. & .. & .. & . & .. & .. & 1 & .. \\
\hline Liguliflorae. & & .. & 1 & 1 & .. & 2 & .. & & .. & . & 2 & .. & .. & .. & .. & .. & .. & .. & .. & .. & .. & .. & .. & .. \\
\hline Lycopodium alpinum-compl.... . & & .. & . & .. & .. & .. & 2 & & .. & .. & .. & .. & .. & .. & $\because$ & .. & .. & .. & .. & .. & . & .. & 1 & .. \\
\hline clavatum........ & & .. & .. & .. & .. & .. & . & & .. & . & .. & .. & .. & .. & 1 & .. & .. & . & .. & . & . & .. & .. & 1 \\
\hline compl. ssp. cham... & & .. & .. & . & .. & .. & .. & & .. & .. & .. & .. & .. & .. & .. & . & . & . & .. & . & . & . & $\because$ & 1 \\
\hline selago $\ldots \ldots \ldots \ldots$ & & $\cdots$ & .. & .. & .. & 1 & .. & & .. & . & $\because$ & .. & . & .. & . & .. & . & . & . & . & .. & .. & 1 & . \\
\hline Malus silvestris . . . . . . . . . & & .. & .. & .. & .. & .. & .. & & .. & .. & 1 & .. & .. & .. & .. & .. & .. & .. & .. & .. & .. & .. & .. & .. \\
\hline $\begin{array}{l}\text { Melampyrum . . } \ldots \ldots \ldots \ldots \ldots \\
\text { Melandrium . . } \ldots \ldots \ldots \ldots \ldots\end{array}$ & & $\cdots$ & 1 & $\begin{array}{l}\cdots \\
\ldots\end{array}$ & $\ddot{1}$ & $\begin{array}{l}\cdots \\
\ldots\end{array}$ & .. & & & & & & & & & & & & & & & & & \\
\hline 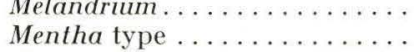 & & $\begin{array}{l}\cdots \\
\cdots\end{array}$ & $\begin{array}{l}\cdots \\
\cdots\end{array}$ & $\begin{array}{l}\cdots \\
. .\end{array}$ & $\ldots$ & $\ddot{1}$ & $\begin{array}{l}\cdots \\
. .\end{array}$ & & $\begin{array}{l}\cdots \\
\ldots\end{array}$ & $\ldots$ & $\begin{array}{l}\cdots \\
\ldots\end{array}$ & $\begin{array}{l}. . \\
. .\end{array}$ & .. & $\begin{array}{l}. . \\
. .\end{array}$ & $\begin{array}{l}\cdots \\
\ldots\end{array}$ & 2 & $\begin{array}{l}\cdots \\
.\end{array}$ & .. & $\begin{array}{l}\cdots \\
.\end{array}$ & $\ddot{1}$ & & $\begin{array}{l}\cdots \\
\ldots\end{array}$ & .. & $\cdot \cdot$ \\
\hline Mercurialis perennis . . . . . . . . & & .. & .. & .. & .. & .. & .. & & .. & . & .. & .. & .. & .. & .. & .. & .. & .. & .. & .. & {$[+]$} & .. & $\begin{array}{l}. . \\
. .\end{array}$ & $\begin{array}{l}\cdots \\
. .\end{array}$ \\
\hline Myrica gale . . . . . . . . . & & .. & .. & .. & .. & .. & .. & & .. & . & .. & .. & .. & .. & .. & .. & .. & .. & [1] & .. & {$[+]$} & .. & .. & .. \\
\hline Ophioglossum vulgatum ....... & & .. & .. & .. & .. & .. & .. & & $\ldots$ & .. & .. & .. & .. & .. & .. & .. & .. & 1 & . & .. & 1 & .. & .. & .. \\
\hline$a \ldots \ldots \ldots \ldots \ldots$ & & .. & .. & $\because$ & .. & .. & $\because$ & & .. & .. &.. & . & .. & . & .. & .. & .. & .. & 1 & .. & .. & .. & .. & 1 \\
\hline lgare........... & & .. & .. & 1 & .. & .. & 1 & & .. & .. & .. & .. & .. & 1 & .. & .. & .. & .. & .. & .. & .. & .. & .. & .. \\
\hline Populus tremula.. & & .. & 1 & . . & .. & 1 & .. & & .. & . & . & . & . & .. & $\cdots$ & .. & . & 1 & 1 & .. & . & .. & 2 & 1 \\
\hline $\begin{array}{l}\text { Potentilla } \ldots \ldots \ldots \ldots \ldots \\
\text { Pteridium aquilinum } \ldots \ldots\end{array}$ & & $\begin{array}{l}. . \\
\ldots\end{array}$ & $\begin{array}{c}3 \\
\ldots\end{array}$ & $\begin{array}{l}2 \\
2\end{array}$ & 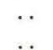 & $\begin{array}{l}\cdots \\
.\end{array}$ & .. & & & & & & & & & & & & & & & & & \\
\hline $\begin{array}{l}\text { Pteridium aquil } \\
\text { Rubus arcticus . }\end{array}$ & & .. & $\begin{array}{l}\cdots \\
. .\end{array}$ & .. & .. & $\begin{array}{l}. . \\
.\end{array}$ & .. & & .. & & .. & .. & & . & .. & .. & 1 & .. & .. & .. & . & .. & .. & \\
\hline - idaeus & & 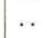 & .. & .. & .. & .. & .. & & $\ldots$ & .. & 1 & .. & .. & .. & .. & .. & . & .. & .. & . & . & $\ldots$ & .. & .. \\
\hline - saxatile. & & .. & .. & .. & .. & .. & . & & .. & .. & .. & .. & .. & .. & .. & .. & 1 & .. & .. & .. & . & . & .. & .. \\
\hline Sanguisorba of ficinalis . ....... & & .. & .. & .. & .. & + & .. & & .. & .. & .. & .. & .. & .. & . & .. & . & .. & .. & .. & .. & 1 & .. & .. \\
\hline minor $\ldots \ldots \ldots \ldots$ & & .. & .. & .. & . & + & .. & & .. & .. & .. & .. & .. & .. & .. & .. & .. & .. & .. & .. & + & .. & .. & .. \\
\hline$\ldots \ldots \ldots$ & & .. & .. & .. & .. & .. & $\ldots$ & & .. & .. & .. & .. & .. & .. & .. & .. & .. & .. & .. & .. & .. & .. & 1 & .. \\
\hline Stellaria holostea... & & .. & .. & . & $\ldots$ & [1] & 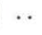 & & 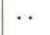 & .. &.. & 1 & + & .. & .. & .. & .. &.. & .. & .. & .. & .. &.. & $\because$ \\
\hline Teucrium montanum. ........ & & . & . & . & . & .. & $\because$ & & 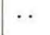 & .. & .. & .. & . & .. & .. & .. & . & .. & .. & .. & . & .. & .. & 1 \\
\hline Thalictrum. & & $\ldots$ & * & 1 & $\begin{array}{l}1 \\
1\end{array}$ & $\ddot{+}$ & 1 & & . & . & .. & .. & 1 & .. & .. &.. & 1 &.. & .. & .. & .. & .. &.. & .. \\
\hline $\begin{array}{l}\text { Thelypteris dryopteris......... } \\
\text { Tilia.................... }\end{array}$ & & & & & & & & & & & & & & & & & & & & & & & & \\
\hline
\end{tabular}


Table 30 (continued)

\begin{tabular}{|c|c|c|c|c|c|c|c|c|c|c|c|c|c|c|c|c|c|c|c|c|c|c|c|c|}
\hline Depth, m & 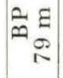 & 욤 & 于 & $\mathscr{F}$ & 아 & ウ & คి & ${ }_{\infty}^{2} \varepsilon$ & $\begin{array}{l}\dot{\infty} \\
+\end{array}$ & $\overline{6}$ & 옹 & $\stackrel{\infty}{\infty}$ & $\stackrel{\infty}{\sim}$ & $\stackrel{\infty}{\sim}$ & $\stackrel{\bullet}{\bullet}$ & $\Xi$ & $\cong$ & 28 & के & ลั & $\approx$ & g & $\begin{array}{l}\text { D } \\
\text { î }\end{array}$ & 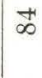 \\
\hline \multirow{2}{*}{ 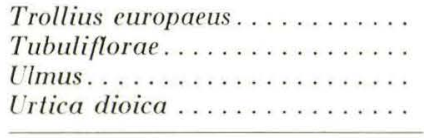 } & & \multirow{2}{*}{$\begin{array}{l}\cdots \\
\cdots \\
\cdots \\
\cdots\end{array}$} & \multirow{2}{*}{$\begin{array}{l}\cdots \\
\cdots \\
\cdots \\
1\end{array}$} & \multirow{2}{*}{$\begin{array}{l}\because \\
1 \\
1 \\
\cdots\end{array}$} & \multirow{2}{*}{$\begin{array}{l}\cdots \\
\cdots \\
\cdots \\
\cdots\end{array}$} & \multirow{2}{*}{$\begin{array}{l}1 \\
\cdots \\
\cdots \\
\cdots\end{array}$} & \multirow{2}{*}{$\begin{array}{l}\ddot{2} \\
2 \\
.\end{array}$} & & \multicolumn{2}{|c|}{$\cdots \quad \cdots$} & & \multicolumn{2}{|c|}{. $\quad}$. & & $\cdots$ & . & .. & .. & .. & .. & .. & . & \multicolumn{2}{|c|}{....} \\
\hline & & & & & & & & & $\cdots$ & $\cdots$ & $\cdots$ & $\cdots$ & $\cdots$ & .. & $\cdots$ & . & .. & . & *. & . & $\cdots$ & . & . & . \\
\hline $\begin{array}{l}\left.\text { Caltha palustris }{ }^{2}\right) \ldots \ldots \ldots . . . . . \\
\text { Drosera anglica-rotundifolia.... }\end{array}$ & & $\begin{array}{l}\cdots \\
\cdots\end{array}$ & $\begin{array}{l}\cdots \\
\cdots\end{array}$ & $\begin{array}{l}\cdots \\
\cdots\end{array}$ & $\begin{array}{l}. . \\
\cdots\end{array}$ & $\begin{array}{c}1 \\
\cdots\end{array}$ & $\begin{array}{l}\cdots \\
\cdots\end{array}$ & & $\begin{array}{l}. . \\
. .\end{array}$ & $\begin{array}{l}. . \\
\cdots\end{array}$ & $\begin{array}{l}. . \\
. .\end{array}$ & $\begin{array}{l}. . \\
\cdots\end{array}$ & $\begin{array}{l}\cdots \\
\cdots\end{array}$ & $\begin{array}{l}\cdots \\
\cdots\end{array}$ & $\begin{array}{l}\cdots \\
\cdots\end{array}$ & $\begin{array}{l}\cdots \\
\cdots\end{array}$ & $\begin{array}{l}. . \\
. .\end{array}$ & $\begin{array}{l}. \\
. .\end{array}$ & $\begin{array}{l}\cdots \\
\cdots\end{array}$ & $\begin{array}{l}2 \\
\cdots\end{array}$ & $\begin{array}{l}. . \\
. .\end{array}$ & $\begin{array}{l}. . \\
\cdots\end{array}$ & $\begin{array}{l}* \\
+\end{array}$ & . \\
\hline $\begin{array}{r}- \text { intermedia } . . . \\
\text { Hydrocotyle vulgaris. }\end{array}$ & & .. & .. & .. & .. & .. & .. & & .. & .. & .. & $\ddot{i}$ & . & .. & .. & .. & . & .. & .. & .. & 1 & .. & .. & .. \\
\hline Lysimachia thyrsiflora & & $\cdots$ & $\begin{array}{l}\cdots \\
\ldots\end{array}$ & $\cdots$ & $\begin{array}{l}\cdots \\
\ldots\end{array}$ & $\begin{array}{l}. . \\
. .\end{array}$ & .. & & $\begin{array}{l}. . \\
. .\end{array}$ & $\ddot{1}$ & $\begin{array}{l}. . \\
. .\end{array}$ & 1 & $\begin{array}{l}. . \\
. .\end{array}$ & $\begin{array}{l}. . \\
. .\end{array}$ & $\ddot{1}$ & $\begin{array}{l}. . \\
. .\end{array}$ & $\begin{array}{l}. . \\
. .\end{array}$ & $\begin{array}{l}. . \\
. .\end{array}$ & $\begin{array}{l}\cdots \\
. .\end{array}$ & $\begin{array}{l}. . \\
. .\end{array}$ & $\begin{array}{l}. . \\
. .\end{array}$ & $\begin{array}{l}. . \\
. .\end{array}$ & $\begin{array}{l}. . \\
. .\end{array}$ & . \\
\hline- & & .. & .. & .. & .. & .. & . & & 1 & .. & 1 & .. & . & .. & .. & .. & .. & .. & .. & .. & . & .. & .. & . \\
\hline Menyanthes trifoli & & 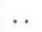 & .. & .. & .. & .. & .. & & .. & .. & .. & .. & $\cdots$ & .. & .. & .. & . & .. & .. & .. & + & r & .. & \\
\hline Myriophyllum verticillatun & & . & . & .. & .. & .. & .. & & .. & .. & .. & .. & . & . & .. & .. & 1 & . & . & .. & .. & .. & .. & \\
\hline Potamogeton sect. Eupotam..... & & .. & . & .. & . & . & .. & & . & . & .. & .. & $\cdots$ & .. & .. & .. & .. & 1 & .. & .. & .. & .. & .. & .. \\
\hline Ranunculus acer type... & & .. & 1 & .. & .. & .. & .. & & 1 & .. & .. & .. & 1 & .. & .. & .. & .. & .. & .. & .. & .. & .. & .. & .. \\
\hline Rumex aquaticus-hydrolapth.... & & .. & .. & .. & .. & .. & .. & & .. & .. & .. & .. & .. & .. & .. & .. & .. & .. & .. & .. & + & .. & .. & . \\
\hline Valeriana dioica . . . . . . . . . . . & & . & . & .. & .. & $\cdots$ & 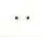 & & .. & .. & 1 & . & -. & .. &.. & $\ldots$ & .. & .. &.. & $\ldots$ &.. & $\ldots$ & $\ldots$ & 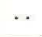 \\
\hline $\begin{array}{l}\text { Pediastrum }^{3} \text { ) . . . . . } \\
\text { Amphitrema flava. . }\end{array}$ & & $\begin{array}{l}* \\
+\end{array}$ & $\begin{array}{l}+ \\
+\end{array}$ & $\begin{array}{l}\cdots \\
\cdots\end{array}$ & $\begin{array}{l}+ \\
+\end{array}$ & $\begin{array}{l}\cdots \\
+\end{array}$ & + & & $\begin{array}{l}\cdots \\
\ldots\end{array}$ & $\begin{array}{l}\cdots \\
\ldots\end{array}$ & $\begin{array}{l}\cdots \\
\ldots\end{array}$ & $\begin{array}{l}\cdots \\
\ldots\end{array}$ & $\begin{array}{l}\cdots \\
\cdots\end{array}$ & $\begin{array}{l}\cdots \\
\ldots\end{array}$ & $\begin{array}{l}+ \\
\ldots\end{array}$ & $\begin{array}{l}. . \\
. .\end{array}$ & $\begin{array}{l}. . \\
. .\end{array}$ & $\begin{array}{l}. . \\
. .\end{array}$ & $\begin{array}{l}+ \\
\ldots\end{array}$ & $\begin{array}{l}+ \\
\ldots\end{array}$ & $\begin{array}{l}+ \\
\ldots\end{array}$ & $\begin{array}{l}+ \\
. .\end{array}$ & $\begin{array}{l}+ \\
\ldots\end{array}$ & $\begin{array}{l}\cdots \\
. .\end{array}$ \\
\hline
\end{tabular}

$\left.{ }^{1}\right)$ See the pollen diagram (Flate IX).

$\left.{ }^{2}\right)$ Omitted from the pollen totals.

$\left.{ }^{3}\right)+$ indicates presence in the sample. 
Table 31 (next page) 
Table 31. Herning. BP 1 (STA), BP

The figures indicate numbers of pollen grains o Tallene angiver antal af pollenkorn og sporer

\begin{tabular}{|c|c|c|c|c|c|c|c|c|c|c|c|c|c|c|c|c|c|c|c|c|c|c|c|c|c|}
\hline Dep & $\vec{a}$ & $\vec{~}$ & 20 & $\stackrel{0}{-1}$ & $\begin{array}{l}8 \\
0 \\
0\end{array} \mid$ & 只 & 只 & 8 & $\begin{array}{l}0 \\
10 \\
10\end{array}$ & 0 & $\begin{array}{r}\tilde{b} \\
\dot{f}\end{array}$ & $\stackrel{g}{+}$ & $\overrightarrow{\mathrm{N}}$ & $\begin{array}{l}\tilde{\sigma} \\
\tilde{\sigma} \\
\dot{\infty}\end{array}$ & 8 & ถึ & 암 & ฟี & $\begin{array}{c}\infty \\
\sigma \\
\sigma \\
\sim \\
-i\end{array}$ & ণิ & $m_{n}^{2}$ & $\begin{array}{l}\infty \\
0 \\
\infty \\
\infty\end{array}$ & 8 & $\infty$ & $\infty$ \\
\hline bies alba & & .. & .. & .. & .. & 1 & .. &.. &.. & .. &.. &.. & 1 & .. & .. & .. & .. &.. &.. & .. & & . & .. &.. & 1 \\
\hline$\ldots \ldots$ & & .. & .. & .. & .. & .. & .. & .. & .. & .. & .. & .. & .. & .. & .. & .. & .. & .. & .. & .. & & 1 & .. & .. & \\
\hline$\ldots \ldots$ & & .. & .. & . & .. & .. & 1 & .. & .. & .. & .. & .. & . & .. & .. & .. & .. & .. & .. & .. & & .. & .. & .. & 1 \\
\hline ostaphyl & & .. & .. & 1 & .. & .. & 13 & .. & .. & .. & .. & .. & 1 & 2 & .. & .. & .. & .. & .. & .. & & .. & .. & .. & .. \\
\hline Armeria maritima. & & .. & .. & .. & .. & .. & .. & 1 & .. & .. & .. & .. & .. & .. & .. & 1 & .. & .. & .. & .. & & .. & .. & .. & .. \\
\hline Artemisia. & & .. & .. & .. & 2 & 1 & 2 & .. & .. & 1 & .. & 1 & . & .. & .. & 1 & .. & .. & .. & 1 & & 1 & .. & .. & .. \\
\hline Bistorta. & & .. & .. & .. & .. & .. & .. & .. & .. & .. & .. & .. & . & .. & .. & .. & .. & .. & .. & .. & & .. & .. & .. & . \\
\hline Botrychium & & .. & .. & + & .. & .. & . & .. & .. & .. & .. & .. & .. & .. & .. & .. & .. & .. & .. & .. & & .. & .. & .. & 1 \\
\hline$\ldots \ldots \ldots$ & & .. & .. & 1 & .. & .. & .. & .. & .. & .. & .. & .. & .. & .. & .. & . &.. & .. & .. & .. & & .. & 2 & .. & 1 \\
\hline$\ldots \ldots \ldots$ & & .. & .. & .. & .. & .. & .. & .. & .. & .. & .. & .. & .. & .. & .. & .. & .. & .. & .. & .. & & .. & .. & .. & . \\
\hline$\ldots \ldots \ldots \ldots$ & & .. & .. & . & .. & .. & .. & .. & 1 & 1 & .. & .. & .. & .. & .. & .. & .. & .. & .. & .. & & .. & .. & .. & 1 \\
\hline$\ldots \ldots \ldots \ldots \ldots$ & & .. & .. & 1 & .. & .. & .. & .. & .. & .. & .. & .. & .. & .. & .. & .. & .. & 1 & .. & .. & & .. & .. & 1 & .. \\
\hline$\ldots \ldots$ & & .. & .. & .. & .. & 1 & .. & .. & .. & .. & ... & 1 & ... & .. & .. & .. & .. & .. & .. & .. & & .. & .. & .. & .. \\
\hline Ephedra dist & & .. & .. & .. & .. & .. & .. & .. & .. & . & .. & .. & . & .. & .. & .. & .. & .. & .. & .. & & .. & .. & .. & .. \\
\hline- & & .. & .. & .. & .. & .. & .. & .. & .. & . & .. & .. & .. & .. & .. & .. & .. & .. & .. & .. & & .. & .. & .. & .. \\
\hline Erica tetralix & & .. & .. & .. & .. & .. & .. & .. & .. & .. & .. & .. & .. & .. & .. & 1 & .. & .. & . & .. & & .. & .. & .. & .. \\
\hline$\ldots \ldots$ & & .. & .. & .. & .. & .. & . & .. & .. & . & .. & .. & .. & .. & .. & .. & .. & .. & .. & .. & &. & . & .. & .. \\
\hline$\ldots \ldots \ldots \ldots$ & & .. & .. & .. & .. & .. & .. & .. & .. & .. & .. & .. & 1 & .. & 1 & .. & .. & 1 & .. & .. & & 1 & 1 & .. & 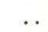 \\
\hline ula alnu & & .. & .. & .. & .. & .. & 2 & .. & 1 & .. & 1 & .. & .. & .. & 1 & 4 & 11 & 1 & 1 & .. & & $\cdots$ & 1 & 1 & 1 \\
\hline Fro & & 8 & 3 & 1 & 3 & 2 & 1 & 1 & 4 & 1 & 1 & .. & .. & 1 & .. & 3 & 1 & .. & 2 & 1 & & 3 & 2 & 2 & 1 \\
\hline Galium type & & 1 & 2 & 1 & .. & 1 & 1 & .. & .. & .. & .. & .. & .. & 1 & .. & 2 & .. & .. & .. & .. & & .. & 2 & 1 & 3 \\
\hline e & & .. & .. & .. & .. & .. & .. & .. & .. & .. & .. & .. & .. & .. & .. & .. & .. & .. & .. & .. & & 1 & .. & .. & .. \\
\hline$a \ldots \ldots \ldots \ldots \ldots$ & & .. & 2 & .. & .. & .. & .. & .. & .. & .. & .. & .. & .. & .. & .. & .. & 1 & .. & .. & .. & & 1 & .. & 1 & .. \\
\hline$\ldots \ldots \ldots \ldots \ldots$ & & .. & .. & .. & .. & .. & .. & .. & .. & .. & .. & .. & .. & .. & .. & .. & .. & .. & . & . & & .. & .. & .. & .. \\
\hline$\ldots \ldots$ & & .. & .. & .. & .. & .. & .. & .. & .. & .. & .. & .. & 1 & .. & .. & .. & .. & .. & .. & 1 & & .. & .. & .. & .. \\
\hline pulina. & & .. & 1 & .. & .. & .. & .. & .. & 1 & . & .. & .. & .. & .. & .. & .. & .. & .. & .. & .. & & .. & .. & .. & .. \\
\hline florae & & .. & .. & .. & .. & 1 & .. & .. & .. & 2 & .. & 1 & . & .. & 1 & .. & .. & .. & .. & .. & & .. & 1 & 1 & .. \\
\hline ra periclymen & & .. & .. & .. & .. & .. & .. & .. & .. & .. & .. & .. & .. & .. & .. & .. & .. & .. & .. & .. & & 1 & .. & .. & .. \\
\hline cf. corni & & .. & .. & .. & .. & .. & . & .. & .. & .. & .. & .. & .. & .. & .. & .. & .. & .. & .. & .. & & .. & .. & .. & .. \\
\hline Lycopodium & & .. & .. & . & .. & .. & .. & .. & .. & .. & .. & .. & .. & .. & .. & .. & .. & .. & 1 & . & & .. & .. & .. & .. \\
\hline- & & .. & .. & 1 & .. & .. & . & .. & .. & .. & .. & .. & .. & .. & .. & .. & .. & .. & .. & .. & & .. & .. & .. & .. \\
\hline - & & .. & .. & .. & .. & .. & .. & .. & .. & .. & .. & 1 & .. & .. & .. & .. & .. & .. & .. & .. & & .. & .. & 1 & .. \\
\hline Ophioglos & & .. & .. & .. & 1 & 2 & .. & .. & .. & .. & .. & .. & .. & .. & .. & .. & .. & .. & .. & .. & & 1 & .. & .. & .. \\
\hline $\mathrm{Pa}$ & & .. & .. & .. & .. & .. & .. & .. & .. & .. & .. & .. & .. & .. & .. & .. & .. & .. & .. & .. & & .. & .. & .. & .. \\
\hline lus trem & & 32 & 12 & 22 & .. & .. & . & .. & .. & .. & .. & .. & . & .. & 1 & $\cdots$ & .. & .. & .. & .. & & 8 & 4 & 9 & .. \\
\hline Plantago lan & & 2 & .. & 1 & .. & 1 & .. & .. & .. & .. & .. & .. & .. & .. & .. & .. & .. & .. & .. & .. & & 1 & 2 & 1 & .. \\
\hline - $\quad m a$ & & .. & .. & .. & 1 & .. & .. & .. & .. & .. & .. & .. & .. & 1 & .. & .. & .. & .. & .. & .. & & .. & 1 & .. & .. \\
\hline- & & .. & .. & .. & 1 & .. & .. & .. & .. & .. & .. & .. & . & .. & .. & .. & .. & .. & .. & . & & .. & .. & .. & .. \\
\hline ria type...... & & .. & .. & .. & .. & .. & .. & .. & .. & . & .. & .. & . & .. & .. & .. & .. & .. & .. & . & & .. & .. & .. & .. \\
\hline Polypodium vulgare. & & 1 & .. & .. & 2 & . & .. & .. & .. & 1 & .. & .. & 1 & .. & .. & .. & .. & .. & 1 & 1 & & 1 &.. & $\cdots$ & .. \\
\hline$P c$ & & . & . & . & $\ldots$ & 1 & 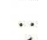 & .. & .. & 1 & .. & 1 & . & . & . & . & .. & .. & .. & .. & & .. & 1 & . & 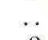 \\
\hline Rut & & 1 & 1 & 2 & 1 & 2 & 1 & .. & .. & .. & .. & .. & 1 & 2 & 1 & 1 & .. & 3 & 1 & .. & & .. & 2 & 2 & 2 \\
\hline Rubus ida & & .. & 1 & .. & $\ldots$ & .. & .. & .. & .. & (n) & .. & .. & .. & .. & .. & .. & .. & .. & .. & .. & & .. & .. & .. & .. \\
\hline - saxati & & .. & 1 & .. & . & .. & .. & $\ldots$ & .. & & .. & .. & . & .. & .. & . & . & .. & .. & .. & & .. & .. & .. & .. \\
\hline Salix .. & & .. & .. & .. & 5 & 4 & 6 & 1 & .. & 10 & .. & 4 & 4 & 3 & 2 & 5 & 1 & 7 & 7 & 5 & & 8 & 4 & 1 & 1 \\
\hline Sanguisorba $I$ & & .. & .. & .. & .. & .. & .. & .. & .. & .. & .. & .. & .. & .. & .. & .. & .. & .. & .. & .. & & .. & .. & 1 & .. \\
\hline- & & .. & .. & .. & .. & .. & .. & .. & .. & .. & .. & .. & .. & .. & .. & .. & .. & .. & .. & .. & & .. & .. & .. & .. \\
\hline . & & .. & .. & .. & .. & 1 & .. & .. & .. & 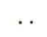 & .. & .. & .. & .. & .. & .. & .. & .. & .. & .. & & .. & .. & .. & . \\
\hline$S$ & & 1 & .. & & .. & .. & 1 & .. & .. & .. & .. & 1 & & .. &.. & 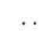 & .. & .. & & . & & $\cdots$ &. & & \\
\hline$T a$. & & 16 & 4 & 5 & .. & $\cdots$ & .. & $\cdots$ & .. & . &.. & .. &. & .. & .. & $\cdots$ &.. &. & 2 & $\cdots$ & & 7 & 1 & 2 & 2 \\
\hline Tha & & .. & . & . & 1 & 1 & .. & .. & .. & & .. & .. & . & .. & 1 & 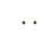 & . & .. & .. & .. & & .. & .. & .. & .. \\
\hline Thelyptes & & .. & 1 & 1 & .. & 2 & .. & .. & .. & $\cdots$ & .. & .. & $\ldots$ & .. & .. & .. & 2 & 1 & 1 & .. & & .. & 2 & .. & 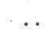 \\
\hline Tilia. . & & .. & 1 & 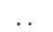 & .. & 1 & 1 & 1 & .. & 1 & .. & .. & .. & .. & 2 & .. & .. & .. & .. & .. & & .. & .. & 1 & $\cdots$ \\
\hline Tubuliflorae & & 1 & 1 & 1 & .. & 2 & $\cdots$ & .. & .. & & .. & .. & & 1 & 1 & 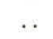 & .. & .. & $\cdots$ & 1 & & 1 & 2 & .. & 1 \\
\hline Ulmu: & & .. & 2 & & 3 & 3 & 3 & 1 & 4 & 1 & 2 & 2 & 1 & 1 & 1 & & 1 & .. & 3 & .. & & 3 & 3 & 4 & \\
\hline Umbellife & & 2 & 1 & 2 & .. & & .. & .. & .. & .. & .. &.. & .. & .. & 1 & .. & .. &.. &.. & .. & & .. & 1 & 1 & \\
\hline
\end{tabular}


Table 31 (continued)

\begin{tabular}{|c|c|c|c|c|c|c|c|c|c|c|c|c|c|c|c|c|c|c|c|c|c|c|c|c|c|}
\hline Depth, m. & $\bar{a}$ & $\vec{n}$ & $\stackrel{10}{2}$ & $\underline{0}$ & $\begin{array}{l}0 \\
0 \\
0\end{array}$ & $N$ & 10 & $\S$ & $\begin{array}{l}0 \\
10\end{array}$ & $\stackrel{0}{-1}$ & $\begin{array}{l}0 \\
\dot{+}\end{array}$ & $\stackrel{g}{+}$ & $\vec{a}$ & 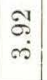 & 8 & is & f & ฟ & $\begin{array}{l}\infty \\
\sigma \\
\sigma\end{array}$ & 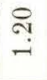 & $\stackrel{\oplus}{\infty}$ & 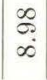 & $\S$ & $\ddot{\infty}$ & $\infty$ \\
\hline Urtica dioica . . . . . . . . . . & & $\cdots$ & . & 1 & . & . & . & . & $\cdots$ & $\cdots$ & . & . & . & . & $\cdots$ & $\cdots$ & . & . & . & 1 & & . & $\cdots$ & 1 & $\cdots$ \\
\hline Vaccinium type ............ & & . & . & . & .. & . & . & . & . & .. & . & . & $\ldots$ & . & . & 2 & . & $\cdots$ & . & . & & . & . & $\ldots$ & . \\
\hline Vicia-Lathyrus ............ & & . & . & . & . & . & . & . & .. & . & . & .. & . & . & $\ldots$ & .. & .. & .. & .. & . & & $\ldots$ & $\cdots$ & .. & 1 \\
\hline Viburnum................ & & . & $\cdots$ & $\cdots$ & $\cdots$ & . & . & $\cdots$ & $\cdots$ & $\cdots$ & $\cdots$ & $\cdots$ & $\cdots$ & . & $\cdots$ & $\cdots$ & $\cdots$ & $\cdots$ & . & . & & $\cdots$ & $\cdots$ & . & . \\
\hline Viscum album ............. & & . & $\cdots$ & $\cdots$ & 1 & $\cdots$ & . & . & . & $\cdots$ & $\cdots$ & $\cdots$ & $\cdots$ & $\cdots$ & $\cdots$ & $\cdots$ & . & $\cdots$ & . & . & & 1 & $\cdots$ & $\cdots$ & $\because$ \\
\hline 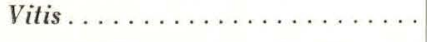 & & . & $\cdots$ & $\cdots$ & 1 & $\cdots$ & . & $\cdots$ & . & $\cdots$ & . & .. & $\cdots$ & . & $\cdots$ & . & . & $\cdots$ & . & . & & . & $\cdots$ & . & 1 \\
\hline Azolla filiculoides ${ }^{1}$ ) . . . . . . . . & & $\cdots$ & $\cdots$ & $\cdots$ & $\cdots$ & $\cdots$ & . & $\cdots$ & $\cdots$ & . & $\cdots$ & 1 & $\cdots$ & .. & .. & . & $\cdots$ & $\cdots$ & . & $\cdots$ & & $\cdots$ & $\cdots$ & $\cdots$ & $\cdots$ \\
\hline Brasenia . . . . . . . . . . . . & & .. & .. & .. & .. & 1 & .. & $\cdots$ & $\cdots$ & $\cdots$ & $\cdots$ & $\cdots$ & $\cdots$ & . & $\cdots$ & $\cdots$ & . & .. & .. & $\cdots$ & & $\cdots$ & .. & $\cdots$ & .. \\
\hline Caltha palustris............ & & $\cdots$ & $\cdots$ & $\cdots$ & $\cdots$ & . & . & $\cdots$ & $\cdots$ & $\cdots$ & $\cdots$ & . & $\cdots$ & $\cdots$ & $\cdots$ & $\cdots$ & $\cdots$ & $\cdots$ & $\cdots$ & . & & . & . & $\cdots$ & $\cdots$ \\
\hline 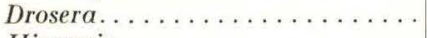 & & $\cdots$ & $\cdots$ & $\cdots$ & $\cdots$ & $\cdots$ & $\cdots$ & $\cdots$ & $\cdots$ & $\cdots$ & $\cdots$ & $\cdots$ & $\cdots$ & $\cdots$ & $\cdots$ & . & $\cdots$ & $\cdots$ & $\cdots$ & $\cdots$ & & $\cdots$ & $\cdots$ & $\cdots$ & $\cdots$ \\
\hline Hippuris...... & & . & $\cdots$ & .. & . & $\because$ & . & $\cdots$ & $\cdots$ & $\cdots$ & $\cdots$ & $\cdots$ & $\cdots$ & . & $\cdots$ & . & . & . & . & $\cdots$ & & $\cdots$ & . & $\cdots$ & $\cdots$ \\
\hline Hydrocotyle vulgaris........... & & $\cdots$ & $\cdots$ & $\because$ & $\cdots$ & 1 & $\cdots$ & $\cdots$ & $\cdots$ & $\cdots$ & $\cdots$ & $\cdots$ & $\cdots$ & $\cdots$ & $\cdots$ & $\cdots$ & $\cdots$ & $\cdots$ & . & $\cdots$ & & $\because$ & $\because$ & $\cdots$ & 1 \\
\hline Littorella uniflora... & & 1 & $\cdots$ & 1 & $\cdots$ & $\cdots$ & . & $\cdots$ & $\cdots$ & $\cdots$ & $\therefore$ & $\cdots$ & $\cdots$ & . & $\cdots$ & $\cdots$ & . & $\cdots$ & . & $\cdots$ & & 3 & 1 & 3 & $\cdots$ \\
\hline Lycopodium inundatum . . . . . . & & $\cdots$ & $\cdots$ & $\cdots$ & $\cdots$ & $\cdots$ & $\cdots$ & $\cdots$ & $\cdots$ & . & $\cdots$ & $\cdots$ & $\cdots$ & $\cdots$ & $\cdots$ & . & $\cdots$ & $\cdots$ & $\cdots$ & $\cdots$ & & $\cdots$ & $\cdots$ & $\cdots$ & $\cdots$ \\
\hline Lysimachia cf. vulgaris. . . . . . . & & 1 & $\cdots$ & 1 & $\cdots$ & $\cdots$ & $\cdots$ & $\cdots$ & $\cdots$ & . & $\cdots$ & $\cdots$ & $\cdots$ & . & $\cdots$ & $\cdots$ & 1 & $\cdots$ & $\cdots$ & $\cdots$ & & $\cdots$ & $\because$ & $\cdots$ & $\cdots$ \\
\hline Lythrum salicaria . . . . . . . . . & & $\cdots$ & $\cdots$ & $\cdots$ & $\cdots$ & $\cdots$ & . & $\cdots$ & $\because$ & . & $\cdots$ & $\cdots$ & . & . & . & . & $\cdots$ & $\cdots$ & $\cdots$ & $\cdots$ & & $\cdots$ & 1 & $\cdots$ & $\cdots$ \\
\hline Menyanthes trifoliata......... & & . & $\cdots$ & .. & $\ldots$ & $\cdots$ & $\cdots$ & . & 1 & . & .. & . & . & . & . & . & . & $\cdots$ & . & . & & . & $\ldots$ & $\cdots$ & $\cdots$ \\
\hline Myriophyllum alterniflorum . .... & & 1 & $\cdots$ & $\cdots$ & $\cdots$ & 5 & 7 & $\cdots$ & $\cdots$ & $\cdots$ & $\cdots$ & $\cdots$ & $\cdots$ & $\cdots$ & $\cdots$ & . & $\cdots$ & 1 & $\cdots$ & $\cdots$ & & $\cdots$ & $\cdots$ & 2 & 1 \\
\hline - $\quad$ spicatum $\ldots \ldots$ & & . & $\cdots$ & $\cdots$ & $\cdots$ & $\cdots$ & $\cdots$ & $\cdots$ & $\cdots$ & $\cdots$ & $\cdots$ & $\cdots$ & $\cdots$ & $\because$ & $\cdots$ & $\cdots$ & $\cdots$ & $\cdots$ & $\cdots$ & $\cdots$ & & $\cdots$ & $\cdots$ & $\cdots$ & . \\
\hline verticillatum ..... & & . & $\cdots$ & . & $\cdots$ & $\cdots$ & $\cdots$ & $\cdots$ & $\cdots$ & . & $\cdots$ & . & . & 1 & $\cdots$ & . & . & $\cdots$ & . & . & & $\because$ & $\cdots$ & $\because$ & $\because$ \\
\hline Nuphar luteum . . & & $\cdots$ & $\cdots$ & 2 & . & $\cdots$ & 1 & $\cdots$ & $\cdots$ & $\cdots$ & $\cdots$ & $\cdots$ & . & 1 & . & . & .. & . & $\cdots$ & . & & 1 & . & 1 & 1 \\
\hline - pumilum. & & $\cdots$ & $\cdots$ & 1 & . & $\cdots$ & $\cdots$ & $\cdots$ & $\because$ & .. & $\cdots$ & $\cdots$ & $\cdots$ & .. & $\cdots$ & . & . & . & . & $\cdots$ & & $\cdots$ & $\cdots$ & $\cdots$ & . \\
\hline Osmunda cf. cinnamomea. ...... & & . & . & 1 & $\cdots$ & . & $\cdots$ & 1 & 7 & . & $\cdots$ & 2 & 1 & $\cdots$ & 3 & 1 & 1 & . & 4 & 1 & & 2 & . & 2 & $\therefore$ \\
\hline - regalis ............ & & . & $\cdots$ & $\because$ & $\cdots$ & $\cdots$ & . & $\cdots$ & $\cdots$ & . & $\cdots$ & $\cdots$ & $\cdots$ & 1 & 2 & $\cdots$ & 2 & 2 & $\cdots$ & 1 & & 1 & $\cdots$ & 1 & $\cdots$ \\
\hline Potamogeton sect. Coleog.... . & & $\cdots$ & $\cdots$ & 1 & $\cdots$ & $\cdots$ & $\cdots$ & $\cdots$ & . & .. & $\cdots$ & . & $\cdots$ & . & $\cdots$ & . & .. & . & .. & $\cdots$ & & . & $\cdots$ & 1 & .. \\
\hline$-\quad-$ Eupotam..... & & . & $\cdots$ & $\because$ & 6 & $\cdots$ & $\cdots$ & $\cdots$ & $\cdots$ & $\cdots$ & $\cdots$ & $\cdots$ & . & . & $\cdots$ & 1 & $\cdots$ & . & $\cdots$ & $\cdots$ & & $\because$ & $\cdots$ & 4 & $\cdots$ \\
\hline Ranunculus acer type ......... & & $\because$ & $\cdots$ & 1 & .. & $\cdots$ & $\because$ & $\cdots$ & . & . & . & . & $\cdots$ & . & $\cdots$ & . & . & . & . & . & & 1 & $\cdots$ & 1 & . \\
\hline - trichoph. type..... & & 1 & $\cdots$ & $\cdots$ & $\cdots$ & $\cdots$ & 1 & $\cdots$ & $\cdots$ & $\cdots$ & $\cdots$ & . & . & $\because$ & $\cdots$ & $\because$ & . & . & .. & . & & . & . & $\cdots$ & $\cdots$ \\
\hline Rubus chamaemorus . . . . . . . . & & $\cdots$ & $\cdots$ & $\cdots$ & $\cdots$ & $\cdots$ & $\cdots$ & $\cdots$ & $\cdots$ & $\cdots$ & $\ldots$ & $\ldots$ & $\ldots$ & 1 & 2 & 1 & . & $\therefore$ & . & $\ldots$ & & $\ldots$ & $\therefore$ & $\therefore$ & $\cdots$ \\
\hline Thelypteris palustris type....... & & 11 & 15 & 5 & 11 & 10 & 8 & 15 & 12 & 9 & 10 & 11 & 2 & 9 & 6 & 6 & 13 & 13 & 10 & 9 & & 11 & 16 & 11 & 12 \\
\hline Trapa natans ............. & & $\cdots$ & $\cdots$ & $\cdots$ & $\cdots$ & $\cdots$ & $\cdots$ & $\cdots$ & $\cdots$ & $\cdots$ & $\cdots$ & $\cdots$ & $\cdots$ & $\cdots$ & $\cdots$ & $\cdots$ & $\cdots$ & $\cdots$ & $\cdots$ & $\cdots$ & & $\cdots$ & $\cdots$ & $\cdots$ & $\cdots$ \\
\hline Typha latifolia : & & $\cdots$ & . & . & $\because$ & $\because$ & $\because$ & $\cdots$ & $\cdots$ & $\cdots$ & $\cdots$ & $\cdots$ & $\because$ & . & $\cdots$ & . & $\cdots$ & . & $\cdots$ & $\cdots$ & & . & $\because$ & $\ldots$ & $\cdots$ \\
\hline Typha-Sparganium........... & & 6 & 2 & 4 & 1 & 2 & 1 & $\ldots$ & $\ldots$ & $\cdots$ & $\ldots$ & 2 & 1 & $\cdots$ & $\cdots$ & $\cdots$ & $\cdots$ & . & 1 & 1 & & 2 & 4 & $\cdots$ & 4 \\
\hline Valeriana dioica ............. & & $\cdots$ & $\cdots$ & $\cdots$ & $\cdots$ & $\cdots$ & $\cdots$ & $\cdots$ & $\cdots$ & $\cdots$ & $\cdots$ & $\cdots$ & .. & $\cdots$ & $\cdots$ & $\cdots$ & $\cdots$ & . & $\cdots$ & $\cdots$ & & . & 1 & . & $\cdots$ \\
\hline Pediastrum ${ }^{3}$ ) & & + & + & 1 & $\ldots$ & + & + & + & + & $\cdots$ & + & + & + & + & + & . & . & + & $\cdots$ & + & & + & + & + & 1 \\
\hline
\end{tabular}

1) Omitted from the pollen totals.

2) See the pollen diagram (plate XIII)

s) + indicates presence in the sample. 


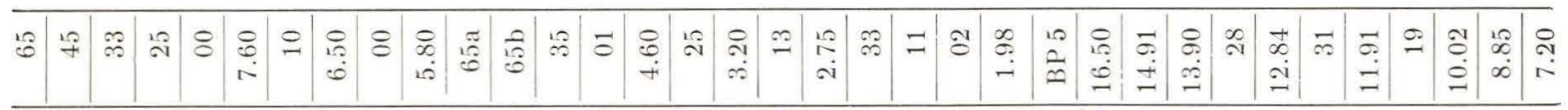

\begin{tabular}{|c|c|c|c|c|c|c|c|c|c|c|c|c|c|c|c|c|c|c|c|c|c|c|c|c|c|c|c|c|c|c|c|c|c|}
\hline . & . & .. & 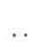 & . . & .. & . & . & . & .. & . & . & $\cdots$ & . & $\ldots$ & .. & . & . & . & . & . & .. & 1 & . & & .. & & $\ldots$ & . & $\ldots$ & .. & .. & 1 & $\cdots$ \\
\hline .. & $\ldots$ & .. &.. &.. & .. & .. & .. & $\ldots$ & .. & .. & .. &.. & .. & .. & $\ldots$ & .. & . & .. & .. & .. & .. & .. & . & . & .. & .. & .. & .. & .. & .. & .. & . & .. \\
\hline . & .. & .. & .. &.. & .. & .. & .. &.. & .. & . &.. & .. & . & $\ldots$ & $\ldots$ & .. & . & .. & . & .. &.. & . & . & . & . & . & .. & . & .. & .. & .. & . & . \\
\hline . & .. & $\ldots$ & $\ldots$ &.. & .. & .. & . & .. & $\ldots$ & .. & .. & $\ldots$ & .. & $\ldots$ & .. & . & $\ldots$ & $\ldots$ & $\ldots$ & .. &.. & $\ldots$ & . & . & $\ldots$ & $\ldots$ & $\ldots$ & $\ldots$ & .. &.. & .. & .. & \\
\hline . & .. & .. & . & .. & .. & . & .. & .. & .. & .. & .. & $\ldots$ & .. & $\ldots$ & $\cdots$ & . & . & $\ldots$ & . & . & .. &.. & . & . & .. & .. &.. & .. & $\ldots$ & $\ldots$ & $\ldots$ & $\ldots$ & .. \\
\hline . & .. & .. & .. & .. &.. & .. & . &.. & .. & .. &.. & 1 & .. & .. & .. & .. & .. & .. & .. & .. & .. &.. & . & .. & .. & . & .. & .. & . &.. & .. & $\ldots$ & .. \\
\hline . & . & . & .. &.. & .. & . & . & .. & .. & . &.. & .. & .. & .. & $\ldots$ & . & . & .. & . & . & .. & . & .. & .. & . & . & .. & . & .. &.. & .. & . & .. \\
\hline. & .. & . & .. &.. & .. & .. & .. &.. & .. &.. &.. & .. & .. & 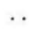 & .. & .. & . & .. &. & .. &.. & .. & . & .. & .. & .. &.. & .. & .. & .. &.. & . & .. \\
\hline .. & .. & 1 & .. & .. & .. & .. & . & .. & 1 & . &.. & 1 & . & $\cdot$. & .. & .. & .. & .. & . & .. & .. & .. & $\cdots$ & .. & .. & . &.. & . & $\cdots$ &.. &.. & . & .. \\
\hline . & .. & .. & .. & .. & .. & .. & . & .. & .. & . & .. &.. & . & .. & . & .. & . & $\ldots$ & . & . & .. & 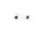 & . & .. & .. & 1 & .. & .. & .. & $\ldots$ & .. & . & .. \\
\hline .. & .. & $\ldots$ & $\ldots$ &.. & .. & $\ldots$ & $\ldots$ & .. & .. & .. & .. & .. & $\ldots$ & .. & 1 & .. & .. & .. & $\ldots$ & .. & .. &.. & .. &.. & .. & .. & $\ldots$ &.. & .. & .. & .. & $\ldots$ & .. \\
\hline.. &.. & .. & .. &.. &.. & .. & .. & .. & .. & .. &.. & .. & .. & .. & $\ldots$ & .. & . & $\ldots$ & .. & . &.. & .. & .. & .. & .. & .. &.. & .. & .. & .. &.. & . & .. \\
\hline.. & 1 & $\ldots$ & $\ldots$ &.. & $\ldots$ & $\ldots$ & $\ldots$ & $\ldots$ & $\ldots$ & $\ldots$ &.. &.. & $\ldots$ & $\ldots$ & $\ldots$ & .. & $\ldots$ & $\ldots$ & $\ldots$ & .. & .. &.. & . &.. & $\ldots$ & $\ldots$ & $\ldots$ & $\ldots$ & .. &.. &.. & $\ldots$ & .. \\
\hline .. & .. & .. & .. & 1 & .. & .. & .. & .. & .. & .. &.. & $\ldots$ & .. & .. & $\ldots$ & .. & . & $\ldots$ & .. & .. & .. & .. & . & $\ldots$ & .. & .. &.. & .. & .. & .. & .. & . & .. \\
\hline.. & . & . & .. &.. & .. & . & .. &.. & .. & $\ldots$ & .. & $\ldots$ & 1 & $\ldots$ & $\ldots$ & .. & . & $\ldots$ & . & .. & .. &.. & . & $\ldots$ & .. & .. & $\ldots$ & $\ldots$ & .. & .. & 1 & .. & .. \\
\hline .. & .. & . & .. & .. & . & .. & . & .. & . & .. & .. & .. & . & .. & $\ldots$ & . & .. & .. & . & $\ldots$ &.. & . & . & .. & .. & .. & .. & .. & .. & $\ldots$ & .. & . & . \\
\hline$\ldots$ & .. & . & .. & .. & .. & . & .. & .. & .. & .. &.. &.. & .. & . & .. & .. & .. & .. & $\ldots$ & . & .. & .. & .. & $\ldots$ & $\ldots$ & .. & $\ldots$ & $\ldots$ & .. &.. &.. & .. & .. \\
\hline .. & 4 & 2 & 6 &.. & .. & . & . & . & . & . & 1 & .. & . & .. & .. & . & .. & .. & . & 1 & 1 & 1 & & & & & & & & & & & \\
\hline .. & .. & .. & .. & .. & . & . & . & .. & . & $\ldots$ &.. & .. & . & .. & .. & $\ldots$ & .. & .. & . & .. & .. & 1 & . & .. & . & .. & .. & . & $\ldots$ & .. & .. & $\ldots$ & .. \\
\hline .. & .. & .. & .. & .. &.. & .. & .. &.. & .. & .. &.. & .. & .. & .. & .. & . & .. & .. & .. & .. &.. & .. & . & .. & .. & .. & .. & .. & .. & .. & 1 & .. & .. \\
\hline .. & .. & .. & .. & .. & .. & .. & . &.. & . & .. & .. &.. & .. & .. & .. & .. & . & .. & .. & .. & .. & .. & $\cdots$ & .. & .. & .. &. & .. & .. & .. & . & 1 & . \\
\hline. & $\ldots$ & $\ldots$ & $\ldots$ & .. & & $\ldots$ & $\ldots$ & $\ldots$ & $\ldots$ & $\ldots$ & . & . & .. & .. & .. & & & $\ldots$ & $\ldots$ & 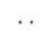 & . & .. & .. & $\ldots$ & & . & .. & & .. & . &. & $\ldots$ & \\
\hline .. & $\ldots$ & .. & 1 & .. & 6 & .. & .. & 1 & $\ldots$ & 1 & 1 & . & $\ldots$ & .. & 6 & $\ldots$ & 2 & 3 & 2 & 3 & .. & & & 1 & 2 & & .. & 1 & 1 & 2 & 1 & & 1 \\
\hline$\ldots$ & .. & .. & $\ldots$ & .. & $\ldots$ & $\ldots$ & $\ldots$ & $\ldots$ & 1 & $\ldots$ & 3 & $\ldots$ & . & $\ldots$ & $\ldots$ & .. & 3 & 2 & $\ldots$ &. &.. & 1 & . & 1 & $\ldots$ & 1 &. & .. & $\ldots$ & 1 & 1 &. & 2 \\
\hline .. & .. & . & $\ldots$ &.. & .. & . & $\ldots$ & ... & $\ldots$ & $\ldots$ & .. & .. & $\ldots$ & .. & .. & $\ldots$ & .. & $\ldots$ & $\ldots$ & $\ldots$ & $\ldots$ & .. & . & $\ldots$ & $\ldots$ & $\ldots$ & $\ldots$ &.. & .. & .. & .. & $\ldots$ & .. \\
\hline.. & .. & .. & 1 &.. & $\ldots$ & .. & $\ldots$ & ... & $\ldots$ & .. & .. & .. & .. & .. & $\ldots$ & . & .. & .. & $\ldots$ & 1 & 1 & .. & .. & $\ldots$ & 1 & .. & 1 & .. & 2 & 1 & $\ldots$ & . & .. \\
\hline .. & .. & .. & 1 &.. & . & .. & $\ldots$ & $\ldots$ & . & $\ldots$ &.. & .. & . & .. & .. & .. & .. & .. & . & . & 1 & .. & . & $\ldots$ & 1 & .. & .. & 1 & .. & $\ldots$ & .. & . & .. \\
\hline.. & 1 & .. & .. &.. & .. & .. & .. & .. & $\ldots$ & . & .. & .. & . & $\ldots$ & .. & .. & . & .. & .. & .. &.. & .. & . & 1 & . & .. & $\ldots$ & $\ldots$ & $\ldots$ & .. & .. & . & .. \\
\hline . & .. & & .. & . & .. & 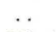 & $\because$ & $\ldots$ & $\cdots$ & $\ldots$ & $\ldots$ & 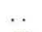 & . & & 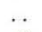 & .. & 1 & 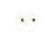 & .. & & 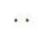 & & & .. & $\ldots$ & & .. & .. & $\cdots$ & .. & . & & \\
\hline 17 & 5 & 17 & 9 & 28 & 18 & 11 & 16 & 10 & 12 & 11 & 15 & 9 & 5 & 3 & 9 & 5 & 15 & 11 & 2 & 10 &.. & 1 & 12 & 9 & 12 & 14 & 7 & 7 & 7 & 13 & 7 & 9 & 6 \\
\hline$\cdots$ & . & .. & $\ldots$ &.. & .. & $\ldots$ & . & .. & .. & .. & .. &.. & $\ldots$ & . & $\cdot \cdot$ & . & . & .. & $\ldots$ & .. & $\cdot \cdot$ & . & .. & $\ldots$ & $\ldots$ &. & .. & .. &. &.$\cdot$ & + & . & • \\
\hline 1 & .. & & .. & .. & .. & . & - & 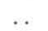 & .. & $\ldots$ & 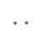 & 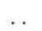 & . & .. & .. & .. & .. & .. & $\ldots$ & & .. & & & .. & .. & .. &. & .. & .. & .. & & & \\
\hline. & 2 & $\ldots$ & 1 & 1 & . & . & 1 & 2 & 1 & .. & 1 & .. & 1 & .. & $\ldots$ & 1 & . & 1 & .. & $\ldots$ & 1 & 1 & 1 & .. & .. & 1 & 1 & .. &. & 1 & 1 & 3 & 1 \\
\hline .. & .. & .. & .. &.. & .. & .. & $\ldots$ & .. & .. & .. &.. &.. & .. & .. & .. & .. & .. & .. & .. & .. & .. & .. & .. & . & . & .. & .. & .. & $\ldots$ &.. & .. & $\ldots$ & .. \\
\hline & & & & & & & & & & & & & & & & & & & & & & & & & & & & & & - & + & 1 & \\
\hline
\end{tabular}


Table 32. Herning. BP 5 (STA), 2.95-5.67 m.

The Figures indicate numbers of pollen grains or spores. [ ] probably derived. Tallene angiver antal af pollenkorn og sporer. [ ] sandlynligvis omlejret.

\begin{tabular}{|c|c|c|c|c|c|c|c|c|c|c|c|c|c|c|}
\hline Depth, m. & 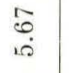 & is & $\exists$ & สี & 's & 8 & $\begin{array}{l}\overrightarrow{5} \\
\dot{f}\end{array}$ & 18 & $\infty$ & $\stackrel{N}{i}$ & 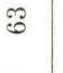 & $\underset{\leftrightarrow}{\stackrel{ \pm}{*}}$ & ริ & 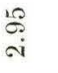 \\
\hline Allium cf. schoenophrasum . . . . . . . . & $\cdots$ & & $\cdots$ & . & & $\cdots$ & & 1 &. & &. & $\cdots$ & $\cdots$ & \\
\hline Arctostaphylos uva-ursi. . . . . . . . & $\ldots$ & {$[4]$} & .. & .. & {$[1]$} & .. & [1] & .. & .. & [2] & .. & .. & .. & [1] \\
\hline Armeria maritima $\ldots \ldots \ldots \ldots \ldots$ & 1 & .. & 1 & .. & .. & .. & .. & . & .. & 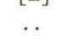 & .. & 1 & + & 1 \\
\hline Astragalus frigidus $\ldots \ldots \ldots \ldots \ldots$ & .. & .. & .. & .. & .. & .. & .. & .. & .. & $\because$ & .. & 1 & . & .. \\
\hline Bistorta $\ldots \ldots \ldots \ldots \ldots \ldots \ldots$ & .. & .. & .. & $\because$ & .. & .. & .. & + & .. & 1 & .. & 2 & 1 & 4 \\
\hline Botrychium ef. lunaria. . . . . . . . . . & . & . & . & 1 & .. & .. & + & .. & .. & .. & .. & .. & . & .. \\
\hline 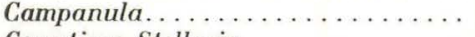 & $\cdots$ & .. & $\cdots$ & $\because$ & . & .. & .. & . & . & . & .. & 1 & 3 & .. \\
\hline Cerastium-Stellaria. ............ & . & . & 2 & 1 & . & .. & + & 2 & 1 & 2 & .. & .. & 2 & .. \\
\hline Ephedra distachya ............ & . & 1 & .. & . & .. & .. & .. & . & .. & .. & . & .. & + & .. \\
\hline - cf. strobilacea. . . . . . . . & .. & .. & 1 & . & .. & .. & .. & .. & .. & .. &.. & .. & .. & .. \\
\hline Erica tetralix............... & .. & .. & . & [1] & $\because$ & . & .. & .. & . & . &. & .. &.. & .. \\
\hline Fragaria $\ldots \ldots \ldots \ldots \ldots \ldots \ldots$ & $\because$ & .. & . & $\therefore$ & 1 & .. & 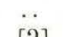 & .. & + & $\cdots$ & $\because i$ & .. & $\ddot{0}$ & . \\
\hline Fraxinus .... & [1] &.. & .. & {$[1]$} & . & .. & [2] & .. & [1] & .. & [1] & .. & [2] & .. \\
\hline Hedera helix................. & [1] & .. & .. & .. & {$[1]$} & .. & .. & .. & .. & .. & . & .. & .. & .. \\
\hline Helianthemum oelandicum type..... & .. & .. & .. & .. & $\cdots$ & . & 1 & .. & . & .. & 1 & .. & . & .. \\
\hline Heracleum . . . . . . . . . . . & .. & .. & .. & . & + & .. & .. & .. & .. & .. & .. & . & .. & .. \\
\hline Hippophaё rham & .. & $\cdots$ & .. & .. & . & .. & .. & + & .. & $\because$ & .. & .. & .. & .. \\
\hline Lycopodium annotinum . . . . . . . & .. & 2 & .. & .. & .. & .. & .. & + & .. & 1 & .. & .. & .. & .. \\
\hline alpinum-complanatum. . & .. & $\because$ & . & .. & . & .. & . & .. & .. & 1 & .. & .. & $\because$ & $\because$ \\
\hline clavatum........... & .. & 1 & .. & $\because$ & $\because$ & .. & .. & .. & .. & .. & .. & .. & 1 & 1 \\
\hline selago $\ldots \ldots \ldots \ldots \ldots$ & $\because$ & .. & .. & 1 & 1 & .. & .. & .. & .. & .. & .. & .. & .. & .. \\
\hline Melampyrum . ............. & 1 & .. & .. & .. & .. & .. & .. & .. & .. & .. & .. & .. & .. & 1 \\
\hline Ophioglossum vulgatum . . . . . . . & .. & .. & .. & .. & .. &. & + & .. & .. & .. &.. & . & .. & 1 \\
\hline Parnassia palustris . . . . . . . . & $\because$ & .. & .. & 1 & .. & 1 & . & . & .. & .. & .. & 1 & 1 & .. \\
\hline Plantago lanceolata ............. & [1] & [1] & .. & .. & .. & .. & .. & . & . & $\because$ & . & . & .. & .. \\
\hline Polygonum convolvolus type........ & $\cdots$ & *. & . & . & *. & .. & .. & + & . & 1 &.. & $\because$ & .. & $\because$ \\
\hline - persicaria type ........ & $\ddot{1}$ & $\cdots$ & * & - & - & $\cdots$ & .. & .. & . & .. & . & 1 & . & 1 \\
\hline Polypodium vulgare............. & 1 & .. & .. & $\cdot$. & $\cdot$. & $\because$ & * & *. & * & . & $\cdot \cdot$ & *. & . & 1 \\
\hline Pteridium aquilinum . . . . . . . . . . . & $\cdot \cdot$ & $\cdots$ & $\cdot \cdot$ & $\cdot \cdot$ & $\cdots$ & {$[1]$} & $\because$ &. & .. & . &.. & $\cdot$. & .. &. \\
\hline 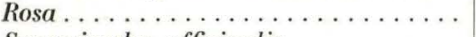 & .. & .. & .. & .. & .. &. & 1 &.. & .. & .. & .. & .. & $\because$ & .. \\
\hline Sanguisorba officinalis........... & . & .. & .. & .. & .. &.. & .. & + & .. & .. & .. & .. & 2 & + \\
\hline Scrophulariaceae......... & $\cdots$ & .. & .. & .. & .. & $\cdots$ & 1 & . & .. & . & .. & . & .. & . \\
\hline Sedum : & $\because$ & $\because$ & 1 & $\because$ &.. & $\cdots$ & .. & $\because$ & .. & . & .. & $\because$ & .. & . \\
\hline Silene-Arenaria . . . . . . . & 1 & 1 & 1 & 1 & .. &. & .. & 1 & . &. & .. & 2 &.. & .. \\
\hline Trifolium alpestre.$\ldots \ldots$ & $\cdots$ & . & $\ldots$ & .. & $\ddot{g}$ & . & .. & *. & + & $\cdot$ & $\cdot$. & &. & $\cdot$. \\
\hline Trollius europaeus........ & 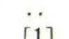 & & & $\ddot{0}$ & 2 & 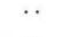 & . & $\cdots$ & $\cdot$ & $\cdot$ & * & $\ddot{11}$ & $\ddot{0}$ & *. \\
\hline$\ldots \ldots \ldots$ & [1] & {$[3]$} & {$[5]$} & [1] & {$[2]$} & 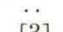 & $\cdots$ & $\cdots$ & $\cdot \cdot$ & $\cdot \cdot$ & $\cdots$ & {$[1]$} & {$[2]$} & 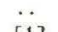 \\
\hline Vaccinium type..$\ldots \ldots \ldots \ldots \ldots$ & .. & .. & . & .. & . & [3] & .. & .. & .. & .. & .. & .. & .. & [1] \\
\hline Valeriana officinalis s.l. ......... & .. & .. & .. & .. & 1 & .. & .. & . & .. & .. & .. & .. & .. & 1 \\
\hline Vicia-Lathyrus . . . . . . . . . & . & .. & .. & .. & & .. & & + & .. & .. & 1 & .. & .. & .. \\
\hline Vitis $\ldots \ldots \ldots \ldots \ldots \ldots \ldots \ldots \ldots$ & * & & 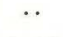 & - & [1] & $\cdot \cdot$ & . & *. & -. & .. & . & . & . & . \\
\hline Callitriche ${ }^{1}$ ). & $\cdots$ & .. & .. & .. & . & . & . & . & .. & .. & . & . & 1 & .. \\
\hline$\cdots$ & & .. & $\therefore$ & .. & .. & .. & .. & .. & .. & .. & + & .. & .. & .. \\
\hline Myriophyllum & {$[3$} & & [1] & .. & $\therefore$ & .. & $\therefore$ &.. & [1] & .. & .. & .. &. & .. \\
\hline Osmunda cf. cinnamomea. . & [2] & [1] & {$[3]$} & .. & {$[2]$} & & {$[\because]$} & {$[+]$} & . & .. & .. & {$[2]$} & [1] & [1] \\
\hline regalis. & $\cdots$ & . & & .. & . & [1] & .. & .. & .. & .. & . & . & .. & . \\
\hline Potamogeton sect. Coleogeton. . & .. & .. & [1] & . & .. & .. & .. & . & .. & . & $\cdots$ & . & * & 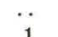 \\
\hline Rubus chamaemorus & .. & . & $\cdots$ & .. & .. & .. & . & . & . & . & . & . & .. & 1 \\
\hline Rumex aquaticus-hydrolapath... & & & & .. & $\ldots$ & .. & .. & .. & . & . & .. & . & $\because$ & 1 \\
\hline Thelypteris palustris type......... & [12] & [7] & {$[3]$} & [11] & {$[10]$} & [7] & [2] & [1] & {$[3]$} & {$[2]$} & {$[4]$} & [9] & [8] & {$[3]$} \\
\hline Typha latifolia $\ldots \ldots \ldots \ldots \ldots \ldots$ & $\cdot \cdot$ & . & . & *. & . & . & . & * & . & .. & . & .. & . & 1 \\
\hline Pediastrum $\left.{ }^{2}\right)$. & + & + & + & + & + & + & + & + & + & + & + & + & + & + \\
\hline
\end{tabular}

1) Omitted from the pollen totals.

2) + indicates presence in the sample. 
Table 33. Nørbølling.

The Figures indicate numbers of pollen grains or spores. [ ] probably derived.

Tallene angiver antal af pollenkorn og sporer. [ ] sandsynligvis omlejret.

\begin{tabular}{|c|c|c|c|c|c|c|c|c|}
\hline Depth, m. & 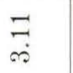 & $\begin{array}{l}10 \\
0 \\
0\end{array}$ & $\underset{\leftrightarrow}{\stackrel{8}{0}}$ & 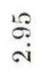 & $\begin{array}{l}\stackrel{8}{ } \\
\text { ii }\end{array}$ & $\begin{array}{l}\vec{\infty} \\
\text { oi }\end{array}$ & $\begin{array}{l}\mathscr{R} \\
i \\
i\end{array}$ & $\begin{array}{l}\overrightarrow{0} \\
\text { - }\end{array}$ \\
\hline 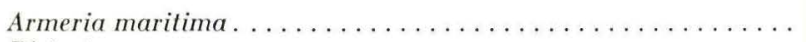 & 2 & .. & .. & .. & .. & .. & .. & .. \\
\hline 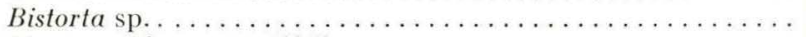 & 1 & + & .. & + & .. & .. & . & . \\
\hline 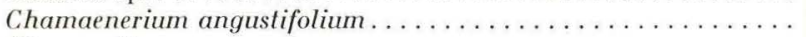 &.. & + & .. & . & . & .. & . & . \\
\hline 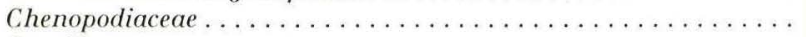 & .. & .. & 2 & . & . & .. & .. & . \\
\hline Cruciferae $\ldots \ldots \ldots \ldots \ldots \ldots \ldots \ldots \ldots \ldots \ldots$ & 1 & .. & .. & .. & .. & .. & .. & .. \\
\hline 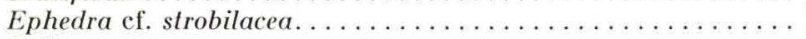 & .. & .. & .. & . & 1 & .. & . & .. \\
\hline 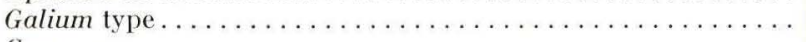 & 1 & .. & 1 & 1 & 1 & .. & 3 & 4 \\
\hline 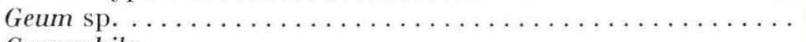 & 1 & .. & .. & .. & . & .. & . & .. \\
\hline 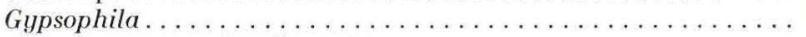 & + & .. & .. & .. & . & .. & . & .. \\
\hline 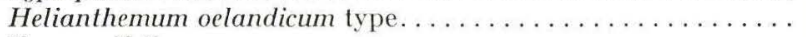 & + & .. & .. & . & .. & .. & . & . \\
\hline 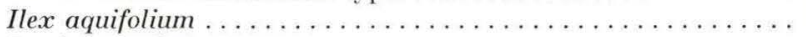 & [1] & .. & .. & .. & .. & .. & .. & .. \\
\hline 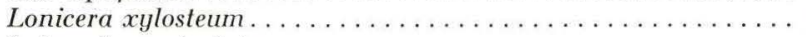 & .. & + & .. & .. & .. & .. & .. & . \\
\hline Lotus cf. corniculatus. ......................... & 1 & .. & .. & . & 1 & 1 & . & .. \\
\hline 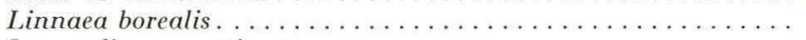 & .. & + & .. & .. & . & .. & .. & . \\
\hline Lycopodium annotinum . ...................... & 2 & + & .. & .. & . & .. & .. & .. \\
\hline 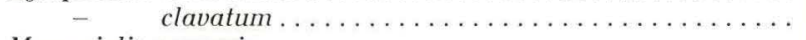 & . & + & .. & + & . & .. & . & .. \\
\hline 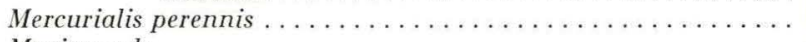 & . & 1 & .. & .. & .. & .. & .. & .. \\
\hline 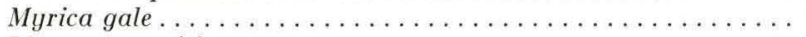 & .. & + & .. & .. & .. & .. & .. & .. \\
\hline Plantago maritima $\ldots \ldots \ldots \ldots \ldots \ldots \ldots \ldots \ldots \ldots \ldots$ & 1 & .. & .. & .. & .. & 1 & .. & .. \\
\hline 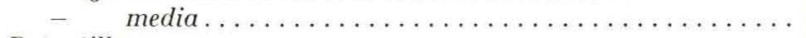 & 1 & $\ldots$ & .. & . & 1 & .. & 1 & .. \\
\hline 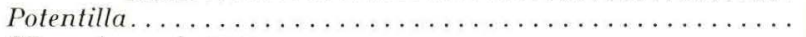 & .. & 3 & 1 & .. & . & .. & .. & . \\
\hline 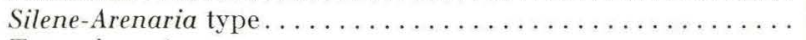 & 3 & . & .. & .. & .. & .. & 1 & . \\
\hline 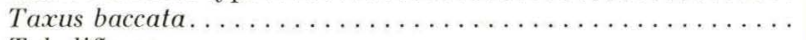 & [1] & [1] & .. & .. & .. & .. & .. & $\cdots$ \\
\hline 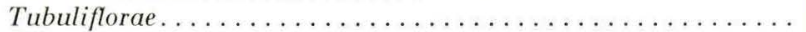 & 1 & 1 & .. & .. & 2 & .. & 1 & 2 \\
\hline 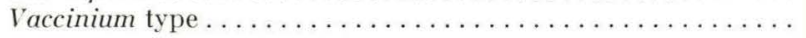 & .. & .. & .. & . & . & 1 & . & . \\
\hline Drosera anglica-rotundifolia........ & & & .. & + & . & .. & .. & .. \\
\hline Lycopodium inundatum ..... & 1 & .. & .. & .. & . & .. & .. & . \\
\hline Lysimachia thyrsiflora $\ldots \ldots \ldots \ldots \ldots \ldots \ldots \ldots \ldots$ & 1 & .. & .. & .. & . & .. & . & . \\
\hline Myriophyllum alterniflorum. . & 1 & 1 & .. & .. & .. & .. & .. & .. \\
\hline spicatum $\ldots \ldots \ldots \ldots \ldots \ldots$ & & [2] & [1] & .. & .. & .. & . & [2] \\
\hline$\ldots \ldots \ldots \ldots \ldots \ldots \ldots$ & [1] & [1] & .. & .. & .. & .. & .. & .. \\
\hline Osmunda cf. cinnamomea $\ldots \ldots \ldots \ldots \ldots \ldots \ldots \ldots \ldots \ldots$ & [1] & & $\ldots$ & .. & .. & .. & .. & .. \\
\hline - regalis. & . & {$[1]$} & .. & . & ... & .. & .. & .. \\
\hline Polygonum amphibium.......... & .. & + & .. &.. & .. & .. & .. & .. \\
\hline 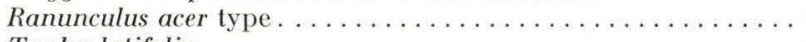 & .. &.. & $\because$ & . & 1 & 2 & .. & $\because$ \\
\hline Typha latifolia $\ldots \ldots \ldots \ldots \ldots$ & 0 & $\because$ & 1 & . & . & .. & . & 1 \\
\hline Typha-Sparganium type ....... & 2 & 2 & . & .. & .. & .. & .. & 1 \\
\hline$\ldots \ldots \ldots \ldots \ldots \ldots \ldots \ldots \ldots$ & + & $\ldots$ & $\ldots$ & $\ldots$ & . & .. & .. & $\ldots$ \\
\hline
\end{tabular}

1) Omitted from the pollen totals.

$\left.{ }^{2}\right)+$ indicates presence in the sample. 


\section{VEGETATIONEN OG DENS KÅR I DANMARK I TIDLIG WEICHSEL GLACIALTID (SIDSTE ISTID)}

\section{INDLEDNING}

Knud Jessen og V. Milthers (1928) offentliggjorde pollendiagrammer fra 2 lokaliteter fra den næstsidste interglacialtid og fra 13 lokaliteter, som kunde dateres til den sidste interglacialtid i Vestjylland, og viste, at en lignende vegetationsudvikling karakteriserer aflejringer af samme alder i NV-Tyskland. Det vistes, at hver interglacialtid havde sin karakteristiske vegetationsudvikling, og pollenanalysen viste sig således at være et nyttigt redskab for en datering af senpleistocene pollenførende lag. Senere undersøgelser $^{1}$ ) har vist, at princippet om regional parallelisme gælder for interglaciale pollendiagrammer fra Nordeuropa, og har støttet henførelsen af Eemhavet til det „Nedre Varme-Stadium“ fra Herning-profilet.

Jessen og Milthers (l. c.) henregnede også det „Øvre Varme-Stadium“ fra Herning til den sidste interglacialtid. Klimasvingninger i tiden efter Eem Interglacialtiden kendes nu ad flere veje, men man har intetsteds kunnet påvise et varmestadium med en vegetation, der ligner den, der fandtes i det „Øvre Varme-Stadium“ fra Herning (med høje pollenfrekvenser for Quercus, Corylus og Alnus, se også kapitel VI). Man betragter derfor nu sædvanligvis kun det „Nedre Varme-Stadium” fra Herning som Eem Interglacialtiden og henfører de derpå følgende stadier til den sidste istid i Nordeuropa ${ }^{2}$ ).

Fraværet af et stadium, der minder om det „Øvre Varme-Stadium” fra Herning, er blevet forklaret ved henvisning til erfaringer andetsteds fra, at en sådan horisont kan være dannet af omlejret, interglacialt materiale. Her skal henvises til undersøgelser af Thomson $(1941,1951)$ i Estland og Tyskland og af Reid (1896) og West (1956) i England, som er refereret i den engelske tekst.

I de 30 år, der er forløbet siden offentliggorelsen af Jessen og Milthers' arbejde, har pollenanalysen været i rivende udvikling, og det var givet, at disse problemer burde undersøges påny i Danmark. Fremskridt af særlig betydning i denne forbindelse er indførelsen af metoder, der gør det muligt at finde tilstrækkeligt pollen i leraflejringer, forståelsen af urtepollenets betydning, specielt ved studiet af skovfattige tidsrum, og opdagelsen af, at sedimenter med stort indhold af alloktont mineralsk materiale kan være forurenet med pollen fra ældre aflejringer (se især Iversen 1936a). Også nye erfaringer med hensyn til pollenanalysens muligheder for at belyse fortidens vegetation og dens kårforhold, især i Senglacialtiden, er af særlig betydning for en forståelse af de problemer, der behandles her (se især Iversen 1954).

1) Literatur er nævnt udførligt i den engelske tekst.

${ }^{2}$ ) "Weichsel Glacialtid" vil i det følgende blive brugt for det tidsrum, der adskiller Eem Interglacialtiden fra Postglacialtiden, se iøvrigt diskussionen i kapitel VI. 
Den her omtalte undersøgelse omfatter lokaliteterne Brørup Hotel Mose, Rodebæk I, Herning og Nørbølling, ved hvilke Jessen og Milthers (1. c.) fandt det „Øvre VarmeStadium“ repræsenteret. Der er også fortaget boringer ved Solsø. Undersøgelsen af lagene fra Eem Interglacialtiden er ikke afsluttet, og kun de derover liggende aflejringer vil blive omtalt detailleret her. Ved Brørup Hotel Mose fandtes en særlig detailleret serie fra tidsrummet, der fulgte Eem Interglacialtiden.

\section{Metoder}

\section{Boreteknik.}

Den anvendte boreteknik muliggjorde udtagelse af intakte kerneprøver i kontinuerlig række.

\section{Sedimenter.}

De enkelte profiler er beskrevet i kapitel III. Beskrivelsen af sedimenterne folger i det væsentlige de principper, som Troels-Sмiтн (1955) har udarbejdet.

Mineralindholdet i sedimenterne består i det væsentlige af silikater. Mængden af indskyllet mineralsk materiale kan således bestemmes ud fra en bestemmelse af indholdet af organisk stof, som omtales nærmere i den engelske tekst. Et højt indhold af alloktone mineraler er karakteristisk for sedimenter fra arktiske søer og fra søer fra Senglacialtiden, og en stigning i indholdet af sådanne mineraler i profilsøjlerne kan tyde på et koldere klima.

Et højt indhold af alloktont mineralsk materiale står ofte i forbindelse med tilstedeværelse af omlejret pollen og sporer, som påvist for senglaciale sedimenter af IvERSEN (1936 a),

Sedimenterne og deres indhold af planterester giver ofte oplysninger om vandstandssvingninger i de lokale bassiner. Disse har i de herværende tilfælde været afløbsløse, og vandstandssvingningerne skyldtes sandsynligvis i høj grad klimaændringer, især ændringer af nedbør og/eller lufttemperatur.

\section{Pollenanalyser.}

Resultaterne af pollenanalyserne er vist i pollendiagrammerne, som viser den relative hyppighed af pollen og sporer fundet i sedimenterne. Man plejer at forsøge at udelukke indflydelsen af facies ved at udelade pollen og sporer fra lokale planter fra beregningerne. De forskellige identificerede kategorier af pollen og sporer (familier, slægter, arter) kan omfatte (1) kun planter fra høj bund, (2) både planter, der kan gro på høj bund, og planter, der kan gro på bund med et højt grundvandsspejl, og (3) kun vandplanter og planter, der foretrækker vandmættet bund.

I de foreliggende pollendiagrammer er pollen og sporer, der formodes at tilhøre gruppe (3) nævnt ovenfor, udeladt fra procentberegningerne. Udeladelse af planter fra gruppe (2), f. eks. græsser og halvgræsser, vilde utvivlsomt give et forkert billede. Imidlertid må det huskes, at billedet kan være stærkt påvirket af lokalt pollen i de torvelag, der forekommer i profilerne.

\section{Pollenzoner.}

De vegetationshistoriske enheder er pollenzoner. Da pollenzoner i første række er afgrænset ved ændringer i pollenindholdet $\mathrm{i}$ visse sedimenter, bør de anses for at være bio-stratigrafiske enheder (sml. Hedberg 1954). Pollenzoner kan gælde som tids- 
enheder i begrænsede områder, men grænserne for pollenzonerne er ikke altid synkrone i et større område, og krono-stratigrafiske enheder bør afgrænses på anden måde (se kapitel VI).

I Jessen's pollenzoner for sidste interglacialtid (Jessen og MiLthers 1928) er pollenet fra urter og buske ikke taget i betragtning, og det har derfor været nødvendigt at definere nye pollenzoner. I fremtiden vil det være nyttigt for overskueligheden at nummerere pollenzoner fra interglacialtider og glacialtider særskilt. Således vil det være praktisk at sætte grænsen for Eem Interglacialtiden i vegetationshistorien ved det punkt af udviklingen, hvor skovvegetationen forsvandt, og skovløse vegetationstyper bredte sig. Nye pollenzoner for den nærmest derefter følgende udvikling er beskrevet (zonerne W 1-W 5, se den engelske tekst side 17-18 og oversigten s. 160).

\section{Bestemmelser}

Alle de bestemte planterester fra pollenzonerne W 1-W 5 er vist i tabel 23 (s. 107-111). Bestemmelserne af makrofossiler hidrører især fra KnuD JEssen's undersøgelse (i Jessen og Milthers 1928). Nye bestemmelser af makrofossiler repræsenteres af Elisma natans og Larix sp. I dette kapitel omtales en række bestemmelser især af pollen og sporer nærmere. Bestemmelser baseret på statistiske undersøgelser (størrelse, poretal) er omtalt $i$ et særligt afsnit.

\section{Beskrivelse af Lokaliteterne}

I dette kapitel beskrives sedimentserierne og pollendiagrammerne fra de enkelte lokaliteter. Der henvises til den engelske tekst, dog skal enkelte hovedtræk og særlige forhold omtales her.

Ved Brørup Hotel Mose påvises det, at de lag, der svarer til det af Jessen og Milthers (1928) beskrevne „,mellemlag“, består af sedimenter med et højt mineralindhold, og at de derover liggende lag har et højt organisk indhold. I lagene med højt mineralindhold forekommer typisk interglaciale pollentyper på en sådan måde, at de må anses for at være omlejrede fra interglaciale lag. Også andre sekundære pollentyper forekommer, men en række pollentyper, fortrinsvis repræsenterende urteagtige landplanter og vandplanter, forekommer på en sådan måde, at de må anses for at være primære. I de øvrige, væsentligst organiske lag, forekommer næsten intet sekundærpollen. Foruden lagene fra Eem Interglacialtiden er pollenzonerne W 1-W 5 repræsenteret i profilerne.

Ved Rodebæk I indeholder lagene over aflejringerne fra Eem Interglacialtiden meget mineralsk materiale, og de har et højt indhold af omlejret interglacialt pollen, med undtagelse af et gytjelag (lag D i Jessen og MiLthers' profiler), som fortrinsvis indeholder primært pollen. Gytjelaget stammer fra pollenzone W 2 (underzone c).

Ved Herning dækkes lagene fra Eem Interglacialtiden af tykke, næsten rent mineralske lag. Den „øvre varme-horisont" genfandtes som en horisont med mange tynde detrituslag. Både „,mellemlaget” og den ,øvre varme-horisont " indeholder interglacialt pollen i høje frekvenser, og de fleste af de i disse lag fundne planterester må anses for at være omlejrede. Over de nævnte lag findes en gytjehorisont (lag F) med et lavt mineralindhold og lave frekvenser for omlejret pollen. Dette gytjelag svarer til den nederste del af pollenzone W 3.

Ved Nørbølling blev der også fundet lag med højt mineralindhold over aflejringerne fra Eem Interglacialtiden. De indeholder meget omlejret pollen, og kun en horisont 
af dy-agtige lag (lag E) indeholder fortrinsvis primært pollen. Dy-lagene tilhører pollenzonerne W 4-W 5.

Ved Solsø findes lag fra Eem Interglacialtiden i betydelig dybde. De overlejres af stærkt mineralholdige lag, som repræsenterer Weichsel Glacialtiden, og af gytje fra Postglacialtiden. En lille sø findes endnu, men den er nu stærkt reduceret ved dræning. De mineralholdige lag indeholder omlejret pollen i store mængder og ingen pollendiagrammer er udarbejdet.

\section{Vegetationen og dens kÅr I Vestjylland I Pollenzonerne W $1-$ W 5}

I det forelagte materiale fra Brørup Hotel Mose, Rodebæk I, Herning og Nørbølling kan palæoøkologiske slutninger drages på baggrund af sedimenternes sammensætning, angivelser om vandstandsændringer og især på oplysninger om vegetationens sammensætning og planternes udbredelsesforhold i nutiden.

Man må her gøre sig klart, at det i reglen kun er en ringe del af selve planterne, der er bevaret. Imidlertid er især makrofossiler som frugter, frø og blomsterdele ofte af høj taksonomisk værdi. Det her omtalte materiale er sammenholdt med nulevende arter. Denne fremgangsmåde begrundes først og fremmest med floraens unge alder og med det faktum, at Hartz (1909) og Jessen (i Jessen og Milthers 1928) kunde identificere planterester fra Eem Interglacialtiden i Danmark med en lang række (132) nulevende nordeuropæiske arter, mens blot to arter nu kun findes repræsenteret uden for Europa.

Eksistensen af fysiologiske racer (biotyper, okotyper, provenienser) og mulighederne for ændringer i arternes indhold af disse repræsenterer et problem for palæoøkologien. Pleistocentidens nedisninger kan have fremkaldt ændringer i visse termofile arters indhold af racer, men som nærmere begrundet i den engelske tekst, behøver sådanne ændringer ikke at have været universelle. Heliofyter har sikkert haft vanskeligheder ved at overleve skovens fremtrængen i Postglacialtiden, og deres populationer er i dag ofte stærkt reducerede. Palæøkologiske slutninger bør helst støttes på enstydige angivelser fra en række arter.

Oplysninger om planternes nuværende krav til kårene på voksestedet kan hentes fra literaturen, men disse krav kendes langtfra altid i detailler. Især er det ofte vanskeligt at bedømme arternes krav til klimaet. Arternes udbredelse kan bestemmes af hele årets temperaturer, men oplysninger om temperaturen for den varmeste og den koldeste måned kan være tilstrækkelige for at afgrænse en arts termosfære (se især IvERSEN 1944). Desværre er oplysninger om vintertemperaturen sjældne i det fossile materiale, og skøn af sommertemperaturen må derfor være ret grove. IvERSEN (1954) grupperede plantearterne efter aftagende værdi som temperaturindikatorer således: (1) træer og buske, (2) vandplanter, (3) skyggetålende urter og dværgbuske, (4) heliofile urter og dværgbuske. De planter, der kræver mest af voksestedet, anses for at være de mest upålidelige temperaturindikatorer. Vandplanternes høje værdi som temperaturindikatorer fremhævedes af Iversen i overensstemmelse med Glück (1927), Samuelsson (1934) og Szafer $(1946,1954)$, men i modsætning til WesenberG-Lund (1909).

Udtrykkene ,,subarktisk“ og ,,subalpin“ vil blive anvendt for det område, der findes mellem nåletræsgrænsen (Picea abies og Pinus silvestris) og birkeskovsgrænsen (Betula tortuosa) i Skandinavien.

En oversigt over forskellige mere vigtige planters hyppighed i de forskellige pollenzoner er vist på tavle XV (baseret på pollenanalyserne fra Brørup Hotel Mose, for zone W 1-W 3, og Nørbolling, for zone W 4-W 5). 


\section{Zone W 1.}

Afslutningen af Eem Interglacialtiden markeres ved en nedgang af thermofile planters pollen og ved en udbredelse af skovløs vegetation. Samtidig skete der åbenbart en vandstandsstigning i de lokale bassiner.

Pinus silvestris, Picea abies, Betula pubescens og Populus tremula forekom muligvis med spredte individer. Buske var fremherskende (især Betula nana, Juniperus communis, Calluna vulgaris, Empetrum nigrum, E. hermaphroditum og Arctostaphylos uvaursi), og vegetationen minder derved om den nutidige vegetation i det subarktiskesubalpine bælte i Nordeuropa, dog med den forskel at Betula tortuosa åbenbart manglede. Urteagtige planter var også almindelige. Vandplantefloraen minder også om den, der findes i det subarktiske-subalpine bælte i Nordeuropa i dag. Klimaet kan derfor karakteriseres som subarktisk, og det var formodentlig ret oceanisk.

Vegetationens sammensætning viser, at nedbøren har været rigelig både om sommeren og om vinteren.

Den udbredte forekomst af hedeagtig vegetation og sjældenheden af basifile planter tyder på, at en fattig jordbund med et surt humuslag har været fremherskende. Da underlaget er kalkholdig moræne fra den sidste nedisning før Eem Interglacialtiden, må denne sure jordbund sikkert ses som resultatet af en fremadskridende udvaskning i Interglacialtiden. Vandplantefloraen karakteriseres af arter, som fortrinsvis findes i søer med fattig vandplantevegetation og neutralt vand (Myriophyllum alterniflorum, Isoëtes echinospora, I. lacustris). I Eem Interglacialtiden var søernes flora udpræget basifil, og fattiggørelsen skyldes utvivlsomt den fremadskridende jordbundsudvaskning.

\section{Zone W 2.}

Denne pollenzone er inddelt i 5 underzoner, a, b, c, d og e. Underzonerne a, c og e forekommer ret gunstige klimatisk set, mens b og d var væsentligt koldere.

Sedimenterne i søerne domineres ganske af alloktont mineralsk indhold, især i underzonerne b og d. I løbet af denne zone blev bassinet i Rodebæk I udfyldt med sedimenter, mens der ved slutningen af zonen stadig fandtes søer i Brørup Hotel Mose, Herning, Nørbølling og Solsø. Alle andre moser eller søer fra Eem Interglacialtiden kendt i Vestjylland må være blevet udfyldt allerede på et tidligt tidspunkt i zone W 2. I hvert fald har erosion og tilførsel af alloktont mineralsk materiale til søerne i denne zone været stærk. Adskillige forhold tyder på, at solifluktion har været medvirkende til at transportere det alloktone materiale ned til søerne. Der anføres grunde til at tro, at den fremherskende form for solifluktion på dette tidspunkt var af den amorfe type. Denne solifluktionstype, hvor en udifferentieret masse bevæger sig nedad på selv svagt hældende skråninger, kan være uaf hængig af pergelisol, idet den kan forekomme, hvor rigelig fugtighed er til stede i overfladelagene. Den karakteriserer især områder med oceanisk klima i arktiske eller subarktiske områder.

Træer manglede muligvis helt, eller de var i hvert fald sjældne. Af buske fandtes Salix-arter, Betula nana, Juniperus communis, mens Ericales var sjældne. Urteagtige planter var fremherskende, og forekomsten af en række heliofyter karakteriserer zonen (se s. 88 og kurve A på tavle XV). Heliofyterne var særlig talrige i underzone c; men disse planter er sikkert upålidelige som temperaturindikatorer. Vandplanter forekommer på en karakteristisk måde. De var åbenbart hyppige i underzonerne a, c og e, mens søerne var nærmest sterile i underzonerne b og d. Det antydes, at klimaet i underzonerne a og e var subarktisk. Det samme var tilfældet for underzone c, som adskiller de to kolde tidsrum, underzonerne b og d, hvor klimaet sikkert var arktisk.

Den ringe hyppighed af Ericales tyder på, at solifluktionen ødelagde den udvaskede 
landoverflade og bragte frisk jordbund op til overfladen. En lignende proces kan iagttages i dag i arktiske eller subarktiske områder. Denne antagelse støttes af forekomsten af en række neutro-basifile arter (se s. 91 og kurve $\mathrm{B}$ på tavle XV). I det hele taget karakteriseres heliofytfloraen ved forekomsten af planter af pionertype, som i dag kan findes på ustabil jordbund under en række forskellige forhold. Det bemærkes, at disse pionerplanter viste en vis forkærlighed for underzonerne a, $\mathrm{cog}$ e, især underzone $\mathrm{c}$. Dette skyldtes måske mindre snedæk ke og tørrere jordbund i disse underzoner. Områder med våd flydejord bærer ofte næsten ingen vegetation, og dette forhold forklarer muligvis vegetationens storre fattigdom $\mathrm{i}$ underzonerne $\mathrm{b}$ og $\mathrm{d}$.

Vandplantefloraerne fra underzonerne a, c og e præges af indifferente, neutro-basifile og basifile arter. Dette viser, at vandet i søerne ikke kan have været surt, men det var snarere neutralt eller svagt basisk, og især i Brørup Hotel Mose herskede der åbenbart en ret rig vandplantevegetation. Denne ændring fra forholdene i zone W 1 skyldtes muligvis, at det vand, søerne modtog fra omgivelserne, indeholdt karbonater igen som et resultat af solifluktionen.

\section{Zone W 3.}

Hele zonen findes klart udviklet i Brørup Hotel Mose. Den er delt i underzonerne $\mathrm{a}, \mathrm{b}, \mathrm{c}, \mathrm{d}$ og e, hvoraf underzonerne b og d er lidt mindre gunstige. Sedimenterne antyder en almindelig sænkning af vandspejlet med svage vandstandsstigninger $\mathrm{i}$ underzonerne b og d.

Betula pubescens var fremherskende, men skoven var ikke mørk, hvilket vises af den hyppige forekomst af de lyskrævende Populus tremula, Betula nana og Juniperus communis, og af det ret hyppige urtepollen. Andre påviste træer eller buske er Prunus cf. padus, Frangula alnus, Lonicera xylosteum og Larix. Der fandtes en ret rig flora af skyggetålende, urteagtige planter, hvoraf nogle er ret sydlige i Skandinavien i dag (Solanum dulcamara, Pteridium aquilinum, Merculialis perennis). I vand- og sumpplantefloraen fandtes en række arter, som ikke overstiger nåleskovsgrænsen i dag (Elisma natans, Littorella uniflora, Lobelia dortmanna, Lysimachia thyrsiftora, Nuphar luteum, Typha latifolia, Valeriana dioica). Alt i alt er floraen thermofil. I underzonerne b og d sænkedes sommertemperaturen noget. Den lokale vegetation antyder ligesom sedimenterne en almindelig lav vandstand med svage vandstandsstigninger i underzonerne b og d.

Nedbøren har sikkert været rigelig.

En række planter antyder en gunstig humusholdig skovbund. En del neutro-basifile arter forekom stadig; men acidofile planter forekom med tiltagende hyppighed. I de lokale vand-og sumpplantefloraer fremherskede neutro-acidofile arter. Elisma natans var almindelig i Brørup Hotel Mose og forekom også i Herning og Nørbølling. Denne vandplante har en ejendommelıg pletvis udbredelse 1 Vesteuropa i dag.

\section{Zone W 4.}

Zonen findes udviklet i Brørup Hotel Mose og især i Nørbølling. I Brørup voksede søen til med sumptørv og skovtørv, men i Nørbølling er sedimentet stadig en søaflejring. Betula pubescens, Pinus silvestris, Picea og Larix fremherskede i skovvegetationen. Picea abies var forst til stede alene, senere indvandrede Picea omoricoides, som er nært beslægtet med den nulevende $P$. omorica, der i dag findes i små reliktforekomster i Jugoslavien. Skoven var åbenbart tættere end i den foregående zone W 3 , sikkert på grund af indvandringen af mere skyggegivende træer. Af buske kan nævnes Frangula alnus, der var meget almindelig, Myrica gale, Erica tetralix og Lonicera xylosteum, der 
alle er ret sydlige i Skandinavien i dag. Blandt de ret skyggetålende urteagtige planter bør nævnes Pteridium, Mercurialis, Linnaea borealis og Symphytum. Symphytum er i dag sikkert ikke spontan i Skandinavien, men den er muligvis spontan i Centraleuropa. Klimaet var sikkert lige så varmt som i zone W 3.

Tilstedeværelsen af atlantiske arter tyder muligvis på ret milde vintre og rigelig nedbør.

Floraen er tydeligt præget af surbundsplanter, og neutro-basifile arter er ret sjældne. Dette tyder på fremadskridende udvaskning og dannelse af sur humus. De lokale floraer er også præget af surbundsplanter.

\section{Zone W 5.}

Skovens sammensætning mindede om den forudgående zone, men Picea og Betula gik noget tilbage. Frangula og Calluna var meget udbredte. I Brørup Hotel Mose fremherskede en højmoseagtig vegetation. Visse ændringer i pollenkurverne tyder muligvis på en lokal vandstandsstigning (svarende til underzone b).

Vegetationens sammensætning tyder på en fremadskridende dannelse af sur humus og muligvis en almindelig udbredelse af højmoser. De lokale floraer er også præget af surbundsplanter.

\section{Zone W x.}

Den øvre tørveserie i Brørup Hotel Mose afbrydes af en erosionsdiskordans. Derover findes et sandet lerlag, som indeholder meget omlejret pollen. Dog antydes det, at en subarktisk vegetation fremherskede. Serien afsluttes af solifluktionslag, sikkert fra Weichsel Glacialtidens koldeste del.

\section{Floralisten.}

En liste over højere planter bestemt på grundlag af makrofossiler eller pollen og sporer fra pollenzonerne W 1-W 5 er vist i tabel 23 (side 107-111). 180 taxa er bestemt til slægt, artsgruppe eller art, men 44 af disse er kun repræsenteret af omlejrede planterester eller af fjerntransporteret pollen. 56 artsbestemmelser er baseret på bestemmelser af makrofossiler af Jessen (i Jessen og Mrlthers 1928). Dateringen af fundene til pollenzonerne W 1-W 5 er omtalt i kapitel IV. Makrofossiler omtalt af Jessen er kun medtaget, forsåvidt de har kunnet dateres i pollenzonerne med en vis sikkerhed.

Listen over bestemmelser er sammenlignet med den tilsvarende liste fra Senglacialtiden publiceret af IVERSEN (1954). Af de 136 slægter, artsgrupper eller arter, som anses for primære, genfindes 88 i den senglaciale liste. 4 af de planter, der mangler i listen fra Senglacialtiden, nåede ikke til Danmark efter Weichsel Glacialtiden (Larix, Picea abies, P. omoricoides, Symphytum). 16 acidofile arter mangler der. Dette skyldes sandsynligvis, at hede- og højmosevegetation var udbredt i pollenzonerne W 1 og W 4-5, mens istidsaflejringerne i Senglacialtiden ikke var udvasket, og sur jordbund stærkt begrænset. En række basifile arter kendt fra Senglacialtiden er ikke repræsenteret i zone W 2 med primære fund. Dette kan tyde på, at den mineralske jordbund, der blev frembragt ved solifluktionen i zone W 2, var noget fattigere på kalk end det uforvitrede moræneler i Senglacialtiden. Ligeledes var Isoëtes echinospora, I. lacustris og Myriophyllum alterniflorum almindelige i pollenzonerne W 1-W 3, men manglede helt eller var sjældne i Senglacialtiden, sikkert på grund af konkurrence fra mere krævende og hurtigt voksende vandplanter.

50 slægter eller arter af heliofyter og planter fra åbne voksesteder forekommer i det nærværende materiale, og 40 af disse genfindes i den senglaciale liste. Dette antyder, 
at pionerfloraerne fra tidlig og sen Weichsel Glacialtid var ensartede. Deres beslægtethed med nutidige vegetationstyper på ustabil jordbund er fremhævet af IvERSEN (1954) og ovenfor.

\title{
VI. Klima og kronologi i tidlig Weichsel Glacialtid
}

i Vestjulland

Geologiske iagttagelser fra Pleistocænet kan ofte sammenlignes med iagttagelser fra nutiden ret direkte, og klimasvingninger kan ofte påvises med stor sikkerhed. Stratigrafiske inddelinger støttes sædvanligvis ikke på slutninger om palæoklimaet (se Hedberg 1954, Troelsen og Sorgenfrei 1956). Geologiske iagttagelser fra Pleistocænet af morænestadier, flodterrassesystemer, løssprofiler, huleaflejringer, strandlinier, vertebrat og invertebrat palæontologi, og vegetationshistorie fremviser stor variation og begrunder en række inddelinger af litho-stratigrafisk eller bio-stratigrafisk natur, men disse inddelinger er ofte fragmentariske.

Vegetationshistorien kan være særlig nyttig for en stratigrafisk inddeling af Pleistocænet, men det må huskes, at dens stadier er bio-stratigrafiske enheder, og deres grænser kan ikke altid anses for at være samtidige i et større område.

Flere forfattere (se literatur i den engelske tekst) har da også foretrukket at afgrænse tidsenheder i Pleistocænet på grundlag af klimasvingninger. Interglacialer og glacialer repræsenterer Pleistocænets hovedtidsenheder efter denne opfattelse. De interglaciale stadier karakteriseres ved langvarige fremadskridende vegetationssuccessioner. De afgrænses af større klimaændringer og adskilles af glaciale stadier. Interstadialer og stadialer anses for underafdelinger af de glaciale stadier. Et interstadial udgør săledes en mindre varme-tid inden for en glacialtid.

Især efter hollandske forfattere (ZAGWIJN 1957 a, 1960, vAN DER VLERK 1957, 1959, ZoNNEveld 1957) kan for tiden folgende hovedstadier adskilles i Nordeuropa:

\author{
Weichselian Glacial \\ Eemian Interglacial \\ Saalian Glacial \\ Hoxnian Interglacial \\ Elsterian Glacial \\ Cromerian Interglacial \\ Menapian Glacial \\ Waalian Interglacial \\ Eburonian Glacial \\ Tiglian Interglacial \\ Pre-Tiglian Glacial
}

Kun de yngste af disse stadier er repræsenteret her i landet.

Weichsel Glacialtiden kan afgrænses som det tidsrum, der adskilte Eem Interglacialtiden fra Postglacialtiden. Adskillige forfattere (se den engelske tekst) henregner nu Senglacialtiden til Weichsel Glacialtiden, hvis øvre grænse således er den fini-glaciale temperaturstigning, som svarer til afslutningen af det sidste storre fremstød af den skandinaviske indlandsis. I den nordeuropæiske vegetationshistorie svarer denne grænse til overgangen pollenzone III-IV i Skandinavien og Holland. På dette tidspunkt blev skoven dominerende og Postglacialtidens langvarige, fremadskridende skovsuccession begyndte. Zonegrænsen er sikkert noget yngre end selve temperaturstigningen, dens alder er efter C-14 bestemmelser ca. 10300 før nu.

Weichsel Glacialtidens nedre grænse og en inddeling af dens ældste del er omtalt i det folgende. 


\begin{tabular}{|c|c|c|c|c|c|c|c|}
\hline \multicolumn{3}{|r|}{ Bio-stratigrafi } & \multirow{2}{*}{ Jordbund } & \multirow{2}{*}{$\begin{array}{l}\text { Juli } \\
\text { temp. }\end{array}$} & \multirow{2}{*}{$\begin{array}{l}\text { Lokal } \\
\text { vandstand }\end{array}$} & \multicolumn{2}{|c|}{ Lokal kronologi } \\
\hline \multicolumn{2}{|c|}{ Zoner } & Vegetation & & & & $\begin{array}{l}\text { Under- } \\
\text { stadier }\end{array}$ & $\begin{array}{l}\text { Hoved- } \\
\text { stadier }\end{array}$ \\
\hline \multicolumn{2}{|c|}{$\mathrm{Wx}$} & $\begin{array}{l}\text { Betula pubescens?, B. nana, Juniperus, } \\
\text { urter }\end{array}$ & $\begin{array}{l}\text { Jordbunds- } \\
\text { erosion }\end{array}$ & $10-12^{\circ}$ & $\begin{array}{l}\text { Stigende vand- } \\
\text { stand (B) }\end{array}$ & \multirow{13}{*}{$\begin{array}{l}\text { Brørup } \\
\text { Inter- } \\
\text { stadial }\end{array}$} & \multirow{17}{*}{$\begin{array}{l}\text { Weichsel } \\
\text { Glacial- } \\
\text { tid }\end{array}$} \\
\hline \multicolumn{6}{|c|}{ Hiatus } & & \\
\hline \multirow{3}{*}{ W 5} & $\mathrm{c}$ & \multirow{3}{*}{$\begin{array}{l}\text { Skov af Pinus, Picea, Betula pubescens, } \\
\text { Larix, Frangula. Calluna, Empetrum }\end{array}$} & \multirow{3}{*}{$\begin{array}{l}\text { Surt humuslag } \\
\text { fremherskende }\end{array}$} & $13-15^{\circ}$ & Lav vandstand & & \\
\hline & $\mathrm{b}$ & & & ca. $13^{\circ} ?$ & $\begin{array}{l}\text { Lidt højere } \\
\text { vandstand (B) }\end{array}$ & & \\
\hline & a & & & $13-15^{\circ}$ & $\begin{array}{l}\text { Lav vandstand } \\
(\mathrm{B}, \mathrm{N})\end{array}$ & & \\
\hline \multicolumn{2}{|c|}{ W 4} & $\begin{array}{l}\text { Skov af Betula pubescens, Picea, Larix, } \\
\text { Frangula. Pinus tiltager }\end{array}$ & $\begin{array}{l}\text { Surt humuslag } \\
\text { tiltagende }\end{array}$ & $13-15^{\circ}$ & $\begin{array}{l}\text { Lav vandstand } \\
\text { (B) }\end{array}$ & & \\
\hline \multirow{5}{*}{ W 3} & $\mathrm{e}$ & $\begin{array}{l}\text { Skov af Betula pubescens, Populus, } \\
\text { Larix, Frangula. B. nana, Juniperus } \\
\text { og urter almindelige. Calluna tiltager }\end{array}$ & $\begin{array}{l}\text { Tiltagende } \\
\text { dannelse af surt } \\
\text { humuslag }\end{array}$ & $13-15^{\circ}$ & $\begin{array}{l}\text { Lav vandstand } \\
\text { (B) }\end{array}$ & & \\
\hline & d & Trævegetationen mere aaben & Svag erosion & ca. $12^{\circ}$ & $\begin{array}{l}\text { Stigning af } \\
\text { vandstanden (B) }\end{array}$ & & \\
\hline & $\mathrm{c}$ & $\begin{array}{l}\text { Skov af Betula pubescens, Populus. } \\
\text { B. nana, Juniperus og urter almindelige }\end{array}$ & $\begin{array}{l}\text { Stabilisering. } \\
\text { Humus dannes }\end{array}$ & $13-15^{\circ}$ & $\begin{array}{l}\text { Lav vandstand } \\
\text { (B) }\end{array}$ & & \\
\hline & $\mathrm{b}$ & Trævegetationen mere åben & Svag erosion & ca. $12^{\circ}$ & $\begin{array}{l}\text { Stigning af } \\
\text { vandstanden } \\
(\mathrm{B}, \mathrm{H})\end{array}$ & & \\
\hline & $\mathrm{a}$ & $\begin{array}{l}\text { Skov af Betula pubescens, Populus. } \\
\text { Betula nana og urter almindelige }\end{array}$ & $\begin{array}{l}\text { Stabilisering. } \\
\text { Humus dannes } \\
\end{array}$ & ca. $13^{\circ}$ & $\begin{array}{l}\text { Lav vandstand } \\
(\mathrm{B}, \mathrm{H})\end{array}$ & & \\
\hline \multirow{5}{*}{ W 2} & $\mathrm{e}$ & $\begin{array}{l}\text { Betula nana og urtevegetation frem- } \\
\text { herskende. B. pubescens og Populus til } \\
\text { stede }\end{array}$ & $\begin{array}{l}\text { Stabilisering. } \\
\text { Frisk jordbund }\end{array}$ & $\begin{array}{l}\text { Stigende } \\
\text { ca. } 12^{\circ}\end{array}$ & \multirow[t]{2}{*}{ Høj vandstand } & & \\
\hline & d & Nøgne solifluktionsområder udbredte & Erosion & $<10^{\circ}$ & & & \\
\hline & $\mathrm{c}$ & $\begin{array}{l}\text { Betula nana, Juniperus og urtevegeta- } \\
\text { tion fremherskende }\end{array}$ & $\begin{array}{l}\text { Stabilisering. } \\
\text { Frisk jordbund }\end{array}$ & $10-12^{\circ}$ & $\begin{array}{l}\text { Lav vandstand } \\
\text { (R) }\end{array}$ & $\begin{array}{l}\text { Rodebæk } \\
\text { Inter- } \\
\text { stadial }\end{array}$ & \\
\hline & $\mathrm{b}$ & Nøgne solifluktionsområder udbredte & Erosion & $<10^{\circ}$ & & & \\
\hline & $\mathrm{a}$ & $\begin{array}{l}\text { Betula nana, Juniperus og urteveseta- } \\
\text { tion fremherskende }\end{array}$ & Erosion tiltager & $10-12^{\circ}$ & Høj vandstand & & \\
\hline \multicolumn{2}{|c|}{ W 1} & $\begin{array}{l}\text { Spredte individer af Pinus, Picea, Betula } \\
\text { pubescens. Hede med Juniperus, B. nana, } \\
\text { Calluna, Empetrum. Urter alm. }\end{array}$ & $\begin{array}{l}\text { Surt humuslag } \\
\text { og podsolering } \\
\text { fremhersker }\end{array}$ & $\begin{array}{l}\text { Afta- } \\
\text { gende } \\
10-12^{\circ}\end{array}$ & $\begin{array}{l}\text { Stigende vand- } \\
\text { stand }(B, R)\end{array}$ & & \\
\hline \multicolumn{2}{|c|}{$\mathrm{h}$} & $\begin{array}{l}\text { Skov domineret af Picea, Pinus, Betula } \\
\text { pubescens. Alnus ret almindelig }\end{array}$ & & $\begin{array}{l}\text { Afta- } \\
\text { gende }\end{array}$ & $\begin{array}{l}\text { Lav vandstand } \\
(B, R)\end{array}$ & & $\begin{array}{l}\text { Eem } \\
\text { Inter- } \\
\text { glacialtid }\end{array}$ \\
\hline
\end{tabular}

\section{Temperatur.}

En oversigt over vegetationshistorie og klimaudvikling i Vestjylland i tiden, der fulgte umiddelbart efter Eem Interglacialtiden, er vist overfor (sml. table 24, s. 115, og kapitel V).

Som omtalt s. 155 er det ønskeligt at kende temperaturen for hele året. Vintertemperaturer kunde ikke bestemmes nøje, men klimaet $\mathrm{i}$ almindelighed har sandsynligvis været ret oceanisk, og vegetationsperiodens længde har sikkert varieret parallelt med temperaturen for den varmeste måned. Mens ændringer i sommertemperaturen ofte kan afsløres med ret stor sikkerhed, kan absolutte gennemsnitstemperaturer kun skonnes ud fra de biologiske data.

En større nedgang i sommertemperaturen begyndte i en sen del af Eem Interglacial- 
tiden. Den fortsatte ved overgangen underzone W $2 \mathrm{a}-\mathrm{b}$, og et minimum nåedes i underzone $\mathrm{W} 2 \mathrm{~b}$. Sommertemperaturen aftog sandsynligvis med $10^{\circ} \mathrm{C}$ eller mere. Vegetationsudviklingen i underzone $\mathrm{W} 2 \mathrm{c}$ viser en afgørende temperaturstigning, men et nyt temperaturminimum nåedes i underzone W $2 \mathrm{~d}$. I underzone W $2 \mathrm{e}$ og zone $\mathrm{W} 3$ afspejler vegetationsudviklingen en ny stigning i sommertemperaturen, muligvis pá $6^{\circ} \mathrm{C}$ eller mere. Sommertemperaturen forblev ret høj i zone W 3, W 4 og W 5 , muligvis $13-15^{\circ} \mathrm{C}$ i Juli, eller mere, med en svag aftagen i underzonerne $\mathrm{W} 3 \mathrm{~b}$ og d. Udviklingen efter zone W 5 kendes ikke i detailler, men en senere nedgang i sommertemperaturen er antydet, og den yngste del af serien ved Brørup er dækket af solifluktionslag (se også fig. 12, s. 133).

\section{Luftfugtighed.}

Det palæobotaniske materiale oplyser ikke meget om nedbøren, men denne var utvivlsomt rigelig.

Oplysninger om mindre ændringer i luftfugtighed kan fås fra angivelser af lokale vandstandsændringer (sml. kapitel II). Således angiver en ændring af den lokale hydrosere til vådere forhold tydeligt en stigning af vandspejlet. Sådanne stigninger er opfort på side 116 (se også side 160), hvor det kan ses, at hver stigning af vandspejlet svarede til en aftagen af sommertemperaturen.

På den anden side kan en sænkning af den lokale vandstand vanskeligt skelnes fra den fremadskridende hydrosere i vegetationsudviklingen. Som det fremgår af listen på side 117 (sml. også side 160), modsvares imidlertid hver stigning af sommertemperaturen af en ændring til et mere tørt vegetationsstadium ved mindst én af lokaliteterne. Dette kan næppe være tilfældigt, og det antydes således, at en stigning i sommertemperaturen svarede til en sænkning af vandspejlet.

Det ser altså ud til, at der var en intim sammenhæng mellem sommertemperaturens ændringer og svingninger i vandspejlet. Dette skyldes sikkert sommertemperaturens indflydelse på fordampningen.

\section{Kronologi. Rodebæk Interstadialet og Brørup Interstadialet.}

Det kan ses af det ovenstående, at ændringer af sommertemperaturen udgjorde de vigtigste klimaændringer i de her studerede tidsrum. Følgende ændringer kan anses for nyttige for en afgrænsning af krono-stratigrafiske enheder:

(1) temperaturnedgangen zone $\mathrm{h}-\mathrm{W} 2 \mathrm{~b}$

(2) temperatursvingningen zone $\mathrm{W} 2 \mathrm{~b}-\mathrm{c}-\mathrm{d}$

(3) temperaturstigningen zone $\mathrm{W} 2 \mathrm{~d}-3$ a

(4) temperatursvigningerne zone $\mathrm{W} 3 \mathrm{a}-\mathrm{b}-\mathrm{c}-\mathrm{d}-\mathrm{e}$

(1) Temperaturnedgangen zone $\mathrm{h}-\mathrm{W} 2 \mathrm{~b}$ afbrød vegetationssuccessionen $\mathrm{i}$ Eem Interglacialet. Den forårsagede udbredelse af skovløs vegetation på et vist tidspunkt under temperatursænkningen, og solifluktion fremherskede i zone W $2 \mathrm{~b}$. Temperaturnedgangen har utvivlsomt givet sig udslag udenfor Danmark, i vegetationsudviklingen, udbredelse af indlandsis, forekomst af periglaciale fænomener og ændringer i havets niveau. Denne klimaændring danner således en passende grænse mellem Eem Interglacialtiden og Weichsel Glacialtiden.

(2) Rodebæk Interstadialet. Temperatursvingningen zone W $2 \mathrm{~b}-\mathrm{c}-\mathrm{d}$ udgjordes af en væsentlig stigning og sænkning af sommertemperaturen. Det varme tidsrum bør derfor anses for et interstadial, lokalt Rodebcek Intersladialet. Det fulgtes af temperaturminimet i underzone W 2 d, hvor solifluktion var udbredt igen. 
(3) Brørup Interstadialet. Temperaturstigningen afspejlet i vegetationsudviklingen zone $\mathrm{W} 2 \mathrm{~d}-\mathrm{W} 3$ a var væsentlig, muligvis $6-8^{\circ} \mathrm{C}$ eller mere, og sommertemperaturen forblev høj i zonerne W 3-W 5. Vegetationen reagerede ret langsomt, de første ændringer kan spores ved overgangen W $2 \mathrm{~d}-\mathrm{e}$, birkeskoven blev fremherskende ved overgangen W $2 \mathrm{e}-\mathrm{W} 3 \mathrm{a}$; men Larix, Pinus og Picea arterne indvandrede først betydelig senere, og de tempererede løvtræer nåede ikke til landet. Denne temperaturstigning har sikkert også sat sig spor i et vidt område (sml. ovenfor). Det gunstige tidsrum afsluttedes tydeligvis af en betydelig temperaturnedgang, som dog ikke er kendt i detailler. Det varme tidsrum bør anses for et større interstadial i Weichsel Glacialtiden, Brorup Interstadialet.

(4) Temperatursvingningerne i zone W 3 var så ubetydelige, at de bør anses for små oscillationer indenfor Brørup Interstadialet.

Det ses således, at den øvre grænse for Eem Interglacialtiden, og to interstadialer fra tidlig Weichsel Glacialtid, Rodebæk Interstadialet og Brørup Interstadialet, kan udskilles på grundlag af de i nærværende arbejde påviste temperatursvingninger.

Den kronologiske inddeling, som er foreslået her, er sammenlignet med JEsSEN og Multuers' inddeling fra 1928 nedenfor (sml. table 25, s. 119). Det kan ses, at disse forfatteres Stadium II med den ,,nedre tempererede flora " svarer til Eem Interglacialtiden. Alle de yngre stadier henregnes til Weichsel Glacialtiden. Rodebæk Interstadialet blev ikke udskilt af Jessen og Milthers. Som omtalt i kapitel IV består Jessen og Milthers' Stadium IV med den ",øvre tempererede flora" fra Herning og andre lokaliteter af omlejret interglacialt materiale og svarer til et koldt tidsrum. Stadium V med den ,øvre subarktiske flora" svarer til det varme Brørup Interstadial.

\begin{tabular}{|c|c|c|c|}
\hline \multicolumn{2}{|c|}{ Jessen og Milthers 1928 (oversat) } & \multicolumn{2}{|c|}{ Nærværende undersøgelse } \\
\hline $\begin{array}{l}\text { Sidste } \\
\text { nedisning }\end{array}$ & & Koldt understadium & \multirow{5}{*}{$\begin{array}{l}\text { Weichsel } \\
\text { Glacialtid }\end{array}$} \\
\hline \multirow{6}{*}{$\begin{array}{l}\text { Sidste } \\
\text { Interglacial }\end{array}$} & V. Øvre subarktiske flora & Brørup Interstadial & \\
\hline & IV. Øvre tempererede flora & Koldt understadium & \\
\hline & \multirow{2}{*}{ III. Subarktisk flora } & Rodebæk Interstadial & \\
\hline & & Koldt understadium & \\
\hline & II. Nedre tempererede flora & & $\begin{array}{l}\text { Eem Inter- } \\
\text { glacialtid }\end{array}$ \\
\hline & $\begin{array}{l}\text { I. Nedre subarktiske og } \\
\text { arktiske flora }\end{array}$ & & $\begin{array}{l}\text { Saale } \\
\text { Glacialtid }\end{array}$ \\
\hline
\end{tabular}

Intet Isfremstød fra Weichsel Glacialtiden kan korreleres direkte med den her beskrevne serie fra Vestjylland. Ved nedisningens maksimum nåede den skandinaviske indlandsis omtrent til Brørup Hotel Mose.

\section{BeMARKNinger om VEgETATIONEN I NV-Europa \\ I tidlig Weichsel Glacialtid}

Serier fra tiden efter Eem Interglacialtiden, der ligner de her omtalte fra Vestjylland, er for nylig undersøgt ved Amersfoort i Holland af Z AGwIJN, og en fælles kronologi opstilledes af ANdersen, de VRies og ZaGwidn (1960). En oversigt over vegetationsudviklingens hovedtræk i de to områder er vist nedenfor (sml. table 26, s. 121). 


\begin{tabular}{|c|c|c|c|c|c|c|c|c|}
\hline & \multicolumn{6}{|c|}{ Bio-stratigrafi } & \multirow{2}{*}{\multicolumn{2}{|c|}{$\begin{array}{l}\text { Krono-stratigrafi } \\
\text { Alm. Kronologi }\end{array}$}} \\
\hline & \multicolumn{3}{|r|}{ Danmark (ANDERSEN) } & \multicolumn{3}{|r|}{ Holland (ZAGWIJN) } & & \\
\hline $\begin{array}{l}\text { Lokale } \\
\text { underst. }\end{array}$ & \multicolumn{2}{|c|}{$\begin{array}{c}\text { Pollen } \\
\text { zoner }\end{array}$} & Vegetation & \multicolumn{2}{|c|}{$\begin{array}{c}\text { Pollen } \\
\text { zoner }\end{array}$} & Vegetation & $\begin{array}{l}\text { Under- } \\
\text { stadier }\end{array}$ & $\begin{array}{l}\text { Hoved- } \\
\text { stadier }\end{array}$ \\
\hline \multirow{5}{*}{$\begin{array}{l}\text { Brørup } \\
\text { Inter- } \\
\text { stadial }\end{array}$} & \multicolumn{2}{|c|}{ W 5} & Skov af Pinus, Betula og Picea & \multirow{4}{*}{ EW IV } & $\mathrm{c}$ & $\begin{array}{l}\text { Pinus, Betula, Picea, Alnus } \\
\text { skov }\end{array}$ & \multirow{4}{*}{$\begin{array}{l}\text { Brorup } \\
\text { Inter- } \\
\text { stadial }\end{array}$} & \multirow{11}{*}{$\begin{array}{l}\text { Weichsel } \\
\text { Glacial- } \\
\text { tid }\end{array}$} \\
\hline & $\mathrm{W}$ & & Skov af Betula, Pinus og Picea & & $\mathrm{b}$ & $\begin{array}{l}\text { Picea, Pinus, Betula og Alnus } \\
\text { skov }\end{array}$ & & \\
\hline & W & & Skov af Betula pubescens & & & & & \\
\hline & \multirow{7}{*}{ W 2} & $\mathrm{e}$ & $\begin{array}{l}\text { Betula nana, B. pubescens, } \\
\text { Populus, urter }\end{array}$ & & a & $\begin{array}{l}\text { Aben skov af Pinus og Betula, } \\
\text { Picea tiltager }\end{array}$ & & \\
\hline & & d & Solifluktion fremherskende & EW I & & $\begin{array}{l}\text { Subarktisk parklandskab med } \\
\text { Betula og Pinus }\end{array}$ & & \\
\hline \multirow{7}{*}{$\begin{array}{l}\text { Rodebæk } \\
\text { Inter- } \\
\text { stadial }\end{array}$} & & & & FW U & $\bar{b}$ & Pinus-Betula skov & Amers- & \\
\hline & & c & Betula nang Juninerus urter & EW II & a & Betula skov & foort & \\
\hline & & & & \multirow{4}{*}{ EW I } & $\mathrm{b}$ & $\begin{array}{l}\text { Åben skov og parklandskab, } \\
\text { meget Salix }\end{array}$ & $\begin{array}{l}\text { Inter- } \\
\text { stadial }\end{array}$ & \\
\hline & & $\mathrm{b}$ & Solifluktion fremherskende & & & & & \\
\hline & & $\bar{a}$ & Betula nana, Juniperus urter & & $a$ & Subarktisk parklandskab med & & \\
\hline & \multicolumn{2}{|c|}{ W 1} & $\begin{array}{l}\text { Subarktisk hede med spredte } \\
\text { træer }\end{array}$ & & a & hede. Pinus, Betula & & \\
\hline & & & Tempereret skov & & & Tempereret skov & & $\begin{array}{l}\text { Eem } \\
\text { Inter- } \\
\text { glacial } \\
\text { tid }\end{array}$ \\
\hline
\end{tabular}

Klimakurver for de to områder sammenstilledes og navnene Amersfoort Interstadial og Brørup Interstadial er foreslået brugt i en almindelig kronologi for de to varme understadier (svarer til Rodebæk Interstadialet og Brørup Interstadialet i Danmark). Klimakurverne er gengivet i fig. 12, s. 133 .

Det formodes at skovens forsvinden og udbredelsen af skovløse vegetationstyper ved slutningen af Eem Interglacialtiden var temmelig samtidig i Nordeuropa. En hedevegetation betinget af sur jordbund fremherskede åbenbart i Nordeuropa, formentlig på grund af en fremadskridende jordbundsudvaskning i Eem Interglacialtiden. I de koldeste tidsrum i zone W 2 (underzonerne b og d) har der sikkert været isfremstød i Skandinavien, og solifluktion fremherskede åbenbart også syd for Danmark. Træfattig vegetation fremherskede i Holland.

Under Amersfoort (Rodebæk) Interstadialet var Danmark skovløst, men syd for Danmark fandtes sikkert skov af nordlig type med Pinus og Betula, som det var tilfældet i Holland.

Under Brørup Interstadialet fremherskede skov af Betula, Populus og senere Larix, Pinus, Picea abies og P. omoricoides i Danmark, og klimaet var sikkert ret varmt. Lignende vegetation fandtes muligvis i Skandinavien. Pinus, Picea, Betula og Alnus forekom i Holland.

Ved Amersfoort overlejres aflejringerne fra Brørup Interstadialet af aflejringer fra middel og sen Weichsel Glacialtid.

Under den største udbredelse af den skandinaviske is i Weichsel Glacialtiden nåede denne omtrent til Brørup, og ældre israndsstadier blev sikkert ødelagt; men interstadiale lag kan tænkes bevaret i det nedisede område. I de følgende sider gives en oversigt over sådanne kendte aflejringer og over lagserier fra nabolandene mod syd og deres mulige korrelation med de ovenfor beskrevne understadier. 
De fra Skærumhedeserien kendte planterester (Jessen, Mrlthers, Nordman, Hartz og Hesselboe 1910) antyder, at den marine serie er interglacial. Det ,gule sand“ fra Ristinge Klint (Madsen, Nordman og Hartz 1908) kan ifølge Wennberg (1949) muligvis tilhøre et interstadial; men de fundne planterester er for sparsomme til at muliggøre en sammenligning med Brørup Interstadialet.

Som det iøvrigt vil fremgå af den givne oversigt (se den engelske tekst) kendes interstadiale lag, der med sikkerhed er yngre end Eem Interglacialtiden, også i Tyskland og Polen. De interstadiale lag ved Loopstedt og Harksheide kan med sandsynlighed henføres til Brørup Interstadialet. Andre af de omtalte planteførende aflejringer kan ikke dateres, men visse af dem (se den engelske tekst s. 129) tilhører muligvis Brørup Interstadialet.

\section{C ${ }^{14}$ DATERINGER}

Man har i den senere tid, især i Holland (DE VRIEs), forsøgt at datere prøver ældre end 30-40 000 år med $\mathrm{C}^{14}$ metoden. Den oprindelige radioaktivitet $\mathrm{i}$ sådanne prøver er ringe, og resultaterne påvirkes derfor let af forskellig forurening. $\mathrm{C}^{\mathbf{1 4}}$ dateringer i dette aldersområde må derfor betragtes med forsigtighed.

Prøver fra det her beskrevne materiale er søgt dateret ved denne metode. Aflejringerne har været dækket af stillestående grundvand, og rødder af ung dato kan næppe have forekommet. Derimod kan tilstedeværelse af infiltreret recent humus ikke udelukkes. Prøver, hvor humus-indholdet ikke var fjernet, viste en aktivitet, som kan skyldes tilstedeværelse af infiltreret recent humus (TAUBER og DE VRIEs 1958). Dette gælder også en prøve dateret i U.S.A. (Y-257, se nedenfor). Prøver fra Brørup Hotel Mose, hvor humus-indholdet var fjernet (GRO-1264, 1263, K-526, GRO-1256, 1466, se listen nedenfor), viste ingen aktivitet, der kunde måles med den anvendte metode, og de er således ældre end 40-50 000 år.

Nye og større prøver (fra BP 1 a og BP 2) er blevet undersøgt af DE VRIEs ved berigelsesmetoden. Denne metode muliggør datering af prøver, der har for lidt radioaktivitet til direkte måling med de eksisterende midler. Radioaktiviteten af prøverne beriges ved passage gennem lange diffusionssøjler, indtil den er tilstrækkelig stor til måling, og da berigelsesgraden også kan måles, kan prøvens oprindelige aktivitet og dens sandsynlige alder beregnes. Denne metode udvikledes af Haring, de Vries og DE VRIEs (1958), og den gør det muligt at datere prøver af en alder op til ca. 70000 år; men den er særdeles langvarig og besværlig, og kun et ringe antal dateringer foreligger. Resultaterne bør derfor indtil videre betragtes afventende. Dateringerne GRO-1729 og GRO-1470 nedenfor er målt på berigede prøver.

Følgende $\mathrm{C}^{14}$ dateringer er opnået (i år før nu):

Herning:

BP 5

Pollenzone W 3 a

$(4.62-4.73$ m.) $\quad \mathrm{Y}-257$

(5.05-5.12 m.) Y-258-3

$19580 \pm 730$

Rodebæk I:

Pollenzone W 2e $\quad(5.05-5.12 \mathrm{~m}.) \quad \mathrm{Y}-258-3 \quad>30000$

BP 57 m. Pollenzone W 2 c $\quad(2.99-3.10$ m.) Y-259-1
Se Barendsen, Deevey og Gralensky (1957).

$>30000$

Brørup Hotel Bog:

\section{BP 1}

$\begin{array}{llll}\text { Pollenzone W 3d-e } & (2.85-2.90 \mathrm{~m} .) & \text { GRO- } 1264 & >50000 \\ \text { Pollenzone W 3c-d } & (3.37-3.48 \mathrm{~m} .) & \text { GRO-1263 } & >50000 \\ \text { Pollenzone W 3b } & (3.96-4.08 \mathrm{~m} .) & \text { K-526 } & >40000 \\ \text { Pollenzone W 2a } & (6.81-6.91 \mathrm{~m} .) & \text { GRO-1256 } & >50000\end{array}$

Se Tauber og de Vries (1958). 


$\begin{array}{llllr}\text { BP 1 a } & \text { Pollenzone W 3c } & \text { GRO-1729 } & 58740 \pm 1000 \\ \text { BP 2 } & \text { Pollenzone W 5b-c } & (2.64-2.70 \mathrm{~m} .) & \text { GRO-1466 } & >50000 \\ & \text { Pollenzone W 4 } & (3.22-3.30 \mathrm{~m} .) & \text { GRO-1470 } & 59430 \pm 1000\end{array}$

Se Andersen, de Vries og Zagwijn (1960).

De opnåede dateringer af de berigede prøver (GRO-1729 og GRO-1470) er så nær hinanden, at de i betragtning af fejlkilderne er ens. I virkeligheden er prøven GRO1729 (pollenzone W 3c) ældre end GRO-1470 (pollenzone W 4); men aldersforskellen mellem de to prøver kan have været ganske ringe.

Pollenzonerne W 3c og W 4 tilhører Brørup Interstadialet, og dateringerne viser derfor at dette Insterstadial sandsynligvis skal dateres til ca. 59000 år før nu. Den næste datering fra Weichsel Glacialtiden i Danmark er fra Allerød Interstadialet, $11880 \pm 340$ år for nu (K-106, Anderson, Levi og Tauber 1953, Iversen 1953). Bølling Interstadialet ligger forud for Allerød Interstadialet, det er i Holland dateret til ca. 12300 år før nu (de Vries, BARENdSEN og WATerbolk 1958). Der forløb således formentlig 50000 år mellem Brørup Interstadialet og Bølling Interstadialet. Om dette tidsrum i Danmark ved vi kun, at det indeholdt Weichselnedisningens maksimum.

Palæotemperaturkurver for Weichsel Glacialtiden i Danmark og Holland er vist i fig. 12 (s. 133).I Holland er Amersfoort (Rodebæk) Interstadialet dateret til $64000 \pm$ 1000 år før nu (GRO-1397, beriget prøve, Andersen, de Vries og ZaGwijn 1. c.). Det antydes således, at det kolde understadie mellem Amersfoort og Brørup Interstadialet varede omkring 3000 år. Længden af det kolde understadie, der adskilte Amersfoort Interstadialet fra Eem Interglacialtiden er ukendt; men det kan anslås, at Eem Interglacialtiden muligvis sluttede for ca. 70000 år siden. Weichsel Glacialtiden varede således formentlig omkring 60000 år.

Fra Moustérien-fundpladsen ved Lebenstedt i Nordtyskland foreligger en $\mathrm{C}^{\mathbf{1 4}}$ datering til $48300 \pm 2000$ år før nu (DE VRIEs 1958). Den daterede prøve stammer fra en kuldeperiode, og hvis dateringen er rigtig, viser den, at Brørup Interstadialet afsluttedes før dette tidspunkt.

En vedprøve fra aflejringen ved Chelford, England (se s. 128), er af DE VRIEs dateret til 57000 år før nu (beriget prøve, Simpson og West 1958). Denne datering stemmer med en korrelation af aflejringen med Brørup Interstadialet (s. 129).

Fra Agro Pontino ved Rom kendes en interessant datering af en stamme af Abies alba til 65000 år før nu (beriget prøve, Blanc 1958). Abies-stammen fandtes over en strandaflejring fra den tyrrhenske transgression og markerer en temperatursænkning, som formentlig svarer til Weichsel Glacialtidens første kolde tidsrum.

EMiliani (1958) fremstillede en kurve for temperaturvariationer i overfladevandet i Nordatlanten i Pleistocæntiden. Temperaturændringerne er dateret ved $\mathrm{C}^{\mathbf{1 4}}$ bestemmelser 20000 år tilbage; men årstal derudover er fundet ved ekstrapolation, og er derfor noget usikre. Emiliani (l. c.) korrelerede en række temperaturminimer mellem $-10000 \mathrm{og}-70000$ år med sidste glacialtid. Hvis denne korrelation er korrekt, svarer temperaturminimet mellem $-60000 \mathrm{og}-70000$ år (EMILIANI's stadium 4) åbenbart til det kolde tidsrum, der adskilte Brørup Interstadialet fra Eem Interglacialtiden. Amersfoort (Rodebæk) Interstadialet var åbenbart for kortvarigt til at blive markeret på kurven. 


\section{LITERATURE}

Aario, L., 1941. Die grössenstatistiche Analyse von Betula-Pollen in Torfproben. Geol. Rundschau, 32. Stuttgart.

Aichinger, E., 1951. Lehrwanderungen in das Bergsturzgebiet der Schutt am Südfuss der Villacher Alpe. Angewandte Pflanzensoziologie, 4. Wien.

Albertson, N., 1950. Das grosse südliche Alvar der Insel Öland. Svensk Bot. Tidskr., 44. Uppsala.

Ananova, E. N., 1954. Spores d'Osmunda cinnamomea L. dans les dépôts interglaciaires Mindel-Riss près de la Ville Likhvine (in Russian, translated by S. Ketchian). Dokk. Akad. Nauk SSSR. 95. Leningrad.

Andersen, S. T., 1957 a. New investigations of interglacial fresh-water deposits in Jutland. A preliminary report. Eiszeitalter und Gegenwart, 8. Öhringen.

1957 b. Species identification of fossil pollen and spores by size-statistical methods. Geobot. Inst. Rübel in Zürich, Veröff., 34. Zürich.

1960. Silicone oil as a mounting medium for pollen grains. Danm. Geol. Unders., IV. R., 4, 1. København.

- Vries, H. De, and Zagwijn, W. H., 1960. Climatic change and radiocarbon dating in the Weichselian Glacial of Denmark and the Netherlands Geol. en Mijnb., 39. Leiden.

Anderson, E. C., Levi, H., and Tauber, H., 1953. Copenhagen natural radiocarbon measurements I. Science, 118. New York.

Andersson, J. G., 1906. Solifluction, a component of subaërial denudation. Journ. Geol., 14. Chicago.

Andersson, G., and Birger, S., 1912. Den norrländska florans geografiska fördelning och invandringshistoria. Norrländskt Handbibliotek, 5. Uppsala and Stockholm.

Andersson, O., 1950. The Scanian sand vegetation - a survey. Bot. Notiser, 1950. Lund.

Arwidsson, T., 1935. Empetrum hermaphroditum and E. nigrum i Norden. Bot. Notiser, 1935. Lund.

Asklund, B., 1936. Frösöns submoräna avlagringar. Sver. Geol. Unders. C. 402. Stockholm.

BaAgøe, J., and Ravn, F. Kølpin, 1896. Ekskursionen til jydske Søer og Vandløb i Sommeren 1895. Bot. Tidsskr., 20. København.

Barendsen, G. W., Deevey, E. S., and Gralensky, L. J., 1957. Yale natural radiocarbon measurements III. Science, 126. New York.

Bertsch, K., 1931. Paläobotanische Monographie des Federseerieds. Bibl. Bot., 103. Stuttgart.

Besкow, G., 1930. Erdfliessen und Stukturböden der Hochgebirge im Lichte der Frosthehung. Geol. Fören. Stockh., Förhandl., 52. Stockholm.

Birger, S., 1904. Vegetationen och floran i Pajala socken med Muonio kapellag i arktiska Norrbotten. Svenska Vetensk.-Akad., Arch. Bot., 3, 4. Stockholm.

Birkenmajer, K., and ŚROdoń, A., 1960. Aurignacian interstadial in the Carpathians. Inst. Geol., Biul., 150. Warszawa.

Bitner, K., 1954. The paleobotanic characteristics of the interglacial deposits at Horoszki near Mielnik in Podlasie. Inst. Geol., Biul., 69. Warszawa.

Blanc, A. C., 1938. Über die Quartärstratigraphie des Agro Pontino un der Bassa Versilia. Verh. III. Intern. Quartär Konf. Wien.

- 1958. Il Congresso Internazionale delle Scienze Preistoriche e Prostoriche Amburgo 24-30 Agosto 1958. Quaternaria, 5. Roma. Quoted in Gross 1958-59.

- Segre, A. C., and Tongiorgi, E., 1953. Le Quaternaire de l'Agro Pontino. INQUA. IV Congr. Internat., Roma-Pisa 1953. Suppl au Livr. guide "Excursion au Mont Cicéo" Roma.

Böcher, T. W., 1937. Nogle studier over Færøernes alpine vegetation. Bot. Tidsskr., 44. København.

- 1938. Biological distributional types in the flora of Greenland. Medd. om Grønl., 106, 2. København.

- 1940. Studies on the plant-geography of the North-Atlantic heath formation I. The heaths of the Færoes. Kgl. Danske Vidensk. Selsk., Biol. Medd., 15, 3. København. 
Böcher, T. W., 1943. Studies on the plant-geography of the North-Atlantic heath formation II. Danish dwarf shrub communities in relation to those of Northern Europe. Kgl. Danske Vidensk. Selsk. Biol. Skr., 2, 7. København.

- 1945. Beiträge zur Pflanzengeographie und Ökologie dänischer Vegetation II. Über die Waldsaum- und Graskrautgesellschaften trockener und halbtrockener Böden der Insel Seeland mit besonderer Berücksichtigung der Strandabhänge und Strandebenen. Kgl. Danske Vidensk. Selsk., Biol. Skr. 4, 1. København.

- 1954. Studies on European calcareous fixed dune communities. Vegetatio, 5-6. Haag.

- $1954 \mathrm{~b}$. Oceanic and continental vegetation complexes in Southwest Greenland. Medd. om Grønl., 148, 1. København.

Bondorff, K. A., 1945. Om humusbestemmelse i jord (English summary). Tidsskr. for Planteavl, 50. København.

Bradley, D. E., 1958. The study of pollen grain surfaces in the electron microscope. New Phytol., 57. Oxford.

Braun-Blanguet, J., 1936. Utber die Trockenrasengesellschaften des Festucion vallesiacae in den Ostalpen. Schweiz. Bot. Ges., Ber. 46. Zürich.

- 1955. Das Sedo-Scleranthion neu für die Westalpen. Österr. Bot. Zeitschr., 102. Wien.

- und Jenny, H., 1926. Vegetationsentwicklung und Bodenbildung in der alpinen Stufe der Zentralalpen. Schweiz. Naturforsch. Ges., Denkschr. 63, 2. Aarau.

Brelie, G. von DeR, 1955. Die Pollenstratigraphie im Jüngeren Pleistozän. Eiszeitalter und Gegenwart, 6. Öhringen.

Brem, M., 1953. Interglacial flora from Ciechanki Krzesimowskie by Leczna. Acta. Geol. Pol., 3. Warszawa.

Bryan, K., 1946. Cryopedology. Amer. Journ. Sci., 244. Baltimore.

BüDEL, J., 1944. Die morphologischen Wirkungen des Eiszeitklimas im gletscher-freien Gebiet. Geol. Rundschau, 34. Stuttgart.

- 1948. Die klima-morphologischen Zonen der Polarländer. Erdkunde, 2. Bonn.

Cailleux, A., and Taylor, G., 1954. Cryopédologie. Actualités Scientif. et Industr., 1203.

Cain, S. A., 1940 a. The identification of species in fossil pollen of Pinus by size-frequency determinations. Am. Journ. Bot., 27. Lancaster.

- 1940 b. Some observations on the concept of species senescense. Ecology, 21. Durham.

- 1948. Palynological studies at Sodon Lake I. Size-frequency studies of fossil spruce pollen. Science, 108. New York.

- and Carn, L. G., 1948 a. Size-frequency characteristics of Pinus echinata. Bot. Gaz., 110. Chicago.

- and CaIn, L. G., 1948 b. Palynological studies at Sodon lake II. Size-frequency studies of pine pollen, fossil and modern. Am. Journ. Bot. 35. Laneaster.

Cajander, A. K., 1903. Beiträge zur Kenntniss der Vegetation der Alluvionen des nördlichen Eurasiens I. Die Alluvionen des unteren Lena-Thales. Soc. Scient. Fenn., Acta, 32. Helsinki.

- 1908. Beiträge zur Kenntniss der Vegetation der Alluvionen des nördlichen Eurasiens II. Die Alluvionen des Onega-Thales. Soc. Scient. Fenn., Acta, 33. Helsinki.

- 1909. Beiträge zur Kenntniss der Vegetation der Alluvionen des nördlichen Eurasiens III. Die Alluvionen der Tornio- und Kemi-Thäler. Soc. Scient. Fenn., Acta, 37. Helsinki.

Christensen, B. Brorson, 1946. Measurement as a means of identifying fossil pollen. Danm. Geol. Unders., IV. R., 3, 2. København.

- 1954. New mounting media for pollen grains. Danm. Geol. Unders., II. R., 80, København.

Clapham, A. R., Tutin, T. G., and Warburg, E. F., 1952. Flora of the British Isles. Cambridge.

Dahl, E., 1956. Rondane. Mountain vegetation in South Norway and its relation to the environment. Norske Vidensk. Akad. Skr., I, Mat.-Nat. Klasse, 1956, 3. Oslo.

Dansereau, P., 1956. Le coincement, un processus ecologique. Acta Biotheoretica, 11. Leiden.

Degerbøl, M., and Krog, H., 1959. The Reindeer (Rangifer tarandus L.) in Denmark. Kgl. Dan. Vidensk. Selsk. Biol. Skr., 10, 4. København.

Ditтmer, E., 1954. Interstadiale Torfe in würmeiszeitlichen Schmelzwassersanden Nordfrieslands. Eiszeitalter und Gegenwart, 4-5. Öhringen.

Donner, J., 1951. Pollen-analytical studies of Late-Glacial deposits in Finland. Soc. Géol. Finl., Compt., 24. Helsinki.

- 1954. Measurements of pollen of Alnus glutinosa and A. incana. Soc. Géol. Finl., Compt., 27. Helsinki.

Dücker, A., 1937. Über Strukturböden im Riesengebirge. Deutsch. Geol. Ges., Zeitschr., 89. Berlin. 
Duigan, S. L., 1956. Pollen analysis of the Nechells interglacial deposit, Birmingham. Geol. Soc. London, Quart. Journ., 112. London.

Du Rietz, G. E., 1924. Studien über die Vegetation der Alpen mit derjenigen Skandinaviens verglichen. Geobot. Inst. Rübel in Zürich, Veröff., 1. Zürich.

- 1954. Die Mineralbodenwasserzeigergrenze als Grundlage einer natürlichen Zweigliederung der nord- und mitteleuropäischen Moore. Vegetatio, 5-6. Den Haag.

Dyakowska, J., 1939. Interglacial in Ściejowice near Cracow. Starunia, 17, Cracow.

- 1947. The interglacial of Kąty near Sromowce Wuznie. Starunia, 23.

- 1952. Pleistocene flora of Nowiny Zukowskie on the Lublin upland. Inst. Geol., Biul., 67. Warszawa.

- 1956. Pleistocene profile from Wylezin (Central Poland). Inst. Geol., Biul., 100.

- 1959. Podrecznik Palynologii. Warszawa.

Earnshaw, F., 1942. Experimental taxonomy V. Cytological studies in sea plantains allied to Plantago maritima L. New Phytol., 41. Cambridge.

Emiliani, C., 1958. Paleotemperature analysis of core 280 and Pleistocene correlations. Journ. of Geology, 66. Chicago.

Eneroth, O. +, 1951. Undersökning rörande möljigheter att i fossilt material urskilja de olika Betula-arternas pollen. Geol. Fören. Stockh., Förhandl., 73. Stockholm.

Erdtman, G., 1938. Pollenanalys och pollenmorphologi. Nya metoder och undersökninger. Svensk Bot. Tidskr., 32. Uppsala.

- 1943. An introduction to pollen analysis. Chronica Botanica. Waltham.

- 1946. Palynologiska synspunkter på pionjärfasen i den svenska florans innvandringshistoria. Svensk Bot. Tidskr., 40. Uppsala.

- 1952. Pollen morphology and plant taxonomy I. Angiosperms. Stockholm and Waltham.

F£GRI, K., 1934. Über die Längenvariationen einiger Gletseher des Jostedalsbre und die dadurch bedingten Pflanzensukzessionen. Bergens Mus., Årbok 1933, Naturvidensk. Rekke, 7. Bergen.

- 1936. Quartärgeologische Untersuchungen im westlichen Norwegen I. Über zwei präboreale Klimaschwankungen im südwestlichen Teil. Bergens Mus. Årbok. 1935, Naturvidensk. Rekke, 8 .

- 1940. Quartärgeologische Untersuchungen im westlichen Norwegen II. Zur spätquartären Geschichte Jærens. Bergens Mus., Årbok 1939-40, Naturvidensk. Rekke, 7.

- 1945. A pollen diagram from the subalpine region of Central South Norway. Norsk. Geol. Tidsskr., 25. Oslo.

- 1956. Palynological studies in NW European Papilionaceae. A preliminary (and premature) communication. Univ. Bergen Bot. Mus. (mimeographed).

- 1957. Discussion, in Andersen, 1957 b.

- 1958. On the climatic demands of oceanic plants. Bot. Notiser, 111. Lund.

- 1960. Maps of the distribution of Norwegian vascular plants I. The distribution of coast plants. Oslo.

- and Iversen, J., 1950. Text-book of modern pollen analysis. København.

Firbas, F., 1927. Beiträge zur Kenntniss der Schieferkohlen des Inntals under der interglazialen Waldgeschichte der Ostalpen. Zeitschr. Gletscherk., 15. Innsbruck.

- 1948. Úber das Verhalten von Artemisia in einigen Pollendiagrammen. Biol. Zentralbl., 67. Leipzig.

- 1949. Waldgeschichte Mitteleuropas. Erster Band. Jena.

- 1958. Über das Fagus-Vorkommen im "Interglazial" von Wasserburg am Inn (Oberbayern). Geobot. Inst. Rübel in Zürich, Veröff., 33. Zürich.

- and Firbas, I., 1935. Zur Frage der grössenstatistischen Pollendiagnosen. Bot. Centralbl., Beihefte, 54, B. Dresden.

- and Grahmann, R., 1928. Über jungdiluviale und alluviale Torflager in der Grube Marga bei Senftenberg (Niederlausitz). Sächs. Akad. Wiss., Math.-Phys. Klasse, Abh., 4. Leipzig.

Fisher, R. A., 1944. Statistical methods for research workers. Cambridge.

Fuerdingstad, E., 1954. The subfossil algal flora of the Lake Bølling Sø and its limnological interpretation. Kgl. Danske Vidensk. Selsk., Biol. Skr., 7, 6. København.

FLINT, R. F., 1957. Glacial and Pleistocene geology. New York.

Florin, R., 1931. Untersuchungen zur Stammesgeschichte der Coniferales under Cordaitales. Kungl. Svenska Vetenskapsakad., Handl., 3. Ser., 10, 1. Stockholm.

Flonschütz, F., 1957. The subdivisions of the Middle and Young Pleistocene up to the LateGlacial in the Netherlands, England and Germany, mainly based on the results of paleobotanical investigations. Geol. en Mijn. N.S., 19. Leiden.

Frey, D. G., 1958. The Late-Glacial Cladoceran fauna of a small lake. Arch. Hydrobiol., 54. 
Frey, D. G. and Stahl, J. B., 1958. Measurements of primary production on Southhampton Island in the Canadian Arctic. Limnology and Oceanogr., 3.

Frö̀in, J., 1918. Über das Verhältniss zwischen Vegetation und Erdfliessen in den alpinen Regionen des schwedischen Lappland. Lund Univ., Årsskr., N.F., Afd. 2, 14, 2, 24. Lund.

Fromм, E., 1958. Ett förmodat interglacialfynd nära Luleå. Geol. Fören Stockh., Förhandl., 80. Stockholm.

Fukarek, P., 1951. Das heutige Verbreitungsgebiet der Omorica-Fichte (Picea omorica Panĉ.) und einige Mitteilungen über ihre Bestände. Biol. Inst. Serajewo, Jahrb, 3. Sarajewvu.

Gams, H., 1921. Einige homologe Pflanzengesellschaften in der subalpinen Stufe der Alpen und Skandinaviens. Schweiz. Naturf. Ges., Verh., 102. Aarau.

- 1923. Die Waldklimate der Schweizer Alpen, ihre Darstellung und ihre Geschichte. Naturf. Ges. Basel., Verh., 35. Basel.

- 1927. Von den Follatéres zur Dent de Morcles. Beitr. zur Geobot. Landesaufnahme d. Schweiz, 15. Bern.

- 1935. Beiträge zur Mikrostratigraphie und Paläontologie des Pliozäns und Pleistozäns von Mittel- und Osteuropa und Westsibirien. Ecl. Geol. Helv. 28, Basel.

- 1953. Das Meerträubl (Ephedra) und seine Ausbreitung in Europa. Ver. Schutze Alpenpfl. und -tiere., Jahrbuch, 1952. München.

Guærevoll, O., 1949. Snøleievegetasjonen i Oviksfjellene. Acta Phyt. Suec., 25. Uppsala.

- 1956. The plant communities of the Scandinavian alpine snow-beds. Kgl. Norske Vidensk. Selsk., Skr., 1956, 1, Oslo.

GLück, H., 1905. Biologische und morphologische Untersuchung über Wasser- und Sumphgewächse I Teil. Die Lebensgeschichte der europäischen Alismaceen. Jena.

- 1908. Alismaceae. In Kirchner, Loew and Schröter: Lebensgeschichte der Blütenpflanzen Mitteleuropas I. Stuttgart.

- 1927. Die Süsswasservegetation von Nordamerika in Gegenwart und Vergangenheit. Magyar Bot. Lap., 25. Budapest.

Godwin, H., 1956. History of the flora of the British Isles. Cambridge.

- and Willis, E. H., 1959. Radiocarbon dating of the Late-Glacial period in Britain. Royal Soc., Proc., B, 150. London.

Gøhrn, V., 1956. Proveniensforsøg med Lærk. Forstl. Forsøgsv. Danm., Beretning, 23. Kobenhavn.

Granlund, E., 1925. Några växtgeografiska regionsgränser. Geogr. Ann., 1925. Stockholm.

Gregor, J. W., 1939. Experimental taxonomy IV. Population differentiation in North American and European sea plantains allied to Plantago maritima L. New Phytol., 37. Oxford.

Gripp, K., 1924. Über die äusserste Grenze der Letzten Vereisung in Nordwest-Deutschland. Geogr. Ges. Hamburg, Mitt., 36. Hamburg.

— 1939. Der Oberflächenabtrag im Alt-Diluvium und seine Bedeutung für das vorkommen paläolitischer Funde. Offa, 4. Neumünster.

— 1940. Die Entstehung der Landschaft um Haithaby. Offa, 5, Neumünster.

Gritchuk, V. P., 1955. The main features of the history of the flora and the vegetation of the Russian plains during the Pleistocene and the oldest glaciation of Eurasia (in Russian). Trudy Komissii po Izuceniju c Cetverticnogo perioda, S.S.S.R., 12. Moskva.

Gross, H., 1956. Das Göttweiger Interstadial, ein zweiter Leithorizont der letzten Vereisung. Eiszeitalter und Gegenwart, 7. Öhringen.

- 1958. Die bisherigen Ergebnisse von $\mathrm{C}^{14}$ Messungen und paläontologischen Untersuchungen für die Gliederung und Chronologie des Jungpleistozäns in Mitteleuropa und den Nachbargebieten. Eiszeitalter und Gegenwart, 9.

- 1958-59. Zur Frage der Zuverlässigkeit und Brauchbarkeit der Radiocarbon-(-C $\left.{ }^{14}\right)$ Methode in Vorgeschichtsforschung und Quartärgeologie. Quartär, 10-11. Bonn.

HAGEM, O., 1947. The dry matter increase of coniferous seedlings in winter. Investigation in oceanic climate. Vestlandets Forstl. Forsøksst., Medd., 26. Bergen.

Haldén, B. E., 1915. Det interglaciala Bollnäsfyndets stratigrafi. Geol. Fören. Stockh., Förhandl., 37. Stockholm.

Hallik, R., 1952. Ein "Weichsel Frühglazial”-Profil in Lüneburg. Eiszeitalter und Gegenwart, 2. Öhringen.

- 1955. Über eine Verlandungsfolge interstadialen Alters in Harksheide bei Hamburg. Eiszeitalter und Gegenwart, 6 .

Hammen, T. van der., 1951. Late-Glacial flora and periglacial phenomena in the Netherlands. Leidse Geol., Med., 17. Leiden.

- 1952. Dating and correlation of periglacial deposits in Middle and Western Europe. Geol. en Mijnb., N.S. 14. Leiden.

- 1957. The stratigraphy of the Late-Glacial. Geol. en Mijngeb., N.S., 19. 
Hansen, H. Mølholm, 1930. Studies on the vegetation of Iceland. The Botany of Iceland, 3, 1. København.

Hansen, K., 1959. Sediments from Danish lakes. Journ. Sediment. Petrol., 29. Tulsa.

Haring, A., Vries, A. E. DE, and Vries, H. DE, 1958. Radiocarbon dating up to 70000 years by isotopic enrichment. Science, 128 . New York.

Hartz, N., 1909. Bidrag til Danmarks tertiære og diluviale flora. Danm. Geol. Unders., II. R., 2. København.

Hedberg, H. D., 1954. Procedure and terminology in stratigraphic classification. Congr. Géol. Internat., Compt. Rendus de la 19. Sess. Alger 1952, Sect. 13, 1. Fasc. 13. Alger.

Hedberg, O., 1946. Pollen morphology in the genus Polygonum L s. lat. and its taxonomic significance. Sv. Bot. Tidskr., 40. Uppsala.

- Mirtensson, O. and Rudberg, S., 1952. Botanical investigations in the Pältsa region of Northernmost Sweden. Bot. Notiser, Suppl., 3, 2. Lund.

Hegi, G., 1908-31. Illustrierte Flora von Mitteleuropa. München.

Heinonen, L., 1957. Studies on the microfossils in the tills of the North European glaciation. Acad. Scient. Fenn., Ann., Ser. A, 3, 52. Helsinki.

Hiltermann, H., 1954. Neue Funde von Azolla im Pleistozän Deutschlands. Geol. Jahrb., 68. Hannover.

Нӧявом, В., 1913. Über die geologische Bedeutung des Frostes. Geol. Inst. Uppsala, Bull., 12. Uppsala.

Ноцмвоє, J., 1925. Einige Grundzüge von der Pflanzengeographie Norwegens. Bergens Mus., Årbok 1924-25. Bergen.

Hustich, I., 1936. Pflanzengeographische Studien im Gebiet der niederen Fielde im westlichen finnischen Lappland I. Über die Beziehung der Flora zu Standort und Höhenlage in der alpinen Region sowie über das Problem "Fjeldpflanzen in der Nadelwaldregion". Acta Bot. Fenn., 19. Helsinki.

- 1952. Barrträdsarternas polara gräns på norra halvklotet. Inst. Forest. Fenn., Comm. 40, 29. Helsinki.

Hylander, N., 1941. Förteckning över Skandinaviens växter. Lund.

- 1953. Nordisk kärlväxtflora I. Stockholm.

Ingwersen, P., 1954. Some microfossils from Danish Late-Tertiary lignites. Danm. Geol Unders., II. R., 80. København.

Iversen, J., 1929. Studien über die pH-Verhältnisse und ihren Einfluss auf die Hydrophytenvegetation. Bot. Tidsskr., 40. København.

- 1936 a. Sekundäres Pollen als Fehlerquelle. Eine Korrektionsmetode zur Pollenanalyse minerogener Sedimente. Danm. Geol. Unders., IV. R., 2, 15. København.

- 1936 b. Biologische Pflanzentypen als Hilfsmittel in der Vegetationsforschung. Skallinglab., Medd., 4. København.

- 1941. Landnam i Danmarks Stenalder. Danm. Geol. Unders., II. R., 66.

- 1944. Hedera, Viscum and Ilex as climatic indicators. Geol. Fören. Stockholm, Förhandl., 66. Stockholm.

- 1947. Plantevækst, Dyreliv og Klima i det senglaciale Danmark. Geol. Fören. Stockh., Förhandl., 69. Stockholm.

- 1953. Radiocarbon dating of the Allerød period. Science, 118. New York.

- 1954. The Late-Glacial flora of Denmark and its relation to climate and soil. Danm. Geol. Unders., II. R., 80 .

- 1958. The bearing of glacial and interglacial epochs on the formation and extinction of plant taxa. Uppsala Univ., Årsskr. 1958. Uppsala.

- and Olsen, S., 1943. Die Verbreitung der Wasserpflanzen in Relation zur Chemie des Wassers. Bot. Tidsskr., 46. København.

- and Troels-Smith, 1950. Pollenmorfologiske Definitioner og Typer. Danm. Geol. Unders., IV. R., 3, 8.

JALAS, J., 1950. Zur Kausalanalyse der Verbreitung einiger nordischen Os- und Sandpflanzen. Ann. Bot. Vanamo, 24, Helsinki.

JennY-Lips, H., 1929. Vegetationsbedingungen und Pflanzengesellschaften auf Felsschutt. Bot. Centralbl., Beihefte, 46, B. Dresden.

Jentys-Szaferowa, J., 1928. La structure des membranes du pollen de Corylus, de Myrica et des espèces européennes de Betula et leur détermination a l'état fossile. L'Acad. Pol. Sci. Lettr., Bull., Cl. Sci. Nat., Sér. B.

- 1958. Importance of Quaternary materials for research on the historical evolution of plants. Geobot. Inst. Rübel in Zürich, Veröff., 34. Zürich.

Jentys-Szaferowa, J., and Truchanowicz, J., 1953. Seeds of Menyanthes L. in Poland from the Pliocene to the present time. Inst. Geol., Prace, 10. Warszawa.

Jessen, A., 1905. Kortbladene Aalborg og Nibe. Danm. Geol. Unders., I. R., 10. København. 
Jessen, A., Madsen, V., Milthers, V., and Nordmann, V., 1918. Brørup-Mosernes Lejringsforhold. Danm. Geol. Unders., IV. R., 1, 9.

- Milthers, V. Nordmann, V., Hartz, N., and Hesselboe, A., 1910. En Boring gennem de kvartære Lag ved Skærumhede. Danm. Geol. Unders., II. R., 25.

Jessen, K., 1949. Studies in the Late Quaternary deposits and flora history of Ireland. Royal Irish Acad., Proc., 52, B. 6. Dublin.

- Andersen, S. T., and Farrington, A., 1959. The interglacial deposit near Gort, Co. Galway, Ireland. Royal Irish Acad., Proc., 60, B, 1.

- and Mrlthers, V., 1928. Stratigraphical and paleontological studies of interglacial fresh-water deposits in Jutland and Northwest Germany. Danm. Geol. Unders., II. R., 48. København.

Kalela, A., 1939. Über Wiesen und wiesenartige Pflanzengesellschaften auf der Fischerhalbinsel in Petsamo Lappland. Acta Forest. Fenn., 48. Helsinki.

Kinlman, A. O., 1890. Pflanzenbiologische Studien aus Russisch Lappland. Ein Beitrag zur Kenntniss der regionalen Gliederung an der polaren Waldgrenze. Soc. Fauna et Flora Fenn., Acta, 6, 3. Helsinki.

Kilander, S., 1955. Det lågalpina bältets övre gräns och underbälten i östra Sydskanderna. Svensk Bot. Tidskr., 44. Stockholm.

Kivinen, E., 1935. Über Elektrolytengehalt und Reaktion der Moorwässer. Moatalouskoel. Maatutkimusosasto, Agrogeol. Julk., 38. Helsinki.

Klika, J., 1931. Die Pflanzengesellschaften und ihre Sukzession auf den entblössten Sandböden in dem mittleren Elbetale. Tschech. Akad. Landwirtsch. Ann., 6. Praha.

- 1936. Sukzession der Pflanzengesellschaften auf den Fluss-Alluvionen der Westkarpathen. Schweiz. Bot. Ges., Ber., 36. Zürich.

- 1939. Die Gesellschaften des Festucion vallesiacae-Verbandes in Mitteleuropa. Stud. Bot. Cechia, 2. Praha.

Køı, M., 1944. Fordelingen af vegetationen i Skern Aa og dens tilløb. Bot. Tidsskr., 46. København.

Kolumbe, E., 1955. Über interglaziale und interstadiale Bildungen von Loopstedt, am Haddebyer Noor bei Schleswig. Eiszeitalter und Gegenwart, 6 . Öhringen.

Kotilainen, M. J., 1928. Untersuchungen über die Beziehungen zwischen der Pflanzendecke der Moore und der Beschaffenheit der Reaktion des Torfbodens. Finn. Moorkulturver., Wissensch. Veröff., 7. Helsinki.

- 1933. Zur Frage der Verbreitung des atlantischen Florenelementes Fennoskandias. Soc. Zool.-Bot. Fenn. Vanamo, Ann. Bot., 4. Helsinki.

- 1951. Über die Verbreitung der meso-eutrophen Moorpflanzen Finnlands. Acad. Sci. Fenn., Ann., A, 4, 17. Helsinki.

Krog, H., 1954. Pollen analytical investigation of a $\mathrm{C}^{14}$-dated Alleröd section from RudsVedby. Danm. Geol. Unders., II. R., 80. København.

Kulling, O., 1945. Om fynd av mammut vid Pilgrimstad i Jämtland. Sver. Geol. Unders., C, 473. Stockholm.

LanG, G., 1952. Späteiszeitliche Pflanzenreste in Südwestdeutschland. Beitr. zur Naturkundl. Forsch. in Süddeutschl., 11.

- 1955. Über spätquartäre Funde von Isoëtes und Najas flexilis im Schwarzwald. Deutsch. Bot. Ges., Ber., 68. Berlin.

LANGLET, O., 1935. Till frågan om sambandet mellan temperatur och växtgränser. Statens Skogs försöksanst., Medd., 28. Stockholm.

Livingstone, D. A., 1957. On the sigmoid growth phase in the history of Lindsley Pond. Am. Journ. Science, 255. New Haven.

Lohammer, G., 1938. Wasserchemie und höhere Vegetation schwedischer Seen. Symb. Bot. Upss., 3. Uppsala.

Losert, H., 1940. Beiträge zur spät und nacheiszeitlichen Vegetationsgeschichte Innerböhmens I. Der "Kommerner See". Bot. Centralbl., Beih., 40. Dresden.

LüdI, W., 1921. Die Pflanzengesellschaften des Lauterbrunnentales un ihre Sukzessionen. Beitr. zur Geobot. Landesaufn. d. Schweiz, 9. Bern.

- 1945. Besiedlung und Vegetationsentwicklung auf den jungen Seitenmoränen des grossen Aletschgletschers. Geobot. Forschungsinst. Rübel in Zürich, Ber., 1944. Zürich.

- 1953. Die Pflanzenwelt des Eiszeitalters im nördlichen Vorland der Schweizeralpen. Geobot. Forschungsinst. Rübel in Zürich, Veröff., 27. Zürich.

- 1958. Beobachtungen über die Besiedlung von Gletschervorfeldern in den Schweizeralpen. Flora, 146. Jena.

Lundouist, G., 1955. Stocken i Öje. Ett säkert interglacialfynd. Geol. Fören. Stockh., Förhandl., 77. Stockholm. 
LundQuist, G., 1957. C ${ }^{14}$-analyser i svensk kvartärgeologi 1955-1957. Sver. Geol. Undersökn., C. 557, Stockholm.

Lundeuist, J., 1955. Interglacialfyndet vid Boliden. Geol. Fören. Stockh., Förhandl., 77. Stockholm.

Madsen, V., Nordmann, V., and Hartz, N., 1908. Eem-Zonerne. Studier over Cyprina-leret og andre Eem-aflejringer i Danmark, Nord-Tyskland og Holland. Danm. Geol. Unders., II. R., 17. København.

Malmer, N. and SJörs, H., 1955. Some determinations of elementary constituents in mire plants and peat. Bot. Notiser, 108, Lund.

MeiJER, W. and Wit, R. J. DE, 1955. Kortenhoef. Eine veldbiologische studie van en hollands verlandingsgebied. Amsterdam 1955.

Metcalfe, G., 1950. The ecology of the Cairngorms. Part II. The mountain Callunetum. Journ. Ecol., 34. Cambridge.

Meusel, H., 1939. Die Vegetationsverhältnisse im Kyffhäuser im südlichen Harzvorland. Hercynia, 2. Halle.

- 1940. Die Grassheiden Mitteleuropas. Bot. Arch., 41. Leipzig.

Milthers, V., 1948. Det danske istidslandskabs terrænformer og dets opstaaen. Danm. Geol. Unders., III. R., 28. København.

Müller, G., and Weber, C. A., 1904. Über eine frühglaziale und vorglaziale Flora bei Lüneburg. König, Preuss. Geol. Landesanst., N.F., 40. Berlin.

Mukerji, S. K., 1936. Contributions to the autecology of Mercurialis perennis L. Journ. Ecology, 24. Cambridge.

Munthe, H., 1904. Den submoräne Härnögyttjan och dess ålder. Sver. Geol. Unders., C, 196. Stockholm.

Nordhagen, 1927. Die Vegetation und Flora des Sylenegebietes. Norske Vidensk. Akad. Oslo. Skr., 1, Matem.-Naturv. Kl., 1. Oslo.

- 1943. Sikilsdalen og Norges fjellbeiter. En plantesociologisk monografi. Bergens Mus. Skr., 22. Bergen.

Nørvang, A., 1943. Profiler gennem flydejord i Jylland. Dansk Geol. Foren., Medd. 10 København.

- 1946. Nogle forekomster af arktisk strukturmark (Brodelboden) bevarede i danske istidsaflejringer. Danm. Geol. Unders., II. R., 74. København.

Oberdorfer, E., 1931. Die postglaziale Klima- und Vegetationsgeschichte des Schluchsees (Schwarzwald). Naturf. Ges. Freib., Ber., 31. Freiburg.

Östlund, H. G., 1959. Stockholm natural radiocarbon measurements II. Am. Journ. Sci. Radiocarbon Suppl., 1. New Haven.

Olsen, C., 1921. Studier over jordbundens brintionkoncentration og dens betydning for vegetationen, særlig for plantefordelingen i naturen. Carlsberg Lab., Medd., 15. København.

Olsen, S., 1950. Aquatic plants and hydrospheric factors. Svensk Bot. Tidskr., 44. Stockholm.

Oppermann, A., 1922. Granens sundhedstilstand i Danmark. Forstl. Forsøgsv. i Danm.. Beretn., 6. København.

Ostenfeld, C. H., 1901. Flora of the Færöes. Phanarogamae and Pteridophyta. The Botany of the Færöes, 1. København.

- and Larsen, C. Syrach, 1930. The species of the genus Larix and their geographical distribution. Kgl. Danske Vidensk. Selsk., Biol. Medd., 9. København.

Paterson, T. T., 1940. The effects of frost-action and solifluction around Baffin Bay and in the Cambridge district. Geol. Soc. London, Quaterl. Journ., 96. London.

Paul, H., 1947. Die Höhenverbreitung der in den Bayerischen Alpen bisher beobachteten Gefässpflanzen. Bayer. Bot. Ges., Ber., 27. München.

Pfaffenberg, K., 1953. Pflanzenreste aus den Fundschichten von Lebenstedt. Eiszeitalter und Gegenwart, 3. Öhringen.

Poнle, R., 1903. Pflanzengeographische Studien über die Halbinsel Kanin und das angrenzende Waldgebiet. Hort. Bot. Univ. Petropolit., Acta 21. Petrograd.

Post, L. von, 1929. Die Zeichenschrift der Pollenstatistik. Geol. Fören., Stockh., Förhandl., 41. Stockholm.

Preul, F., 1953. Die geologische Bearbeitung des paläolitischen Fundplatzes bei SalzgitterLebenstedt. Eiszeitalter und Gegenwart, 3. Öhringen.

Rabien, I., 1953. Die Vegetationsentwicklung des Interglazials in der Hilsmulde. Eiszeitalter und Gegenwart, 3. Öhringen.

RavN, F. KöLPIN, 1895. Om flydeevnen hos frøene af vore vand- og sumpplanter. Bot. Tidsskr., 19. København. 
REgEL, C., 1924. Nordische und alpine Vegetation. Geobot. Forschungsinst. Rübel in Zürich, Veröff., 1. Zürich.

- 1936. Über lithauische Wiesen. Schweiz. Bot. Ges., Ber., 46. Zürich.

ReIch, H., 1953. Die Vegetationsentwicklung der Interglaziale von Grossweil-Ohlstadt und Pfefferbichl im Bayerischen Alpenvorland. Flora, 140. Jena.

ReID, C., 1896. The relation of Palaeolithic man to the Glacial Epoch. Britt. Ass., Rep.

Richter, K., 1953. Geröllmorphologische und Einregelungsstudien in der pleistozänen Sedimenten der paläolitischen Fundstelle Salzgitter-Lebenstedt. Eiszeitalter und Gegenwart 3 , Öhringen.

Rовак, H., 1948. Lerkekreft og frost. Skogen og Klimaet. Utgitt av Bergens Museum. Bergen.

Rudberg, S., 1958. Some observations concerning mass movement on slopes in Sweden. Geol. Fören. Stockh., Förhandl, 80, Stockholm.

Rubner, K., 1934. Die pflanzengeographischen Grundlagen des Waldbaus. Neudamm.

- and Reinhold, F., 1953. Das natürliche Waldbild Europas. Hamburg.

Salisbury, E. J., 1925. Note on edaphic successions in some dune soils with special reference to the time factor. Journ. Ecol., 13. Cambridge.

Salomon, W., 1916. Die Bedeutung der Solifluktion für die Erklärung deutscher Landschafts- und Bodenformen. Geol. Rundschau, 7. Stuttgart.

Samuelsson, G., 1915. Über den Rückgang der Haselgrenze und anderer pflanzengeographischer Grenzlinien in Skandinavien. Inst. Geol. Uppsala, Bull., 13. Uppsala.

- 1934. Die Verbreitung der höheren Wasserpflanzen in Nordeuropa (Fennoskandien und Dänemark). Acta Phytogeogr. Suec., 6. Uppsala.

Schoch-Bodmer, H., 1940. The influence of nutrition upon pollen grains in Lythrum salicaria. Journ. Genetics, 40.

Schretzenmayer, M., 1950. Sukzessionsverhältnisse des Isaraues südlich Lenggries. Bayer. Bot. Ges., Ber., 28. München.

Seidenfaden, G., 1931. Moving soil and vegetation in East Greenland. Medd. om Grønl., 87, 2. København.

Selander, S., 1950. Floristic phytogeography of Southwestern Lule Lappmark. Acta Phytogeogr. Suec., 27. Uppsala.

Selle, W., 1941. Beiträge zur Mikrostratigraphie und Paläontologie der nordwestdeutschen Interglaziale. Reichst. für Bodenforsch., Jahrb., 60. Berlin.

- 1952, Die Interstadiale der Weichselvereisung. Eiszeitalter und Gegenwart, 2. Öhringen.

- 1953 a. Gesetzmässigkeiten im pleistozänen und holozänen Klimaablauf. Naturwiss. Verein Bremen, Abh., 33. Bremen.

- 1953 b. Pollenanalytische Untersuchungen an der paläolitischen Fundstelle bei Salzgitter-Lebenstedt. Eiszeitalter und Gegenwart, 3.

- 1954. Das Vechelder Interstadial. Eiszeitalter und Gegenwart, 4/5.

Sernander, R., 1905. Flytjord i svenska fjälltrakter. Geol. Fören. Stockh. Förhandl., 27. Stockholm.

Simpson, I. M., and West, R. G., 1958. On the stratigraphy and palaeobotany of a latepleistocene organic deposit at Chelford, Cheshire. New. Phytol., 57. Oxford.

Sృörs, H., 1950. Regional studies in North Swedish mire vegetation. Bot. Notiser, 1950. Lund.

Sobolewska, M., 1956 a. Azolla filiculoides in the Older Interglacial of Poland. Inst. Geol., Biul., 100. Warszawa.

- 1956 b. Pleistocene vegetation of Syrniki on the river Wieprz. Inst. Geol. Biul., 100.

Środoñ, A., 1952. Last Glacial and Postglacial in the Carpathians. Inst. Geol., Biul., 67. Warszawa.

- 1954. Pleistocene floras from Tarzymiechy on the river Wieprz. Inst. Geol., Biul., 69.

- 1957. Interglacial flora from Gosciecin near Kozle (Sudeten Foreland). Inst. Geol., Biul., 118.

Stark, P. and Overbeck, F., 1932. Eine diluviale Flora von Johnsbach bei Wartha (Schlesien). Planta, 17. Berlin.

Steeves, M. W., and Barghoorn, E. S., 1959. The pollen of Ephedra. Arnold Arb., Journ., 40, Jamaica Plain.

Steffen, H., 1928. Beiträge zur Flora und Pflanzengeographie von Nowaja Zemlja, Waigatsch und Kolgujew. Bot. Centralbl., Beiheft, 44. Dresden.

Steindorssón, S., 1945. Studies on the vegetation of the central highland of Iceland. The Botany of Iceland, 4, 4. København.

Sterner, R., 1922 a. The continental element in the flora of South Sweden. Geogr. Ann., 4. Stockholm.

- 1922 b. Ekologiska iakttagelser över Helianthemum oelandicum (L) Willd. Hort. Gothoburg., Acta, 11. Göteborg. 
Sundius, N. and Sandegren, R., 1948. Interglacialfyndet vid Långsele. Sver. Geol. Unders., C, 495, Stockholm.

Szafer, W., 1946. The Pliocene flora of Krościenko in Poland. Pol. Akad. Umiej. Rozpr. Wydz., 3. Cracow.

- 1953. Pleistocene stratigraphy of Poland from the floristical point of view. Polsk. Tow. Geol., Rocz., 22. Cracow.

- 1954. Pliocene flora from the vicinity of Czorsztyn (West Carpathians) and its relationship to the Pleistocene, Inst. Geol., Prace, 11. Warszawa.

Sørensen, H., 1948. Studies on the ecology of Danish water and bog mosses. Dansk Bot. Arkiv., 12. København.

Sørensen, T., 1935. Bodenformen und Pflanzendecke in Nordöstgrönland. Medd. om Grønl., 94, 4. København.

Tauber, H., and Vries H. De., 1958. Radiocarbon measurements of Würm-interstadial samples from Jutland. Eiszeitalter und Gegenwart, 9. Öhringen.

Terrasmaë, J., 1951. On the pollen morphology of Betula nana. Svensk Bot. Tidskr., 45. Stockholm.

Thomson, P. W., 1941. Die Klima- und Waldentwicklung des von K. Orviku entdeckten Interglazials von Ringen bei Dorpat. Deutsch. Geol. Ges., Zeitschr., 93. Hannover.

- 1951. Das Interglazial von Wallensen im Hils. Eiszeitalter und Gegenwart, 1. Öhringen.

ThorsLund, P., 1939. Kvartärgeologiska iakttagelser inom östra Storsjöområdet i Jämtland. Sver. Geol., Unders., C, 429, Stockholm.

Tongiongi, E., 1936. Ricerche sulla vegetazione dell'Etruria marittima. V. Documenti per la storia della vegetazione della Toscana e del Lazio. Nuovo Giorn. Bot. Ital., N.S., 4.3. Pisa.

Trautmann, W., 1953. Zur Unterscheidung fossiler Spaltöffnungen der mitteleuropäischen Coniferen. Flora, 140. Jena.

Troelsen, J. C. and Sorgenfrei, T., 1956. Principerne for stratigrafisk inddeling og nomenklatur. Dansk Geol. Foren., Medd., 13. København.

Troels-Smith, J., 1955. Karakterisering af løse jordarter. Characterization of unconsolidated sediments. Danm. Geol. Unders., IV. R., 3, 10. København.

Troll, C., 1944. Strukturböden, Solifluktion und Frostklimate der Erde. Geol. Rundschau, 34 , Stuttgart.

- 1947. Die Formen der Solifluktion und die periglaziale Bodenabtragung. Erdkunde, 1. Bonn.

- 1948. Der subnivale oder periglaziale Zyklus der Denudation. Erdkunde, 2. Bonn.

Tüxen, R., 1937. Die Pflanzengesellschaften Nordwestdeutschlands. Florist.-soziol. Arbeitsgem. in Niedersachsen, Mitt., 3. Hannover.

Turesson, G., 1922. The genotypical response of the plant species to the habitation. Lund.

Tutin, T. G., 1953. Natural factors contributing to a change in our flora. The Changing Flora of Britain. Arbroath.

VLERK, I. M. VAN DER, 1955. The significance of interglacials for the stratigraphy of the Pleistocene. Quaternaria, 2. Roma.

- 1957. Pleistocene correlations between the Netherlands and adjacent areas: A symposium. Conclusion. Geol. en Mijnb., N.S. 19. Leiden.

- 1959. Problems and principles of Tertiary and Quaternary stratigraphy. Geol. Soc. London, Quarterl. Journ., 115. London.

— and Florschütz, F., 1950. Nederland in het ijstijdswak. Utrecht.

- and Florschütz, F., 1953. The paleontological base of the subdivision of the Pleistocene in the Netherlands. Koninkl. Nederl. Akad. Wetensch., Verhandl., Afd. Natuurk., I. R., 22, 2. Amsterdam.

Volk, O. H., 1931. Beiträge zur Ökologie der Sandvegetation der oberrheinischen Tiefebene. Zeitschr. für Bot., 24. Jena.

- 1940. Soziologische und ökologische Untersuchungen an der Auenvegetation im Churer Rheintal und Domleschg. Naturf. Ges. Graubünden, Jahresber., 76. Chur.

Vries, H. DE, 1958. Radiocarbon dates for upper Eem- and Würm-interstadial samples. Eiszeitalter und Gegenwart, 9, Öhringen.

- 1959. Radiocarbon dating of the fossil soils at Ober Fellabrunn. Koninkl. Nederl. Akad. Wetensch. Proc., B. 62. 1. Amsterdam.

- Barendsen, G. W., and Waterbolk, H. T., 1958. Groningen radiocarbon dates II. Science, 127, New York.

Wagenitz, G., 1955. Über die Änderungen der Pollengrösse von Getreide durch verschiedene Ernährungsbedingungen. Deutsch. Bot. Ges., Ber., 68 .

- 1956. Pollenmorphologie der mitteleuropäischen Valerianaceen. Flora, 143. Jena. 
Walker, D., 1955. Studies in the Postglacial history of British vegetation XIV. Skelsmergh Tarn and Kentmere, Westmoreland. New Phytol., 54. Cambridge.

Walter, H., 1951. Einführung in die Phytologie. III. Grundlagen der Pflanzenverbreitung. Stuttgart.

Watt, A. S., and Jones, E. W., 1948. The ecology of the Cairngorms. Part I. The environment and the altitudinal zonation of the vegetation. Journ. Ecol., 36. Cambridge.

Watts, W. A., 1959. Interglacial deposits at Kilbeg and Newtown, Co. Waterford. Royal Irish Acad., Proc., 60, B. 2. Dublin.

Weber, C. A., 1898. Über eine Omorika-artige Fichte aus einer dem älteren Quartäre Sachsens angehörenden Moorbildung. Englers Bot. Jahrb., 24. Leipzig.

Welten, M., 1944. Pollenanalytische, stratigraphische und geochronologische Untersuchungen aus dem Faulenseemoos bei Spiez. Geobot. Inst. Rübel in Zürich, Veröff., 21. Zürich.

- 1957. Uber das glaziale and spätglaziale Vorkommen von Ephedra am nordwestlichen Alpenrand. Schweiz. Bot. Ges., Ber., 67. Zürich.

Wendelberger-Zelinka, E., 1952. Die Vegetation der Donauauen bei Wallsee. Wels.

Wennberg, G., 1949. Differentialrörelser i inlandsisen. Lunds Geol.-Min. Inst., Medd., 114. Lund.

Wenner, C.-G., 1947. Pollen diagrams from Labrador. Geografiska Annaler, 29. Stockholm.

- 1953. Investigation into the possibility of distinguishing the pollen of the various species of Betula in fossil material. Geol. Fören. Stockh., Förhandl., 75. Stockholm.

Wesenberg-Lund, C., 1906. Om kvartærgeologernes stilling til begrebet biologisk variation. Dansk Geol. Foren., Medd., 12.

- 1909. Om Limnologiens betydning for kvartærgeologien særlig med hensyn til postglaciale tidsbestemmelser og temperaturangivelser. Geol. Fören., Förhandl.31. Stockholm.

West, R. G., 1956. The Quaternary deposits at Hoxne, Suffolk. Royal Soc. London, Phil. Trans., B, 239. London.

- 1957. Interglacial deposits at Bobbitshole, Ipswich. Royal Soc. London, Phil. Trans., B, 241. London.

Woldstedt, P., 1949. Ǔber die stratigraphische Stellung einiger wichtiger Interglazialbildungen im Randgebiet der nordeuropäischen Vergletscherung. Deutsch. Geol. Ges., Zeitschr., 99. Hannover.

- 1950. Norddeutschland und angrenzende Gebiete im Eiszeitalter. Stuttgart.

- 1953. Über die Benennung einiger Unterabteilungen des Pleistozäns. Eiszeitalter und Gegenwart, 3. Öhringen.

- 1954 a. Das Eiszeitalter, I. 2. Auflage. Stuttgart.

- 1954 b. Saaleeiszeit, Warthestadium und Weichseleiszeit in Norddeutschland. Eiszeitalter und Gegenwart, 4-5.

- 1956. Über die Gliederung der Würm-Eiszeit und die Stellung der Lösse in ihr. Eiszeitalter und Gegenwart, 7.

- 1958. Das Eiszeitalter, II. Stuttgart.

ZAGwisn, W. H., 1957 a. Vegetation, climate and time-correlations in the Early Pleistocene of Europe. Geol. en Mijnb., N.S., 19. Leiden.

- 1957 b. Pollenanalytical investigations at the Eemian type-locality and their bearing on the subdivisions of the Last Glacial Stage. INQUA. V. Congr. Internat., Rés. des Comm. Madrid-Barcelona.

- 1960. Aspect of the Pliocene and Early Pleistocene vegetation in the Netherlands. Geol. Stichting, Mededel., C, 3, 1, 5. Maastricht.

- and Zonneveld, J. I. S., 1956. The interglacial of Westerhoven. Geol. en Mijnb., N.S., 18. Leiden.

Zeuner, F., 1954. Riss or Würm? Eiszeitalter und Gegenwart, 4-5. Öhringen.

Zonneveld, J. I. S., 1957. River terraces and quaternary chronology in the Netherlands. Geol. en Mijnb., N.S., 19. Leiden. 


\section{Plate I.}

1. Larix sp., leaf epidermis with stomata, $500 \times$ (see description on p. 22). Pollen zone W 4. Brørup Hotel Bog.

2. Larix sp., pollen grain, $500 \times$ (see description on p. 22). Pollen zone W 4. Brørup Hotel Bog.

3-5. Elisma natans, achenes, $20 \times$ (see description on p. 23). Pollen zone W 3. Brorup Hotel Bog.

6-8. Elisma natans, pollen grains, $1000 \times$ (see description on p. 23). Pollen zone W 3b. Brørup Hotel Bog.

6: focus 2 (phase contrast, note: indistinct annuli, muri with densely crowded columellae). 7 : focus 1 (note: indistinct annuli) 8 : focus -1 (note: coarse microechini). 
PLATE I
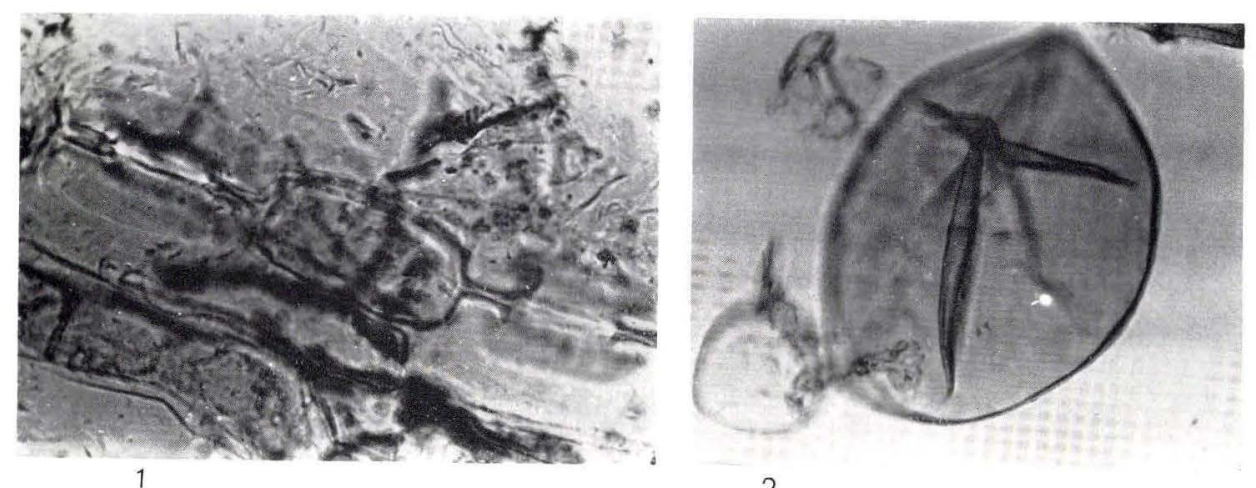

2
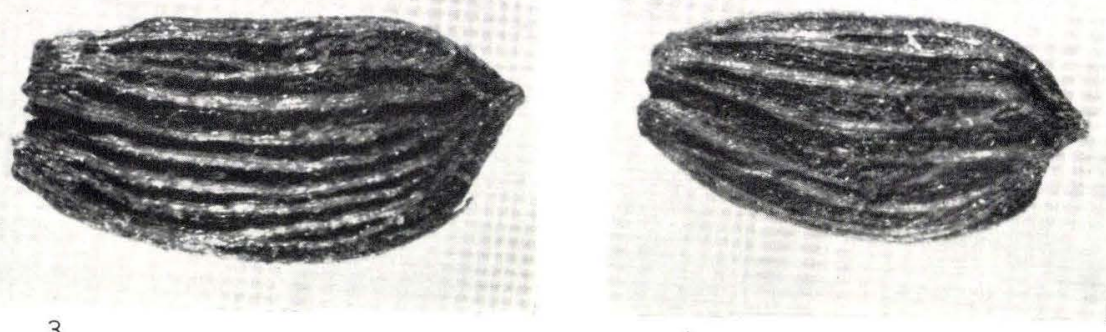

3

4
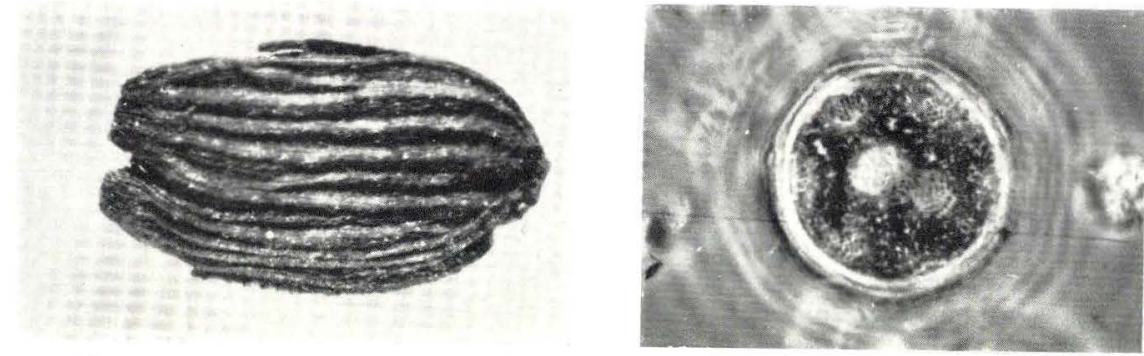

5

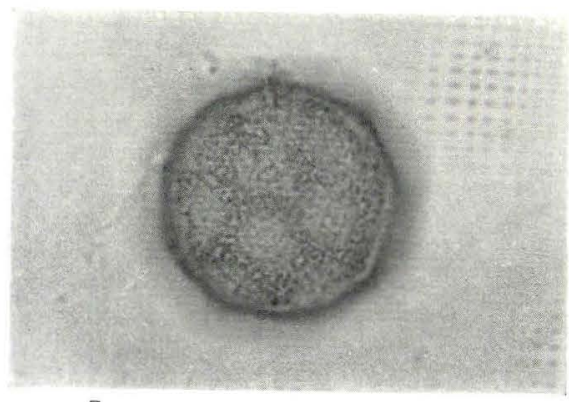

6

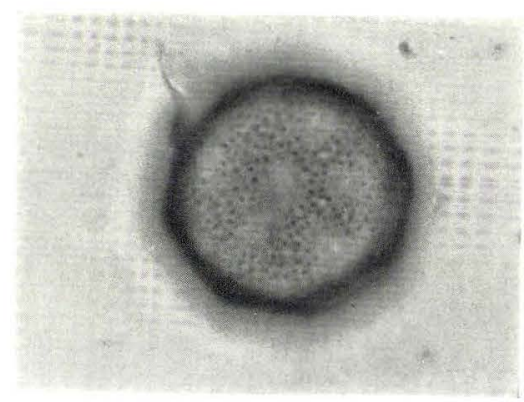

8 


\section{Plate II.}

1-2. Scleranthus perennis, pollen grain, $1000 \times$ (see description on p. 24). Pollen zone W 2c. Brørup Hotel Bog.

1: focus 0 (note: perforations seen in negative as small black dots). 2: focus 2 (note: coarse columellae, annuli).

3-4. Astragalus danicus, pollen grain, $1000 \times$ (see description on p. 26). Pollen zone W 2e. Brørup Hotel Bog.

3: focus 1 (note sculpture). 4: focus 5 (note: pore configuration).

5-8. Swertia perennis, pollen grain, $1000 \times$ (see description on p. 25). Pollen zone W 2a. Brørup Hotel Bog.

5: focus 0 (note: irregular striation, perforations seen in negative as dark dots). 6: focus 1 (note: perforations seen as white dots). 7: focus 2. 8: focus 5 . 
PLATE II

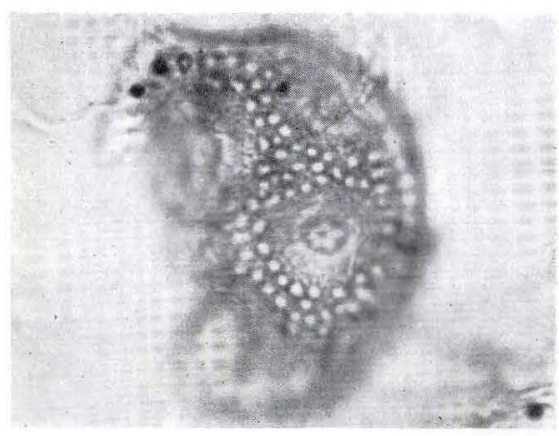

1

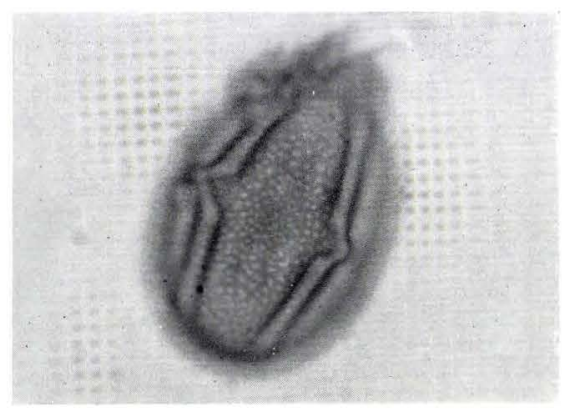

3

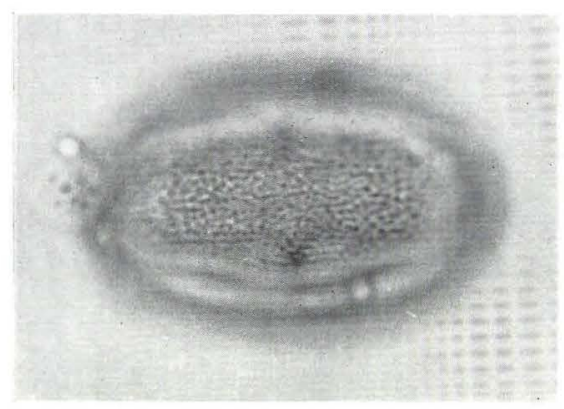

5

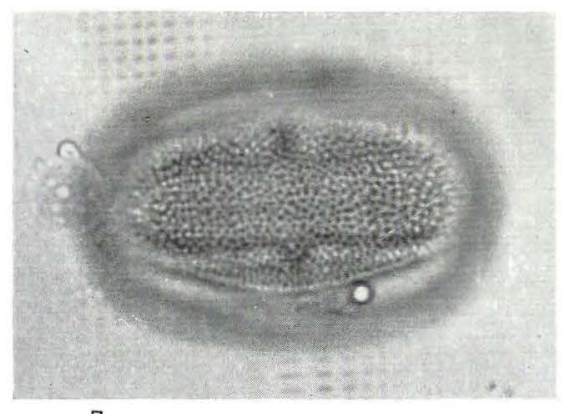

7
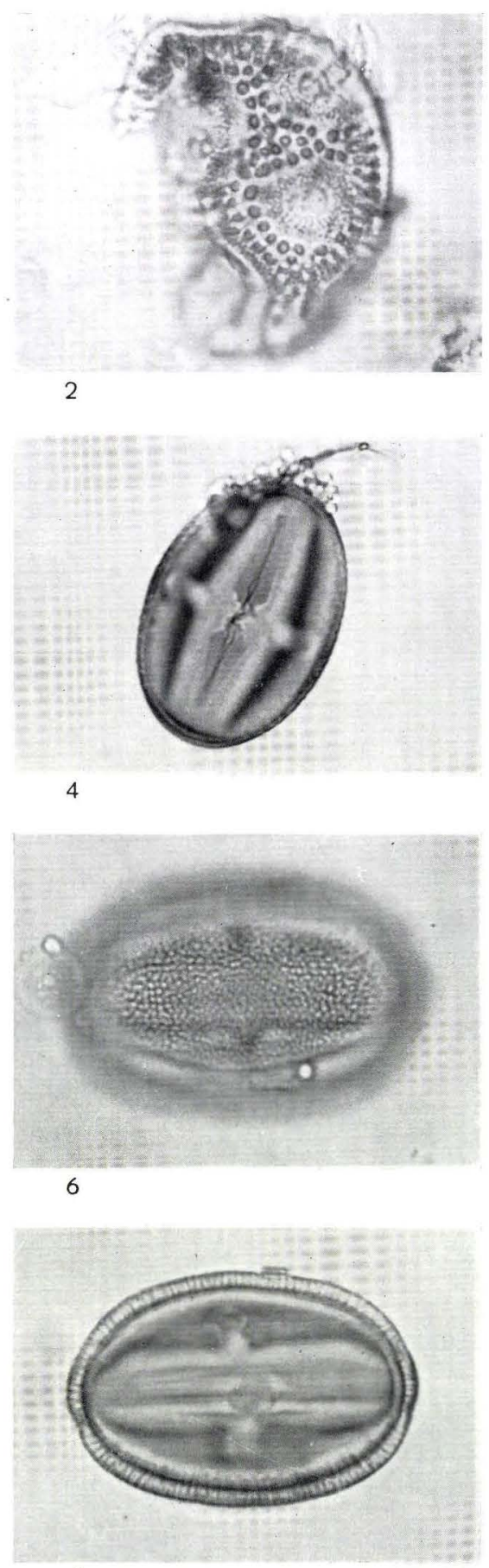

8 
Plate III.

1-2. Teucrium montanum, pollen grain, $1000 \times$ (see description on p. 25$)$.

1: focus 2 (note: columellae, microechini). 2: focus 5 (note: tectum thickened near the poles).

3-4. Linum austriacum type, fragment of a pollen grain, $1000 \times$ (see description on p. 27). Pollen zone W 2d. Brorup Hotel Bog.

3: focus 2 (note: transect of verrucae). 4: foc 5 (note: flat-topped verrucae).

4-8. Plantago lanceolata, pollen grain, $1000 \times$ (see description on p. 42). Pollen zone W 2e. Herning.

5 : focus 1 (note: microechini). 6 : focus 3 (note: annuli). 7 : focus 1 (phase contrast, note: microechini). 8: focus 2 (phase contrast, note: columellae, operculum). 
PLATE III
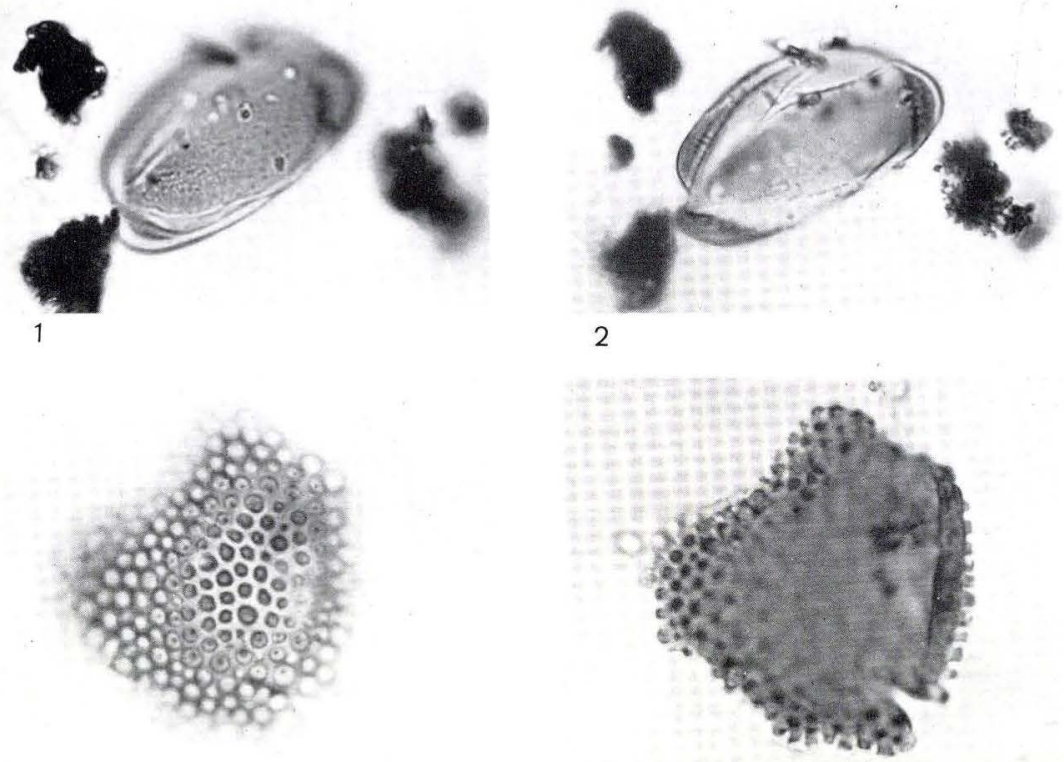

3

4

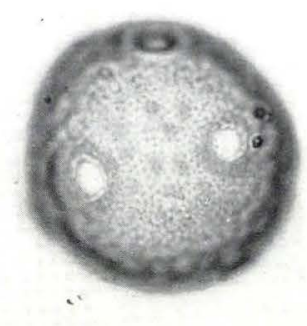

5

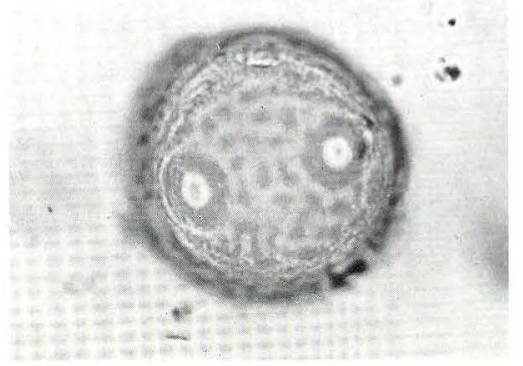

6
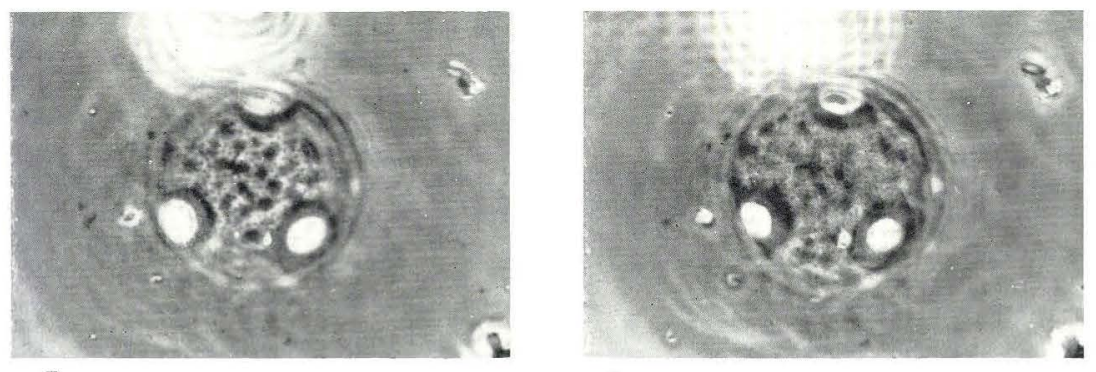
Plate IV.

1-2. Plantago maritima, pollen grain, $1000 \times$ (non-annulate type, see description on p. 42). Pollen zone W 3a. Herning.

1: focus 1 (note: microechini, granulate pore). 2: foc 5 (note: non-annulate pores).

3-7. Plantago maritima, pollen grain, $1000 \times$ (annulate type, see description on p. 42). Pollen zone W 2c. Rodebæk I.

3: focus 1 (note: microechini, annuli). 4: focus 5 (note: annuli). 5: focus -1 (note: granulate pores). 6: focus 1 (phase contrast, note: microechini). 7 : focus 2 (phase contrast, note: columellae).

8. Symphylum sp., pollen grain, $1000 \times$ (see description on p. 23). Zone W 4. Brorup Hotel Bog. 
PLATE IV
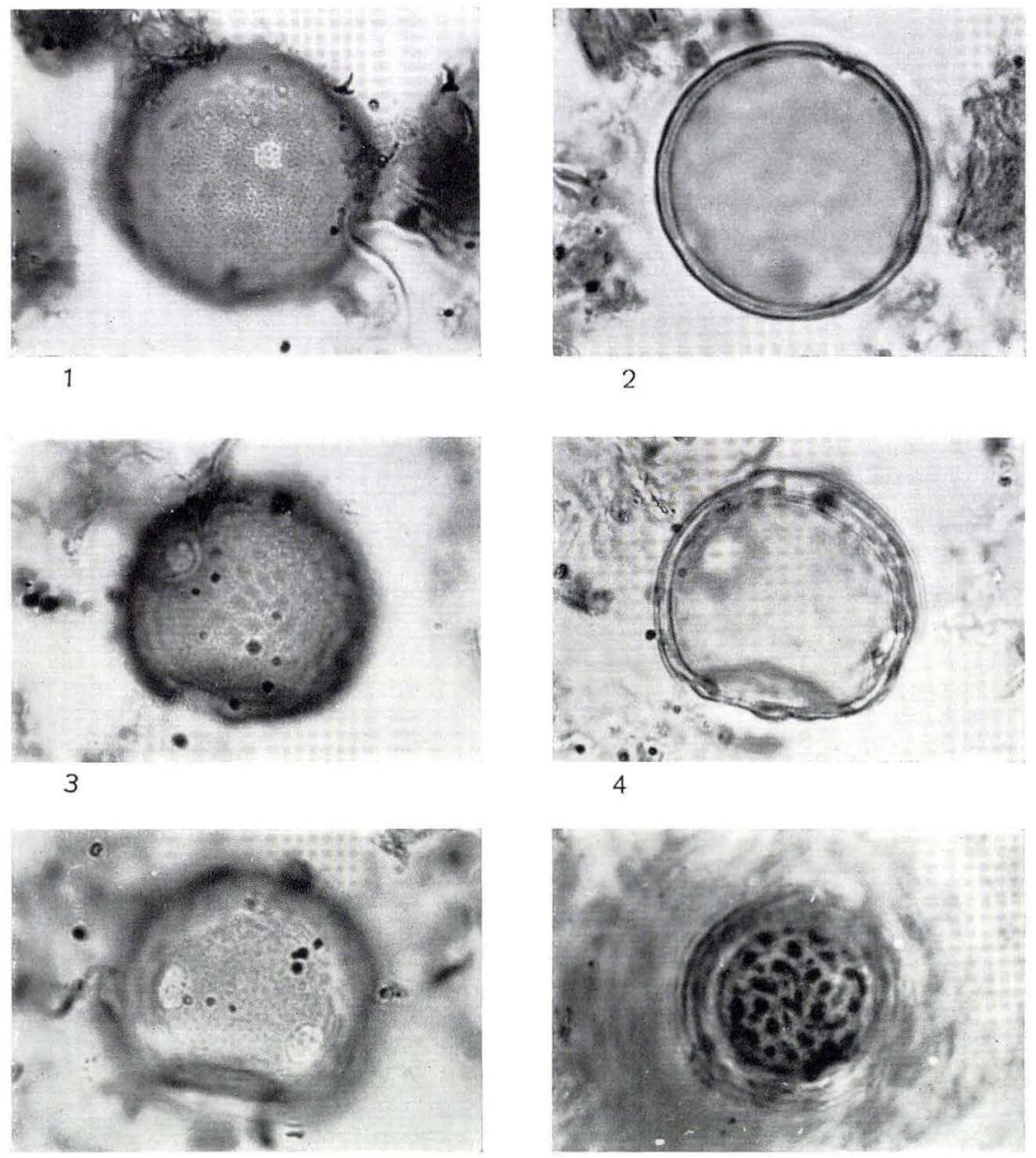

5
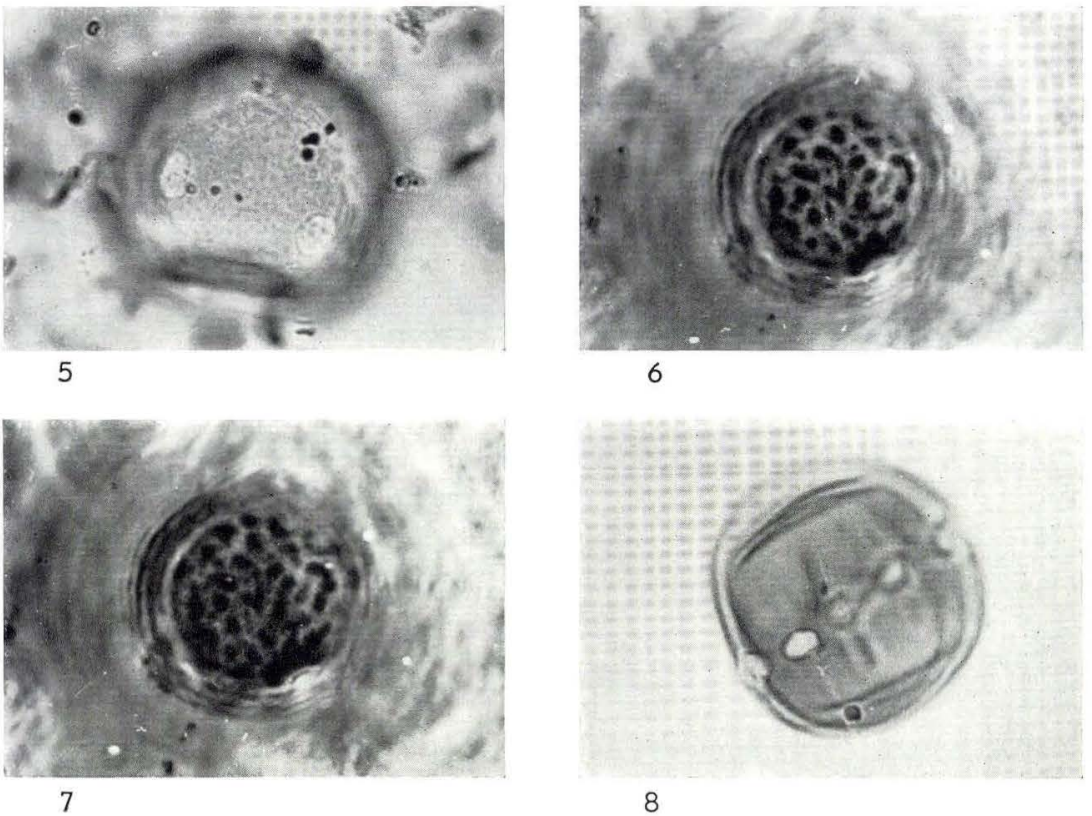
PLATE V

S h - Substantia humosa (humous substance)

T $1^{4}$ - Turfa lignosa (tree roots, stumps, etc., strongly decomposed)

$\mathrm{T} \mathrm{h}^{4}$ - Turfa herbacea (herbaceous roots, etc. strongly decomposed)

$\mathrm{T} \mathrm{h}^{2}$ - Turfa herbacea (herbaceous roots, etc., slightly decomposed)

D h - Detritus herbosus (herbaceous plant fragments)

D g - Detritus granosus (coarse-detritus)

$\mathrm{L} \mathrm{d}^{3}$ - Limus humosus c. detritu (fine-detritus + much humous substance)

$\mathrm{L} \mathrm{d}^{2}$ - Limus humoso-detrituosus (fine-detritus + some humous substance)

$\left[\begin{array}{l}L L_{L} L_{L} L_{L} L \\ L\end{array} \quad\right.$ A $\quad-$ Argilla (mineral particles, $<0.06 \mathrm{~mm}$., clay and silt)

$\mathrm{Ga}+\mathrm{s}-$ Grana arenosa + saburralia (mineral particles, 2.0$0.06 \mathrm{~mm}$. , sand)

Gg - Grana glareosa (mineral particles, 20.0-2.0 mm., gravel)

Plate V.

Signatures for sediment components (see the text, p. 12).

Signaturer for sedimenternes bestanddele (se s. 12). 







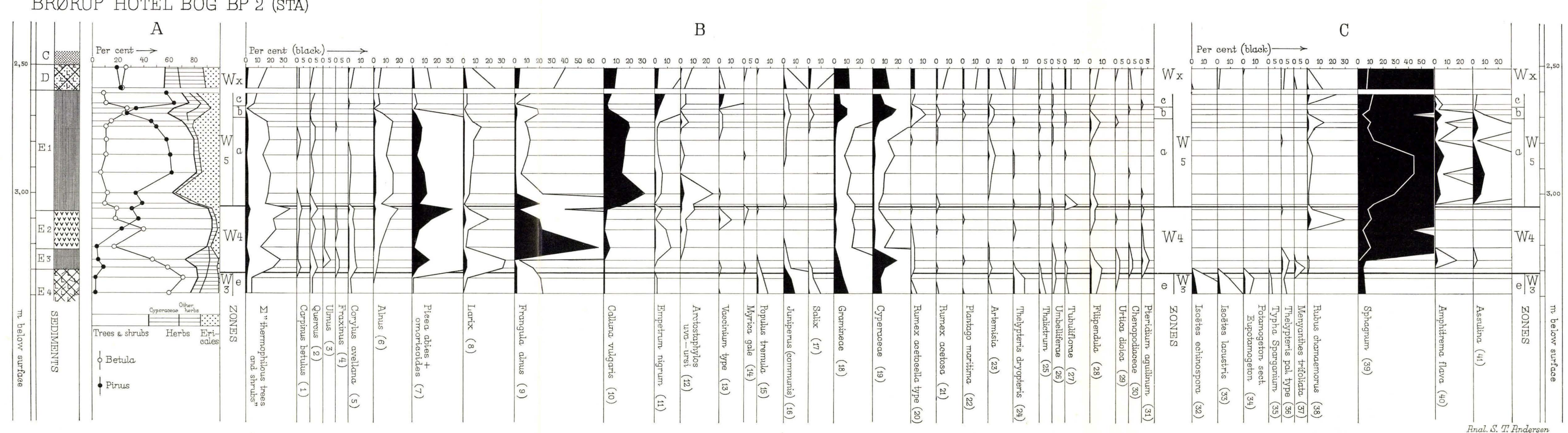


Plate VIII.

Section. Rodebæk I.

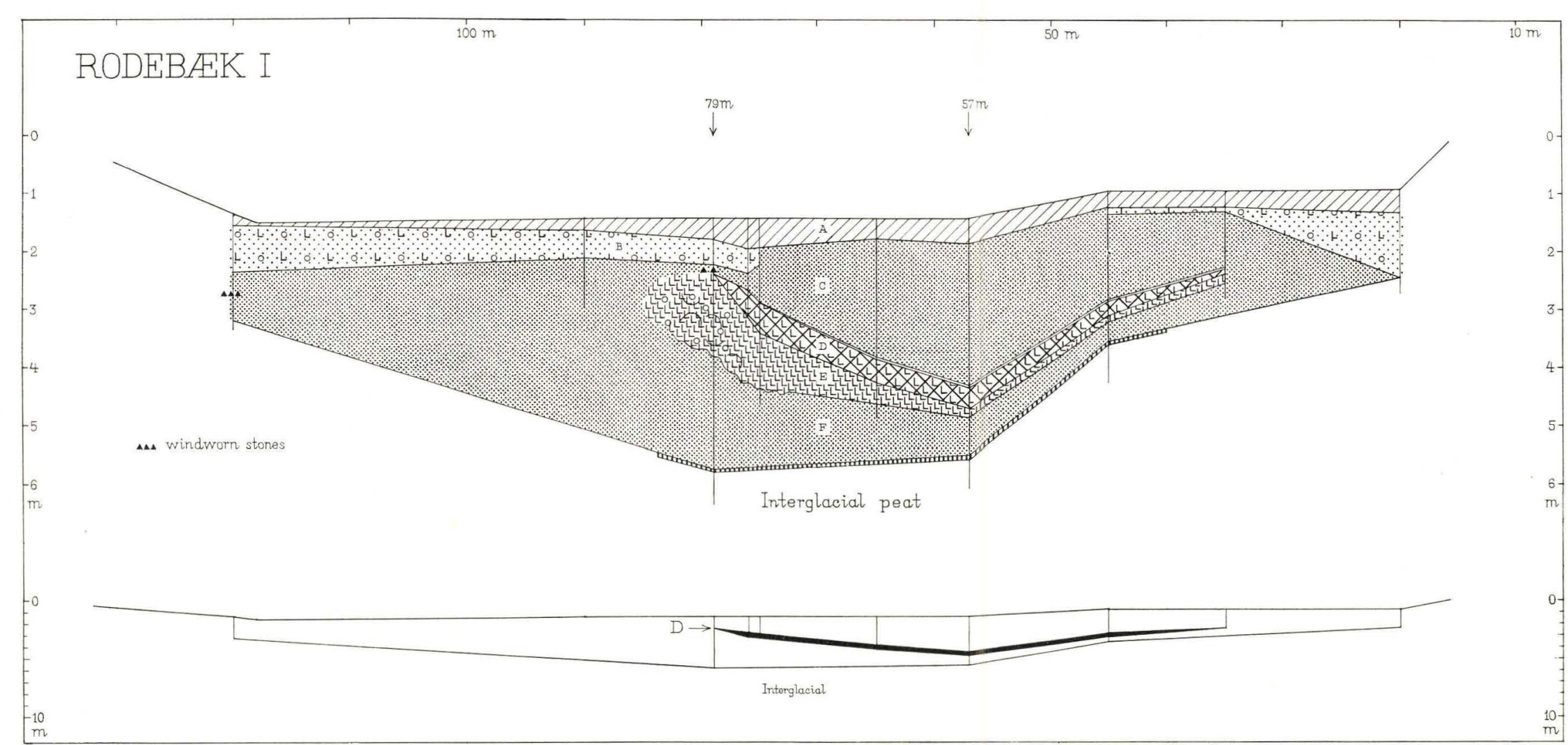




Plate $X$.

Profiles at BP 1-5 (STA). Herning.

The location of the borings are indicated on the map, fig. 10 (p. 66).

Boringernes beliggenhed er vist på kortet fig. 10 (s. 66).

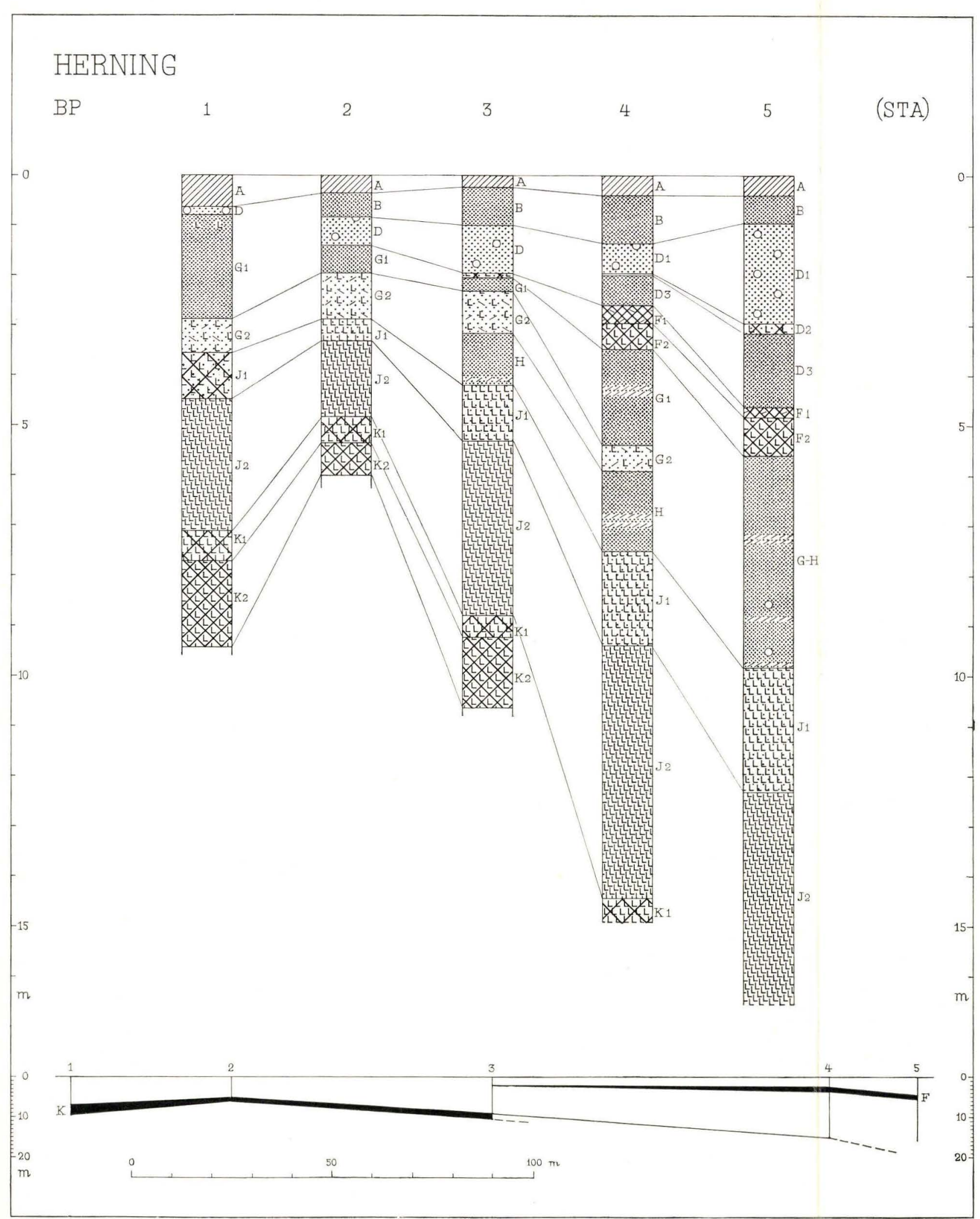



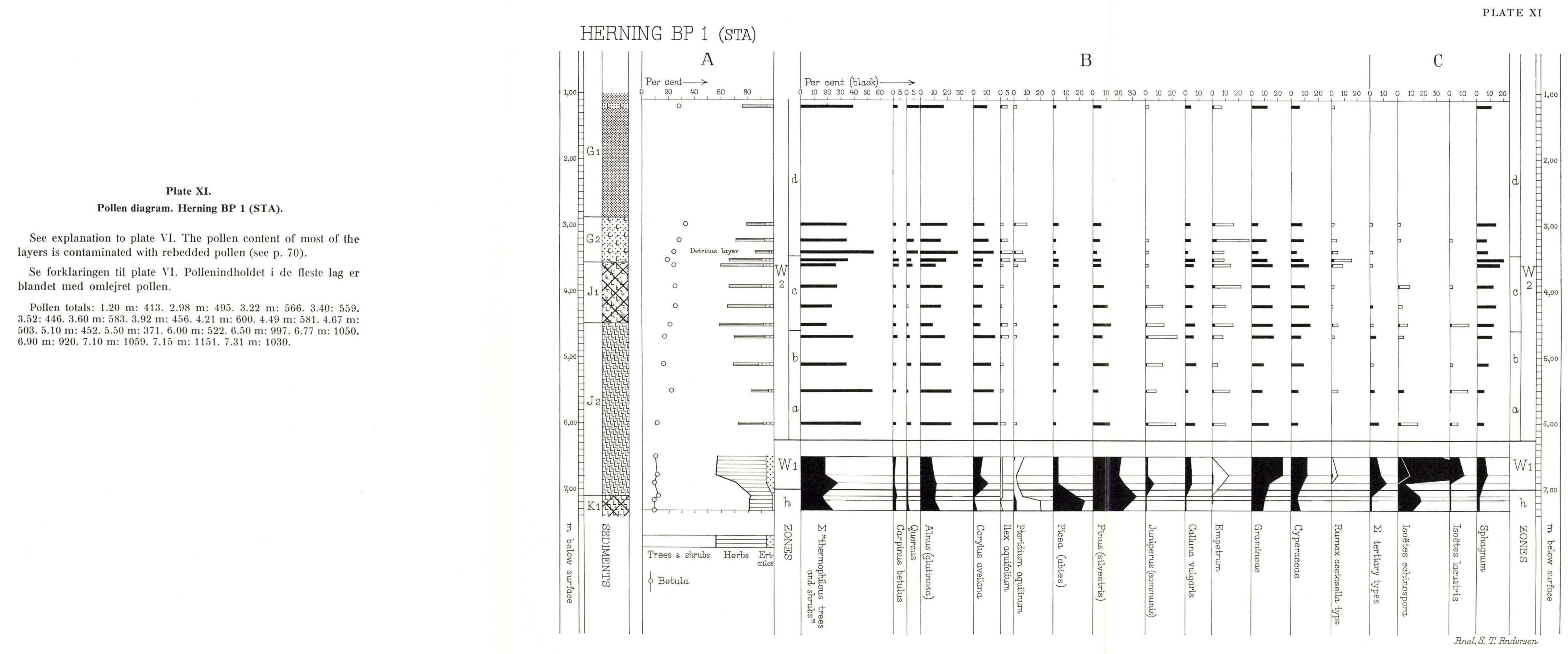
Plate XII.

Pollen diagram. Herning BP 3 (STA).

See explanation to plate VI. The pollen content of most of the

Se forklaringen til plate VI. Pollenindholdet $i$ de fleste lag blandet med omlejret pollen.

Pollen totals: $1.98 \mathrm{~m}: 522.2 .02 \mathrm{~m}: 532.2 .11 \mathrm{~m}: 591.2 .33 \mathrm{~m}: 554$.
$2.75 \mathrm{~m}: 543.3 .13 \mathrm{~m}: 508.3 .20 \mathrm{~m}: 558.4 .25 \mathrm{~m}: 544.4 .60 \mathrm{~m}: 491$

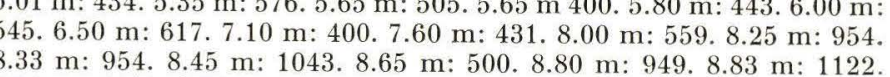

HERNING BP 3 (STA)

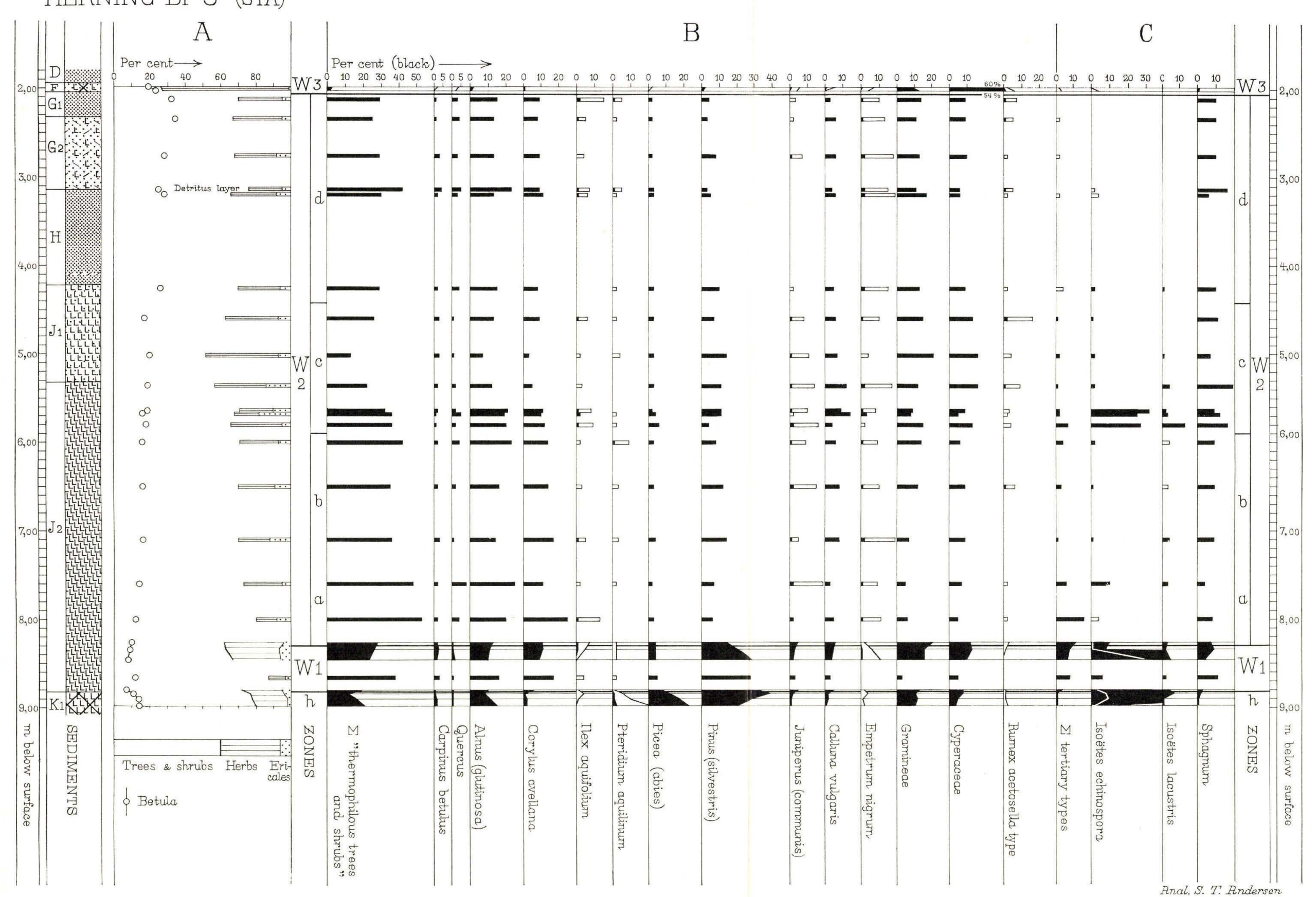


Pollen diagram. Herning BP 5 (STA) Diagram 1.

See explanation to plate VI. Most of the layers are contaminated . $02 \mathrm{~m}: 4.9 \% .3 .14 \mathrm{~m}: 7.0 \%$ (black silhouette instead of the white one

Se forklaringen til plate VI. De fleste af lagene indeholder mlejret pollen.

Pollen totals: 2.95: 1046. 3.02: 1175. 3.14: 1093. 4.63: 1127. 4.72 .

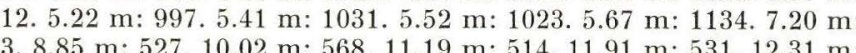
$673.8 .85 \mathrm{~m}: 527.10 .02 \mathrm{~m}: 568.111 .19 \mathrm{~m}: 514.11 .91 \mathrm{~m}: 531.12 .31 \mathrm{~m}:$
$526.12 .84 \mathrm{~m}: 482.13 .28 \mathrm{~m}: 422.13 .90 \mathrm{~m}: 407.14 .91 \mathrm{~m}: 436.16 .50 \mathrm{~m}:$

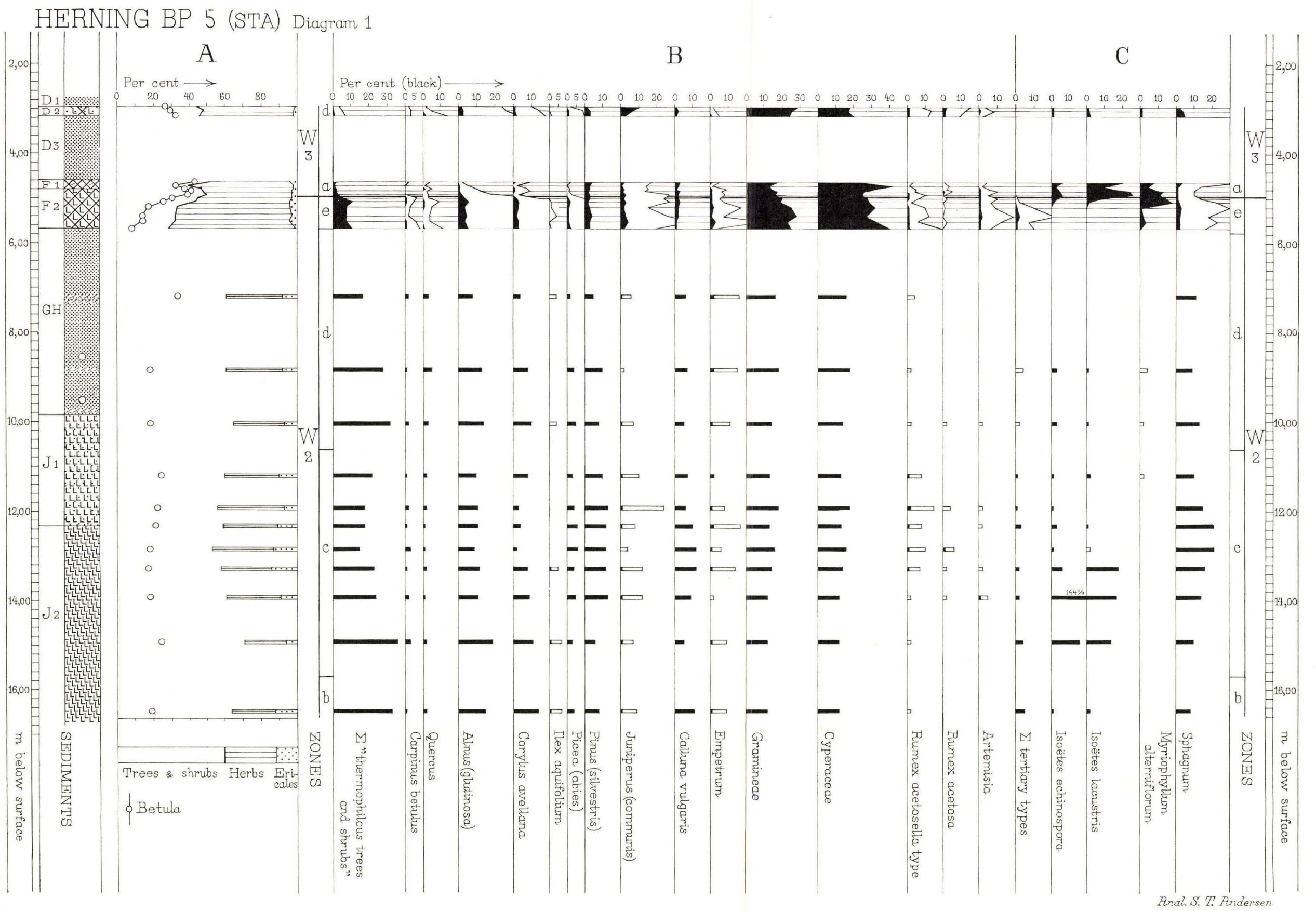



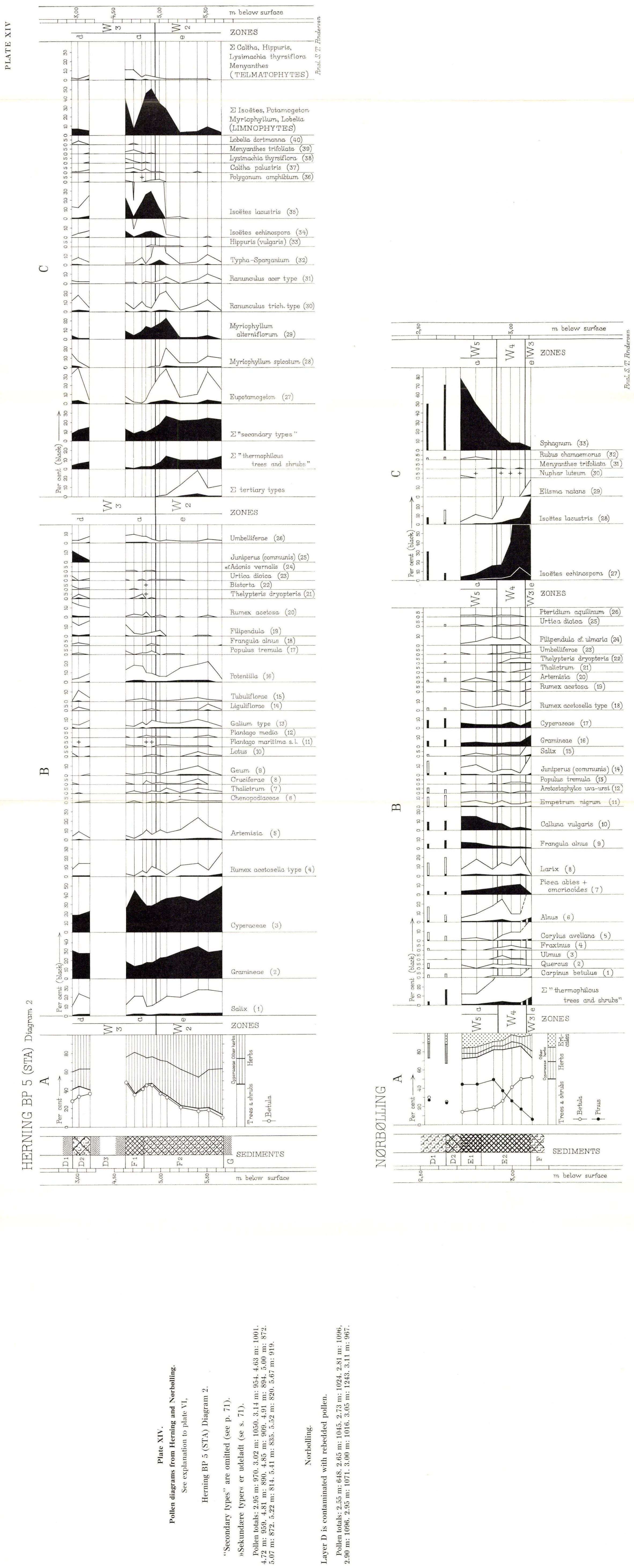
Plate XV.

Average frequencies for pollen and spore types. Gennemsnitsfrekvenser for pollen og spore type

See the explanation on p. 81. The figures in brackets indicate III, the white silhouettes in zone W 2 and $\mathrm{W} 3$ indicate that the pollen or spores are considered rebedded from interglacial layers.

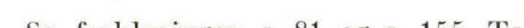

Se forklaringen S. 81 og S. 155. Tallene i parentes viser an

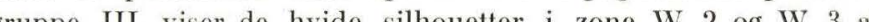
pollenet eller sporerne anses for omlejiede fra interglaciale las folge diskussionen på s. 50-55.

Pollen totals: Zone W 1: 4055. Zone W 2a: 4247, b: 3906, c: 2317

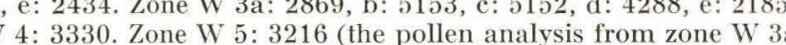
was supplemented with an extra count to bring the pollen total on an

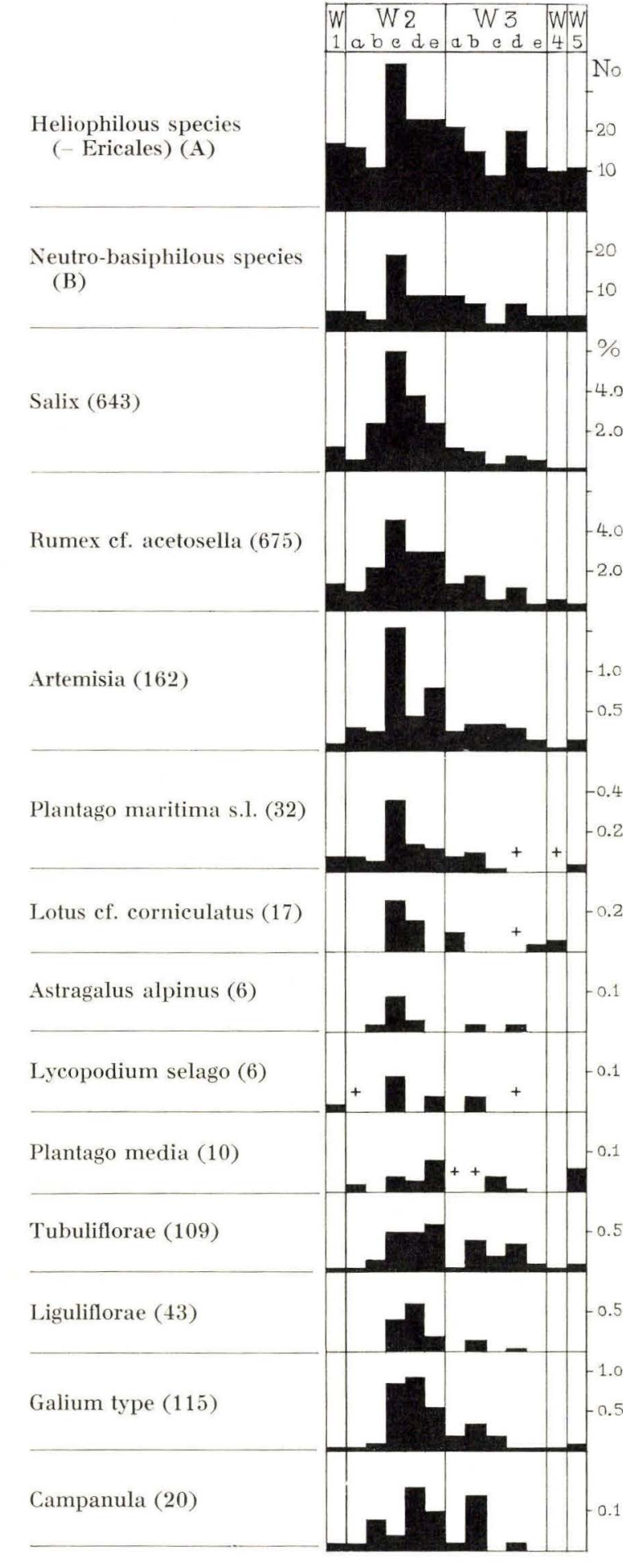

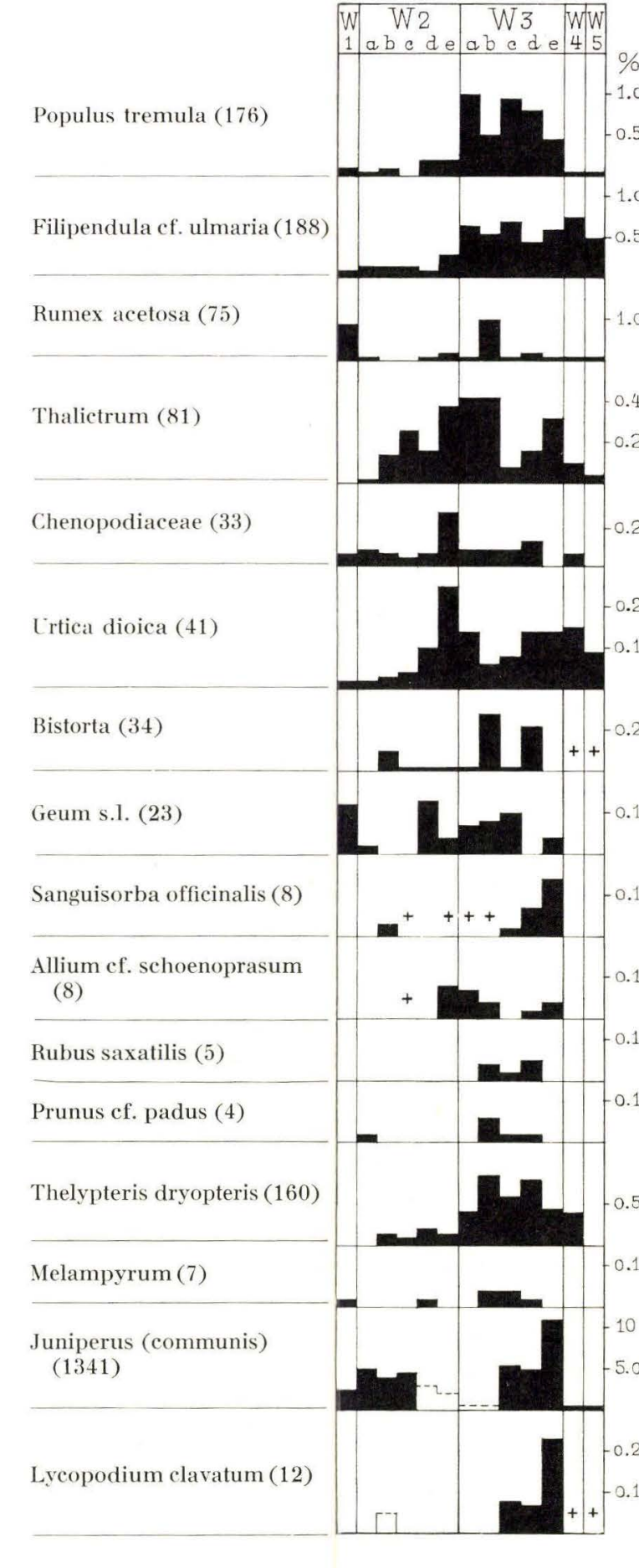

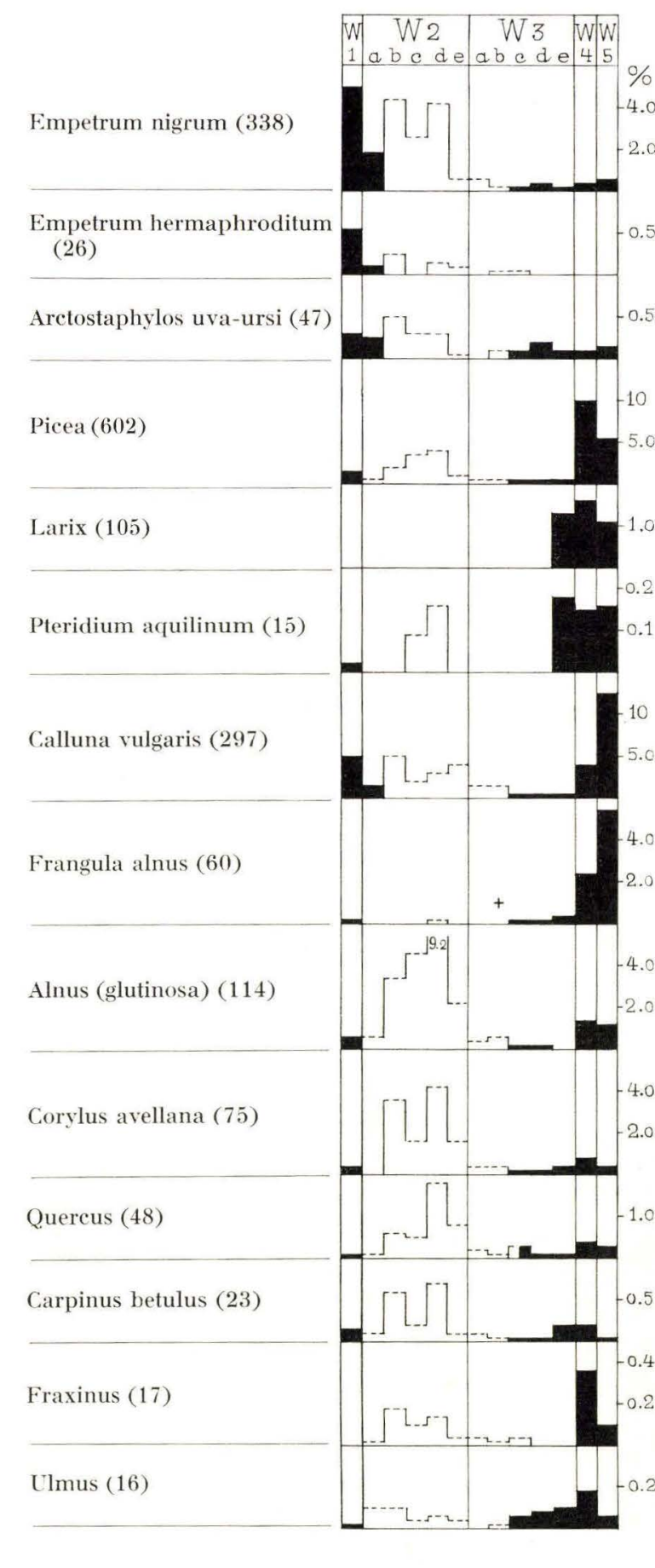

